\author{
UNIVERSIDADE DE SÃO PAULO \\ ESCOLA DE ENGENHARIA DE SÃO CARLOS \\ DEPARTAMENTO DE ENGENHARIA DE PRODUÇÃO
}

ELAINE MARIA DOS SANTOS

\title{
ARQUITETURA DE ORIENTAÇÃO PARA AVALIAÇÃO DE PROGRAMAS DE EDUCAÇÃO A DISTÂNCIA: desenvolvimento, implementação e análise
}




\section{ARQUITETURA DE ORIENTAÇÃO PARA AVALIAÇÃO DE PROGRAMAS DE EDUCAÇÃO A DISTÂNCIA: desenvolvimento, implementação e análise}

Tese apresentada à Universidade de São Paulo, Escola de Engenharia de São Carlos, para obtenção do título de Doutor em Engenharia de Produção.

Área de Concentração: Economia, Organizações e Gestão do Conhecimento.

Orientador: Prof. Dr. José Dutra de Oliveira Neto 
AUTORIZO A REPRODUÇÃO E DIVULGAÇÃO TOTAL OU PARCIAL DESTE TRABALHO, POR QUALQUER MEIO CONVENCIONAL OU ELETROONICO, PARA FINS DE ESTUDO E PESQUISA, DESDE QUE CITADA A FONTE.

Ficha catalográfica preparada pela Seçăo de Tratamento

da Informaçăo do Serviço de Biblioteca - EESC/USP

Santos, Blaine Maria dos

$5237 \mathrm{a}$

Arquitetura de orientapio para avaliacto de programas de educapa a distincia $t$ desenrolrimento, 1uplementacio - andise / Elaine Mar1a dos santos ; orientador José Dutra de oliveira Neto. -- sdo Carlos, 2011.

Iese (Doutorado - Programa de Pós-Graduaça em Engenbar1a de Froduçăo a Area de Concentraça en. Economia, Organizaçós a Cestao do Conhecinento) Escola de Engenharia de sto Carlos da Universidade de sto Paulo, 2011.

1. Educapso a distincia - 1nstrumentos de araliaço validade - confiab1lidade. 2. Assessment. I. Iitulo. 


\section{FOLIIA DE .IULGAMFNTO}

\section{Candidato(a)̀: Tecnólogo ELAINE MARIA DOS SANTOS.}

Tese defendida e julgada um 22.02.2011 perante a Comissăo Julgadora:

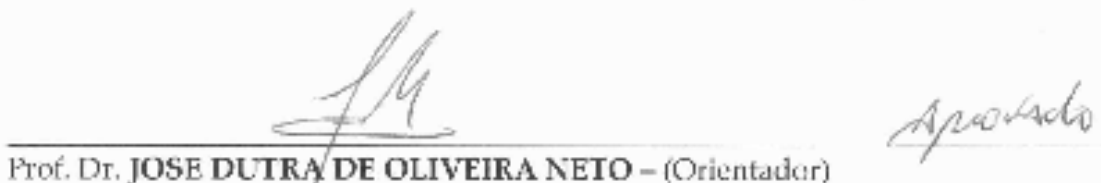

(Faculdade de Economia, Administrą̧âo e Contabilidade de Ribeirão Preto:FEARP)
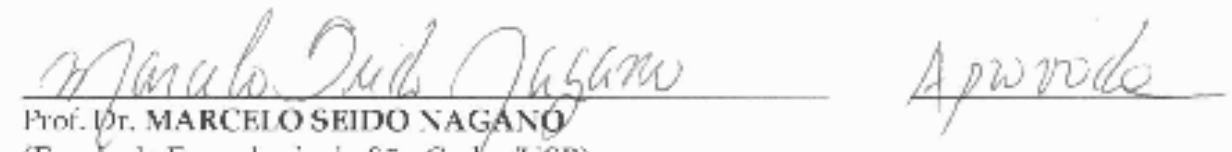

(Fsersla de Fngenharia de Sāo Cartoşi(SP)

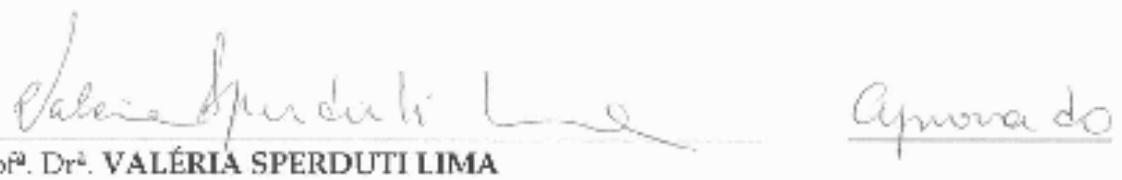

Prof $F^{3}$. Dri. VALÉRIA SPERDUTI LIMA

(1)niversidade Federal de Sấo CarlassiLF5Car)

\section{PARTICIPACZRO POR VDEOCONFERENCIA}

Profa. Associada ADRIANA BACKX NORONHA VIANA

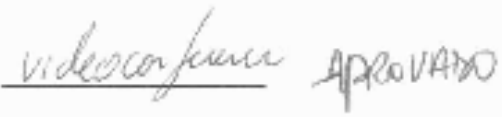

(Taculdade de Economia, Administração e Contabilidade de Ribeirăı PretoiГT.ARP)

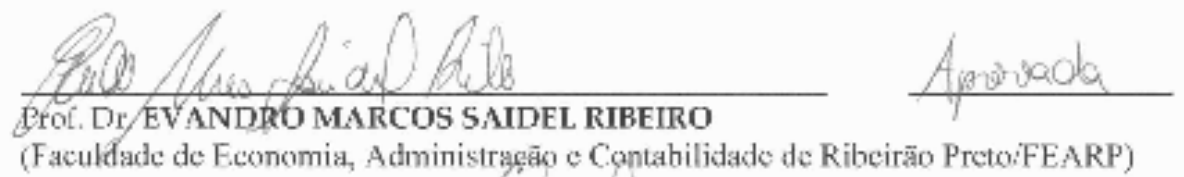

(Faculdade de Economia, Administraçāo e Contahilidade de Ribeiräo PretoiFEARP)

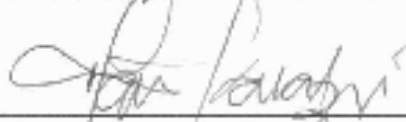

Prof. Associado AQUULES ELIE CUIMARĀES KALATZIS

Coordenador do Programa dé Pós-Graduaçăo cm

Engemaria de Produçăo

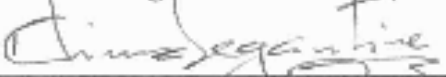

Prof. Associado PAULO CÉSAR LIKA SEGANTINE

Presidente da Comísäo da Poss-Ciraduaţăo da FF.SC. 
Ao meu esposo Juliano, companheiro de todos os momentos e meu grande incentivador. 


\section{AGRADECIMENTOS}

A Deus, pelo dom da vida.

Aos meus pais, José e Cida, pelo exemplo e apoio.

Às minhas irmãs, Joselaine e Mayele, pelo incentivo, amor e carinho sempre a mim dedicados.

Ao Professor Dutra, pelas inúmeras contribuições na realização deste estudo.

Ao Professor Renato Vairo Belhot, pelas sábias sugestões no alinhamento da pesquisa.

Aos participantes da pesquisa, que prontamente colaboraram e contribuíram fortemente nesta investigação.

À Professora Klevi, Fabíola e todos que, direta ou indiretamente, me auxiliaram na pesquisa de campo.

À amiga Elenise meu agradecimento especial, pois não mediu esforços para me auxiliar no desenvolvimento desta pesquisa e de outros trabalhos.

A todos os colegas da pós-graduação, que alegraram e preencheram minha vida no período em que residia em São Carlos, bem como me mostraram o verdadeiro sentido da amizade.

Aos funcionários do Departamento de Engenharia de Produção, José Luiz, Sueli, Claudete e Luiz Fernando, pela atenção e disposição com que me ajudaram sempre que precisei.

À Universidade Estadual do Centro-Oeste/PR pela liberação das atividades para cursar doutorado.

À CAPES, pelo auxílio financeiro. 


\section{RESUMO}

\section{SANTOS, E.M. (2011). Arquitetura de Orientação para Avaliação de Programas}

de Educação a Distância: desenvol vimento, implementação e análise. $267 \mathrm{f}$. Tese (Doutorado) - Escola de Engenharia de São Carlos, Universidade de São Paulo, São Carlos.

Com a expansão da Educação a Distância (EaD) no Brasil, nos últimos anos, avaliações são fundamentais para mensurar o seu desempenho. Contudo, a qualidade é muitas vezes questionada e possivelmente uma das causas é a falta de confiabilidade e validade dos instrumentos utilizados. Desta forma, o objetivo deste estudo foi criar uma arquitetura de orientação para a construção de instrumentos de avaliação de Programas de Educação a Distância com evidências de confiabilidade e validade. A investigação é uma pesquisa descritiva e explicativa, que congrega os enfoques qualitativo e quantitativo e é sustentada por um arcabouço teórico e metodológico. Além disso, parte do pressuposto de um sistema integrado, cuja natureza cíclica do método confere dinamicidade e flexibilidade, sobretudo em ações que lastreiam qualidade ao produto final. Para isso, propõe-se um conjunto de elementos que podem ser utilizados como referência para a construção de diferentes instrumentos de avaliação. A partir da arquitetura de orientação desenvolvida criou-se um plano de assessment, o qual foi aplicado em um caso específico. Os resultados demonstram que a arquitetura é viável e tem capacidade de atender diferentes modelos e contextos de $\mathrm{EaD}$, de forma que qualquer tipo de Instituição de Ensino pode utilizá-la para a construção de seus instrumentos avaliativos (assessment) de Educação a Distância. Conclui-se, portanto, que a arquitetura de orientação integra componentes de confiabilidade e validade, o que assegura uma tomada de decisão segura e precisa.

Palavras-chave: Educação a Distância; Instrumento de Avaliação; Assessment; Confiabilidade; Validade. 


\begin{abstract}
SANTOS, E.M. (2011). Architecture Guidance for Program Assessment in Distance Education: de velopment, implementation and analysis. $267 \mathrm{f}$. Thesis (Doctor Degree) - School of Engineering of São Carlos, University of São Paulo, São Carlos.

With the expansion of Distance Education (DE) in Brazil in recent years, assessments are crucial to measure its performance. However, its quality has been frequently questioned and one of the reasons may be the lack of reliability and validity in the tools used for it. Therefore, the objective of this study was to create an architecture to guide the construction of assessment tools for Distance Education Programs, with evidences of reliability and validity. The investigation is a descriptive and explanatory research, which brings together the qualitative and quantitative approaches and is underpinned by a theoretical and methodological framework. Moreover, it is based on an integrated system whose method's cyclical nature allows dynamicity and flexibility, mainly in actions that ass ure quality to the final product. Hence, it proposes a a set of elements that can be used as reference for the construction of different assessment instruments. From the architectural guidance designed to create an assessment plan, which was applied in a particular case. The results show that the architecture is feasible and has the capacity to suit different contexts and models of distance education, so that any type of Education Institution can use it for building their evaluative instruments (assessment) of Distance Education. Therefore, it is concluded that the Architecture Guidance integrates components of reliability and validity, which assure a precise and trustworthy decision taking.
\end{abstract}

Keywords: Distance Education; Assessment Tools; Evaluation; Reliability, Validity. 


\section{LISTA DE FIGURAS}

Figura 1 - Estruturação da Tese................................................................................... 26

Figura 2 - Diagrama de comparação entre a ssessment e evaluation.............................. 32

Figura 3 - Concep̧̧ão de validade, adaptado de Messick (1989) ................................ 66

Figura 4 - Modelo Lógico de Avaliação, adaptado de Marynowski (2006)................ 73

Figura 5 - Modelo Sistemático para Avaliação de E-Learning, adaptado de Mungania

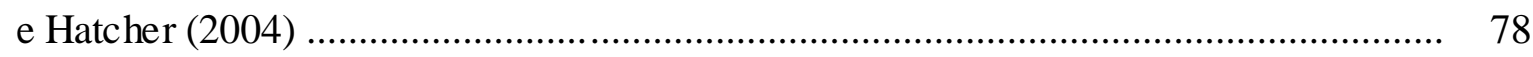

Figura 6 - Quando Avaliar e-Learning, adaptado de Mungania e Hatcher, (2004)..... 79

Figura 7 - Framework para avaliação da Educação a Distância, adaptado de Rossi, Freeman e Lipsey (1999) e Worthen, Sanders e Fitzpatrick (1997) .............................. 82

Figura 8 - Modelo Van Slyke, Kittner e Belanger (1998)........................................... 90

Figura 9 - Framework Belanger e Jordan (2000)...................................................... 91

Figura 10 - Modelo ACTION de Bates (1995),............................................................. 92

Figura 11 - Modelo E-Learning, segundo Hughes e Attwell's (2002)............................ 94

Figura 12 - Modelo e3Learning, adaptado de Lam e McNaught (2005)...................... 95

Figura 13 - Modelo de avaliação de usabilidade para aplicações e- learning, adaptado de Zaharias (2005) ........................................................................................... 96

Figura 14 - Abordagem sistemática para avaliação, segundo Russ-Eft e Preskill (2001, 2009).

Figura 15 - Resumo dos quatro primeiros capítulos.................................................... 109

Figura 16 - Sistematização do referencial da pesquisa................................................ 109

Figura 17 - Modelo de Gaps em qualidade em serviço, adaptado de Parasuraman et al. (1985)

Figura 18 - Esboço das Fases da Arquitetura de Orientação........................................... 123

Figura 19 - Fase Exploratória da Arquitetura de Orientação......................................... 130

Figura 20 - Relação da questão chave com o método de coleta de dados....................... 134

Figura 21 - Etapas da construção de um questionário, adaptado de Synodinos (2003). 142

Figura 22 - Etapas da construção de um questionário.................................................... 143

Figura 23 - Design pós-teste apenas...................................................................... 154

Figura 24 - Design pré-teste retrospectivo e pós-teste.................................................... 155

Figura 25 - Design pré e pós-teste.......................................................................... 155 
Figura 26 - Design pré e pós-teste com comparação entre grupos............................... 156

Figura 27 - Design pré e pós-teste com comparação e com acompanhamento........... 156

Figura 28 - Design testes intermediários e pós-teste................................................ 157

Figura 29 - Design regressão-descontinuidade..................................................... 158

Figura 30 - Design Solomon em quatro grupos.................................................... 159

Figura 31 - Processo de análise qualitativa de dados, adaptado de Sampieri, Collado

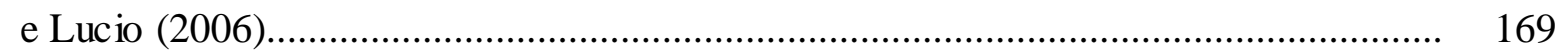

Figura 32 - Fase Diagnó stico da Arquitetura de Orientação......................................... 172

Figura 33 - Fase Estabelecimento da Arquitetura de Orientação................................ 175

Figura 34 - Fase Implementação da Arquitetura de Orientação.................................. 177

Figura 35 - Fase Aprendizagem da Arquitetura de Orientação.................................... 179

Figura 36 - Modelo lógico do assessment ................................................................. 193 


\section{LISTA DE TABELAS}

Tabela 1 - Os quatro níveis de avaliação de Kirkpatrick (1959)................................ 86

Tabela 2 - Kaufman's Five Level of Evaluation (1994)....................... 87

Tabela 3 - O esquema de 5 níveis para ROI em Avaliação......................................... 89

Tabela 4 - Modelo CIAO de avaliação, para aprendizagem assistida por computador.. 93

Tabela 5 - Categorias de Avaliação (Credenciamento)............................................. 97

Tabela 6 - Cate gorias de Avaliação (Autorização)................................................... 100 


\section{LISTA DE QUADROS}

Quadro 1 - Principais diferenças entre assessment e evaluation, adaptado de Angelo e Cross (1993)

Quadro 2 - Dimensões e elementos integrantes de um plano de assessment ou evaluation.

Quadro 3 - Utilização dos 5W2H no plano de assessment.

Quadro 4 - Principais pontos críticos para a validade interna, adaptado de Silvares e Arantes (2010) e Chagas (2004)...... 70

Quadro 5 - Principais pontos críticos para a validade externa 71

Quadro 6 - Dimensões e critérios para credenciamento de polos de apoio presencial.... 100

Quadro 7 - Estratégias utilizadas para o alcance dos objetivos................................... 111

Quadro 8 - Checklist dos Elementos da Fase Exploratória............................................. 132

Quadro 9 - Ponto de controle para a Fase Exploratória..................................................... 133

Quadro 10 - Síntese de alguns métodos de coleta de dados, adaptado de Russ-Eft;

Preskill (2001) e McNamara (2008)

Quadro 11 - Modelo de Planejamento de Análise de Dados

Quadro 12 - Checklist dos Elementos da Fase Diagnóstico. 169

Quadro 13 - Ponto de controle para a Fase Diagnóstico.

Quadro 14 - Ponto de controle para a Fase Estabelecimento.

Quadro 15 - Ponto de controle para a Fase Implementação.

Quadro 16-Checklist com os elementos da Fase Aprendizagem.

Quadro 17 - Ponto de controle para a Fase Aprendizagem

Quadro 18 - Relação entre os métodos de coleta de dados e as questões chave da avaliação.

Quadro 19 - Relação entre os métodos de coleta de dados e os métodos de triangulação

Quadro 20 - Distribuição dos Indicadores de Diferença para todas as questões do questionário

Quadro 21 - Indicador de diferença para todas as questões.

Quadro 22 - Indicador de Diferença Ponderada para as 55 questões.

Quadro 23 - Ordenação crescente de Indicador de Diferença Ponderada. 
Quadro 24 - Resumo das análises utilizando o teste de Mann-Whitney...................... 219

Quadro 25 - Resumo das análises utilizando o teste de Wilcoxon................................ 222

Quadro 26 - Exemplos de distribuição de frequência.................................................. 265 


\section{LISTA DE GRÁFICOS}

Gráfico 1- Idades dos participantes......................................................................... 203

Gráfico 2 - Experiência dos professores em EaD...................................................... 204

Gráfico 3 - Grau de satisfação dos professores com relação ao curso em que atuaram 210

Gráfico 4 - Cruzamento entre Indicador IDP x ID...................................................... 218 


\section{SUMÁRIO}

\section{CAPÍtULO 1}

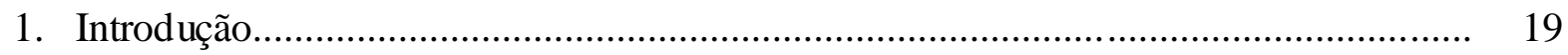

1.1. Contextualização e problema................................................................................... 21

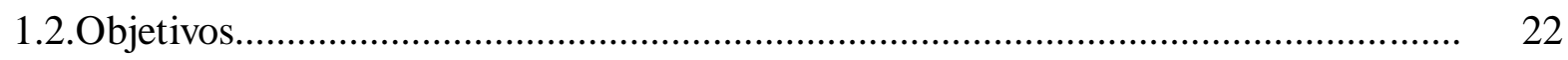

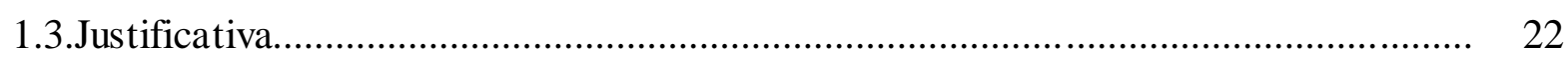

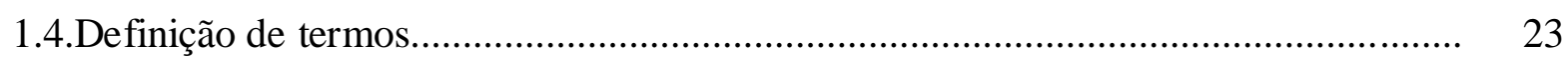

1.5.Estrutura do trabalho....................................................................................... 24

\section{CAPÍtULO 2}

2. A Importância da Avaliação: Assessment e Evaluation............................................. 27

2.1.Contexto da Avaliação................................................................................... 27

2.2.Evaluation e Assessment .................................................................................... 32

2.3.Padrões internacionais para o processo de avaliação................................................ 34

2.4.A avaliação na Educação Superior do Brasil.............................................................. 38

2.4.1. A avaliação institucional........................................................................... 40

2.5.Assessment e Evaluation como critério de qualidade em EaD................................... 42

2.5.1. Referenciais de qualidade para a EaD no Brasil................................................ 46

\section{CAPÍTULO 3}

3. Evidências Científicas: confiabilidade, validade e triangulação................................. 51

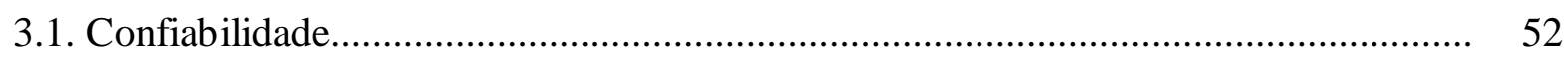

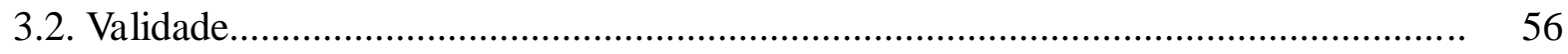

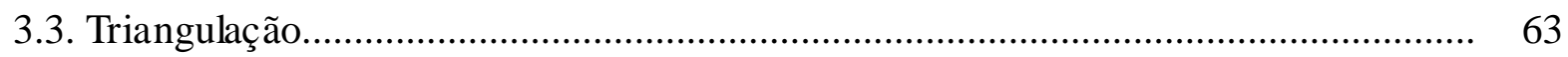

3.4.Messick's framework para validade da avaliação..................................................... 65

3.5.Pontos críticos para a validade interna e externa...................................................... 69

\section{CAPÍTULO 4}

4. Modelos de Avaliação no Contexto da EaD: teoria e prática ……………………...... 72

4.1. Modelo Lógico de Avaliação segundo Marynowski (2006)........................................ 72

4.2.Modelo Sistemático para Avaliação do E-Learning, segundo Mungania e Hatcher (2004)...

4.3.A Practical Framework for Evaluation Online Distance Education Program, segundo Rovai (2003). 
4.4.The Kirkpatrick's Four Level of Evaluation (1959)........................ 86

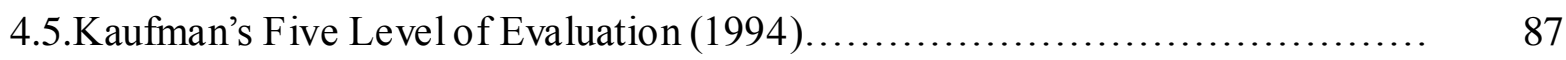

4.6.CIRO (Context, Input, Reaction, Outcome) Approach (1997).................. 87

4.7.Esquema dos cinco níveis de retorno sobre investimento (1997).............................. 88

4.8.Modelo de Avaliação de Van Slyke, Kittner e Belanger (1998)................................ 89

4.9.Framework Belanger e Jordan (2000)..................................................................... 90

4.10. Modelo AC TION de Betes (1995).................................................................. 92

4.11. Modelo CIAO de Scanlon et al. (2000) ............................................................ 93

4.12. Modelo E-Learning, segundo Hughes e Attwell's (2002).................................. 93

4.13. Modelo e3Learning, segundo Lam \& McNaught (2005) ................................... 94

4.14. Modelo de avaliação de usabilidade para aplicações e-learning, segundo

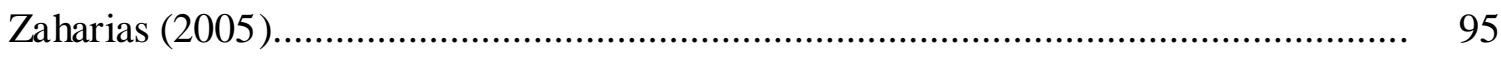

4.15. Sistema Nacional de Avaliação da Educação Superior no Brasil (2004)............ 97

4.15.1. Instrumento de Credenciamento Institucional para a Oferta da Modalidade de Educação a Distância (MEC/INEP, 2009)............................................................. 97

4.15.2. Instrumento de Credenciamento de Polo de Apoio Presencial Modalidade de Educação a Distância (MEC/INEP, 2009).

4.15.3. Instrumento de Autorização de Cursos para a Oferta na Modalidade de Educação a Distância (MEC/INEP, 2009).

4.16. Abordagem Sistemática para Avaliação, segundo Russ-Eft e Preskill (2001, 2009)

4.17. Matriz de enquadramento dos modelos no roteiro adaptado Messick's Framework (1989) - dimensão x elementos x modelos

\section{CAPÍTULO 5}

5. Metodologia.

5.1. Contextos Metodológicos da Pesquisa.

5.1.1. Caracterização da Pesquisa

5.1.2. Local do Estudo

5.1.3. População.

5.2. Etapas do Desenvolvimento da Pesquisa.

\section{CAPÍTULO 6}

6. Descrição da Construção da Arquitetura de Orientação 
6.2. Gaps da qualidade percebida (ideal x real) .......................................................... 118

6.3. Fases da Arquitetura de Orientação................................................................................ 123

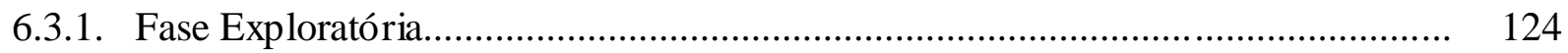

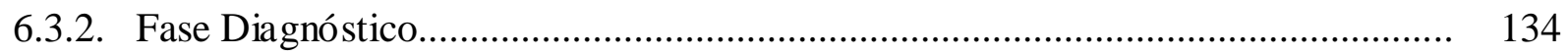

6.3.2.1.Métodos e Instrumentos de Coleta de Dados.......................................................... 134

6.3.2.2.Pré-teste ou teste piloto...................................................................................... 153

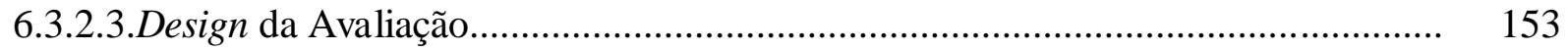

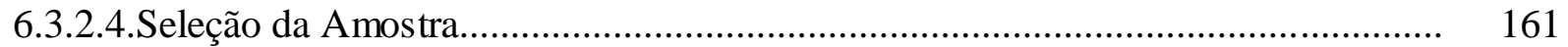

6.3.2.5. Operacionalização da Coleta de Dados................................................................ 165

6.3.2.6. Métodos e Instrumentos para a Análise e Interpretação de Dados ...................... 166

6.3.3. Fase Estabelecimento................................................................................. 175

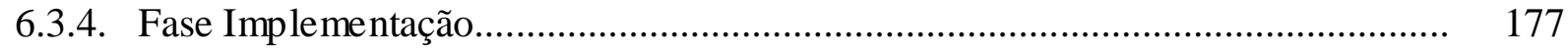

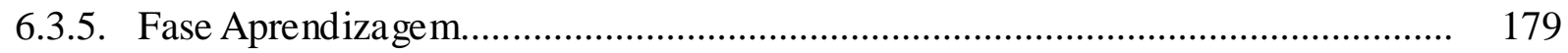

6.3.6. Síntese dos componentes da Arquitetura de Orientação......................................... 183

\section{CAPÍTULO 7}

7. Desenvolvimento de uma Solução Baseada na Arquitetura de Orientação para Assessment de Programas de Educação a Distância.

7.1.Construção do Plano de Assessment para analisar a percepção do professor em relação à participação em um curso de Especialização a distância.

\section{CAPÍtULO 8}

8. Aplicação da solução desenvolvida a partir da arquitetura de orientação para assessment de Programas de Educação a Distância.

8.1.Análise qualitativa

8.2.Análise quantitativa.

8.2.1. Abordagem Descritiva.

8.2.2. Abordagem Inferencial Não-Paramétrica.

8.3. Análise Geral.

\section{CAPítulO 9}

9. Conclusões e Considerações Finais.

APÊNDICE A - Detalhamento dos Padrões Internacionais de Avaliação.

APÊNDICE B - Modelo de Relatório do Plano de Assessment.. 
APÊNDICE D - Detalhamento sobre Análise Quantitativa de Dados........................... 259

APÊNDICE E - Termo de Consentimento Livre e Esclarecido......................................... 267 


\section{CAPÍTULO 1 - Introdução}

A educação superior evolui conforme as necessidades da sociedade e isso passa pela construção do conhecimento como principal fonte de riqueza, a qual está atrelada à transformação constante da realidade.

No entanto, cada vez mais a educação superior é alvo de avaliações e acompanhamentos, tendo em vista a importância da qualidade e dos indicadores, uma vez que comparações sempre vão existir, principalmente com indicadores internacionais. Essa situação leva cada vez mais os gestores a buscarem políticas públicas efetivas, capazes de melhorar os indicadores da educação no Brasil, tanto no aspecto qualitativo como quantitativo.

Para identificar indicadores necessariamente deve-se transitar pela avaliação, a qual pode ser compreendida como uma atividade contínua, que visa medir e monitorar o progresso de uma determinada ação ou projeto, cuja base está na definição clara dos objetivos, estratégias e resultados esperados. Contudo, a avaliação torna-se o elemento fundamental para o aperfeiçoamento da instituição dentro de seu escopo de atuação.

Sabe-se que dentre os diferentes escopos de atuação, a educação se sobressai pela urgência em democratizar o conhecimento, bem como em assegurar uma formação integral de qualidade, por meio de sistemas educacionais de inclusão social que respeitem a diversidade brasileira e tenham como objetivo a transformação da realidade.

Para que a transformação da sociedade aconteça e que de fato haja inclusão social é importante a implantação de novas formas de ensino, dentre as quais a Educação a Distância (EaD) se destaca, visto que aponta para uma inserção política, pedagógica e social de todos os seus agentes (stakeholders) nesta construção. Portanto, a EaD deve ser um componente de inovação nos processos de ensino e aprendizagem, uma vez que o advento das tecnologias de informação e comunicação na $\mathrm{EaD}$ proporcionou sua revitalização, o que colabora para a inovação dos processos de ensino e aprendizagem.

Além disso, a EaD tem sido vista como ferramenta relevante para a construção de políticas públicas de inclusão social (MATIAS-PEREIRA, 2008).

No Brasil, assim como em outros países, houve um crescimento significativo da EaD nos últimos anos. Com isso, surge a necessidade de acompanhar essa expansão, avaliando o desenvolvimento dos processos e os resultados obtidos. Essa avaliação pode ser compreendida em seu sentido qualitativo (valor, mérito e importância) e/ou quantitativo 
(mensuração de resultado), uma vez que esse procedimento fornece indicativos para a obtenção de sucesso. Logo, dispor de modelos flexíveis no uso, porém robustos em resultados, torna-se imperativo neste contexto.

Analisando o contexto brasileiro, se percebe a falta de uma avaliação sistemática que possa apontar as fraquezas e identificar oportunidades, cujos resultados possam sinalizar caminhos de melhoria contínua da qualidade da EaD no Brasil. Tendo em vista que é grande a carência de dados quantitativos e qualitativos sobre a EaD no sistema de educação superior, observa-se a importância de se ter modelos que possam auxiliar na concepção, planejamento e execução da avaliação de maneira a contribuir para que diferentes informações se tornem subsídios para a tomada de decisão, bem como para fortalecer o corpo teórico e prático da $\mathrm{EaD}$ no Brasil, com reconhecimentos e qualificações capazes de assegurar o acesso e a conclusão, com sucesso, do ensino superior na modalidade a distância.

No Brasil há uma grande diversidade de modelos de $\mathrm{EaD}$, o que é naturalmente aceitável considerando as suas características territoriais. Cada instituição procura criar modelos de avaliação conforme suas especificidades, entretanto, percebe-se que a construção de modelos/frameworks necessita de evidências de confiabilidade e validade, pois somente desta forma será possível ter credibilidade nos resultados obtidos pelo instrumento de avaliação criado. No entanto, ao analisar a literatura nacional sobre $\mathrm{EaD}$, não fica evidente esta preocupação, conforme verificado, por exemplo, nos artigos publicados na biblioteca científica Scielo, onde ao se buscar por uma combinação de palavras-chave (EaD confiabilidade - validade) tem-se pequeno retorno.

Em muitos casos os instrumentos são adaptados sem o devido rigor científico, proporcionando ameaças à validade e confiabilidade, bem como modelos internacionais são aplicados de forma acrítica, o que consequentemente coloca em dúvida a acurácia dos resultados.

Embora existam diversos modelos de avaliação, é sempre necessário tratar a EaD de forma individualizada, pois as necessidades são próprias de uma determinada realidade e a simples adequação ou mesmo a construção de modelos sem rigor científico acaba ocasionando o não atendimento de sua totalidade, bem como a necessidade de informações confiáveis e válidas.

Observa-se que existe um gap entre os modelos de avaliação utilizados e a necessidade de rigor científico, ou seja, evidências de confiabilidade e validade.

Diante deste contexto e considerando que se trata de um estudo científico, em que se pretende desenvolver, aplicar e avaliar a percepção de uma realidade, na qual os dados 
necessitam ser os mais fiéis, adotou-se uma seleção cuidadosa de indagações que formarão o corpo desta investigação, cuja centralidade está no público a ser analisado. Desta forma, uma arquitetura de avaliação (assessment), como esta se propõe, é uma tentativa de abstrair a realidade de um universo que se quer analisar, bem como obter dados conclusivos sobre a realid ade.

Nessa perspectiva, a proposta desta investigação é criar uma arquitetura de orientação para a construção de instrumentos que possam avaliar programas de EaD. Utilizou-se uma metodologia que, baseada em evidências científicas, transforma os dados obtidos em possíveis padrões para subsidiar diagnósticos, análises e melhorias contínuas, voltados aos agentes envolvidos com a EaD.

Para isso, o conceito de EaD adotado neste estudo é:

“A Educação a Distância é a modalidade educacional na qual a mediação didático-pedagógica nos processos de ensino e aprendizagem ocorre com a utilização de meios e tecnologias de informação e comunicação via Internet, com estudantes e professores desenvolvendo atividades educativas em lugares e/ou tempos diversos" (Adaptada do DECRETO 5.622, de 19/12/2005).

Todavia, o desenvolvimento de uma arquitetura de orientação e/ou modelos de referência são sempre hipóteses provisórias do real (ALVES, 1994), que, assim, necessitam ser testadas e avaliadas ao longo do tempo, uma vez que cada instituição deve ser tratada individualmente com suas características e especificidades, o que naturalmente pode se alterar no percurso de sua existência.

\subsection{Problema Abordado}

A diversidade brasileira proporciona uma variedade de metodologias, técnicas, métodos, instrumentos e dimensões ao se avaliar programas de EaD. Contudo, verifica-se a necessidade de que este instrumental tenha evidências de confiabilidade e validade, independentemente de seu contexto.

Assim, a partir desta constatação, extraiu-se um problema prático de pesquisa: Qual a estrutura de uma arquitetura de orientação que, a partir da realidade brasileira, oriente a construção de instrumentos com evidência de confiabilidade e validade para avaliação (assessment) de Programas de EaD? 


\subsection{OBJETIVOS}

Derivados do problema, foram traçados os objetivos que são apresentados na sequência.

\section{GERAL:}

Propor uma arquitetura que oriente a construção de instrumentos para avaliação (assessment) de Programas de Educação a Distância, com evidências de confiabilidade e validade.

\section{ESPECÍFICOS:}

- Sistematizar conceitos de metodologia de pesquisa para o contexto da avaliação (assessment).

- Definir um conjunto de requisitos, padrões e informações necessários ao desenvolvimento de uma arquitetura de orientação para avaliação (assessment) de Programa de EaD.

- Desenvolver um Plano de Assessment para mapear a percepção de EaD de professores atuantes em um curso de especialização ofertado na modalidade a distância, a partir da arquitetura proposta.

- Aplicar o Plano de Assessment desenvolvido em estudo de caso.

- Analisar os resultados dos instrumentos desenvolvidos no Plano de Assessment.

- Examinar a confiabilidade e a validade da arquitetura de orientação e do instrumento desenvolvidos.

\subsection{JUSTIFICATIVA}

Conforme comentado, existe um gap entre os modelos de avaliação existentes e o rigor científico necessário, uma vez que cada instituição de ensino cria e/ou adapta seus instrumentos conforme suas características e especificidades, sem muitas vezes se preocupar com as evidências de confiabilidade e validade, bem como o rigor científico, tão necessárias para que seus resultados possam ser utilizados com segurança na tomada de decisão.

Nesse sentido, a originalidade deste estudo está no desenvolvimento de uma arquitetura de orientação, que a partir de requisitos objetivos de caráter qualitativo e quantitativo, permite avaliar Programas de EaD. 
A relevância da pesquisa está em propiciar à sociedade uma arquitetura de orientação para a construção de instrumentos de avaliação (assessment) para programas de $\mathrm{EaD}$, com evidências de confiabilidade e validade, de forma que cada curso/programa seja tratado de forma individualizada, respeitando seus diferentes contextos e especificidades. Além disso, busca atender uma ampla gama de situações, uma vez que por meio da arquitetura diferentes os instrumentos de assessment podem ser desenvolvidos.

Nessa perspectiva, a principal contribuição da pesquisa é teórico-metodológica, considerando o arcabouço teórico e os procedimentos passo-a-passo que são apresentados, o que facilita a construção de instrumentos de assessment com evidências de confiabilidade e validade, de acordo com as necessidades e especificidades dos programas de $\mathrm{EaD}$.

\subsection{DEFINIÇÃO DE TERMOS}

Arquitetura de Referência: é basicamente um padrão ou conjunto de padrões de arquitetura predefinido, possivelmente parcial ou totalmente instanciado, projetado e testado em determinados contextos de negócios e técnicos com artefatos de suporte que permitam seu uso. Geralmente, esses artefatos são resultantes de projetos anteriores (http://www.wthreex.com/rup/process/ artifact/ar_refarch.htm). Trata-se de um conjunto de padrões que definem uma aplicação, independentemente do objeto (adaptada de MICHAELIS, 2009).

Crité rio: usado no sentido "o que precisa ser medido?".

Indicador: usado no sentido "o que pode ser utilizado para medir?".

Programa de EaD: entende-se como programa, curso e/ou disciplina ofertado na modalidade a distância.

Processar: é o verbo que indica a ação de avançar, ir para frente. É o conjunto sequencial e peculiar de ações que objetivam atingir uma meta. Sucessão sistemática de mudanças numa direção definida. Série de ações sistemáticas visando certo resultado. É usado para criar, inventar, projetar, transformar, produzir, controlar, manter e usar produtos ou sistemas (adaptada de MICHAELIS, 2009).

Evaluation: é o julgamento ou determinação da qualidade do desempenho, do produto ou da utilização de um processo frente a um padrão (PARKER et al., 2001).

Assessment: é o processo de medição de desempenho, produto de um trabalho ou capacidade de aprendizagem que apresenta realimentação, documenta o crescimento e fornece diretrizes para melhorar o desempenho futuro (PARKER et al., 2001). Facilita o processo de melhoria, o 
qual é multidimensional e integrado.

Confiabilidade: A confiabilidade, fidedignidade ou precisão de um teste diz respeito à característica que ele deve possuir, a de medir sem erros, ou seja, o mesmo teste medindo os mesmos sujeitos em ocasiões diferentes ou testes equivalentes medindo os mesmos sujeitos na mesma ocasião produzem resultados idênticos. A correlação entre essas duas medidas deve ser de 1, sendo que o coeficiente de correlação expressa o nível de relação ou a correspondência que existe entre os dois eventos (PASQUALI, 1997).

Validade: é a capacidade de um instrumento medir aquilo que se propõe a medir, ou seja, mede o que se deseja (RICHARDSON, 1999).

\subsection{ESTRUTURA DO TRABALHO}

Este estudo está organizado em nove capítulos, sendo que o primeiro, já apresentado, refere-se à introdução, apresentando uma visão geral da investigação, com destaque para o problema abordado e os objetivos.

O Capítulo 2 ressalta a importância da avaliação (assessment e/ou evaluation) como tema de estudo e nele são relatados os principais conceitos, métodos, instrumentos e princípios, bem como os indicativos de qualidade atrelados à avaliação.

Este capítulo tem, ainda, o propósito de embasar o estudo, sobretudo no tocante a padrões internacionais. Além disso, apresenta uma variedade de elementos essenciais a uma avaliação que, por conseguinte, comporá a arquitetura de orientação, proposta deste estudo.

O Capítulo 3 apresenta um arcabouço teórico sobre a confiabilidade, validade e triangulação, relatando a importância dessas evidências na construção de instrumentos de avaliação, bem como suas possíveis ameaças e/ou pontos críticos. Além disso, toma um modelo de validade existente como referência para a adaptação de um roteiro de dimensões para a arquitetura de orientação, no qual ressalta, sobretudo, a importância dos elementos [das dimensões] para sustentar a construção de instrumentos avaliativos.

O Capítulo 4 apresenta uma fundamentação de alguns modelos já existentes para a avaliação em geral e para o contexto da $\mathrm{EaD}$, abordando aspectos teóricos e práticos de sua construção e aplicação sob diferentes perspectivas. Finaliza-se com uma matriz de enquadramento segundo o roteiro desenvolvido no capítulo anterior.

O Capítulo 5 descreve a trajetória metodológica para a realização desta investigação, apresentando a caracterização e procedimentos realizados na pesquisa, bem como relaciona as estratégias utilizadas para atingir aos objetivos propostos. 
O Capítulo 6 relaciona e descreve o arcabouço teórico e prático utilizado para fundamentar e sustentar a construção da arquitetura de orientação.

Neste capítulo são apresentadas todas as fases da arquitetura de orientação proposta, bem como os componentes utilizados em sua construção.

O Capítulo 7 apresenta o desenvolvimento de uma solução baseada na arquitetura de orientação proposta, ou seja, é elaborado um Plano de Assessment para uma realidade prática.

Neste capítulo é apresentada a construção deste Plano seguindo etapa por etapa da arquitetura de orientação desenvolvida, como forma de identificar e validar os seus componentes.

O Capítulo 8 apresenta os resultados, as análises e discussão, ou seja, discute e analisa a criação da arquitetura, o desenvolvimento da solução (Plano de Assessment) a partir da arquitetura proposta e a aplicação desta solução.

No Capítulo 9 são apresentadas as conclusões e considerações finais desenvolvidas a partir de todo o estudo.

Para finalizar, são apresentadas as referências bibliográficas e os apêndices utilizados na pesquisa.

A figura 1 ilustra esta estruturação em capítulos, sendo possível ter uma visão geral do desenvolvimento da tese. 

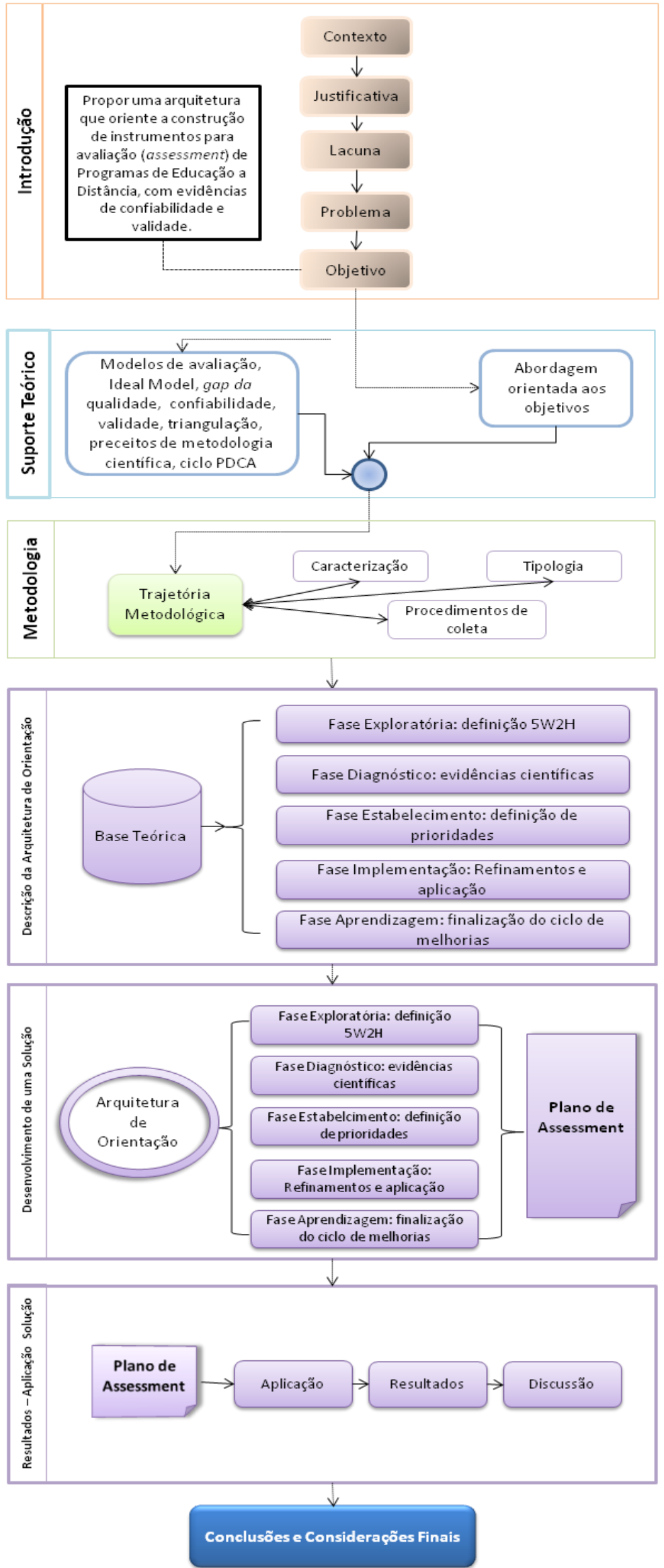

Figura 1 - Estruturação da Tese 


\section{CAPÍTULO 2 - A importância da avaliação: Assessment e Evaluation}

Neste capítulo são tratados diversos conceitos relacionados à avaliação (assessment e evaluation) e a pesquisa científica, bem como suas interfaces com a EaD. Esta fundamentação tem o propósito de embasar o estudo, sobretudo no tocante a padrões internacionais. Além disso, apresenta uma variedade de elementos essenciais a uma avaliação, os quais, por conseguinte, comporão a arquitetura de orientação.

\subsection{ConteXto Da Avaliação}

A avaliação [de programas] surgiu, de forma sistemática, a partir da aplicação de métodos de pesquisa científica aos problemas sociais. Os primeiros esforços foram observados antes mesmo da Primeira Guerra Mundial, quando se tentou avaliar os programas de alfabetização e treinamento profissionalizante e os programas de redução da mortalidade e da morbidade causadas por doenças infecciosas (ROSSI \& FREEMAN, 1993).

Ainda de acordo com Rossi e Freeman (1993), na década de 30 muitos esforços foram estendidos a outras áreas e novas técnicas de pesquisa foram amplamente aplicadas na avaliação de programas sociais. No final dos anos 50, a avaliação de programas ganhou novo impulso, ampliando-se consideravelmente em países industrializados e em desenvolvimento. Além disso, técnicas de análise quantitativa complexas passaram a ser utilizadas durante o processo de avaliação.

Segundo Rossi e Freeman (1993), a pesquisa na área de avaliação cresceu significativamente no período pós-guerra face ao desenvolvimento de métodos estatísticos e de pesquisas aplicáveis ao estudo dos problemas sociais, dos processos sociais e das relações interpessoais. Esse expressivo crescimento fez com que a década de 60 caracterizasse o boom da avaliação. As décadas seguintes continuaram reconhecendo a importância e relevância da avaliação. Tudo isso exigiu métodos sofisticados de avaliação, o que estimulou o trabalho metodológico em prol da avaliação.

A avaliação teve diversos significados e propósitos, ao longo da história, nos diferentes segmentos da sociedade, de forma a convencer sobre a sua importância, valor, mérito e mensuração. Nesse sentido, serve como elemento de "acreditação" de qualquer tipo de programa, tendo como finalidade ajudar no planejamento e acompanhamento de programas para o sucesso dos resultados. 
Existe uma diversidade de definições sobre avaliação, sendo que Carol Weiss (1972) a define como uma atividade na qual se procura medir os efeitos de um programa em relação aos objetivos almejados, como forma de contribuir para a tomada de decisões sobre o programa e aperfeiçoar programações futuras.

Para Verdung (1993), a avaliação é um mecanismo ex post para explicar e medir a implementação, os resultados e o alcance das políticas e programas públicos, com o propósito de gerar decisões futuras. Corroborando, Belloni (1995) destaca a avaliação como um processo de aferição de ações que permite o autoconhecimento institucional, a correção e o aperfeiçoamento das ações institucionais.

Rossi e Freeman (1993) definem a avaliação como sendo uma aplicação sistemática de procedimentos de pesquisa científica para verificar a conceitualização, o design, a implementação e a utilidade. Para eles, a avaliação é, antes de tudo, uma atividade complexa que envolve decisões políticas e administrativas.

De acordo com Rossi, Lipsey e Freeman (2004), a definição básica de avaliação passa por três variações: (a) pode ser sistemática e focada em determinar um objetivo de valor; (b) a definição geral é alargada para destacar uma série de critérios genéricos e importantes para avaliar programas e (c) mais expandida a fim de delinear as principais etapas envolvidas na realização de uma boa avaliação, salientando a importância de se obter uma informação descritiva e confiável. Logo, considera-se adequada esta definição porque (1) concentra a atenção sobre a essência da avaliação, (2) pode ser útil quando se fala com clientes sobre os valores que deverão ser referenciados ao avaliar um programa e (3) é relevante quando destaca o planejamento como neces sário à avaliação.

Para o Joint Committee's (1994), “avaliação é uma análise sistemática do valor ou mérito de um objeto”. A vantagem desta definição é que ela é concisa, consistente com os significados comuns da avaliação, além de ser adotada pelo Joint Commitee's on Standards for Education Evaluation. Percebe-se que esta definição é relevante ao se tratar de avaliação em nível geral.

A avaliação é uma coleção sistemática e detalhada de informações sobre as atividades, características e resultados dos programas para o julgamento deles, melhorando sua eficácia e/ou apresentando elementos para as decisões futuras (MARYNOWSKI, 2006).

A avaliação pode ajudar a determinar quão bem está o programa ou se os seus resultados estão ou não atendendo a certos critérios. Além disso, apresenta feedback, o qual é útil para todos os interessados.

Enfim, uma avaliação inclui um amplo espectro de atividades envolvidas na coleta de 
dados e na transformação deles em resultados úteis, proporcionando informações fundamentais para o processo de tomada de decisões (administrativas, planejamentos didáticos, pedagógicos...), tendo diferentes definições para diferentes interesses. Muitas vezes a avaliação é vista como um processo sistemático e contínuo.

Para Scriven (1991) avaliação é um processo que determina o mérito, importância ou valor de uma coisa ou processo ou produto. Entretanto, quando se avalia programas, processos, produtos ou sistemas, dentro de uma organização, é impossível e irresponsável ignorar o elemento humano (RUSS-EFT; PRESKILL, 2001). Desta forma, o indivíduo deve ser visto como um componente ou característica de sucesso em um processo de avaliação.

Como se observa, a definição do termo avaliação tem abordagens diferentes, estando associada à realização dos objetivos comportamentais, passando pela ênfase do julgamento profissional, visto que se acredita na coleção e análise da informação para a tomada de decisão (ROSSI, LIPSEY \& FREEMAN, 2004).

A avaliação acontece em todos os momentos, sendo que as pessoas e as organizações estão sempre avaliando alguma coisa. No entanto, quais são as razões da avaliação? Segundo Russ-Eft e Preskill (2001), podem ser:

- a avaliação assegura qualidade;

- a avaliação contribui para o aumento do conhecimento dos membros da organização;

- a avaliação ajuda a priorizar recursos;

- a avaliação ajuda a planejar e a executar as iniciativas; e

- os resultados da avaliação podem ajudar a convencer os outros sobre a necessidade e/ou efetividade de uma iniciativa.

Sabe-se que o processo de avaliação deve ser cuidadosamente planejado para ser efetivo, bem como pode ter interesses e razões diferentes em cada uma de suas etapas. Normalmente, um processo de avaliação deve ter começo, meio e fim, separado por diferentes estágios e/ou etapas, cujos resultados são refletidos nos objetivos da avaliação.

Considerando que a avaliação pode ser aplicada em diferentes contextos e para diferentes objetivos, os quais necessitam ser tratados adequadamente para que se obtenham resultados satisfatórios, Palomba e Banta (1999) descrevem alguns princípios que devem ser considerados no processo de avaliação:

- a avaliação deve distinguir os diferentes usos (formativo, somativo...);

- deve-se utilizar diferentes métodos;

- os resultados da avaliação devem ser socializados e utilizados;

- o processo de avaliação deve ser avaliado. 
Desta forma, é notório que quando se fala em avaliação, não se faz referência sempre à mesma coisa; isso porque não há um só tipo de avaliação sobre o qual exista consenso. Contudo, é sempre importante destacar que a tarefa de avaliação é complexa e árdua, e, segundo Turra et al. (1998), requer:

- definição de atributos significativos para o julgamento de valor do que vai ser avaliado (o que usar?);

- procedimentos de descrição dos atributos de maneira objetiva e precisa (como usar?);

- síntese das evidências alcançadas por esses procedimentos, em um julgamento final de valor (obtenção dos resultados).

As avaliações são classificadas em diferentes tipos e, de acordo com Turra et al. (1998), no contexto acadêmico destacam-se os seguintes:

- DIAGNÓSTICA: é aquela realizada no início do curso a fim de constatar se os discentes possuem os conhecimentos, habilidades e comportamentos necessários para as novas aprendizagens.

- FORMATIVA: tem como base o acompanhamento e a orientação do aprendiz durante o desenvolvimento de tarefas planejadas para levá-lo a um engajamento ativo na construção dos seus conhecimentos.

- SOMATIVA: deve ser realizada no final do curso e geralmente tem em vista a promoção de um grau para outro.

Para Scriven (1991) avaliação formativa é tipicamente conduzida durante o desenvolvimento ou melhoria de um programa, processo ou produto e é conduzida frequentemente por mais de uma vez com a intenção de melhorar.

Russ-Eft \& Preskill (2001) relatam que a avaliação somativa possui subtipos, tais como:

- Monitoramento e Auditoria: frequentemente associado com a necessidade de verificação e checagem da implementação do programa, atestando se está sendo desenvolvido conforme planejado e aprovado. As auditorias são mais focadas nos programa financeiros, de forma a investigar se estão utilizando os recursos apropriadamente.

- Avaliação de Resultados : é o processo e os procedimentos para avaliar, em uma base regular, os resultados de um programa. Em essência, resultados se referem aos benefícios ou mudanças no conhecimento, atitudes, valores, habilidades, comportamento, cond ição ou status dos participantes da avaliação.

- Avaliação de Impacto: foca os resultados da intervenção ou programa sobre os 
participantes.

- Medição de Desempenho: é um conjunto de medidas referentes à organização como um todo, às suas partições (divisões, departamento, seção, etc.), aos seus processos e às suas atividades organizadas em blocos bem definidos, de forma a refletir certas características do desempenho para cada nível gerencial interessado (MOREIRA, 1996). Logo, o objetivo do Sistema de Medição de Desempenho na empresa é estabelecer o grau de evolução ou estagnação de seus processos e atividades; assim como a adequação ao uso de seus bens e serviços, fornecendo informação precisa no momento adequado, a fim de efetuar ações preventivas e/ou corretivas que levem à conquista das metas e objetivos da empresa.

Além desses tipos, existe também uma lógica para a avaliação, que, segundo Fournier (1995), envolve:

- estabelecer critérios;

- construir padrões;

- medir desempenho e comparar com os padrões; e

- sintetizar e integrar evidências dentro do julgamento de importância.

A lógica da avaliação também inclui o desenvolvimento de recomendações para ações futuras. Entretanto, para que estas recomendações sejam efetivas é importante observar as principais características de um bom instrumento de avaliação, as quais, segundo Tarouco (2007), são:

- Validade: mede o que se propõe a medir e permite generalizações apropriadas.

- Consistência: requer definição clara sobre o que se espera da avaliação.

- Coerência: apresenta conexão com os objetivos.

- Abrangência: envolve todo o conhecimento e habilidades necessários.

- Clareza: deixa claro o que é esperado; não confunde nem induz respostas (evita ambiguidades, etc.).

- Equidade: deve contemplar igualmente os grupos (não privilegia um ou outro grupo). Todavia, ao se falar em avaliação no Brasil, se tem a ideia de resultado (avaliação somativa), sendo que esta proposição só é desfeita quando se acrescenta a possibilidade de ser formativa ou diagnóstica. No entanto, ao se pesquisar sobre avaliação na literatura internacional dois termos, assessment e evaluation, aparecem frequentemente, os quais possuem conceitos diferenciados, embora com algumas similaridades. 


\subsection{ASSESSMET E EVALUATION}

Numa atividade de investigação científica uma abordagem passo-a-passo facilita o processo e possibilita melhores respostas. E esse passo-a-passo pode incluir assessment, definição de objetivos, planos, implementações e evaluation. O assessment constitui o primeiro passo de um processo científico ou de uma investigação, ou seja, é a base para evaluation, uma vez que são consideradas as evidências preliminares do estudo, cujo principal objetivo é trazer melhorias para o tema em estudo; o qual pode ser de qualquer tipo ou natureza.

O assessment é um processo para determinar "o que é" e fornece informações numéricas ou não para facilitar a tomada de decisão eficaz e de qualidade. Já o evaluation utiliza as informações geradas pelo assessment para realizar julgamentos de valor.

De acordo com Linn e Miller (2005), assessment é um processo sistemático e contínuo de coleta, análise e uso de informações de várias fontes para tirar conclusões sobre as características de alunos, programas ou instituições, para fins de tomada de decisão com o propósito de melhorar o processo de aprendizagem. Para Rossi, Lipsey e Freeman (2004) evaluation é "o processo sistemático de coleta, análise e uso de informações de várias fontes para julgar o mérito ou valor de um programa, projeto ou entidade".

Embora apresentem conceitos diferentes, observam-se algumas semelhanças entre os termos e, corroborando com isso, Jensen (2010) desenvolveu um diagrama de comparação entre assessment e evaluation, conforme Figura 2.

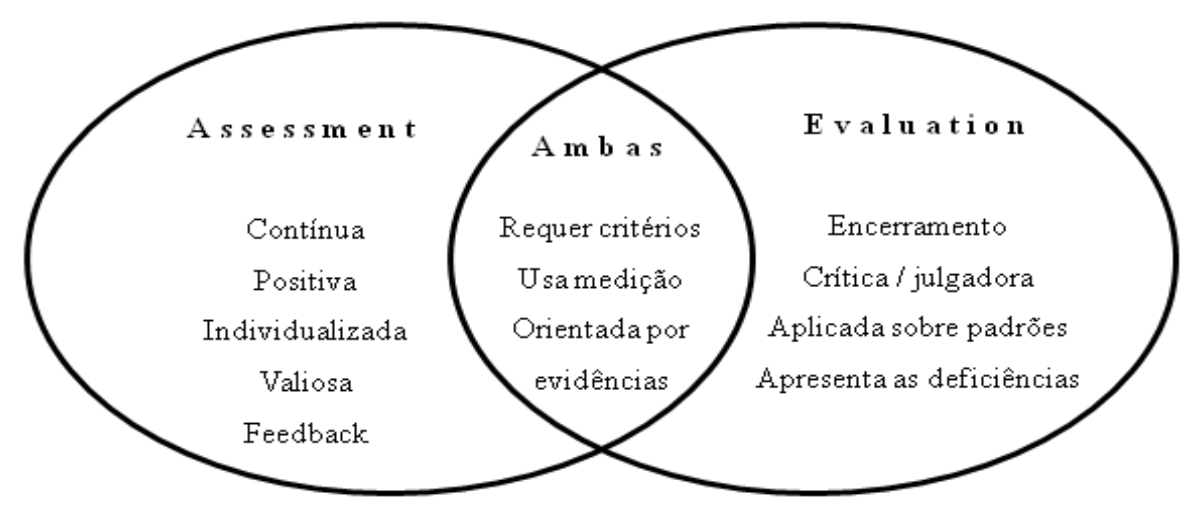

Figura 2 - Diagrama de comparação entre assessment e evaluation

Ao se observar as características comuns entre as duas palavras, encontram-se as razões da confusão entre os termos nos Estados Unidos e Europa. O termo assessment pode 
ser visto como o percurso e o evaluation como o "retrato" de uma situação. Logo, asse ssment refere-se à coleta de dados para descrever, ou melhor, entender um assunto, e evaluation refere-se à comparação dos dados a um padrão, com o propósito de julgar importância/valor ou mérito/qualidade (HUITT, HUMMEL, KAECK, 2001).

Angelo e Cross (1993) sumarizam as principais diferenças entre assessment e evaluation, conforme Quadro 1.

\begin{tabular}{|lll|}
\hline \multicolumn{1}{|c|}{ Dimensões das Dife renças } & \multicolumn{1}{c|}{ Assessment } & \multicolumn{1}{c|}{ Evaluation } \\
\hline Conteúdo: principal objetivo & Formativa: contínua, visando & Somativa: final, para aferição \\
& melhorias & de resultados \\
Orientação: foco em medição & Orientada ao processo: como & Orientada ao produto: o que \\
& está acontecendo & foi aprendido \\
Aplicações: uso & Diagnóstica: identificar áreas & Julgadora: chegar a uma \\
& de melhorias & classificação global/pontuação. \\
\hline
\end{tabular}

Quadro 1 - Principais diferenças entre assessment e evaluation, adaptado de Angelo e Cross (1993)

Ao inter-relacionar as diferenças entre assessment e evaluation ao contexto brasileiro, observa-se a predominância da avaliação com sentido de assessment.

Assim, o termo avaliação será utilizado neste estudo no sentido de assessment, ou seja, para construir um planejamento sistemático e articulado de métodos de pesquisa. Tais métodos consideram a coleta, a análise e interpretação das evidências de desempenho sobre o design, a implementação, o impacto e os resultados alcançados por determinado programa de $\mathrm{EaD}$, como forma de contribuir para a tomada de decisão e para o aprimoramento do desempenho futuro (melhoria contínua). 


\subsection{Padrões Internacionais Para o Processo de AvaliaÇão}

A avaliação pode acontecer tanto no âmbito público como no privado. Por meio dela é possível determinar a qualidade do segmento avaliado, bem como definir direções para o processo de melhoria contínua de desempenho.

Ao planejar uma avaliação diversos elementos são imprescindíveis para que se obtenha sucesso em sua construção e aplicação. Dentre estes elementos fundamentais é de suma importância atentar-se para os padrões de: utilidade (U), viabilidade (V), propriedade (P) e precisão/acurácia (A), que são descritos pelo The Joint Commitee on Standards for Educacional Evaluation (2009):

- Utilidade: as normas de utilidade visam assegurar que a avaliação atenderá às necessidades de informação dos envolvidos no processo.

○ U1 - identificação dos interessados: pessoas envolvidas ou afetadas pela avaliação devem ser identificadas, de modo que suas necessidades sejam atendidas.

○ U2 - credibilidade do avaliador: as pessoas que dirigem a avaliação de verão ser confiáveis e competentes, de modo que os resultados da avaliação possam atingir a máxima credibilidade e aceitação.

○ U3 - escopo e seleção da informação: as informações coletadas devem ser amplamente selecionadas para abordar questões pertinentes ao programa e responder às necessidades e interesses de todos os envolvidos.

○ U4 - identificação de valores: as perspectivas, os procedimentos e a lógica utilizada para interpretar os resultados devem ser cuidadosamente descritos, de modo que as bases para os julgamentos de valor sejam claras.

○ U5 - clareza dos relatórios: os relatórios da avaliação devem descrever claramente o programa que está sendo avaliado, incluindo o seu contexto, propósito, procedimentos e resultados da avaliação, de maneira que as informações essenciais sejam fornecidas e de fácil compreensão.

○ U6 - relatório de oportunidade e disseminação: os resultados significativos e os relatórios de avaliação devem ser divulgados para os interessados a que se destinam, de forma a serem utilizados em tempo hábil.

○ U7 - impacto da avaliação: as avaliações devem ser planejadas, conduzidas e relatadas de forma a estimular o acompanhamento pelas partes interessadas e possibilitar maior uso da avaliação. 
- Viabilidade: se destina a assegurar que uma avaliação será realista, prudente, diplomática e simples.

○ V1 - procedimentos práticos: os procedimentos da avaliação devem ser práticos para manter a interrupção a um mínimo, enquanto as informações necessárias são obtidas.

○ V2 - viabilidade política: a avaliação deve ser planejada e conduzida com antecipação das diferentes posições dos vários grupos de interesse, de maneira que a cooperação possa ser obtida e assim as tentativas de qualquer um dos grupos para prejudicar as ações de avaliação ou a parcialidade ou a não aplicação dos resultados possam ser evitadas ou combatidas.

○ V3 - custo efetivo: a avaliação deve ser eficiente e produzir informações de valor suficiente, de modo que os recursos gastos possam ser justificados.

- Propriedade: destina-se a assegurar que uma avaliação será conduzida legalmente, eticamente e considerando o bem-estar das pessoas envolvidas, bem como daquelas afetadas pelos resultados.

○ P1 - orientação ao serviço: as avaliações devem ser concebidas para auxiliar as organizações a abordar e atender efetivamente às necessidades de todos os participantes-alvos.

○ P2 - acordos formais: as obrigações das partes formais de uma avaliação (o que está sendo feito, como, por quem e quando) devem ser acordadas por escrito, para que os envolvidos sejam obrigados a aderir a todas as condições do contrato ou renegociá-lo formalmente.

○ P3 - direitos dos seres humanos: as avaliações devem ser concebidas e realizadas para respeitar e proteger os direitos e bem-estar dos seres humanos.

○ P4 - interações humanas: os avaliadores devem respeitar a dignidade humana e o valor de suas interações com outras pessoas associadas a uma avaliação para que os participantes não sejam ameaçados ou lesados.

○ P5 - avaliação completa e justa: a avaliação deve ser completa e justa na sua análise e registro dos pontos fortes e fracos do programa que está sendo avaliado, de modo a fortalecer os pontos fortes e ajustar as áreas problemáticas.

○ P6 - divulgação dos resultados: as partes formais de uma avaliação devem assegurar que todo o conjunto de resultados, juntamente com as limitações pertinentes, sejam acessíveis às pessoas afetadas pela avaliação e quaisquer outros com direitos legais expressos de receber os respectivos resultados. 
○ P7 - conflito de interesses: deve ser tratado abertamente e honestamente, de modo que não comprometa os processos e resultados da avaliação.

○ P8 - responsabilidade fiscal: as despesas com os recursos e contratação de avaliador devem refletir os procedimentos de responsabilidade e ética, de modo que os gastos sejam apropriados e contabilizados.

- Precisão/Acurácia: os padrões de precisão destinam-se a assegurar que uma avaliação revele e transmita informações tecnicamente adequadas sobre os aspectos que determinam o valor ou mérito do programa que está sendo avaliado.

○ A1 - documentação do programa: o programa a ser avaliado deve ser descrito e documentado de forma clara e precisa, objetivando sua identificação.

○ A2 - análise do contexto: o contexto em que o programa existe deve ser examinado em detalhes, de modo que suas influências prováveis sejam identificadas.

○ A3 - descrição dos propósitos e procedimentos: os objetivos e procedimentos da avaliação devem ser monitorados e descritos em detalhes, propiciando sua identificação e a valiação.

○ A4 - fontes de informações justificáveis: as fontes de informação utilizadas em um programa de avaliação devem ser descritas em detalhes suficientes para que a adequação das informações possa ser avaliada.

○ A5 - validade das informações: os procedimentos de coleta de informações devem ser escolhidos ou desenvolvidos e então implementados, de forma que possam assegurar que a interpretação seja válida para o uso pretendido.

○ A6 - confiabilidade das informações: os procedimentos de coleta de informações devem ser escolhidos ou desenvolvidos e então implementados, de maneira a assegurar que a informação obtida seja suficientemente confiável para o uso pretendido.

○ A7 - informação sistemática: as informações coletadas, processadas e relatadas em uma avaliação devem ser sistematicamente revisadas e quaisquer erros encontrados devem ser corrigidos.

○ A8 - análise quantitativa das informações: as informações quantitativas em uma avaliação devem ser apropriadas e sistematicamente analisadas, de maneira que as questões da avaliação sejam efetivamente respondidas.

○ A9 - análise qualitativa das informações: as informações qualitativas em uma avaliação devem ser apropriadas e sistematicamente analisadas, de forma que as 
questões da avaliação sejam efetivamente respondidas.

○ A10 - conclusões justifica das: as conclusões atingidas em uma avaliação deverão ser explicitamente justificadas para que todos os interessados possam avaliá- las.

○ A11 - relatório imparcial: os relatórios produzidos devem evitar as distorções causadas por sentimentos pessoais e pré-conceitos em qualquer parte da avaliação, de modo que os relatórios possam refletir os resultados reais.

○ A12 - meta-avaliação: a própria avaliação deve ser formativa e somativamente avaliada em relação a estes e outros padrões pertinentes, de maneira que sua condução seja apropriada e, ao término, todos os interessados possam examinar os seus pontos fortes e suas limitações.

Para The Evaluation Center (2009) existem alguns pontos fortes e limitações para os padrões de avaliação dos estudantes, sendo:

\section{Pontos fortes:}

- Pesquisa e revisão em uma base regular.

- Formato amigável ao usuário com linguagem não técnica.

- Certificado pelo American National Standards Institute (ANSI).

- Métodos e diretrizes para a avaliação da qualidade das a valiações dos estudantes.

- Os estudantes incluídos em suas próprias a valiações.

- Assegura que os estudantes compreendam o processo de avaliação.

- Define e explica o papel da avaliação.

- Assegura que as pessoas atingidas pela avaliação possam desempenhar funções de apoio construtivo no processo de avaliação.

\section{Limitações:}

- Desenvolvida para os Estados Unidos, não tendo uso apropriado em outros países.

- Não aborda diretamente os testes padronizados como os relacionados com a reforma da escola e os de responsabilidade estadual.

- Não endereça testes padrões como os relacionados às decisões de orientação para a instrução do estudante no dia-a-dia, bem como no desenvolvimento da aprendizagem. 


\subsection{A AVALIAÇÃO NA EDUCAÇÃo SUPERIOR DO BRASIL}

O processo de avaliação da Educação Superior no Brasil é marcado por uma longa trajetória.Este processo foi gradativamente discutido, negociado e aprimorado, atingindo um status inovador quando observado sob a ótica da totalidade da avaliação, uma vez que aperfeiçoa, amplia e combina instrumentos, de forma a propiciar resultados válidos para a tomada de decisão.

De acordo com Polidori (2009), a evolução do processo avaliativo no Brasil passa por uma divisão em quatro ciclos, sendo:

- Primeiro ciclo (1986 a 1992) - várias iniciativas de organização de um processo de avaliação e a existência de avaliações isoladas no país, não se constituindo em uma avaliação de caráter nacional.

- Segundo ciclo (1993 a 1995) - denominado como formulação de políticas. Foi o período de instalação do Programa de Avaliação Institucional das Universidades Brasileiras (PAIUB).

- Terceiro ciclo (1996 a 2003) - denominado como consolidação ou implementação da proposta governamental. Nele ocorreu o desenvolvimento do Exame Nacional de Cursos (ENC), o Provão e Avaliação das Condições de Oferta (ACO), a qual passou, posteriormente, a ser chamada de Avaliação das Condições de Ensino (ACE). Por fim, houve, ainda, algumas Portarias para regulamentar e organizar a avaliação das Instituições de Ensino Superior (IES's).

- Quarto ciclo (2003 a atual) - denominado como construção da avaliação emancipatória, com a implantação do Sistema Nacional de Avaliação da Educação Superior (SINAES), numa proposta de se desenvolver uma avaliação formativa e que considerasse as especificidades das IES's do país (FELIX, 2008; FONSECA, 2007).

Desta forma, o SINAES foi instituído pela Lei $\mathrm{n}^{\mathrm{o}}$ 10.861, de 14 de abril de 2004 (BRASIL, 2004), com o objetivo de assegurar o processo nacional de avaliação das Instituições de Educação Superior, dos cursos de graduação e do desempenho acadêmico de seus estudantes, buscando a melhoria da qualidade do ensino superior no país, conforme os termos do art. 9º incisos VI, VIII e IX, da Lei ${ }^{\circ}$ 9.394, de 20 de dezembro de 1996 (BRASIL, 1996).

Assim, o parágrafo $1^{\circ}$ da Lei $\mathrm{n}^{\mathrm{o}} 10.861$ aponta que o SINAES tem por finalidade:

- melhoria da qualidade da educação superior; 
- $\quad$ orientação da expansão da oferta;

- aumento permanente da eficácia institucional;

- aumento da efetividade acadêmica e social;

- promoção do aprofundamento dos compromissos e responsabilidades sociais das instituições de educação superior, por meio da valorização de sua missão pública, da promoção dos valores democráticos, do respeito à diferença e à diversidade, da afirmação da autonomia e da identidade institucional.

Com isso, os resultados da avaliação devem subsidiar os processos de regulação e supervisão da educação superior que compreendem as ações de autorização, reconhecimento e renovação de reconhecimento de cursos de graduação, além de credenciamento e recredenciamento de Instituições de Ensino Superior (POLIDORI, 2009).

Nesse sentido, é importante ressaltar que o SINAES busca reconhecer a diversidade do sistema de educação superior do país, respeitando a identidade, a missão e a história das IES's, entendendo que estes aspectos precisam ser avaliados de forma sistêmica e contínua para que haja aprimoramento e melhorias nas ações empreendidas. Assim, o sistema integra três modalidades principais: (a) avaliação institucional, (b) avaliação de cursos e (c) avaliação do desempenho acadêmico dos estudantes.

Avaliação Institucional: considerada como centro de referência e articulação do SINAES, sendo desenvolvida em duas etapas principais - auto-avaliação e a valiação externa, e tem como objetivo identificar o perfil e o significado de atuação da instituição.

Avaliação dos Cursos de Graduação: é o momento da avaliação do conjunto de dimensões, que se referem ao perfil docente, instalações físicas e organização didáticopedagógica por meio de instrumentos e procedimentos que incluem visitas in loco.

Avaliação do Desempenho dos Estudantes: avalia os estudantes com relação aos conteúdos fornecidos pelas orientações curriculares dos seus respectivos cursos de graduação. Também avalia a adequação a novos requisitos decorrentes da evolução do conhecimento e suas competências para compreender tópicos relativos às questões brasileiras e internacionais e outras áreas de conhecimento. É aplicada em uma amostra de estudantes do primeiro e do último ano de curso.

Dessa maneira, ao avaliar as três modalidades do sistema, busca-se assegurar:

- a avaliação institucional, interna e externa, contemplando a análise global e integrada das dimensões, estruturas, relações, compromisso social, atividades, finalidades e responsabilidades sociais das IES's e de seus cursos; 
- o caráter público de todos os procedimentos, dados e resultados dos processos a valiativos;

- o respeito à identidade e à diversidade de instituições e de cursos;

- a participação do corpo discente, docente e técnico-administrativo das IEs's e da sociedade civil, por meio de suas representações.

Enfim, a avaliação nas IES's deve ser formativa, participativa e construída coletivamente, de modo a fornecer subsídios que permitam o refinamento de suas missões, finalidades, programas, projetos; isto é, um mecanismo que possibilite a prestação de contas de seus resultados, "[...] ou seja, devem apresentar indicadores que demonstrem que as metas estabelecidas foram cumpridas e que são eficientes" (DIAS SOBRINHO, 2003).

A avaliação analisada nesta perspectiva proporciona indicadores para a compreensão da realidade de uma instituição de ensino superior, pois instaura processos de diagnóstico e subsidia o planejamento de estratégias para a tomada de decisão, aprimorando a gestão acadêmica.

\subsubsection{A AVALIAÇÃo INSTITUCIONAL}

A avaliação institucional nas IES's é um dos temas de grande discussão no Brasil, sendo reconhecida como uma necessidade por todos os envolvidos com a vida universitária, uma vez que busca traduzir as exigências legais em um plano de ação adequado à realidade da instituição.

Todavia, buscar modelos de excelência para as instituições de ensino torna-se fundamental. Para isto as universidades brasileiras estão criando mecanismos e procedimentos que atendam aos propósitos de qualidade institucional, buscando suprir as necessidades intelectuais e materiais com a preocupação constante de avaliar, reavaliar e tomar decisões acertadas para cada situação.

A avaliação institucional, entendida como programa educativo, é um exercício democrático, podendo ser um importante recurso para a implementação da dinamicidade transformadora exigida pelos projetos pedagógicos dos cursos de graduação e pela gestão universitária porque um programa de avaliação é uma construção coletiva que produz as condições teóricas e as ações correspondentes que se cumprem com vistas a objetivos socialmente desejados. Um programa de Avaliação Institucional deve inevitavelmente ter caráter pedagógico e passar a fazer parte das estruturas permanentes do cotidiano pedagógico das instituições, tendo como agentes nucleares os sujeitos do próprio processo educativo: os alunos, os docentes, os servidores técnicos e administrativos e os gestores (FRIZZO, 2003). 
Envolve, sobretudo, por ser uma ação pedagógica e de política institucional, concepções, princípios, finalidades e operacionalidade que se voltam diretamente para o encaminhamento da "vida" institucional (DIAS SOBRINHO, 2005).

Mediante a avaliação institucional é possível propor ações pontuais para solução de problemas variados de forma crítica e participativa, além da possibilidade de se ter um planejamento estratégico adequado que permita uma análise das possibilidades e limitações da instituição, com vistas à qualidade acadêmica.

A discussão referente à avaliação institucional teve início em julho de 1993 quando a Secretaria de Ensino Superior (SESu/MEC) reuniu variados setores da universidade brasileira, por meio de suas entidades representativas, para que elaborassem um documento básico sobre Avaliação Institucional (MEC, 1994).

Depois de muitas controvérsias, chegou-se a um consenso de que a avaliação institucional deveria ser fundamentada no objetivo de aprimorar a qualidade do ensino, da pesquisa, da extensão e da gestão das IES's, levando em consideração as diferenças regionais e a história de cada instituição. Para isso, foram observados alguns princípios, tais como: globalidade, comparabilidade, respeito à identidade institucional, não punição ou premiação, adesão voluntária, legitimidade e continuidade (MEC, 1994).

A avaliação institucional não implica que as discordâncias, dúvidas e contradições, características do cotidiano acadêmico sejam solucionadas, mas deve servir para revelar, preservar e estimular a pluralidade acadêmica visando o aprimoramento de cada uma.

Sabe-se que a avaliação institucional é uma atividade complexa, de extrema importância para todos aqueles que atuam no ensino superior. Contudo, é vista como uma das prioridades do ensino superior, fazendo parte de um processo de recolher informações, as quais serão analisadas de forma crítica e criteriosa com o intuito de aplicar alternativas de intervenção na realidade interna e externa da instituição.

Corroborando, Bertelli e Eyng (2004) afirmam que "a melhora institucional requer conhecimento analítico e crítico da realidade interna e externa da instituição. Esse conhecimento advém do processo que pode ser denominado aprendizagem institucional que tem na avaliação institucional sua mais destacada estratégia".

Por fim, a avaliação institucional propicia a oportunidade de construção participativa e coletiva, que discute e assegura os principais conceitos, princípios, objetivos, estratégias e diretrizes institucionais que convergem para a missão da instituição. Além disso, tem potencial para promover a ação transformadora dos envolvidos no processo educacional. Para isso, necessita alinhar a avaliação institucional com a gestão acadêmico-administrativa. 


\subsection{ASSESSMENT E EVALUATION COMO CRITÉRIO DE QUALIDAdE EM EDUCAÇÃo A DISTÂNCIA}

Atualmente, elevar os padrões de qualidade da $\mathrm{EaD}$ tem sido o grande desafio das instituições de ensino, sobretudo no que diz respeito às boas práticas para melhoria e evolução. Para isso, as organizações utilizam ferramentas de qualidade, de forma a ter clareza dos objetivos a serem alcançados, pois, segundo Kaplan e Norton (1997), o que não é medido não é gerenciado e o desempenho da organização deve ser avaliado de forma integrada em seus sistemas.

Autores como Canen (1999), Luckesi (1996, 2001), Neder (1996, 1999), Demo (1981, 1990), Hoffmann (1991a, 1991b, 1994) e outros chamam a atenção para o fato de que a avaliação, enquanto mecanismo efetivo de aferição da qualidade desempenha um papel essencial e norteia todo o processo de ensino e aprendizagem. Deve ser vista como um processo constante e contínuo, em que há predominância dos aspectos qualitativos e quantitativos. Esses autores também mencionam que a avaliação não pode ser tratada isoladamente, pois só faz sentido se estiver fundamentada em um projeto pedagógico adequado à clientela a que se destina.

Para Mezomo (1997), a busca da qualidade está vinculada à fidelidade da instituição à sua própria missão, visão e objetivos. Para ele, "qualidade é uma propriedade ou um conjunto de propriedades de um produto ou serviço que o torna adequado à missão de uma organização comprometida com o pleno atendimento das necessidades de seus clientes".

De acordo com Marchesi (2003), qualidade se associa a valor, à excelência, àquilo que é digno de reconhecimento, à obra bem acabada, sendo que a palavra "qualidade" pretende outorgar um selo de garantia e reconhecimento à realidade a qual se aplica. Além disso, qualidade é vista como um desejo de perfeição, um objetivo do qual se quer aproximar.

Ao se considerar a abordagem da avaliação para a EaD é fundamental "considerar a importância da avaliação institucional, a qual deverá obedecer aos mesmos critérios e padrões regulamentados para os cursos presenciais, respeitando as suas peculiaridades" (BRASIL, 2002). Esta proposta é definitivamente incorporada na regulamentação de 2005: "O sistema de avaliação da educação superior, nos termos da Lei no 10.861 , de 14 de abril de 2004, aplica-se integralmente à educação superior à distância" (BRASIL, 2005a, Art. 16). Contudo, é importante trazer os desafios da modalidade de EaD para a discussão do novo projeto, que se propõe a definir diretrizes das funções de regulação, supervisão e avaliação de IES e cursos 
por elas oferecidos (BRASIL, 2006e).

Para Segenreich (2006), qualquer proposta de avaliação tem que levar em consideração dois âmbitos: (1) âmbito do referente - nele são definidas as características, por exemplo, do que deve ser um curso de EaD, para um determinado modelo de proposta pedagógica (incluindo os critérios que o definem); e (2) âmbito do referido - nele se procuram aspectos do funcionamento real do curso ou indicadores que dão conta das características procuradas (critérios de qualidade). A autora sugere que deve haver um estudo aprofundado sobre: (a) a avaliação dos atuais critérios de qualidade utilizados pelo MEC no desempenho de suas funções de regulação, supervisão e avaliação da modalidade de Educação a Distância; (b) a avaliação da quantidade e da qualidade dos dados disponíveis para permitir o desempenho destas funções; e (c) uma definição de até onde é necessário regular o sistema sem asfixiá- lo.

Percebe-se que existem diversas abordagens que norteiam o conceito de qualidade, principalmente quando este está atrelado à avaliação. Desta forma, Paladini (1990), a partir do estudo de Garvin (1984), apresenta cinco grandes abordagens para definir qualidade:

- A abordagem transcendental, que, segundo seus precursores, parte do princípio da impossibilidade de descrever e identificar atributos objetivos para definir o que seria qualidade de produtos ou processos, já que se baseia na observação imediata ou na experiência dos indivíduos em relação ao que eles percebem como dotado de qualidade.

- A abordagem centrada no produto, que enfatiza o aspecto objetivo presente na noção de qualidade por meio da utilização de padrões de medida.

- A abordagem centrada no valor, em que a qualidade é resultante de melhor composição de custos na produção.

- A abordagem centrada na fabricação, na qual a qualidade decorre do cumprimento e observância dos requisitos e prescrições estabelecidos para a elaboração de um determinado produto.

- A abordagem centrada no usuário, que direciona a qualidade à satisfação das necessidades do consumidor/cliente.

A apresentação destas abordagens evidencia sua aplicação em organizações que possuem algum tipo de atividade econômica, sendo predominante na maior parte da literatura sobre qualidade. Com isso, é notório que os pressupostos da qualidade são amplamente utilizados e estudados pelas empresas, entretanto, na educação ainda é muito incipiente a discussão e construção de instrumentos de medição. Corroborando com esta colocação, 
Casanova (1999) destaca que a "qualidade aplicada na educação não goza de boa imagem, está sob suspeita pela utilização que habitualmente se faz dela, [...] sendo preciso afirmar que as coisas não ocorrem por comodidade, mas sim por qualquer resultado que é consequência de um processo".

Sabe-se que as universidades perseguem indicadores de qualidade e que algumas possuem, inclusive, status de excelência em determinada área e/ou atividade. Entretanto, observa-se um descompasso entre as diferentes perspectivas da qualidade, pois muitas vezes uma se sobressai em detrimento da outra. Nesse sentido, Sander (1995), considerando que as instituições de ensino vêm mudando paradigmas, experimentando modificações, procurando usufruir e adaptar-se ao modelo de evolução administrativo, propõe eixos norteadores para este processo, tais como: a administração para a eficiência (ótica econômica), a administração para a eficácia (ótica pedagógica), a administração para a efetividade (ótica política) e a administração para a relevância (ótica antropológica).

Conforme se interpreta em Sander (1995), a proposta destes eixos norteadores são maneiras possíveis de orientação metodológica para a busca da qualidade, frente à diversidade existente no contexto educacional, de forma que ao conceber os quatro eixos acima citados, como sendo quatro caminhos paralelos a serem percorridos, proporcionará percepções e interpretações das realidades educacionais, bem como dos fenômenos administrativos por parte dos atores que compõem o sistema de ensino.

Dentre estas colocações, Buarque (1994) já definia qualidade como um atributo básico das universidades. Observava, também, que "na universidade, sobretudo em momento de transição, além da busca por qualidade, é preciso definir qualidade. A quantidade da qualidade não basta, é preciso qualificar a qualidade".

Neste contexto, a avaliação tornou-se um ato que subsidia um resultado mais satisfatório, que colhe dados da realidade para verificar como esta pode ser melhorada. Possibilita diagnosticar lacunas a serem superadas, aferir os resultados alcançados, considerando as competências a serem constituídas e identifica mudanças de percurso, eventualmente necessárias (LUCKESI, 2001). Desta forma, a avaliação passa a existir para diagnosticar e reorientar uma determinada situação.

A necessidade de diagnosticar e reorientar uma situação remete para uma demanda de estudos sobre qualidade nas IES's, que dependem de um programa de avaliação teoricamente consistente e democraticamente construído. Isso é, a avaliação institucional é a chave para o processo de investigação da qualidade nas universidades (TRIGUEIRO, 1994; TUBINO, 1997; RISTOFF, 1999; DIAS SOBRINHO, 1999). 
E quando se trata de programa de avaliação a partir da perspectiva da avaliação institucional e aplicado ao contexto da $\mathrm{EaD}$, tudo fica ainda mais complexo, haja vista que a $\mathrm{EaD}$ via Internet ainda é uma modalidade muito recente, que necessita de um corpo teórico consistente, definição de boas práticas que atendam às especificidades instrucionais e institucionais e à diversidade existente no Brasil.

Com isso, os cursos de EaD exigem previsão e antecipação de demandas estruturais e ações que possam ser realizadas em (por) seus agentes (estudantes, professores, equipe multidisciplinar, coordenadores, equipe de apoio, dentre outros), cuja avaliação torna-se elemento essencial e determinante para a realização dos ajustes para a melhoria de desempenho, sobretudo para o sucesso do curso a distância.

Assim, Pereira (2003) relata que o estudante, enquanto agente de uma organização universitária, guarda uma distinção importante quando comparado com o cliente tradicional, no tocante à qualidade, pois lhe falta conhecimento sobre os requisitos específicos do produto adquirido, ou seja, uma boa parte dos requisitos específicos do cliente/estudante será revelada somente após serem consumidos. No final da disciplina ou curso, no dia da formatura, ou quando o ex-aluno for trabalhar e aplicar o que foi adquirido na universidade.

Nessa perspectiva, as obrigações da universidade são de difícil cumprimento e é função da universidade conhecer os requisitos da educação desejada pelo estudante, antecipando-os. Portanto, é fundamental que a universidade fique antenada às necessidades, expectativas, preferências e desejos de seus agentes, de modo a satisfazê-los, uma vez que essas informações passam a ser áreas relevantes para a qualidade.

Todavia, o cenário atual das instituições universitárias atravessa um momento de ruptura com o passado, cuja gestão da qualidade surge como uma ferramenta útil, porém ainda com pouca utilização no ambiente universitário. As IES's que têm usado a gestão da qualidade vislumbram novas formas de criar diferenciais competitivos ou melhorar o desempenho organizacional (WIDRICK; MERGEN; GRANT, 2002).

Desta forma, o grande desafio para as instituições de ensino é trabalhar o as sessment e o evaluation da qualidade, reconhecendo a diversidade e as especificidades institucionais, uma vez que o as sessment deve ser contínuo e abrangente para atingir melhorias significativas e possibilitar resolução de problemas, pois não existe um modelo pronto de EaD. São necessárias constantes investigações, reavaliações e retroalimentações sobre os cursos implementados para identificar os ajustes necessários e delinear as possíveis e desejáveis transformações.

Assim, tendo em vista a polêmica e a diversidade de entendimento sobre qualidade e 
os cuidados apontados por alguns pesquisadores em relação à forma de abordá-la em instituições de ensino, optou-se por investigar qualidade a partir de uma sistematização metodológica que possibilite o desenvolvimento de uma arquitetura de orientação que viabilize a construção de instrumentos para avaliação (assessment) da EaD.

\subsubsection{REFERENCIAIS DE QUALIDADE PARA A EDUCAÇÃo A DISTÂNCIA NO BRASIL}

A autorização, o credenciamento, o reconhecimento e a realização de cursos na modalidade a distância no Brasil são normatizados por legislação específica e coordenadas pela Secretaria de Educação a Distância (SEED) do Ministério de Educação e Cultura (MEC). O MEC adota os mesmos critérios utilizados para cursos presenciais para os processos de autorização e credenciamento de cursos na modalidade $\mathrm{EaD}$ e propõe indicadores de qualidade para orientar as IES's, assim como as comissões de especialistas que fazem verificação in loco.

Em 2007, após amplo debate e longas discussões com apreciação pública, o MEC divulgou um documento denominado Referenciais de Qualidade para Educação Superior a Distância, que não tem força de lei, mas é utilizado para subsidiar atos legais do poder público no que se refere aos processos específicos de regulação, supervisão e avaliação da modalidade citada (MEC, 2007).

Esses referenciais norteiam a elaboração de Projeto Político Pedagógico de um curso na modalidade a distância, uma vez que no Brasil existe uma diversidade significativa de modelos, métodos, técnicas, desenhos e metodologias utilizadas, o que impede a utilização de um padrão único.

Assim, dada a complexidade e a necessidade da elaboração de projetos que contemplem aspectos pedagógicos, recursos humanos e infraestrutura, os Referenciais de Qualidade (MEC, 2007) sugerem que estas dimensões sejam integralmente expressas no Projeto Político Pedagógico, com os tópicos principais:

(i) Concepção de educação e currículo no processo de ensino e aprendizagem.

(ii) Sistemas de comunicação.

(iii) Material didático.

(iv) Avaliação.

(v) Equipe multidisciplinar.

(vi) Infraestrutura de apoio. 
(vii) Gestão Acadêmico-Administrativa.

(viii) Sustentabilidade financeira.

Segundo o MEC (2007), os tópicos supracitados não são entidades isoladas, se interpenetram e se desdobram em outros sub tópicos. Assim, com o objetivo de caracterizá- los de forma individualizada, segue, resumidamente, os elementos constituintes fundamentais.

\section{(I) Concepção de educação e currículo no processo de ensino e aprendizagem}

O projeto político pedagógico deve apresentar claramente sua opção epistemológica de educação, de currículo, de ensino, de aprendizagem, de perfil do estudante que deseja formar; com definição, a partir dessa opção, de como se desenvolverão os processos de produção do material didático, de tutoria, de comunicação e de avaliação, delineando princípios e diretrizes que alicerçarão o desenvolvimento do processo de ensino e aprendizagem.

\section{(II) Sistemas de Comunicação}

Os princípios da interação e da interatividade são fundamentais para o processo de comunicação e devem ser garantidos no uso de qualquer meio tecnológico a ser disponibilizado. Isto irá proporcionar aos estudantes efetiva participação no seu processo de ensino-aprendizagem, comunicação no sistema com garantia de oportunidades para o desenvolvimento de projetos compartilhados e o reconhecimento e o respeito às diferentes culturas e de construir o conhecimento.

\section{(III) Material Didático}

O material didático do ponto de vista da abordagem do conteúdo e da forma, deve ser concebido de acordo com os princípios epistemológicos, metodológicos e políticos explicitados no projeto pedagógico, de modo a facilitar a construção do conhecimento e mediar a interlocução entre estudante e professor. Deve passar por rigoroso processo de avaliação prévia (pré-testagem), com o objetivo de identificar necessidades de ajustes, visando o seu aperfeiçoamento.

Em consonância com o projeto pedagógico do curso, o material didático deve desenvolver habilidades e competências específicas, recorrendo a um conjunto de mídias compatíveis com a proposta e com o contexto socioeconômico do público-alvo.

\section{(IV) Avaliação}

Duas dimensões devem ser contempladas na proposta de avaliação de um projeto de educação a distância:

a) a que diz respeito ao processo de aprendizagem;

b) a que se refere à avaliação institucional.

(a) A Avaliação da Aprendizagem 
$\mathrm{Na}$ educação a distância o modelo de avaliação da aprendizagem deve ajudar o estudante a desenvolver graus mais complexos de competências cognitivas, habilidades e atitudes, lhe possibilitando alcançar os objetivos propostos. Para tanto, esta avaliação deve comportar um processo contínuo para verificar constantemente o progresso dos estudantes, estimulando-os a serem ativos na construção do conhecimento. Desse modo, devem ter mecanismos articulados que promovam o permanente acompanhamento dos estudantes, no intuito de identificar eventuais dificuldades na aprendizagem e saná-las ainda durante o processo de ensino-aprendizagem.

\section{(b) A Avaliação Institucional}

As instituições devem planejar e implementar sistemas de avaliação institucional, incluindo ouvidoria, que produzam efetivas melhorias de qualidade nas condições de oferta dos cursos e no processo pedagógico. Esta avaliação deve se configurar em um processo permanente e consequente, de forma a subsidiar o aperfeiçoamento dos sistemas de gestão e pedagógico, produzindo efetivamente correções na direção da melhoria da qualidade do processo pedagógico coerentemente com o SINAES. Para ter sucesso, essa avaliação precisa envolver os diversos atores: estudantes, professores, tutores e quadro técnico-administrativo.

Assim, a instituição deve instituir uma avaliação contínua quanto:

- Organização Didático-Pedagógica.

- Corpo Docente, Corpo de Tutores, Corpo Técnico-Administrativo e Discentes.

- Instalações físicas.

- Meta-avaliação.

\section{(V) Equipe Multidisciplinar}

Em educação a distância há uma diversidade de modelos que resulta em possibilidades diferenciadas de composição dos recursos humanos necessários à estruturação e funcionamento de cursos nessa modalidade. No entanto, qualquer que seja a opção estabelecida, os recursos humanos devem configurar uma equipe multidisciplinar com funções de planejamento, implementação e gestão dos cursos a distância, sendo que três categorias profissionais devem estar em constante qualificação e são essenciais para uma oferta de qualidade: (a) docentes, (b) tutores e (c) pessoal técnico-administrativo.

\section{(VI) Infraestrutura de apoio}

Além de mobilizar recursos humanos e educacionais, um curso a distância exige infraestrutura material proporcional ao número de estudantes, aos recursos tecnológicos envolvidos e à extensão de território a ser alcançada, o que representa um significativo 
investimento para a instituição. Essa infraestrutura física deve estar disponível tanto na sede como nos polos de apoio presencial.

\section{(VII) Gestão acadêmico-administrativa}

A gestão acadêmica de um projeto de curso de educação a distância deve estar integrada aos demais processos da instituição, ou seja, é de fundamental importância que o estudante de um curso a distância tenha as mesmas condições e suporte que o presencial, bem como o sistema acadêmico deve priorizar isso.

Em particular, a logística que envolve um projeto de educação a distância - os processos de tutoria, produção e distribuição de material didático, acompanhamento e avaliação do estudante - precisam ser rigorosamente gerenciados e supervisionados, sob pena de desestimular o estudante, levando-o ao abandono do curso ou a não permitir devidamente os registros necessários para a convalidação do processo de aprendizagem.

\section{(VIII) Sustentabilidade Financeira}

A educação superior a distância de qualidade envolve uma série de investimentos iniciais elevados para a produção de material didático, a capacitação das equipes multid isciplinares, a implantação de polos de apoio presencial e a disponibilização dos demais recursos educacionais, assim como a implantação (metodologia e equipe) da gestão do sistema de educação a distância.

Inicialmente, não há uma adequada relação custo/benefício, sendo viável apenas levando-se em consideração a amortização do investimento inicial em médio prazo. No entanto, para alguns analistas, um projeto acompanhado e avaliado permanentemente, combinado com os avanços tecnológicos, faz com que um curso a distância esteja sempre em processo de aperfeiçoamento, o que mantém elevado o investimento nos projetos.

Para garantir a continuidade em médio prazo de um curso superior, em especial de graduação, a instituição deve montar a planilha de custos do projeto como um todo, em consonância com o projeto político-pedagógico e a previsão de seus recursos.

Estas diretrizes apresentadas pelo MEC têm como objetivo nortear os envolvidos na elaboração de projetos de cursos a distância, bem como alinhar a proposta aos instrumentos legais de acompanhamento e avaliação do estudo, propiciando um aprimoramento na qualidade dos cursos ofertados nesta modalidade.

Em termos de organismos internacionais, o Institute for Higher Education Policy (IHEP, 2000) realizou um estudo em que compilou 24 (vinte e quatro) padrões de qualidade em 7 (sete) dimensões, as quais são consideradas essenciais aos cursos ofertados na modalidade a distância, tais como: 
1. Suporte Institucional. Os padrões dessa categoria incluem medidas de segurança eletrônica que asseguram os padrões de qualidade, integridade e validade da informação, bem como as políticas que orientam o desenvolvimento do ensino pela Internet.

2. Desenvolvimento do curso. Esta categoria inclui itens relativos ao desenvolvimento do curso pela Internet (análise, planejamento, implementação, testes, avaliação, manutenção, etc.).

3. Processo de Ensino e Aprendizado. A interação dos estudantes com outros estudantes e com professores é uma característica essencial e deve ser facilitada pela tecnologia. Além disso, o feedback aos alunos deve ser construtivo e oportuno. Os estudantes devem ser instruídos sobre os métodos apropriados para uma investigação eficaz, incluindo a avaliação da validade dos recursos.

4. Estrutura do Curso. Define as políticas e procedimentos que fornecem suporte ao processo de tecnologia e aprendizado e inclue a definição dos objetivos do curso, disponibilidade de recursos bibliográficos, tipos de materiais disponíveis para estudantes, tempo de resposta aos estudantes e a valiação das expectativas dos estudantes.

5. Suporte ao Estudante. Esta categoria inclui um conjunto de serviços oferecidos em suporte às atividades dos estudantes, tais como; treinamento e assistência no uso dos recursos on-line.

6. Suporte ao Corpo Docente. Os itens dessa categoria relacionam algumas atividades de assistência e suporte fornecidos por outros membros mais experientes ou por terceiros.

7. Avaliação e auditoria. Os itens nessa categoria são políticas e procedimentos que definem como as instituições de vem avaliar a qualidade de seus cursos.

Estas diretrizes ressaltam a importância de se adotar padrões de qualidade que possam conduzir os programas de educação a distância à excelência.

A partir deste apanhado sobre avaliação (assessment e evaluation) é possível conhecer e discernir diferentes formas e aplicações de avaliação, sobretudo no que tange à perspectiva da qualidade.

Neste contexto, atreladas ao processo de avaliação (assessment e/ou evaluation), as evidências científicas são elementos fundamentais que devem permear todo o processo, cujo objetivo é assegurar a precisão e segurança nos resultados. Para tanto, o capítulo seguinte trata desta temática. 


\section{CAPÍTULO 3 - Evidências científicas: confiabilidade, validade e triangulação}

Neste capítulo, sem a pretensão de esgotar o assunto, são apresentados diversos conceitos de confiabilidade, validade, triangulação e pontos críticos da validade, para que se possa ter elementos suficientes para uma escolha adequada e possível, segundo o contexto investigado.

Sabe-se que a construção do conhecimento na humanidade é marcada pela busca de evidências que sustentem determinadas suposições. Desta forma, as evidências científicas estão atreladas ao rigor científico, podendo ser reconhecidas como critérios científicos, os quais são fundamentais na comunidade científica nacional e internacional. Isso faz com que todo pesquisador de qualquer área do conhecimento e de qualquer parte do mundo tenha uma opinião consensual sobre o rigor científico. Todavia, o rigor científico exige um sólido aparato teórico e metodológico (NATURE JOURNAL, 2009).

Com base nestes pressupostos, o conhecimento científico avança pela regularidade da observação sistemática, bem como a possibilidade de medição dos diversos fenômenos.

De acordo com Jovell e Navarro-Rubio (1995), as evidências científicas se diferenciam em função do rigor científico do estudo. Estas evidências se constroem a partir do reconhecimento da capacidade diferencial dos diversos tipos de estudos, cujas c aracterísticas determinam, por sua vez, a magnitude do rigor científico, bem como as recomendações, sendo estas muito similares entre si.

Enfim, é importante analisar criticamente o que está sendo produzido, bem como buscar caminhos para o contínuo aprimoramento.

Nesse sentido, a confiabilidade e a validade são termos considerados positivos e de grande importância na comunidade científica. A confiabilidade é basicamente um assunto empírico focado no desempenho das medidas empíricas. Em contraste, a validade é usualmente mais uma orientação teórica, pois parte sempre da questão: "válido para qual propósito?".

Um aspecto relevante ao se construir um instrumento confiável e válido é quanto à perspectiva da avaliação, uma vez que tais instrumentos podem ser genéricos ou específicos. Os genéricos são aqueles desenvolvidos para refletir um impacto de eventos de ampla variedade de populações, permitem comparação entre indivíduos e grupos diferenciados e procuram englobar todas as características importantes relacionadas a um conceito. Os 
específicos preocupam-se em avaliar aspectos que afetam os indivíduos de determinados grupos, tendo como vantagem a capacidade de detectar particularidades em situações peculiares (CICONELLI, 1997; MINAYO; HARTZ; BUSS, 2000).

Nesse sentido, o processo de medição de uma realidade, por meio de instrumentos validados, pode fazer uso de modelos já existentes ou ser realizado a partir de criação de um novo modelo, com a inserção de características específicas da população na qual se deseja aplicá-lo. Estes conceitos serão inseridos na construção da arquitetura para gerar evidências confiáveis e válidas nos instrumentos propostos.

\subsection{Confiabilidade}

A confiabilidade, fidedignidade ou precisão de um teste diz respeito à característica que ele deve possuir, a de medir sem erros, ou seja, o mesmo teste, medindo os mesmos sujeitos em ocasiões diferentes, ou testes equivalentes medindo os mesmos sujeitos na mesma ocasião produzem resultados idênticos, isto é, a correlação entre essas duas medidas deve ser de 1 , sendo que o coeficiente de correlação expressa o nível de relação ou a correspondência que existe entre os dois eventos (PASQUALI, 1997).

Neste sentido, a confiabilidade de um instrumento pode ser definida como sendo a probabilidade de produtos e/ou processos desempenharem as funções para as quais foram projetados, em um determinado instante ou intervalo de tempo, ou seja, a avaliação da confiabilidade de um instrumento é feita mediante a comparação de diversas aplicações do instrumento ao mesmo indivíduo.

Segundo Galetti, (2006), a confiabilidade refere-se à capacidade do instrumento reproduzir uma mesma medida, isto é, ao grau de concordância entre múltiplas medidas de um mesmo objeto. Desta forma, uma medida é dita confiável quando o erro de medida randômico é baixo; a variabilidade da medida é então explicada pela variabilidade do critério. Algumas propriedades mínimas devem ser satisfeitas para que um instrumento seja considerado confiável: (1) consistência interna, em que itens medindo os mesmos atributos produzem escores fortemente correlacionados (coeficiente alfa de Cronbach); reprodutibilidade, em que a ferramenta testada de modo idêntico em diferentes momentos produz resultados estáveis ao longo do tempo (método teste / reteste); (3) confiabilidade interobservador, quando questionários não auto administrados são testados de modos idênticos por dois diferentes entrevistadores e produzem resultados que não são sensíveis ao entrevistador (MINIS TÉRIO DA SAÚDE, 2007). 
De acordo com Litwin (1995) e Carmines e Zeller (1979), existem 6 tipos de confiabilidade:

\section{Teste-reteste:}

É o método mais comumente usado para medir confiabilidade. Envolve a aplicação do mesmo instrumento aos mesmos indivíduos em duas diferentes ocasiões para então correlacionar os resultados. O coeficiente do teste e reteste varia de +1.00 a -1.00 e reflete o grau em que o resultado varia ao longo do tempo e geralmente, a correlação entre os coeficientes ou o r-valor é considerada boa quando igual ou maior que 0.70. A limitação deste método é o espaço de tempo entre a primeira e a segunda aplicação, na qual o respondente pode lembrar dos itens do instrumento e responder por conveniência, ou seja, responder baseado em sua memória. Outro problema encontrado se refere à motivação do respondente, o qual pode ou não estar sensibilizado com a investigação proposta.

\section{Forma Alternativa:}

É um método fortemente utilizado na educação para estimar a confiabilidade de todos os tipos de testes. É similar ao reteste, requer duas situações de teste com as mesmas pessoas. A diferença dos métodos está no fato de que na segunda aplicação usa-se uma forma alternativa do mesmo teste, ou seja, na forma alternativa, muda-se as palavras, porém, mantém-se os atributos dos itens, produzindo assim, dois itens que são similares mas não idênticos. Deve-se ter o cuidado para manter o mesmo nível de vocabulário e mesmo nível de dificuldade do teste.

A limitação do método forma alternativa para avaliar a confiabilidade é a dificuldade prática para construir formas alternativas que são paralelas, mantendo as mesmas propriedades para medição.

\section{Split-Halves:}

Diferente do teste-reteste e da forma alternativa, o split-halves pode ser conduzido em uma única ocasião, cujos itens do instrumento são divididos em duas metades e os escores de cada metade são correlacionados para obter uma estimativa da confiabilidade. As metades podem ser consideradas aproximações da forma alternativa. Caso o instrumento seja muito grande, os itens do mesmo podem ser divididos em três, quatro, cinco (...) partes.

A limitação deste método para avaliar a confiabilidade é que os coeficientes obtidos de diferentes caminhos da subdivisão do total podem não ser os mesmos. 


\section{Consistência Interna:}

A consistência interna é outra medida psicométrica comumente usada para avaliar a confiabilidade de instrumentos. É aplicada não em itens, mas em grupos de itens para medir diferentes aspectos do mesmo conceito. A consistência interna é um indicador para medir quão bem os diferentes itens medem o mesmo assunto.

A consistência interna é medida calculando a estatística conhecida como coeficiente alfa de Cronbach, o qual mensura a confiabilidade da consistência interna entre um grupo de itens combinados para formar uma escala única. Ele reflete quão bem os diferentes itens complementam-se entre si, na mensuração dos diferentes aspectos ou na qualidade da mesma variável. Contudo, o coeficiente alfa de Cronbach mede construtos latentes determinando a consistência interna dos itens por meio da correlação média das questões dentro de um item. Quanto maior o coeficiente alfa, mais este contribui na construção da escala. Como regra geral, a confiabilidade não deveria ser abaixo de 0.80 .

\section{Interobservador (interrater):}

Envolve o ato de 2 ou mais avaliadores aplicarem o instrumento para o mesmo respondente e encontrarem o mesmo resultado. Os escores encontrados são correlacionados e é possível calcular um coeficiente. Este coeficiente que varia de -1.00 a +1.00 diz o quanto o instrumento é confiável quando us ado por examinadores diferentes.

A confiabilidade do método entre examinadores é frequentemente usado quando o processo de medição é menos quantitativo do que as variáveis medidas.

\section{Intra-observador:}

Mensura a estabilidade das respostas ao longo do tempo de um mesmo respondente individual. Requer a aplicação do instrumento por um indivíduo em uma amostra, em dois diferentes e apropriados pontos do tempo.

Os pontos no tempo são também para separar e distanciar a aplicação, pois os mesmos podem influenciar na estimativa da confiabilidade que reflete a mudança atual sobre o tempo em uma variável de interesse.

Segundo Pasquali $(1997,1999)$ existem três tipos de procedimentos experimentais para coleta de informação (delineamento) e dois tipos ou modelos de análises estatísticas dos dados coletados, tais como: 


\section{Delineamentos:}

1. Uma amostra de sujeitos, um mesmo teste e uma única ocasião (Duas metades): aplicase a uma amostra aleatória de sujeitos um teste numa única ocasião e analisam-se os dados em termos de consistência interna dos itens via duas metades ou técnicas de alfa.

2. Uma amostra de sujeitos, dois testes em uma única ocasião (Formas paralelas): aplicase a uma amostra aleatória de sujeitos duas formas paralelas do teste ou dois testes paralelos ( $\mathrm{T}_{1}$ e $\left.\mathrm{T}_{2}\right)$ numa única ocasião e faz-se a análise da correlação entre as distribuições dos dois testes ou formas paralelas.

3. Uma amostra de sujeitos, um mesmo teste e duas ocasiões (Teste-reteste): aplica-se a uma amostra aleatória de sujeitos um teste na ocasião $1\left(\mathrm{O}_{1}\right)$ e reaplica-se à mesma amostra o mesmo teste em uma ocasião posterior $\left(\mathrm{O}_{2}\right)$, fazendo-se a correlação entre os dois conjuntos de dados.

\section{Análises estatísticas:}

Ainda de acordo com o mesmo autor acima citado, embora haja dezenas de índices de fidelidade, há basicamente duas técnicas estatísticas para a estimação de seu coeficiente: a correlação simples e a(s) técnica(s) alfa. A primeira trabalha com a correlação e a segunda com a variância.

1. Correlação: o coeficiente de correlação expressa o nível de relação ou a correspondência que existe entre dois eventos. Para obter este coeficiente de fidedignidade utilizam-se os dados coletados via um dos três delineamentos.

2. Coeficiente alfa: eles visam verificar a consistência interna do instrumento pela análise da consistência interna dos itens, verificando a congruência deque cada item do instrumento com o restante dos itens do mesmo instrumento. O caso mais geral deste tipo de análise é o coeficiente alfa de Cronbach.

Para Pasquali (1997) a obtenção do coeficiente alfa demanda o cálculo de três parâmetros: (a) a variância total do teste, (b) a variância de cada item individualmente e (c) a soma das variâncias desses itens. Assim, a fórmula Cronbach mostra que todos os itens variam do mesmo jeito, isto é, se não houver variância entre os itens individualmente, o alfa será igual a 1; quer dizer, os itens serão totalmente homogêneos, produzindo exatamente a mesma variância (evento este pouco provável). Desta forma, o coeficiente alfa vai de 0 a 1 , indicando que 0 (zero) é a ausência de consistência interna dos itens e 1 (um), presença de consistência de $100 \%$.

Neste contexto, Galetti (2006) salienta que a consistência interna (alfa Cronbach) é 
um escore sumário de confiabilidade geral de um instrumento. $\mathrm{O}$ escore pode variar de zero a um e, por convenção, o escore mínimo aceitável para a consistência interna é 0,70 ; um escore bom gira em torno de 0,80, e um escore de 0,90 é considerado excelente. Contudo, um alfa muito próximo de 1 indica co-variância, sugerindo que possivelmente o conjunto de itens em questão poderia ser substituído por apenas 1, aquele que for mais representativo. Assim sendo, é desejável que os itens de cada uma das escalas apresentem boa consistência interna, porém que não seja demasiada elevada para garantir uma complementaridade entre os mesmos e uma avaliação abrangente.

Em relação aos fatores que podem influenciar a confiabilidade do instrumento, Pasquali (1997) destaca:

- Variabilidade da amostra de sujeitos: o tamanho da amostra afeta a correlação, ou seja, quanto maior e variável a amostra de sujeitos maior será o coeficiente de correlação e consequentemente, o índice de fidedignidade. O coeficiente de fidedignidade não é fixo, mas varia conforme aumenta ou diminui a variabilidade da amostra de sujeitos.

- Comprimento do teste: quanto maior o número de itens no instrumento, maior será seu índice de precisão.

Corroborando com esta temática, Litwin (1995) também relaciona fatores que podem influenciar a confiabilidade:

- Cond ições nas quais o instrumento é aplicado, as quais podem não ser as mesmas.

- Variabilidade inter-observador: pode haver divergência na interpretação/entendimento do instrumento.

- Variabilidade intra-observador: o instrumento pode ter influência na interpretação que realiza um observador em dois momentos distintos

\subsection{Validade}

A validade de um instrumento pode ser definida como a capacidade de realmente medir aquilo a que se propõe medir.

Para Richardson (1999), a validade de um instrumento de medição é a característica de maior importância para avaliar sua efetividade, pois o instrumento é válido quando ele mede o que se deseja. $\mathrm{O}$ instrumento para ser válido deve ser confiável.

Para Galetti (2006), a validade apresenta: (1) um aspecto conceitual que depende do julgamento subjetivo do pesquisador se o instrumento mede o que deveria e é influenciado 
pelo panorama de conceitos e teorias aceitas na época; (2) um aspecto operacional, que pode ser avaliado com métodos estatísticos. Esta última é geralmente medida comparando-se o instrumento com outra medida externa já existente e considerada "padrão ouro" e denominase validade convergente ou validade cruzada.

Segundo Pasquali (1997), existem técnicas para demonstrar a validade dos instrumentos, as quais fundamentalmente podem ser reduzidas a três grandes classes (o modelo trinitário): técnicas que visam à validade de constructo, à validade de conteúdo e à validade de critério. Entretanto, Litwin (1995) acrescenta, além destas técnicas relacionadas, a validade aparente (face validity).

Para o primeiro autor, o conceito de validade irá reduzir-se à validade de constructo, sendo o de conteúdo e o de critério apenas aspectos da validade de construto.

Corroborando com Litwin (1995) acerca dos tipos de validade, Galetti (2006) ressalta que dentro do aspecto conceitual deve-se considerar a validade aparente. A validade aparente (face validity) é o grau com que uma medida intuitivamente parece avaliar o que se propõe. Diz respeito a um critério de credibilidade na formulação dos itens. O item deve ser formulado de modo que não pareça ridículo, despropositado ou infantil (PASQUALI, 2000).

\subsubsection{Validade de Construto}

A validade de construto é a presença de uma correlação positiva entre um grupo de características ou variáveis e a entidade principal que está sendo medida. Diz respeito à cons trução dos itens, sob embasamento teórico, a partir das características do que se pretende medir (GALETTI, 2006).

A validade diz respeito ao aspecto da medida ser congruente com a propriedade medida dos objetos e não com a exatidão com que a mensuração deste objeto é feita. A validade existe quando o procedimento faz exatamente o que ele propõe fazer (RICHARDSON, 1999).

A validade de construto ou conceito é considerada a forma mais fundamental de validade dos instrumentos, haja vista que ela constitui a maneira mais direta de verificar a hipótese da legitimidade dos traços latentes ou representação comportamental. A validade de construto historicamente já existia sob outros nomes, tais como validade intrínseca, validade fatorial e até validade aparente (face validity). Essas terminologias demonstram a confusa noção que construto possuía. Nesse tipo de validade, o problema não é descobrir o construto a partir de uma representação existente (teste), mas sim descobrir se a representação (teste) 
constitui uma representação legítima, adequada ao construto (PASQUALI, 1997).

A validade de construto é o método mais difícil para avaliar um instrumento e frequentemente é vista como uma estrutura de quão bom é o desempenho de um instrumento que aplicado em uma multidão ou um grupo de populações por um número de anos (LITWIN, 1995).

Tomando-se como referência Pasquali (2003), a validade de construto pode ser trabalhada sob vários ângulos:

a) Análise da representação comportamental.

b) Análise por hipótese.

c) Curva de informação da Teoria de Resposta ao Item (TRI).

d) Falsete estatístico do erro de estimação da Teoria Clássica do Teste (TCT).

Análise da Representação: são utilizadas duas técnicas como demonstração da adequação da representação do construto pelo teste: (a) análise de consistência interna e (b) análise fatorial.

1. Análise de Consistência Interna do Teste: consiste em calcular a correlação que existe entre cada item do teste e o restante dos itens ou o total dos itens (escore total). Assim, a correlação legítima será a do item com o restante dos itens.

2. Análise Fatorial: tem como lógica verificar quantos construtos comuns são necessários para explicar as covariâncias (as intercorrelações) dos itens. As correlações entre os itens são explicados, pela análise fatorial, como resultantes de variáveis-fonte que são os construtos ou traços latentes. A análise fatorial também postula que um número menor de traços latentes (variáveis-fonte) é suficiente para explicar um número maior de variáveis observadas (itens).

A análise fatorial apresenta dois problemas: (a) o modelo fatorial se fundamenta em equações lineares entre variáveis e fatos e (b) problema de rotação dos eixos para a qual não existe nenhum critério objetivo. Contudo, se o teste foi construído via teoria psicológica de traços latentes, tem-se aí um critério objetivo de rotação dos eixos.

Análise por Hipótese: fundamenta-se no poder de um teste ser capaz de discriminar ou predizer um critério externo a ele mesmo. Este critério é procurado de quatro formas:

1. Validade convergente-discriminante: parte do princípio de que para demonstrar a validade de construto de um teste é preciso determinar duas coisas (a) o teste deve correlacionar significativamente com outras variáveis com as quais o construto medido pelo teste deveria, pela teoria, estar relacionado (validade convergente) e (b) não se correlacionar com variáveis com as quais ele teoricamente deveria diferir (validade discriminante). 
2. Idade: é utilizada para a validação de construto de um teste quando este mede traços latentes que são intrinsecamente dependentes de mudanças no desenvolvimento cognitivo/afetivo dos indivíduos. Logo, o traço X muda claramente com a idade. $\mathrm{O}$ problema desta técnica é que assume dimensões e conotações diferentes em distintas culturas e dentro de uma mesma cultura, se apresenta como importante para a determinação da validade de construto.

3. Correlação com Outros Testes: a correlação com outros testes que meçam o mesmo traço também é utilizada como demonstração de validade de construto. O problema desta técnica é que um teste de um traço qualquer não se apresenta com tal pureza para se afirmar que ele mede exclusivamente tal traço.

4. Intervenção Experimental: consiste em verificar se o teste discrimina claramente gruposcritério "produzidos" experimentalmente em termos do traço do objeto. Esta se caracteriza a melhor técnica para se decidir a validade de construto de um teste.

\section{Curva de Informação da TRI:}

A Teoria de Resposta ao Item (TRI) trabalha a validade dos testes mediante poderosos métodos chamados funções de informação e de eficiência.

A curva de informação do teste mostra para que faixa de níveis de $\theta$ (teta) do teste é particularmente válido e para que faixas ele não é.

Erro de Estimação (EE): este modelo se fundamenta exclusivamente nos dados empíricos coletados de um conjunto de itens agrupados de maneira intuitiva. O conjunto de itens é constituído mediante a seleção de uma amostra coletada de um universo que parece medir um dado construto.

Neste contexto, a psicologia clássica procura legitimar a validade de um instrumento dentro do conceito de erro de estimação, isto é, quando o escore obtido pelo sujeito do teste se afasta do escore verdadeiro.

De acordo com Litwin (1995), a validade de construto se subdivide em (a) validade convergente e (b) validade divergente.

a) Validade Convergente: implica em uso de diferentes métodos para obter a mesma informação. Para obter a mesma informação sobre um traço ou conceito, produzem resultados similares. Geralmente, tem vários investigadores com diferentes abordagens.

b) Validade Divergente (discriminante): é a habilidade de uma medida estimar a base (fundamento) verdadeira de uma determinada área. Para um instrumento ter validade divergente não pode apresentar correlação, mas traços ou conceitos distintos.

Neste contexto, observa-se que a validade de construto pode ser resultado de um uso 
continuado do instrumento para medir traços, qualidade ou "constructo".

\subsubsection{Validade de Conteúdo}

O estabelecimento da validade de conteúdo de uma escala envolve uma avaliação sistemática mas subjetiva da habilidade da escala para medir o que deve medir. Geralmente, envolve a consulta de uma pequena amostra de especialistas típicos para julgar a adequação dos itens escolhidos para representar o constructo (HAIR; BABIN; SAMOUEL, 2005; LITWIN, 1995).

A validade de conteúdo preocupa-se com a adequação da cobertura da área de conteúdo que está sendo medida. Neste contexto, a questão da validade é: As questões deste teste são representativas do universo de todas as questões que podem ser feitas sobre o tópico? Desta forma, o desenvolvimento de um novo instrumento inicia-se pela conceitualização minuciosa do construto de interesse, para que a medida possa captar adequadamente todo o âmbito (POLIT, BECK e HUNGLER, 2004).

De acordo com Pasquali (2003), para viabilizar um teste com validade de conteúdo é preciso que se façam as especificações do teste antes da construção dos itens. Estas especificações comportam a definição de três grandes temas: (1) definição do conteúdo, (2) explicitação dos objetivos (processos psicológicos) a serem avaliados e (3) determinação da proporção relativa de representação no teste de cada tópico do conteúdo.

Quanto ao conteúdo, trata-se de detalhá-lo em termos de tópicos (unidades) e subtópicos, bem como de explicitar a importância relativa a cada tópico dentro do teste. Tais procedimentos evitam a super-representação indevida de alguns tópicos e sub-representação de outros por vieses do a valiador (PASQUALI, 2003).

Ainda de acordo com Pasquali (2003), a validade de conteúdo de um teste é praticamente garantida pela técnica de construção do mesmo. Esta técnica comporta os seguintes passos:

1. Definição do domínio cognitivo: definir os objetivos que se quer avaliar no teste, tais como:

- conhecer tais e tais tópicos;

- compreender tais e tais tópicos;

- aplicar tais e tais tópicos;

- analisar tais e tais tópicos. 
2. Definição do universo do conteúdo: é preciso definir e delimitar o universo do conteúdo programático em termo de divisões e subdivisões (tópicos e subtópicos).

3. Definição da representatividade do conteúdo: definir a proporção com que cada tópico e subtópico devem ser representados no teste, decidindo assim, a importância com que cada um deles aparece no conteúdo total do universo.

4. Elaboração da tabela de especificação: na qual serão relacionados os conteúdos com os processos cognitivos a avaliar, bem como a importância relativa a ser dada a cada unidade.

5. Construção do teste: elaborar os itens que irão representar o teste.

6. Análise teórica dos itens: esta análise visa verificar a compreensão das tarefas propostas no teste por parte dos testandos (análise semântica) e a avaliação da pertinência dos itens em relação às unidades pelos juízes (análise de juízes).

7. Análise empírica dos itens: esta análise implica basicamente na determinação dos níveis de dificuldade e de discriminação dos itens. A técnica da teoria de resposta ao item (TRI) pode ser usada nesta etapa.

Diante desse panorama, verifica-se que na validade de conteúdo pouco se usa a estatística, ela está mais voltada à análise de julgamento, embora ela não seja uma medida científica para avaliação da acurácia do instrumento (LITWIN, 1995), ela apresenta uma boa fundamentação em que o rigor metodológico pode avaliar a validade do ins trumento.

\subsubsection{Validade de Critério}

A validade de critério avalia se um construto tem o desempenho esperado em relação a outras variáveis identificadas como critérios significativos (HAIR; BABIN; SAMOUEL, 2005). Na investigação da validade de critério é necessário estabelecer uma relação entre os escores do instrumento e algum critério externo.

Segundo Litwin (1995), a validade de critério provê maior evidência quantitativa sobre a acurácia do instrumento e costuma-se distinguir dois tipos de validade de critério (1) validade preditiva e (2) validade concorrente. A diferença fundamental entre os dois tipos é basicamente uma questão de tempo que ocorre entre a coleta da informação pelo teste a ser avaliado e a coleta da informação sobre o critério. Se as coletas forem (mais ou menos) simultâneas, a validade será do tipo concorrente; caso os dados sobre o critério sejam coletados após a coleta da informação sobre o teste, fala-se de validade preditiva (PASQUALI, 2003).

Segundo Hair Jr., Babin, Samouel (2005), para demonstrar a validade concorrente de 
um construto alguma as sociação predeterminada deve ser estabelecida entre os escores do constructo que está sendo avaliado e os escores de uma variável dependente. Os escores de ambas as variáveis são obtidos aproximadamente no mesmo ponto no tempo e devem ser altamente correlacionados. Já a validade preditiva avalia a habilidade de um constructo medido em um ponto no tempo para prever outra variável de critério ou uma escala de itens múltiplos. Desta forma, para que um constructo tenha validade preditiva, deve ser possível prever valores futuros de uma variável dependente a partir de escores obtidos no constructo que está sendo testado.

Entretanto, a dificuldade está em definir um critério válido e adequado. Assim, Pasquali (2003) afirma que vários critérios podem ser utilizados, tais como:

1. Desempenho acadêmico: consiste no nível de desempenho escolar dos alunos, seja pela nota dada pelo professor, seja a média acadêmica geral do aluno. Embora amplamente utilizado, este critério recebe críticas pela deficiência que ocorre na avaliação, visto que existe uma tendenciosidade do professor. Para sanar este problema os professores deveriam aplicar teste com validade de conteúdo, e como esta tarefa é dispendiosa, o professor não se dá ao trabalho de validar (validade de conteúdo) suas avaliações acadêmicas.

2. Desempenho em treinamento especializado: trata-se do desempenho obtido em cursos de treinamento em situações específicas, nas quais ao final do treinamento faz-se uma avaliação que produz dados úteis para servirem de critério de desempenho do aluno. As mesmas observações críticas feitas no item anterior se aplicam a este.

3. Desempenho profissional: trata-se de comparar os resultados do teste com o sucesso/fracasso ou o nível de qualidade do sucesso dos sujeitos na própria situação de trabalho.

4. Diagnóstico psiquiátrico: muito utilizado para validar testes de personalidade/ psiquiátricos.

5. Diagnóstico subjetivo: avaliações feitas por colegas e amigos podem servir de base para estabelecer grupos-critérios.

6. Outros testes disponíveis: os resultados obtidos mediante outro teste válido, que prediga o mesmo desempenho que o teste a ser avaliado.

Analisando as colocações de Polit, Beck e Hungler (2004), fica claro que tanto a validade como a confiabilidade não é uma característica de "tudo" ou "nada" de um instrumento. Não se pode dizer que um instrumento é ou não válido, é uma questão de grau. 
Desta forma, o pesquisador não valida o instrumento, mas alguma aplicação deste instrumento, pois a validação é um processo sem fim, ou seja, quanto mais evidências puderem ser reunidas de que o instrumento está medindo o que deve medir, maior será a confiança que os pesquisadores terão em sua validade.

\subsection{Triangulação}

Oriunda das pesquisas qualitativas, a triangulação é um método que verifica e estabelece validade em seus estudos, se refere ao uso de diversas medidas para capturar um constructo. Entretanto, esta estratégia de triangulação pode ser aplicada a diversos tratamentos, manipulação, teorias, análises, metodologias e design de pesquisa (FEELEY, 2001; GUION, 2002).

A triangulação busca dar maior credibilidade aos métodos adotados, bem como aos resultados obtidos, contribuindo para o rigor científico. Desta forma, Feeley (2001) apresenta quatro tipos: (a) triangulação de dados, (b) triangulação de investigador, (c) triangulação de teoria e (d) triangulação metodoló gica, ressaltando que podem ser subdivididos em três tipos: (a) tempo, (b) espaço e (c) pessoas.

Corroborando com Feeley (2001), Guion (2002) comenta sobre os quatro tipos e acrescenta mais um quinto tipo, a triangulação ambiental, conforme apresentadas abaixo.

\section{1) Triangulação de Dados}

Envolve o uso de diferentes fontes de dados/informações. A estratégia chave é categorizar cada grupo ou tipo de interessado (stakeholders) no programa que está sendo avaliado. Para tanto, inclui um número comparável de pessoas em cada grupo no estudo da avaliação. Este tipo talvez seja o mais popular e fácil de implementar.

Corroborando com a temática, Feeley (2001) ressalta que a triangulação no aspecto de tempo se refere tanto ao tempo (dias) como ao cenário histórico, podendo também ser referenciada como as mudanças associadas às pessoas. Similarmente, o elemento espaço, pode delinear fronteira geográfica, bem como diferenças de localidade. Além disso, os efeitos do espaço podem ser reconhecidos nas pessoas.

\section{2) Triangulação de Investigadores/avaliadores}

Envolve a utilização de diferentes investigadores/avaliadores em projeto de avaliação, cuja triangulação consiste em cada diferente investigador/avaliador estudar o programa usando os mesmos métodos de coleta de dados (entrevista, observação, estudo de caso ou focus group), de forma que os resultados encontrados por cada avaliador são comparados e se 
os resultados obtidos chegarem às mesmas conclusões, a validade foi estabelecida. Caso contrário, se os resultados diferirem substancialmente, o estudo deve ser replanejado.

Embora esta seja uma estratégia de triangulação efetiva, pode não ser prática, haja vista a necessidade de diversos avaliadores, custo e tempo disponível para tal.

\section{3) Triangulação de Teoria}

Envolve o uso de diversas perspectivas de profissionais para interpretar um grupo de dados/informações. Normalmente, trabalha-se com profissionais fora de seu campo de estudo. Uma abordagem popular é construir junto com as pessoas de diferentes áreas. Entretanto, os indivíduos devem ocupar posições diferentes.

Em teoria, acredita-se que as pessoas de diferentes posições possuem perspectivas diferentes. Desta forma, caso as pessoas (avaliadores) de diferentes áreas interpretem as informações na mesma diretriz (chegando às mesmas conclusões), então a validade foi estabelecida.

Embora seja uma estratégia efetiva, pode não ser viável aplicá-la em todas as situações, haja vista o tempo gasto para envolver diferentes pessoas de diversas áreas para a interpretação das informações.

\section{4) Triangulação Metodológica}

Envolve o uso de vários métodos qualitativos e/ou quantitativos para estudar o programa. Se a conclusão de cada um dos métodos for a mesma, então há validade.

Esta é uma estratégia de triangulação popular e amplamente utilizada. Entretanto, na prática, esta estratégia pode requerer mais recursos para avaliar o programa usando diferentes métodos. Da mesma forma, irá requerer mais tempo para a análise dos dados/informações em funções dos diferentes métodos adotados.

\section{5) Triangulação Ambiental}

Envolve o uso de locais diferentes, definições e outros fatores-chave relacionados ao ambiente em que o estudo será realizado, tais como: hora do dia, dia da semana ou estação do ano. O elemento chave é identificar quais fatores ambientais podem influenciar as informações recebidas durante o estudo. $\mathrm{O}$ fator ambientalé alterado para ver se os resultados são os mesmos. Se os resultados permanecerem os mesmos em diferentes condições ambientais, então a validade foi estabelecida.

Não diferente dos outros tipos, a triangulação ambiental não pode ser utilizada em todos os casos. Ela é somente usada quando os resultados podem ser influenciados pelo mesmo fator ambiental.

Com es se panorama sobre confiabilidade, validade e triangulação é possível verificar o 
quão relevante são essas evidências, bem como formas para obtê-las, haja vista a necessidade de assegurar que tanto o instrumento proposto como os resultados gerados pelo mesmo seja permeado por tais evidências.

\subsection{Messick's Framework para Validade da Avaliação}

Temas relacionados à validade são amplamente discutidos em diversos segmentos e/ou áreas do conhecimento, cuja tendência é a busca pela validação de instrumento mediante as categorias de validade.

Seguindo esta tendência, a American Educational Research Association (AERA), American Psychological Association (APA) e National Council on Measurement in Education (NCME) (1999) publicaram os Standards for educational and psychological testing, que definiram a validade como "o grau em que todas as evidências acumuladas corroboram a interpretação pretendida dos escores de um teste para a finalidade a que se propõe".

As diretrizes da AERA, APA e NCME (1999) mantêm as técnicas utilizadas nos estudos de validade de conteúdo, critério e construto, mas ampliam suas possibilidades de análise. Segundo Urbina (2004), evidências de validade dos escores de um teste podem ser obtidas por meio de qualquer pesquisa sistemática que confirme ou acrescente algo ao seu sentido, independente de quando ela ocorre ou de quem a realiza. Porém, é necessária uma ampla fonte de evidências de validade para considerar um instrumento válido.

A validade é um processo contínuo em que, na medida que o conhecimento avança sobre determinado fenômeno, as hipóteses são alteradas para acompanhar esta evolução. Portanto, novos testes precisam ser realizados.

Para Messick (1989) a validade é um julgamento avaliativo integrado dos graus em que a evidência empírica e a fundamentação teórica suportam a adequação e a pertinência das inferências e ações baseadas em resultados de testes ou outros modos de avaliação. Assim, validade é um conceito unificado e validação é uma atividade científica baseada em múltiplos métodos de coleta e diversos tipos de evidência (MESSICK, 1989; ZUMBO, 1998, 2007).

Diante da concepção de validade como um conceito unificado, Messick (1989) ressalta a existência de quatro facetas formadas pelo cruzamento da prova evidencial com as bases consequenciais da interpretação e uso do teste (Figura 3 ). 


\begin{tabular}{|c|c|c|}
\hline \multirow{2}{*}{ Justificativa } & \multicolumn{2}{|c|}{ Resultados } \\
\cline { 2 - 3 } & Interpre tação do teste & Uso do teste \\
\hline \multirow{2}{*}{ Bases evidenciais } & Validade de constructo & VC + relevância/utilidade \\
& $(\mathrm{VC})$ & (RU) \\
\hline \multirow{2}{*}{ Bases consequenciais } & $\begin{array}{c}\text { Implicações de valor } \\
(\mathrm{VC}+\mathrm{RU}+\mathrm{IV})\end{array}$ & $\begin{array}{c}\text { Consequências sociais } \\
(\mathrm{VC}+\mathrm{RU}+\mathrm{IV}+\mathrm{CNE}\end{array}$ \\
\hline
\end{tabular}

Figura 3 - Concepção de validade, adaptado de Messick (1989).

Legenda: VC: validade de constructo; RU: relevância/utilidade; IV: implicações de valor; CNE: consequências não esperadas

Nos dois boxes superiores a base evidencial da validade refere-se às evidências científicas tradicionais, sendo que no box superior à esquerda estão as medidas psicométricas tradicionais e o direito consiste na relevância para os aprendizes e para a socied ade, bem como o custo-benefício. Nos dois boxes inferiores, as bases consequenciais incluem implicações de valores e consequências sociais. O termo implicações de valores refere-se aos valores fundamentais. Já consequências sociais são definidas como efeitos não esperados, incluindo os efeitos atuais e potenciais do uso do teste (MESSICK, 1989).

As bases evidenciais para interpretação de um teste é uma apreciação das evidências científicas para a validade de constructo. Um constructo é a definição de habilidades e conhecimentos incluídos no domínio que será mensurado por ferramentas ou por testes (RECKASE, 1998b). Nesta faceta, os quatro tipos de validade são incluídos, ou seja, validade de constructo, validade de conteúdo, validade preditiva e validade concorrente.

Nessa perspectiva, cada categoria é avaliada por meio de métodos específicos a partir do entendimento de validade como o grau em que um teste mede o que pretende medir (PASQUALI, 2003). Desta forma, Urbina (2004) relata que as fontes de evidência da validade do cons tructo de um teste envolvem a avaliação dos aspectos:

a) representatividade e relevância do conteúdo do teste e dos processos de resposta às tarefas;

b) aparência superficial do teste;

c) consistência interna do teste;

d) correlações de testes e subtestes;

e) diferenciações nos escores a partir de diferenças com base em uma variável de status, tal como a idade;

f) matriz multitraço-multimétodo;

g) resultados experimentais; 
h) análise fatorial exploratória;

i) técnicas de modelagem de equação estrutural;

j) correlações entre escores do teste e critérios existentes (validade concorrente); e

k) correlações entre escores do teste e critérios preditos (validade preditiva).

Em relação às bases evidenciais para o uso do teste, inclui-se medidas de validade preditiva e custo-benefício, o qual se refere a uma análise do cus to comparado aos benefícios. Contudo, em educação os benefícios são medidas difíceis de quantificar.

Com relação às bases consequenciais - implicações de valor - Messick (1989) relata que estão relacionadas à retórica, teorias e ideologias. Corroborando, Van Dijk (1998) relaciona valores a uma linguagem compartilhada, teorias, crenças e visão de mundo. Já as consequências não esperadas estão relacionadas aos efeitos produzidos pelo uso do teste em esfera individual, institucional, sistêmico e social; não contemplando o não uso do teste (MESSICK, 1989). Além disso, as consequências não esperadas podem ser positivas ou negativas. Assim, o framework de Messick (1989) é entendido como uma matriz progressiva em que as quatro facetas são altamente entrelaças e sobrepostas.

Diante do framework proposto por Messick (1989) para programas de avaliação e tendo em vista que no Brasil algumas características propostas pelo autor não são totalmente aplicáveis, decidiu-se adaptar o modelo, criando um roteiro de elementos julgados importantes para compor uma arquitetura de orientação para a construção de instrumentos de assessment em EaD (objetivo deste estudo), propiciando uma ação compreensiva e integrada em que múltiplas fontes de evidências são utilizadas no instrumento, proporcionando uma maior interface com a realidade brasileira, conforme descritas no Quadro 2.

\begin{tabular}{|c|c|}
\hline Dimensão & Ele mentos \\
\hline FUNDAMENTOS & $\begin{array}{l}\text { - } \text { Enquadramento em assessment ou evaluation } \\
\text { - Missão da instituição } \\
\text { - Valores institucionais } \\
\text { - Objetivos e metas do curso/programa de EaD } \\
\text { - Definição do problema existente } \\
\text { - Consulta às fontes formais e informais } \\
\text { - Apresentação de gap entre o ideal e o real } \\
\text { - Lógica do assessment } \\
\text { - Objetivo do assessment } \\
\text { - Interessado no assessment (stakeholders) } \\
\text { - Modelo lógico da avaliação } \\
\text { - Participantes do assessment }\end{array}$ \\
\hline
\end{tabular}




\begin{tabular}{|c|c|}
\hline Continuação & $\begin{array}{l}\text { - } \text { Questões chave para o assessment } \\
\text { - Modelo/Abordagem de a valiação utilizado } \\
\text { - } \text { Método de investigação } \\
\text { - Design do assessment } \\
\text { - Natureza do assessment } \\
\text { - Designação da equipe de a valiação } \\
\text { - Custo prévio da avaliação }\end{array}$ \\
\hline $\begin{array}{l}\text { EVIDÊNCIAS } \\
\text { CIENTÍFICAS }\end{array}$ & $\begin{array}{l}\text { - Métodos e instrumentos para a coleta de dados } \\
\text { - Triangulação } \\
\text { - Consistência interna } \\
\text { - Análise fatorial } \\
\text { - Análise por hipótese } \\
\text { - Correlação } \\
\text { - Alfa de Cronbach } \\
\text { - Teste piloto } \\
\text { - Treinamento para entre vistador } \\
\text { - Evidência de confiabilidade } \\
\text { - Evidências de validade } \\
\text { - Pontos críticos da validade } \\
\text { - Características da amostra } \\
\text { - Métodos e instrumentos para a análise de dados } \\
\text { - Padrões de a valiação }\end{array}$ \\
\hline RELEVÂNCIA/UTILIDADE & $\begin{array}{l}\text { - } \text { Divulgação e uso dos resultados } \\
\text { - } \text { Feedback aos stakeholders } \\
\text { - } \text { Relação custo-benefício } \\
\text { - Limitações/res trições } \\
\text { - } \\
\text { - } \text { Impocumentação do assessment e medidas de desempenho }\end{array}$ \\
\hline $\begin{array}{l}\text { CONSEQUÊNCIAS } \\
\text { (positivas ou negativas) }\end{array}$ & $\begin{array}{ll}\text { - } & \text { Sociais } \\
\text { - } & \text { Institucionais } \\
\text { - } & \text { Instrucionais }\end{array}$ \\
\hline
\end{tabular}

Quadro 2 - Dimensões e elementos integrantes de um plano de assessment ou evaluation

Ao utilizar o framewok de Messick e a partir dele construir este roteiro, a justificativa está fundamentada no fato de que cada uma das dimensões fornece diversos critérios que podem ser utilizados como guia na construção de instrumentos de assessment, prospectando ferramentas que podem ser utilizadas para coletar evidências sobre cada um dos elementos, bem como deixar claro e evidente no plano de assessment que os 5W2H estão contemplados, conforme apresentado no Quadro 3. 


\begin{tabular}{|ccc|}
\hline Perguntas & Problemas & Soluções \\
\hline O quê / What & Eo problema? & Vai ser feito? Qual a ação? \\
Por quê / Why & Ocorre ? & Foi definida esta solução? \\
Quando / When & (Desde quando) ele ocorre? & Será feito? \\
Onde / Where & Ele se encontra? & Será implantada? \\
Quem / Who & Está envolvido? & Será o responsável? \\
Como / How & Surgiu o problema? & Vai ser implementada? \\
Quanto Custa / How Much & Ter este problema? & Esta solução? \\
\hline
\end{tabular}

Quadro 3 - Utilização dos 5W2H no plano de assessment

Dessa forma, as múltiplas medidas asseguram credibilidade à investigação além de possibilitar a triangulação dos resultados utilizando diversos métodos com diferentes bases (FITZPATRICK; SANDERS; WORTHEN, 2004; BERG, 2007; RUHE e ZUMBO, 2009). Contudo, o interesse principal são as evidências científicas, haja vista que por meio delas é possível assegurar confiabilidade e validade a um instrumento de assessment [ou evaluation], que é o objetivo principal desse estudo.

Além disso, esse roteiro é flexível de tal forma que nem todos os elementos das dimensões evidências científicas e consequências são obrigatórios em um plano de assessment ou evaluation, visto que o contexto, bem como as especificidades do curso/programa, devem ser considerados. Entretanto, sugere-se que se utilize o máximo possível de elementos, o que proporcionará diferentes estratégias para obtenção de confiabilidade e validade.

\subsection{Pontos críticos para a validade interna e externa}

A validade interna é um conceito que se refere à extensão em que um experimento elimina as explicações alternativas para os resultados. Quando os resultados podem ser atribuídos com pouca ou nenhuma ambiguidade aos efeitos da validade interna, o experimento é considerado internamente válido (SILVARES e ARANTES, 2010). No entanto, algumas ameaças, conforme Campbell e Stanley (1963); Cook e Campbell (1979); e Shadish, Cook, e Campbell, (2002), podem interferir na validade, tais como:

\section{Validade interna}

- História.

- Maturação.

- Testagem. 
- Instrumentação.

- Regressão estatística.

- Seleção diferencial dos sujeitos.

- Mortalidade ou evasão.

- Interação.

O Quadro 4 sumariza e detalha os principais pontos críticos para a validade interna.

\begin{tabular}{|c|l|}
\hline Ponto Crítico & \multicolumn{1}{c|}{ Explicação } \\
\hline História & $\begin{array}{l}\text { Acontecimentos específicos que ocorreram entre a primeira e a segunda medição e } \\
\text { que tem efeitos na(s) variável(is) dependente(s) em estudo. }\end{array}$ \\
\hline Maturação & $\begin{array}{l}\text { Qualquer mudança ao longo do tempo que possa resultar de processos internos do } \\
\text { sujeito. Tais processos podem incluir o envelhecer, o fortalecer, o tornar-se mais } \\
\text { sadio, mais esperto e mais entediado ou cansado. }\end{array}$ \\
\hline Testagem & $\begin{array}{l}\text { Qualquer mudança que possa ser atribuída aos efeitos da avaliação repetida. O testar } \\
\text { em si constitui uma experiência que, dependendo da medida, pode levar a mudanças } \\
\text { sistemáticas no desempenho, ou seja, os sujeitos podem ter aprendido algo ao } \\
\text { realizar o pré-teste. }\end{array}$ \\
\hline Instrumentação & $\begin{array}{l}\text { Qualquer mudança que ocorra no instrumento de medida ou no procedimento de } \\
\text { avaliação ao longo do tempo. Falta de confiabilidade ou consistência nos } \\
\text { instrumentos de coleta de dados e respectiva utilização. }\end{array}$ \\
\hline Regressão \\
estatística & $\begin{array}{l}\text { Consequência de se ter escolhido sujeitos com base em resultados extremos. Ex. } \\
\text { estudantes com melhor e pior aproveitamento. }\end{array}$ \\
\hline Seleção dos & $\begin{array}{l}\text { Quaisquer diferenças entre grupos que possam ser derivadas de seleção diferencial } \\
\text { ou da atribuição de sujeitos a grupos. Os grupos podem diferir em função das } \\
\text { condições de seleção inicial, e não em função de condições diferentes que tenham } \\
\text { sido definidas como parte do experimento, ou seja, são resultantes do modo como } \\
\text { os sujeitos foram selecionados. }\end{array}$ \\
\hline evasão & $\begin{array}{l}\text { Perda diferencial dos sujeitos em um grupo. Os sujeitos podem desistir ou serem } \\
\text { perdidos por quaisquer razões, o que pode fazer com que os resultados grupais } \\
\text { totais pareçam ter mudado. }\end{array}$ \\
\hline Interação entre os diferentes fatores. \\
\hline morta
\end{tabular}

Quadro 4 - Principais pontos críticos para a validade interna, adaptado de Silvares e Arantes (2010) e Chagas (2004) 
A validade interna refere-se à extensão em que um experimento demonstra de forma não ambígua que a intervenção é a responsável pela mudança; já a validade extema volta-se para uma questão mais ampla e refere-se à extensão em que os resultados de um experimento podem ser generalizados para além das condições particulares do experimento. Desta forma, as características que limitam a generalidade dos resultados são considerados como pontos críticos para a validade externa (SILVARES e ARANTES, 2010).

De acordo com Chagas (2004), Shadish, Cook e Campbell, (2002); Cook e Campbell (1979) e Campbell e Stanley (1963), as principais ameaças à validade externa são sintetizadas no quadro 5.

\begin{tabular}{|c|l|}
\hline Pontos Críticos & \multicolumn{1}{|c|}{ Explicação } \\
\hline $\begin{array}{c}\text { Interação do pré-teste } \\
\text {-tratamento }\end{array}$ & \begin{tabular}{l} 
Acontece quando os suje itos reagem diferentemente ao tratamento porque \\
foram submetidos a um pré-teste. \\
\hline $\begin{array}{c}\text { Influência do pós- } \\
\text { teste }\end{array}$
\end{tabular} \\
\hline $\begin{array}{c}\text { Interferência de } \\
\text { tratamentos múltiplos }\end{array}$ & Ocorre quando os mesmos sujeitos recebem uma sucessão de tratamentos. \\
\hline $\begin{array}{c}\text { Interação seleção- } \\
\text { tratamento }\end{array}$ & $\begin{array}{l}\text { Consequência de uma seleção não aleatória. A representatividade da } \\
\text { amostra é posta em causa. }\end{array}$ \\
\hline $\begin{array}{c}\text { Especificidade das } \\
\text { variáveis }\end{array}$ & $\begin{array}{l}\text { Refere-se às particularidades do estudo: (1) sujeitos, (2) definição das } \\
\text { variáveis, (3) instrumentos de coleta de dados, (4) aplicação e (5) } \\
\text { circunstâncias específicas. }\end{array}$ \\
\hline $\begin{array}{c}\text { Efeitos resultantes do } \\
\text { investigador }\end{array}$ & Características de personalidade e expectativas. \\
\hline Arranjos reativos & $\begin{array}{l}\text { Fatores associados ao modo como o estudo é conduzido e os sentimentos e } \\
\text { atitudes dos sujeitos. }\end{array}$ \\
\hline
\end{tabular}

Quadro 5 - Principais pontos críticos para a validade externa

Conforme apontado, os pontos críticos (ameaças) da validade interna e externa podem influenciar os resultados quanto à precisão e generalização. Portanto, é de suma importância que estas sejam eliminadas ou pelo menos minimizadas na construção de instrumentos de avaliação (assessment e evaluation).

Este capítulo apresentou um arcabouço teórico sobre evidências de confiabilidade, validade, triangulação e pontos críticos de validade, o que sustenta uma escolha adequada, que respeita o contexto a ser investigado. Além disso, ao apresentar um roteiro de dimensões, possibilita a execução passo a passo para a construção de instrumentos avaliativos permeados por evidências científicas. 


\section{CAPÍTULO 4 - Modelos de avaliação no contexto da EaD: teoria e prática}

Este capítulo apresenta alguns modelos de avaliação já existentes, mostrando sua teoria e prática de aplicação, cujo propósito é verificar quais os elementos do roteiro eles contemplam, visto que a arquitetura de orientação proposta nesse estudo sistematiza, integra e atrela os elementos apresentados.

Nesse sentido, um processo avaliativo permite transformações nos pressupostos teóricos e práticos, sobretudo pelo fato de também ser transformado ao longo de sua execução. A avaliação pode acontecer em diferentes e complexos contextos, e estes exigem abordagens diferenciadas para cada situação.

Os modelos não somente guiam o processo de avaliação como também incluem importantes aspectos de valor, delineamento das etapas do processo avaliativo e sinalizam estratégias para o sucesso da avaliação. A utilização de um modelo de avaliação adequado amplia a qualidade técnica e possibilita uma visão integrada e articulada do fenômeno avaliado.

Ao se tratar de modelos de avaliação, eles podem ser classificados e/ou agrupados de acordo com suas características predominantes. Assim, Fitzpatrick, Sanders e Worthen (2004) categorizam os modelos de avaliação da seguinte maneira: (a) orientados aos objetivos, (b) orientados ao gerenciamento, (c) orientados ao cliente, (d) orientados à expertise, (e) orientados aos participantes.

Para Stufflebeam (2001) as classificações são: (a) pseudoavaliações, (b) abordagens orientadas às questões e métodos, (c) abordagens orientadas à melhoria e (d) modelos de apoio social.

Diante deste contexto, o foco deste capítulo é apresentar alguns modelos existentes de avaliação, cuja aplicação pode ser estendida aos programas de educação a distância, bem como enquadrá- los no roteiro da arquitetura de orientação.

\subsection{Modelo Lógico de Avaliação segundo Mary no wski (2006)}

Marynowski (2006) apresenta um modelo lógico, o qual é uma ferramenta para conduzir Programa de Avaliação, visto como um simples passo-a-passo.

Este modelo lógico pode guiar o desenvolvimento do plano de avaliação, mostrando 
quais os insumos necessários (entradas) ao programa e o que se pode obter com as realizações, resultados e impactos. O modelo lógico também esclarece como e quando avaliar o programa.

A figura 4 apresenta os componentes básicos do modelo lógico, bem como os estágios e os tipos de avaliação.

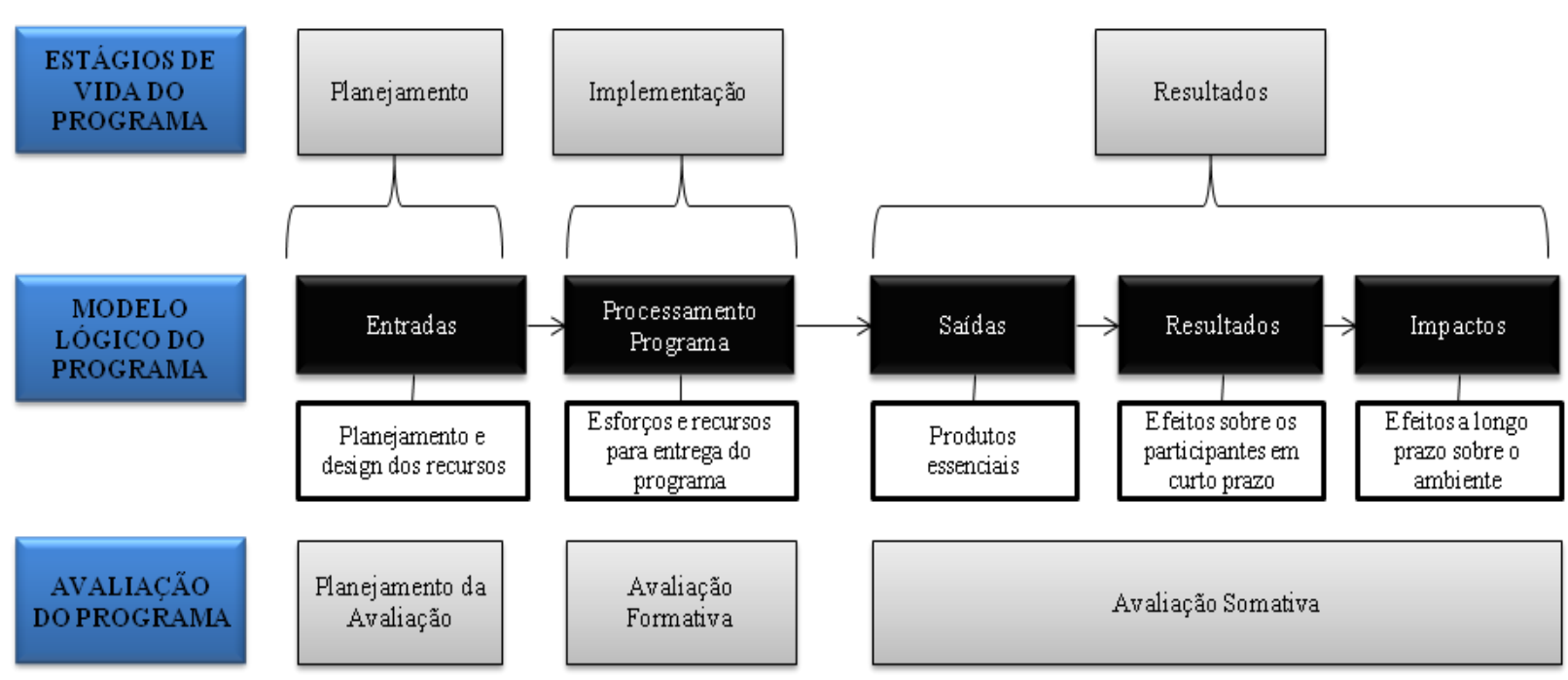

Figura 4 - Modelo Lógico de Avaliação, adaptado de Marynowski (2006)

Nesse modelo a autora considera:

\section{Primeiro Passo}

Estágio de Planejamento: Quais os problemas ou necessidades o programa investiga? Quais os recursos disponíveis para o planejamento do programa? Qual a forma desejada para o programa?

- Entradas: são os recursos disponíveis para o programa, tais como: pessoal, recursos financeiros, materiais e equipamentos.

Estágio de Implementação: Como o programa será entregue? Quais serão os melhores meios? Quais os recursos necessários para a entrega do programa?

- Processamento do programa: inclui ferramentas, materiais, eventos, ações, tecnologias e pessoas que ajudarão a produzir o programa.

Estágio de Resultados: Quais são os resultados esperados do programa? Quais os potenciais 
efeitos a curto e longo prazo? O programa atingiu aos seus objetivos?

- Saídas: são os produtos essenciais de um programa e inclui itens como o número de sessões, de participantes, os custos do programa e o feedback dos participantes.

- Resultados: são as mudanças que ocorrem nos participantes como resultados do programa. Estas mudanças incluem conhecimento, atitudes, habilidades, motivações, decisões e mudança de comportamento.

- Impactos: são as mudanças a longo prazo nos ambientes sociais, econômicos, comunitários ou nas condições organizacionais que ocorrem como um resultado do programa.

\section{Segundo Passo}

\section{Determinar o propósito da avaliação}

Algumas questões são necessárias para ajudar a pensar sobre o propósito da avaliação, tais como:

- Qual a razão desta avaliação? O que se espera alcançar com esta avaliação? O propósito da avaliação pode incluir: informar sobre o desenvolvimento e melhoria do programa; determinar se o programa cumpre os objetivos; mensurar se o programa proporciona mudanças em seus participantes; mostrar se o programa é bem sucedido; validar o programa como apoio à missão organizacional; obter fina nciamento adicional; promover a aprendizagem pessoal e organizacional ou para justificar o programa para administradores relutantes.

- Que tipo de avaliação será realizada? Estes tipos incluem planejamento (avaliação das necessidades), formativa (realizado durante o início do programa para execução de melhoria ou modificações) ou somativa (realizada para resumir o programa de realizações, resultados e impactos).

- Quem vai utilizar as informações da avaliação? Pense sobre os interessados nas informações obtidas na avaliação.

- Como as informações serão utilizadas? A avaliação é conduzida para abordar uma necessidade. Desta forma, atente-se para saber como os resultados da avaliação serão utilizados. O que se vai fazer com as informações coletadas? Que decisões serão tomadas com base nas informações obtidas? Que ações poderão ser realizadas? A avaliação é realizada fundamentalmente sobre a influência e valores de uma organização - é vital para 
que se possa obter melhoria de desempenho.

\section{$\underline{\text { Terceiro Passo }}$}

\section{Entender programas similares}

Os programas e as pesquisas existentes podem fornecer preciosas informações para apoiar os esforços de avaliação. Existem duas grandes fontes de informações que serão úteis: (1) programas de avaliação semelhantes ao que se pretende desenvolver e (2) a informação existente sobre o próprio programa que será desenvolvido.

\section{Quarto Passo}

\section{Montar a equipe de avaliação}

Os membros da equipe de avaliação são as pessoas que tem forte interesse nos resultados, além dos mesmos serem de suma importância para o processo de avaliação. Relacione quem terá influência na definição das questões e processo da avaliação.

O envolvimento da equipe assegurará a obtenção de diferentes perspectivas sobre as necessidades de avaliação, bem como as necessidades esse nciais serão encontradas.

O envolvimento dos membros da equipe possibilitará:

- Recolher informações importantes para as pessoas-chave envolvidas no programa;

- Assegurar que não se perca nas partes críticas de coleta de informação;

- Aumento de apoio da equipe para desenvolver um melhor trabalho de conhecimento do programa;

- Aumento de apoio e utilização dos resultados da avaliação.

\section{Quinto Passo}

\section{Estabelecer os recursos de entrada e os obstáculos}

Devido às limitações, pode-se não conseguir avaliar todos os aspectos do programa de avaliação, entretanto, uma parte essencial será produzir benefícios tangíveis.

À luz do(s) objetivo(s) definido(s) para a avaliação, analisar os recursos correntemente disponíveis. Estabelecer quais recursos adicionais poderá necessitar e como satisfazer essas necessidades. 
É importante ser realista sobre o que se pode fazer e o que se quer fazer. É necessário que haja um equilíbrio entre a praticidade com o rigor científico. A avaliação será muito mais tranquila se houver níveis adequados de tempo, dinheiro e pessoal assegurados para a avaliação.

\section{$\underline{\text { Sexto Passo }}$}

\section{Criar questões e selecionar os indicadores}

Determinar as necessidades de informação crítica que irá lançar nas bases para a avaliação. Qual o objetivo da avaliação? O que se precisa saber sobre o programa de melhoria? Quais informações necessárias para os interessados-chave na avaliação? Estas três questões auxiliarão na determinação das questões centrais da avaliação.

As questões mais importantes da avaliação surgirão com base nas discussões sobre os objetivos e metas do programa de avaliação. Limita as questões de avaliação em poucos objetivos, características ou necessidades de informação.

Ao definir as perguntas da avaliação:

- Decida qual a informação é mais importante coletar.

- Simule as perguntas da avaliação.

- Selecione potenciais indicadores - para cada indicador deverá ter uma fonte de informação.

- Selecione as potenciais fontes de informação.

- Reduza a lista das perguntas mais importantes - examine cada questão e os indicadores associados, de modo a visualizar se eles atendem as necessidades da avaliação.

- Certifique-se que os indicadores podem ser mensurados.

- Certifique-se que tenha objetivos e expectativas realistas.

\section{$\underline{\text { Sétimo Passo }}$}

\section{Desenvolver a abordage m de avaliação}

A etapa final do planejamento da avaliação é selecionar uma ou mais abordagens para seu plano de desenvolvimento, o qual ajudará a reunir as informações necessárias para responder às questões da avaliação.

A tarefa mais difícil será estabelecer o nível apropriado de esforços para a avaliação, 
cuja necessidade de informação seja balanceada com as habilidades e recursos disponíveis para a realização da avaliação.

Existem diferentes métodos e ferramentas para a coleta de dados, esses dependerão das questões da avaliação, da informação que se necessita coletar, do tamanho da avaliação e dos recursos disponíveis. Sugere-se que mais de uma ferramenta de avaliação seja utilizada e que se possível, seja realizada uma triangulação ou confirmação dos resultados sob diferentes perspectivas.

Ao analisar o modelo de Marynowski (2006), verifica-se que se trata de um assessment, embora receba o nome de avaliação (evaluation). Além disso, não contempla os elementos relacionados à missão e valor da instituição, bem como objetivos e metas do curso/programa que está avaliando. Entretanto, a dimensão dos fundamentos é a mais contemplada. Na dimensão evidências científicas apenas comenta sobre os métodos e instrumentos de coleta de dados, e a necessidade de triangulação de informações. Nas dimensões seguintes, relevância/utilidade e consequência, aborda apenas um elemento de cada uma, sendo divulgação e uso dos resultados e consequência (impactos - em geral), respectivamente.

\subsection{Modelo Sistemático para Avaliação do E-Learning, segundo Mungania e Hatcher} (2004)

O modelo de avaliação proposto por Mungania e Hatcher (2004), descreve como avaliar o e-learning, identificando as fases do programa de avaliação (quando), as potenciais fontes de dados (quem) e as variáveis para avaliar (o quê). Desta forma, propõem um modelo sistemático para avaliação, conforme figura 5 . 


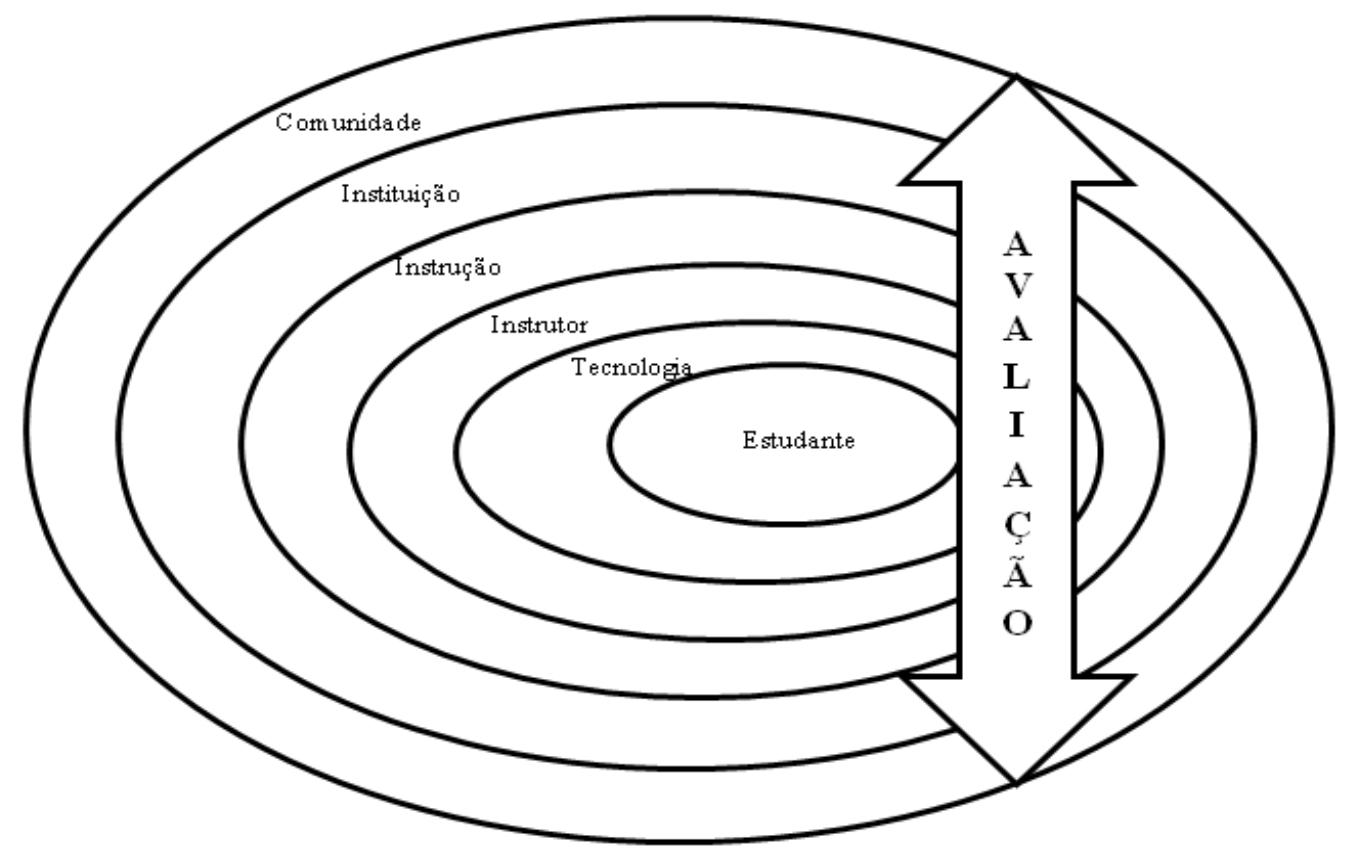

Figura 5 - Modelo Sistemático para Avaliação do E-Learning, adaptado de Mungania e Hatcher (2004)

Os autores, ao descreverem esse modelo, fazem analogia a uma cebola, cuja qualidade é percebida normalmente, pela aparência exterior, mas a verdadeira qualidade é determinada pelo corte ou pela retirada das camadas. Do mesmo modo, ao avaliar a qualidade de um programa de e-learning, uma rápida "olhada" não revela muito. É necessário avaliar camada por camada, componente por componente, para se ter uma avaliação real da situação, assim como na cebola, pois muitas coisas parecem óbvias, entretanto, não são diretamente visíveis.

De acordo com Belanger e Jordan (2000), há mais a avaliar do que é visto pelos olhos, por isso que a avaliação deve ser um processo contínuo, o qual é constituído por várias camadas.

Nesse sentido, é importante que o avaliador conheça quais os fatores, sujeitos e variáveis são necessários a cada passo de uma avaliação.

Um instrumento de avaliação deve ser determinado por várias considerações que justifiquem a necessidade de um modelo flexível, tais como:

- Recursos disponíveis para a avaliação: tempo, dinheiro e recursos humanos, bem co mo os limites impostos por cada um desses elementos.

- Obstáculos políticos e éticos.

- Resultados da avaliação - como os resultados serão utilizados ou aplicados?

- Competência e expertise do avaliador. 
- Acesso aos sujeitos ou participantes, evidentemente aos recursos e capacidades do ambiente organizacional para decidir quem, o quê, quando e como avaliar, bem como a amplitude e profundidade da avaliação. Isso exige flexibilidade organizacional.

A recomendação é que a avaliação seja realizada em vários pontos, ta is como: antes do curso iniciar (precurso), durante o curso (formativa) e ao término do curso (somativa), de maneira que o feedback contínuo seja formado e distribuído pelo sistema, conforme figura 6 .

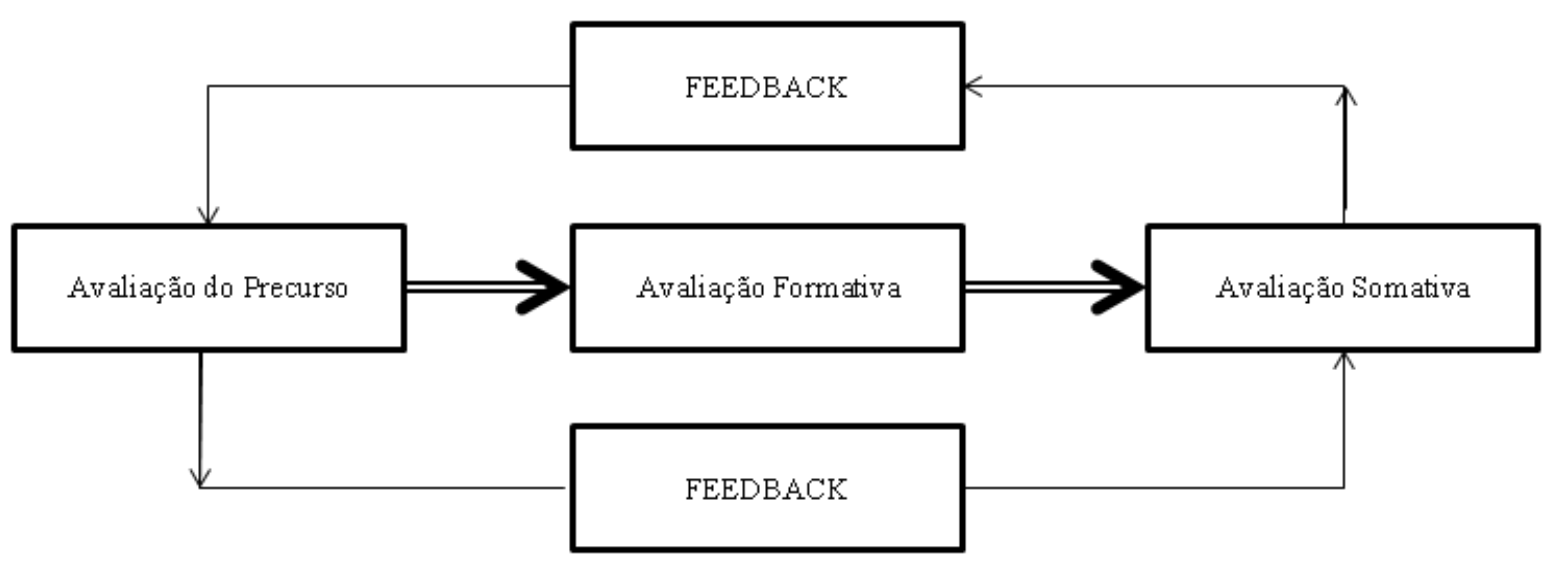

Figura 6 - Quando Avaliar e-Learning, adaptado de Mungania e Hatcher, (2004)

De acordo com a figura 6, a avaliação deve ser realizada em diferentes fases dos cursos, de forma a proporcionar feedbacks contínuos, visto que, ao tratar de fatores, verificase que em cada um deles pode-se incluir diversas variáveis, as quais cabem em qualquer instrumento de avaliação.

Segundo os mesmos autores, estas variáveis fornecem informações e orientações sobre as perguntas da avaliação. Desta forma, a escolha delas depende das necessidades organizacionais. Segue um detalhamento de cada um dos seis fatores:

\section{Estudante}

Eles são o centro de qualquer instrução; assim suas características devem ser consideradas durante a análise, concepção, desenvolvimento, implementação e avaliação. É importante utilizar a análise do estudante para obter informações sobre seus interesses, expectativas e experiências, de forma a satisfazer as suas necessidades em ambientes de $e$ learning.

Os dados reunidos fornecem informações sobre os estudantes, tais como: suas experiências prévias, necessidades e habilidades. O conhecimento e a compreensão sobre o público alvo pode tornar o conteúdo, tecnologia e métodos mais adequados às suas 
necessidades. As características dos estudantes também são importantes para a tomada de decisão, entretanto, a configuração de um cenário pode não funcionar para outro. Portanto, é necessário identificar as variáveis que são importantes para um determinado público e acompanhar a realização das metas (DICK; CAREY; CAREY, 2001).

\section{Tecnologia}

A tecnologia é uma ferramenta que pode ligar os estudantes a distância com os instrutores, funcionários, administradores e comunidades de aprendizagem. As tecnologias elearning marcam a diferença mais significativa entre as tradicionais avaliações e as avaliações e-learning, tendo em vista que a tecnologia é peça integrante do e-learning (TANQUIST, 2000).

Mungania e Hatcher (2004) enfatizam a necessidade de ser crítico com a tecnologia, pois na era do conhecimento a tecnologia pode trazer ganhos e perdas, uma vez que os cursos e-learning não existem para servir a tecnologia, mas sim as pessoas (CHIDAMBARAM; ZIGURS, 2001).

\section{Instrucão}

Antes de investir tempo e dinheiro em e-learning, a avaliação deve ser feita durante o desenvolvimento de materiais (DRISCOLL, 1998). De acordo com Schilke (2001), as barreiras relacionadas a um curso podem ser a principal razão para a evasão e os problemas de design instrucional e que são os mais comuns a todos os estudantes pesquisados, bem como a frustração com a apresentação do material de estudo, os quais funcionam como fatores decisivos para a desistência.

\section{Instrutor}

Além da avaliação realizada pelo estudante sobre o instrutor, é importante a autoavaliação. O sucesso do e-learning passa pelo desempenho dos professores. Uma avaliação via survey ou focus group com professores e estudantes pode ser realizada para identificar a eficácia, capacidade de comunicação, qualidade e frequência do feedback, conhecimento do conteúdo, atitudes, motivação, desafios, acesso e interações.

\section{Instituição}

As variáveis que poderiam ser integradas em um plano para avaliar a instrução são: valor/aula, disponibilidade de serviços de apoio, confiabilidade dos serviços de apoio, 
estratégias de marketing, suficiência do serviço de biblioteca, rigor acadêmico, gestão de serviços de e-learning, estrutura organizacional, eficiência dos serviços, segurança, parceria/colaboração, padrões de acreditação, dentre outras.

\section{Comunidade}

Neste fator examina-se em que medida o programa de melhoria de desempenho tem envolvido a sociedade e o ambiente da organização.

Kaufman e Keller (1994) propuseram um nível adicional de avaliação, o qual determinava o impacto do e-learning na comunidade.

Este modelo de avaliação se caracteriza como avaliação multidimensional, permitindo uma compreensão de todo o processo, entretanto, requer ferramentas adicionais que avaliem os processos e os resultados.

Ao analisar o modelo de Mungania e Hatcher, (2004) observa-se que pode ser utilizado em condição de assessment e/ou evaluation, dependendo das variáveis e questões tratadas. Entretanto, ao enquadrá-lo no roteiro percebe-se que a dimensão das evidências científicas possui apenas o elemento métodos e instrumento de coleta de dados contemplado, não estando evidente nenhuma preocupação com os demais itens que favorecem a confiabilidade e validade do instrumento. $\mathrm{Na}$ dimensão dos fundamentos não aborda sobre a missão e valores institucionais, assim como trata apenas de consequência social. Em relevância/utilidade trata-se da divulgação e uso dos resultados, feedback aos stakeholders e limitações/restrições.

\subsection{A Practical Framework for Evaluation Online Distance Education Program, segundo Rovai (2003)}

O modelo proposto por Rovai (2003) faz uma síntese da literatura sobre os programas de avaliação e educação a distância e extrai elementos essenciais para a construção de um framework para conduzir a avaliação em programa on-line.

Ao tratar de avaliação em programa de educação a distância, Keegan (1996) recomenda que este tipo de avaliação deve focar quatro aspectos: (a) aprendizagem (taxa de concluintes, número de matrículas, novos mercados para os formandos); (b) a qualidade da aprendizagem (eficácia dos cursos ou programas assegurando bons resultados aos estudantes); (c) status da aprendizagem (transferência entre cursos e reconhecimento do certificado pelo empregador); e (d) custo relativo da aprendizagem (relação custo/benefício). 
Nesse sentido, Rovai (2003) ressalta que uma avaliação compreensiva da efetividade dos programas de educação a distância deveria ser baseada em múltiplas fontes de evidência e na convergência de diferentes medidas. Por isso, a proposta de seu framework inicia com a identificação do propósito do programa de avaliação.

Uma vez compreendido o propósito, o tipo de avaliação pode ser definido, sendo que as estratégias e questões podem ser determinadas em paralelo. As questões específicas da avaliação para ser utilizadas por qualquer programa de avaliação devem ser baseadas nas necessidades de informações dos usuários e tomadores de decisão; e as estratégias usadas para responder estas questões deveriam ser selecionadas com base no amplo entendimento do contexto em que o programa opera. A Figura 7 apresenta o modelo comentado.

Propósito da Avaliação

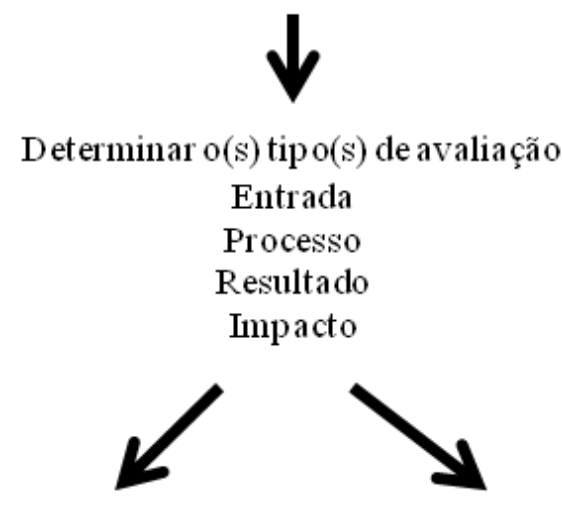

Determinar as estr atégias de avaliação Orientada a os objetivos
Orientadas a o ger enciamento Desenvolver as questões da avaliação Orientada ao consumidor Orientada a expertise Orientada ao concorr ente Orientada a $\mathrm{p}$ articipante

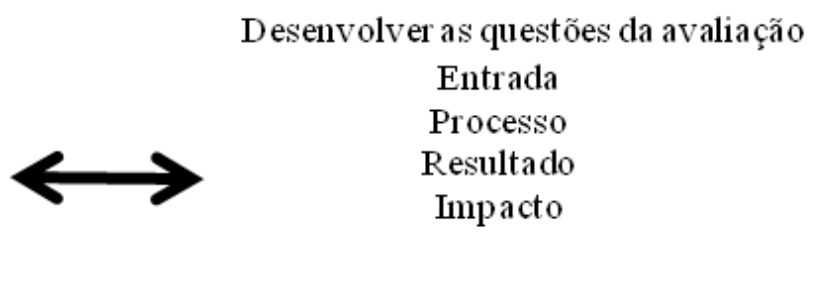

Entrada

Processo

Restitacio

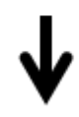

Condução da Avaliação

Figura 7 - Framework para avaliação da Educação a Distância, adaptado de Rossi, Freeman e Lipsey (1999) e Worthen, Sanders e Fitzpatrick (1997)

\section{Tipos de Avaliação}

O processo de identificar e selecionar questões de avaliação ocupa posição central e normalmente representa um passo anterior no processo de planejamento do programa de avaliação. Uma vez selecionadas, as questões da avaliação fornecem uma direção para o 
programa, e os planos são desenvolvidos para reunir evidências que permitam ao avaliador responder tais questões (ROVAI, 2003).

Segundo o mesmo autor, um método comum de categorização das avaliações do programa é verificar se serão formativas ou somativas ou a combinação dos dois métodos. Frequentemente todos os tipos são inseridos na mesma avaliação. Uma observação importante ao decidir sobre o método a ser utilizado é considerar que o feedback interno e externo é essencial para o ajustamento e melhoria do programa de avaliação.

\section{Entrada da Avaliação}

Uma entrada na avaliação identifica e avalia as capacidades do siste ma para incluir equipamentos e expertise técnica, estratégias alternativas ao programa e o design utilizado para atingir ao(s) objetivo(s) dos interessados, bem como satisfazer suas necessidades. $\mathrm{O}$ propósito é prover informações de qualidade sobre os recursos utilizados no programa e determinar qual será o melhor uso desses recursos para a realização dos objetivos.

\section{Processo de Avaliação}

No processo de avaliação, o avaliador confere todo o programa, analisando o que está acontecendo, como ele está sendo implementado e também o que deveria estar acontecendo e não está, pois isso fornecerá informações sobre o estado de todos os componentes, possibilitando o acompanhamento da efetividade do programa.

\section{Saída da Avaliação}

A saída da avaliação visa determinar os efeitos diretos e imediatos ao programa. Ela consiste em recolher, analisar e avaliar os resultados, tais como: o quanto o programa foi utilizado, quantas pessoas foram atingidas, a média em que os objetivos do programa foram alcançados e as mudanças nas habilidades, conhecimento ou atitudes.

\section{Impactos da Avaliação}

Apresenta os impactos ou resultados do programa de avaliação a longo prazo e a extensão em que este reduziu ou eliminou as necessidades dos estudantes e os efeitos do programa sobre a sociedade em geral. Também determina como as atitudes, comportamentos e objetivos dos interessados mudaram por causa do programa de avaliação. 


\section{Estratégias de Avaliação}

Dentro do contexto dos tipos de avaliação (entrada, processo, resultado ou impactos) as estratégias são usadas para a coleta de dados. Uma vez selecionada a estratégia ou a combinação delas, o avaliador deve considerar as necessidades de todos os envolvidos na avaliação e se estes interesses serão atendidos.

Worthen et al. (1997) identificou seis estratégias de avaliação que são frequentemente utilizadas individualmente ou em combinação:

\section{Estratégia orientada aos objetivos}

É a mais popular. Sua principal característica é que foca em determinar a extensão em que os objetivos do programa foram atingidos. Consequentemente esta abordagem é altamente adequada para programa de educação a distância, os quais tem os objetivos muito bem definidos, e o propósito da avaliação é determinar em que medida estes objetivos foram cumpridos.

\section{Estratégia orientada ao gerenciamento}

Foi concebida para servir aos tomadores de decisão e é particularmente útil para a decisão sobre a realocação de fundos. A justificativa para o uso desta estratégia é que a informação avaliativa é uma parte essencial de uma boa tomada de decisão e que o avaliador pode ser mais eficaz, atendendo aos diferentes interessados que precisam de boa informação avaliativa.

\section{Estratégia orientada ao consumidor}

O tema central desta estratégia é o desenvolvimento de informações sobre os produtos de uso dos consumidores (ex. estudantes). A limitação desta estratégia para aplicação no contexto da educação a distância surge com as diferenças individuais dos estudantes em seus diferentes aspectos.

\section{Estratégia orientada a expertise}

Esta abordagem de avaliação é amplamente usada por agências credenciadas e depende fundamentalmente da experiência profissional para julgar um programa educacional, pois muitas vezes o expert conhece os assuntos da área, mas não conhece os detalhes.

\section{Estratégia orientada ao concorrente}

Esta estratégia tenta reduzir o viés ao tentar garantir equidade, incorporando visões positivas e negativas da avaliação em si. Vários modelos têm sido utilizados, a fim de incluir debates públicos e estruturados, bem como a utilização de avaliadores opostos para debaterem sobre o assunto em questão.

\section{Estratégia orientada ao participante}


Esta estratégia envolve todos os interessados (stakeholders) e é usada em estudos de pesquisa qualitativa.

Uma possível fraqueza desta abordagem é que cada interessado pode ter diferente critério a respeito do valor e da eficácia do programa.

\section{Questões de Avaliação}

Estas questões não representam uma lista exaustiva. Em vez disso, elas respondem às potenciais áreas de fraqueza dos programas, identificados na literatura profissional e a partir da experiência de profissionais.

Um plano não pode ser utilizado em todos os tipos de avaliação. A natureza do programa e as exigências dos tomadores de decisão irão influenciar o conjunto específico de questões de avaliação selecionadas pelo avaliador.

Posavac e Carey (2002) sugeriram que as respostas às perguntas abaixo frequentemente ajudam no desenvolvimento das questões de avaliação:

1. O que será avaliado no programa? Qual o sistema de e-learning é utilizado para entregar o programa?

2. Quem utilizará os resultados da avaliação?

3. Qualé o propósito da avaliação? Quais as questões levantadas, como por exemplo, a baixa taxa de persistência, baixa satisfação do estudante ou baixo número de inscrição? Como os resultados serão utilizados? Quais as decisões necessárias acerca do programa, por exemplo, manutenção, expansão, redução de custos?

4. Quemé que vai conduzir o programa de avaliação?

5. Como o programa de avaliação será conduzido? Quais os métodos que devem ser utilizados? Quais são os recursos disponíveis? Quais são as limitações (por exemplo, tempo e dinheiro)?

As estratégias e as informações requeridas na definição das questões da avaliação devem levar em consideração as peculiaridades do objeto de avaliação.

Ao analisar o modelo de Rovai (2003), percebe-se que os elementos que podem conferir confiabilidade e validade ao instrumento não estão aparentes, sendo contemplados apenas métodos e instrumentos para coleta e análise de dados, sem nenhum atrelamento aos aspectos evidenciais. Entretanto, denota uma preocupação com as consequências sociais e instrucionais. Na dimensão dos fundamentos, não estão claros os elementos relacionados à missão e valores institucionais. Além disso, o modelo se enquadrada melhor na concepção de evaluation, embora apresente algum recorte de assessment. 


\subsection{The Kirkpatrick's Four Level of Evaluation (1959)}

Idealizado por Donald Kirkpatrick, é um dos mais antigos modelos para a avaliação, criado em 1959. Ainda hoje é amplamente utilizado e seus quatro níveis são apresentados na tabela 1 .

Tabela 1 - Os quatro níveis de avaliação de Kirkpatrick (1959)

Nível 1: Reação

(Reaction)

Níve1 2: Aprendizagem

(Learning)

Níve1 3: Comportamento

(Behavior)

Níve 14: Resultados

(Results)
Medida de satisfação

- Os participantes ficaram satisfeitos?

- O que eles planejam fazer com o que aprenderam?

Medida de aprendizagem

- Quais as habilidades, conhecimentos ou atitudes foram mudados? Por quanto tempo?

Medida para mudança de comportamento

- Os participantes mudaram seu comportamento baseando-se no que foi aprendido no programa?

Medida de resultados

- A mudança de comportamento afetou positivamente a organização?

- Houve melhoria da qualidade?

Fonte: Adaptado de Stone e Watson (1999)

O modelo de Kirkpatrick (1959) é um programa de treinamento em geral, amplamente utilizado, que tem sido também aplicado em outros contextos, tornando-se popular para avaliar programas de aprendizagem baseada na tecnologia. Entretanto, não detalha o como fazer, uma vez que está atrelado à necessidade de avaliação e nessa perspectiva determina os elementos necessários.

Nessa perspectiva, observa-se que todos os níveis de medição tem caráter de julgamento, corroborando com a ideia de que o modelo se enquadra nos pressupostos de evaluation. 


\subsection{Kaufman's Five Level of Evaluation (1994)}

Alguns pesquisadores reconheceram algumas limitações dos quatro níveis de avaliação de Kirkpatrick (1959) e, a partir disso, Kaufman e Keller (1994) propõem um framework que expande a definição do nível um e adiciona um quinto nível, o que trata das questões sociais (PHILLIPS, 1997). Conforme Tabela 2.

Tabela 2 - Kaufman's Five Level of Evaluation (1994)

\begin{tabular}{c|l|l}
\hline Nível & \multicolumn{1}{|c|}{ Avaliação } & \multicolumn{1}{c}{ Foco } \\
\hline 5 & Resultados Sociais & $\begin{array}{l}\text { Compromisso social com o cliente, consequências e } \\
\text { pagamentos. }\end{array}$ \\
\hline 4 & Resultado Organizacional & Contribuição organizacional. \\
\hline 3 & Aplicação & $\begin{array}{l}\text { Utilização (produtos) individual e em pequenos grupos } \\
\text { dentro da organização. }\end{array}$ \\
\hline 2 & Aquisição & Maestria e competência individual e em pequenos grupos. \\
\hline $1 b$ & Reação & Métodos, meios e processos de aceitabilidade e eficiência. \\
\hline 1 a & Ativos & $\begin{array}{l}\text { Disponibilidade e qualidade de recursos humanos, } \\
\text { financeiros e físicos internamente. }\end{array}$ \\
\hline
\end{tabular}

Fonte: Phillips (1997)

O nível 1 está pautado na disponibilidade de vários recursos necessários para o sucesso da intervenção. No nível 5 está a avaliação da sociedade e a capacidade de resposta ao cliente, bem como suas consequências. Esta avaliação se move além da organização e examina a extensão em que o programa tem proporcionado melhoria de desempenho; a sociedade e o ambiente em torno da organização.

Avaliando Kaufman's Five Level of Evaluation, verifica-se que está focado em mensuração e preocupa-se com recursos, infraestrutura, resultados e consequências. Não deixa claro como o processo acontece, ou seja, como pode assegurar confiabilidade e validade.

\subsection{CIRO (Context, Input, Reaction, Outcome) Approach}

Trata-se de outra abordagem em quatro níveis, originalmente desenvolvida por Warr, Bird e Rackman (1970), e é uma maneira de classificar o processo de avaliação. Inicialmente usado na Europa, este esquema tem amplo escopo no uso tradicional do termo "avaliação" 
utilizado nos Estados Unidos. Tal como acontece em outras abordagens, quatro categorias gerais de avaliação são descritas: Contexto, Entrada, Reação e Resultados (PHILLIPS, 1997).

O contexto da avaliação inclui obter e usar a informação sobre as recentes condições operacionais (ou o contexto) para determinar as necessidades e objetivos de treinamento. A categoria entrada na avaliação inclui a coleta e uso da informação sobre possíveis recursos de treinamento para selecionar as entradas alternativas ao processo de treinamento. A categoria reação inclui obtenção e utilização de informações acerca das reações dos estudantes sobre a melhoria do processo de treinamento. A categoria resultados inclui obtenção e utilização das informações acerca das conclusões e resultados do treinamento, e geralmente é considerada como a parte mais importante da avaliação. Para que os resultados da avaliação sejam bem sucedidos, é necessária uma cuidadosa preparação antes do início do programa de treinamento (PHILLIPS, 1997).

Este modelo pode ser enquadrado como evaluation. Na dimensão fundamentos aborda a definição do problema, objetivos e participantes; já em evidências científica, somente menciona métodos e instrumentos para coleta de dados. Os elementos da dimensão das consequências não são abordados e em relevância/utilidade preocupa-se com a divulgação e utilização dos resultados.

\subsection{O esquema dos cinco níveis do retorno sobre investimento (1997)}

De acordo com Shepherd (1999), o retorno sobre investimento (ROI) é uma medição dos benefícios monetários obtidos por uma organização ao longo de um período de tempo especificado, em troca de um determinado investimento em um programa de treinamento. Por outro lado, o ROI é a extensão em que as saídas do treinamento excedem as entradas e pode ser usado tanto para justificar um plano de investimento como para avaliar em que medida o retorno desejado foi alcançado. Entretanto, não se podem mensurar todos os aspectos para o sucesso do treinamento: se os alunos não gostarem do treinamento, o número de estudantes participantes do treinamento e as extensões em que os objetivos pessoais dos alunos foram realizados. Phillips (1997) apresenta uma tabela síntese do esquema ROI, (Tabela 3). 
Tabela 3 - O esquema de 5 níveis para ROI em Avaliação

\begin{tabular}{|c|c|c|}
\hline Nível & Avaliação & Foco \\
\hline 1 & Reação e Ação Planejada & $\begin{array}{l}\text { Medidas de reação do participante no programa e } \\
\text { definiçãa dos planos específicos de implementação. }\end{array}$ \\
\hline 2 & Aprendizagem & $\begin{array}{l}\text { Medidas para mudanças nas habilidades, conhecimentos } \\
\text { ou atitudes. }\end{array}$ \\
\hline 3 & Aplicações no Trabalho & $\begin{array}{l}\text { Medidas para mudanças no comportamento no trabalho } \\
\text { e aplicação específica do material do treinamento. }\end{array}$ \\
\hline 4 & Resultados no Negócio & Medição do impacto do programa no negócio. \\
\hline 5 & $\begin{array}{l}\text { Retorno sobre } \\
\text { Investimento }\end{array}$ & $\begin{array}{l}\text { Medidas de valor monetário dos resultados e custos para } \\
\text { o programa, usualmente expressas em porcentagens. }\end{array}$ \\
\hline
\end{tabular}

Fonte: Phillips (1997)

Para Parry (1996), o ROI adiciona um quinto nível no modelo de Kirkpatrick (1959), entretanto, há alguns prós e contras no cálculo do ROI em um programa de treinamento, uma vez que os custos no treinamento são conhecidos e expressos em termos monetários, e, por sua vez, os benefícios são, na maioria das vezes, subjetivos, difíceis de serem quantificados e convertidos em termos monetários.

Os custos são conhecidos antes do início do treinamento, mas os benefícios podem acumular-se lentamente ao longo do tempo. Mas, por outro lado, os objetivos e o conteúdo do curso serão mais enxutos, relevante e comportamental com o foco nos resultados monetários e não na aquisição de informação.

Ao comparar o esquema dos cinco níveis do retorno sobre investimento de Phillips, (1997), verifica-se uma preocupação com a dimensão relevância/utilidade que contempla o maior número de elementos essenciais. Além disso, trata das consequências de forma geral, sem se ater a um tipo específico. No entanto, avaliando a dimensão evidências científicas, percebe-se que somente métodos e instrumentos para coleta de dados foram mencionados, o que naturalmente dificulta a confiabilidade e validade do instrumento, podendo ser enquadrado como evaluation.

\subsection{Modelo de Avaliação de Van Slyke, Kittner e Belanger (1998)}

O modelo de avaliação de Van Slyke, Kittner e Belanger (1998) é um modelo de curso ambiente, especificamente para a relação entre as variáveis do contexto (entrada) e as 
variáveis de saída (produto). Este modelo de avaliação possui dois níveis e consiste em variáveis prognósticas (estudante, curso, aprendizagem a distância e características institucionais, incluindo objetivos, métodos de entrega e estrutura de suporte) e variáveis de resultado (institucionais e estudantes). Os resultados institucionais incluem baixo custo, maior produtividade dos instrutores, recursos comuns com outras instituições e ampliação da área geográfica atingida.

Os autores acreditam que todas estas variáveis interagem em um complexo sistema, entretanto, não mencionam a fundamentação dos valores, bem como as consequências (Figura 8)

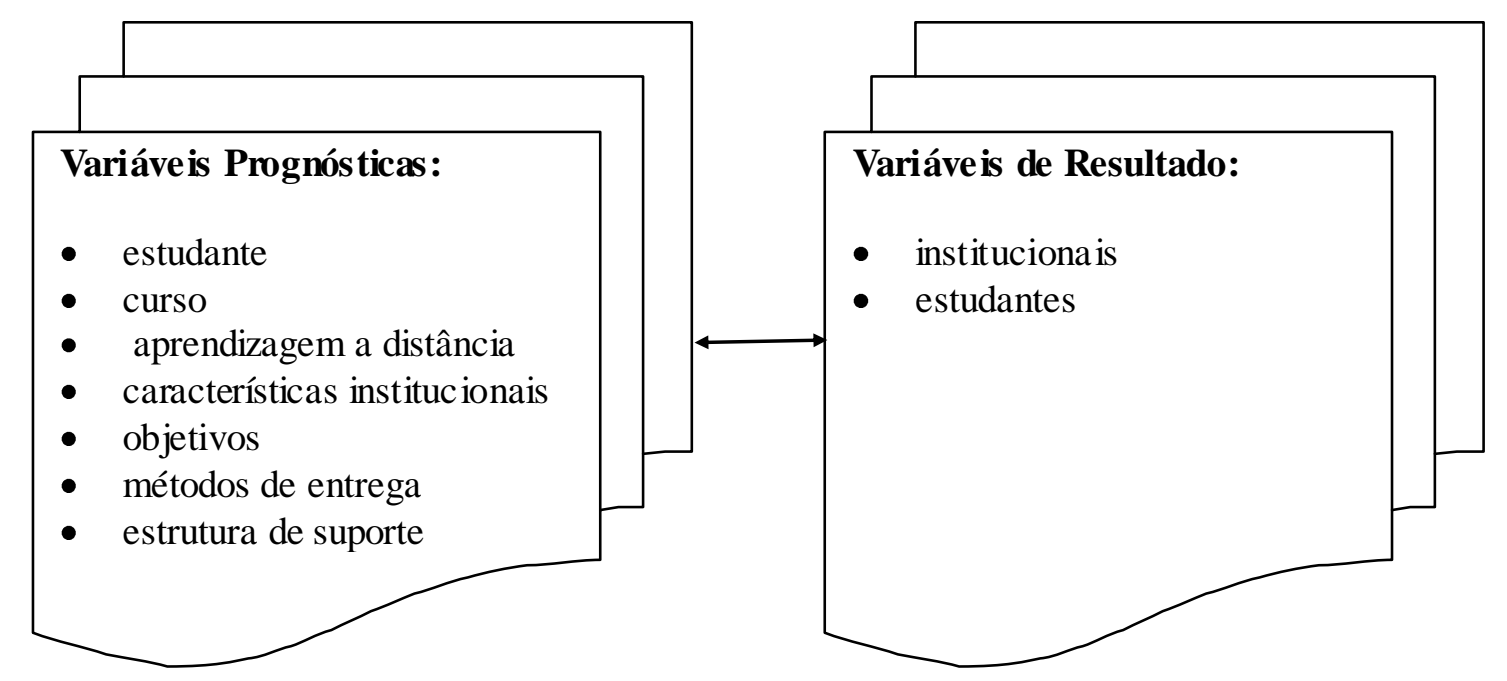

Figura 8 - Modelo Van Slyke, Kittner e Belanger (1998)

Fonte: elaborado pe la pesquisadora

Ao enquadrar o Modelo Van Slyke, Kittner e Belanger (1998) no roteiro, nota-se a preocupação com informações institucionais, bem como recursos e infraestrutura. Na dimensão de evidências científicas, apenas métodos e instrumentos para coleta de dados é mencionado. Apenas um item da dimensão relevância/utilidade é contemplado. Quanto às consequências aborda sobre as institucionais e instrucionais. O modelo pode ser enquadrado tanto em assessment como em evaluation.

\subsection{Framework Belanger e Jordan (2000)}

O framework proposto por Belanger e Jordan (2000) é semelhante ao modelo de Van Slyke, Kittner e Belanger. (1998). Entretanto, eles apresentam quatro níveis de variáveis de resultados impactadas pela aprendizagem a distância: (1) estudantes, 
instrutores/professores, (3) instituições e (4) sociedade, conforme Figura 9.

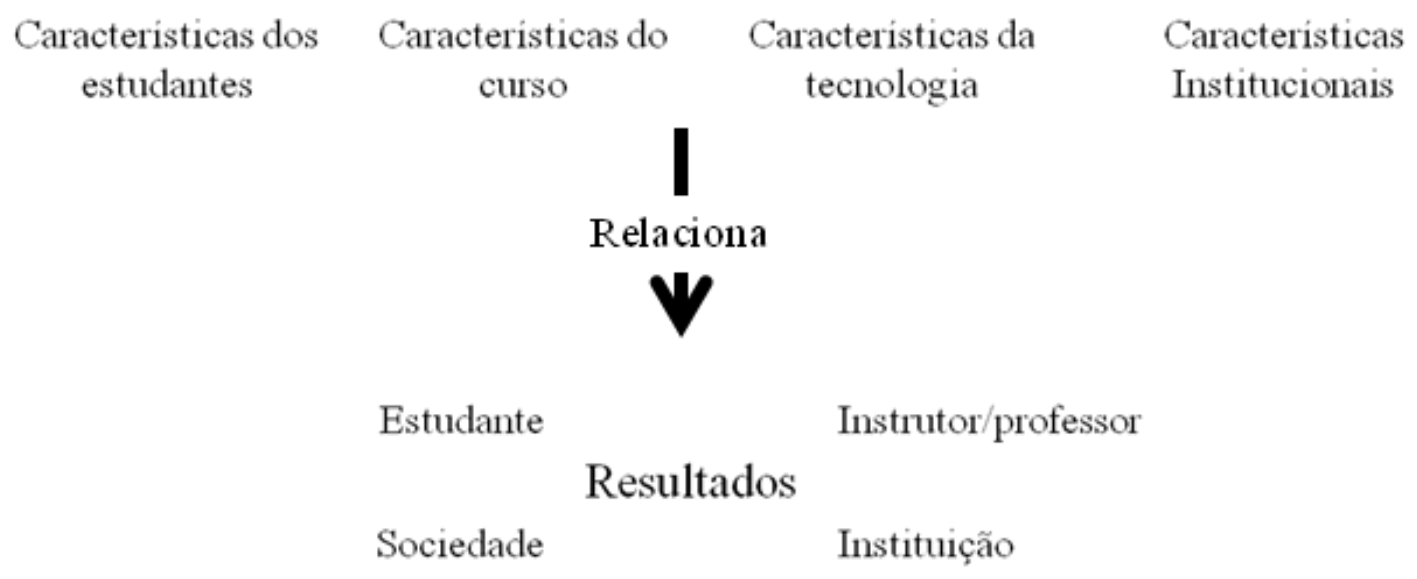

Figura 9 - Framework Belanger e Jordan (2000)

Características dos estudantes: incluem os objetivos dos estudantes, as habilidades pessoais, assim como a auto-suficiência, o uso do computador, gerenciamento do tempo, comunicação interpessoal, solução de problemas, planejamento, experiência com a tecnologia, experiências anteriores e atitude.

Características do curso: incluem projetos em grupos, métodos de avaliação e componentes do curso.

Características da tecnologia: incluem a transição para um ambiente "qualquer hora", "qualquer lugar".

Resultados dos estudantes: inclui incremento da habilidade tecnológica, bem como qualidade das interações com maior acesso aos instrutores/professores.

Resultados institucionais: diminuição dos custos, maior área geográfica atingida, aumento da produtividade dos instrutores/professores e divisão dos recursos instrucionais com outras instituições.

Resultados sociais: inclui maior força de trabalho profissional, aumento da qualidade de vida e acesso à educação.

De acordo com Belanger e Jordan (2000), o framework é um modelo flexível em que as variáveis de um programa de $\mathrm{EaD}$ interagem em um dinâmico sistema, cujas características do curso e as variáveis do contexto devem ser cuidadosamente examinadas juntas e não separadamente.

O framework de Belanger e Jordan (2000) é considerado assessment e foca nos resultados e custos. Contudo, a dimensão de evidências científicas não deixa claro como as 
informações serão coletas e analisadas, bem como as estratégias utilizadas para assegurar confiabilidade e validade.

\subsection{Modelo ACTION de Bates (1995)}

O modelo ACTION proposto por Bates (1995) consiste dos seguintes critérios de avaliação:

- Acesso: Quão acessívele flexívelé a tecnologia?

- Custo: Qual é o custo da estrutura? Quais são as unidades de cus to por estudante?

- Ensino e Aprendizagem: Qual a aprendizagem, abordagens instrucionais e tecnologias são as melhores?

- Interatividade e amizade entre os usuários: Que tipo de interação é praticado? Quão fácil este tipo é? Como é a confiabilidade da tecnologia? Falhas ou paradas acontecem frequentemente?

- Questões Organizacionais: Quais são as necessidades e barreiras organizacionais?

- Novidade/Inovação: Quão nova é a tecnologia?

- Velocidade: Qual o tempo gasto para que o curso possa ser alterado ou atualizado?

Este modelo atua em dois níveis, uma vez que acesso, ensino e aprendizagem, interatividade e custos são avaliados individualmente, enquanto questões organizacionais, novidade/ino vação e velocidade são a valiados em nível organizacional (Figura 10).

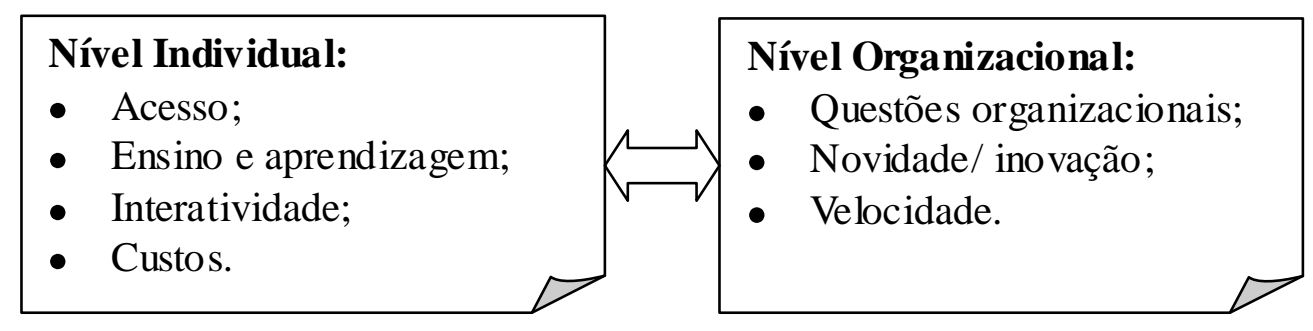

Figura 10 - Modelo ACTION de Bates (1995)

Fonte: elaborada pela pesquisadora

Este modelo não inclui elementos da dimensão de evidências científicas e consequências. Em fundamentos, subentende-se a existência apenas do gap entre o ideal e o real. Pode ser considerado evaluation. 


\subsection{Modelo CIAO de Scanlon et al. (2000)}

O modelo proposto por Scanlon et al. (2000) consiste nas seguintes variáveis: contexto, interações e resultados, cruzando com lógica, dados e métodos. Além disso, é apropriado para aprendizagem assistida pelo computador, conforme apresentado na Tabela 4.

Tabela 4 - Modelo CIAO de avaliação, para aprendizagem assistida por computador

\begin{tabular}{|c|c|c|c|}
\hline & Contexto & Inte rações & Resultados \\
\hline Lógica & $\begin{array}{l}\text { Objetivo e contexto do } \\
\text { uso da aprendizagem } \\
\text { assistida pelo } \\
\text { computador. }\end{array}$ & $\begin{array}{l}\text { Processamento de } \\
\text { dados para entender o } \\
\text { se, como e por quê } \\
\text { alguns elementos } \\
\text { interagem em si. }\end{array}$ & $\begin{array}{c}\text { Resultados da } \\
\text { aprendizagem afetiva e } \\
\text { cognitiva; atribuição da } \\
\text { aprendizagem assistida } \\
\text { pelo computador é } \\
\text { dificultada. }\end{array}$ \\
\hline Dados & $\begin{array}{c}\text { Objetivos da equipe de } \\
\text { designers do curso; } \\
\text { política para reunir } \\
\text { documentos e relatórios. }\end{array}$ & $\begin{array}{l}\text { Relatórios da interação } \\
\text { dos estudantes, } \log \text { s on- } \\
\text { line e diários. }\end{array}$ & $\begin{array}{c}\text { Medidas de } \\
\text { aprendizagem; mudança } \\
\text { nas atitudes e percepções } \\
\text { dos estudantes. }\end{array}$ \\
\hline Métodos & $\begin{array}{c}\text { Entrevista com os } \\
\text { designers e equipe do } \\
\text { curso; política de análise } \\
\text { dos documentos. }\end{array}$ & $\begin{array}{l}\text { Observação, diário, } \\
\text { relatórios de } \\
\text { áudio/vídeo e de } \\
\text { computadores. }\end{array}$ & $\begin{array}{c}\text { Entrevistas, questionários } \\
\text { e testes. }\end{array}$ \\
\hline
\end{tabular}

Fonte: Scanlon et al. (2000).

De acordo com Scanlon et al. (2000), o modelo enfatiza os resultados de aprendizagem, entretanto, reconhecem as dificuldades em atribuir resultados de aprendizagem para tec nologias.

O modelo pode ser enquadrado como assessment e contempla os métodos e instrumentos para coleta e análise de dados, contidos na dimensão evidências científicas. Contudo, não fica evidente como será tratada a questão da confiabilidade e validade. Além disso, nenhuma consequência é abordada.

\subsection{Modelo E-Learning, segundo Hughes e Attwell's (2002)}

Segundo Hughes e Attwell's (2002), o framework para e-learning tem cinco grandes clusters de variáveis: (1) estudante, (2) aprendizagem, (3) tecnologia, (4) contexto e (5) pedagógico. O grupo Estudante inclui variáveis demográficas, história de aprendizagem, 
atitudes, motivação e familiaridade com a tecnologia. A aprendizagem inclui ambiente físico, institucional e varáveis ambientais. As variáveis contextuais incluem o contexto político, embasamento cultural, localização geográfica. As variáveis tecnológicas incluem hardware, software e conectividade, entre outros.

Já as variáveis pedagógicas incluem nível e natureza do sistema de suporte ao estudante, acessibilidade, acreditação/reconhecimento e certificação (Figura 11).

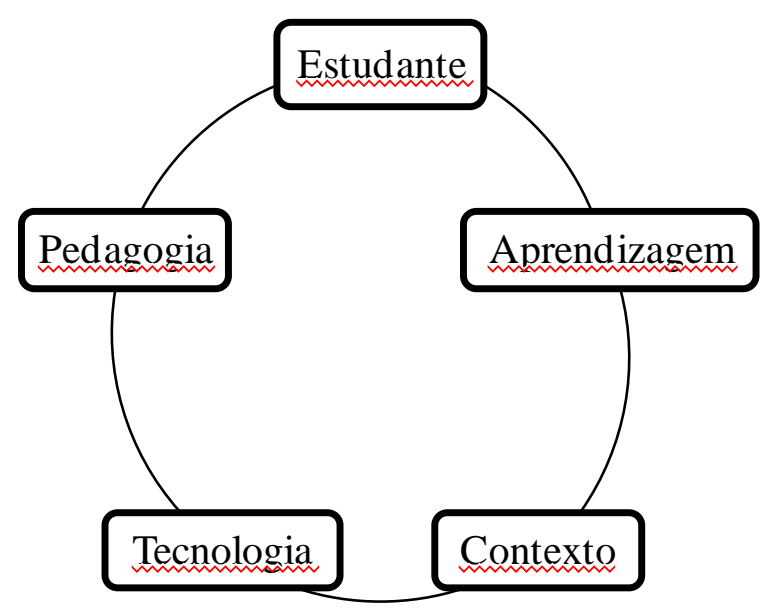

Figura 11 - Modelo E-Learning, segundo Hughes e Attwell's (2002)

Fonte: elaborada pela pesquisadora.

Observa-se que este modelo é amplo e trata dos diferentes agentes do processo de $e$ learning. Pode ser considerado como assessment. Embora aborde diversos clusters, não deixa claro como as evidências de confiabilidade e validade poderão ser asseguradas, sugere apenas métodos e instrumentos de coleta de dados.

\subsection{Modelo e3Learning, segundo Lam e McNaught (2005)}

De acordo com Lam e McNaught (2005), o e3Learning é um modelo em cinco passos de um processo complexo, detalhado e participativo para avaliação de websites de e-learning, conforme figura 12. 


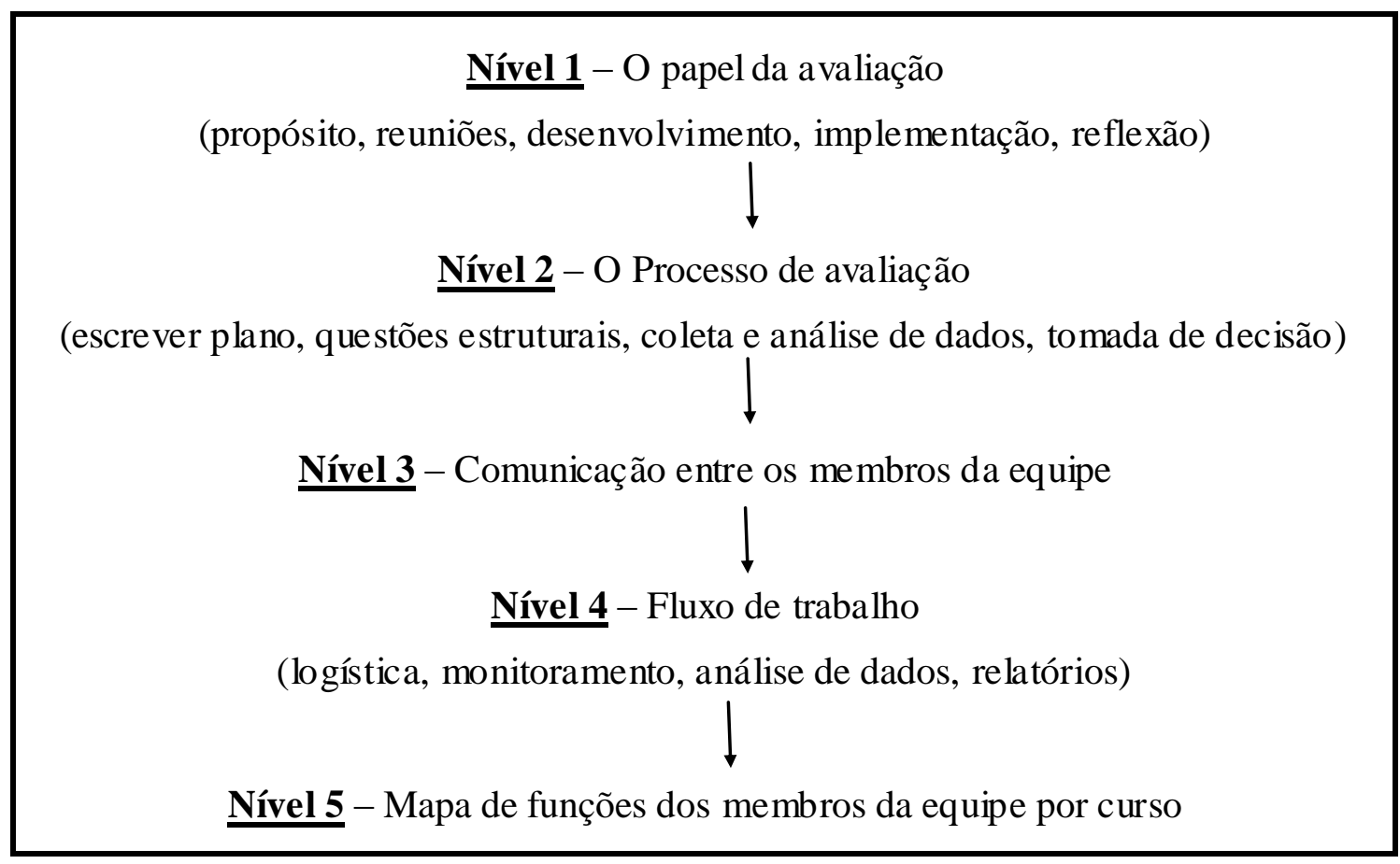

Figura 12 - Modelo e3Learning, adaptado de Lam e McNaught (2005)

Este é um modelo complexo e em multicamadas, composto por cinco diagramas complexos, um repositório de questões e uma matriz de decisão, de cinco camadas, possuindo um repositório com mais de 450 questões compiladas, cujas perguntas foram agrupadas em cinco dimensões (pré-desenvolvimento, ambiente, processo ensino e aprendizagem, resultados de aprendizagem e outros), se tornando uma matriz de decisão (LAM; McNAUGHT, 2005).

Desta forma, o modelo permite aos membros da equipe refletir e colaborar para a criação de um fluxo de trabalho estável que permita melhoria contínua.

$\mathrm{O}$ modelo e3Learning é enquadrado como assessment, tem forte preocupação com o seu propósito, com isso aborda elementos relacionados ao contexto institucional. Em relação à dimensão de evidências científicas, relata sobre o plano de avaliação, entretanto não apresenta as estratégias que podem assegurar a confiabilidade e validade aos elementos citados, bem como os métodos e instrumentos de coleta e análise de dados. A dimensão consequências não é mencionada no modelo.

4.14. Modelo de avaliação de usabilidade para aplicações e-learning, segundo Zaharias (2005)

O modelo conceitual de avaliação de usabilidade para aplicações e-learning 
assíncronas foi desenvolvido por Zaharias $(2004,2005)$ e teve aplicação em programa de treinamento para estudantes adultos.

O modelo pressupõe a motivação para aprender por meio de uma combinação da usabilidade web com os parâmetros do design instrucional. As dimensões do design da usabilidade incluem: (a) conteúdo, (b) aprendizagem e suporte, (c) design visual, (d) navegação, (e) acessibilidade, (f) interatividade, e (g) autoavaliação e capacidade para aprender.

Este modelo desenvolveu um questionário que foi testado usando os parâmetros da psicometria. Desta forma, para avaliar um programa de e-learning, o avaliador deveria utilizar o questionário desenvolvido por Zacarias (2005) e executar o modelo de regressão, cujos resultados deveriam indicar se o programa instrucional prediz motivação para aprender. Esta abordagem pode ser usada para avaliação formativa e somativa (ZAHARIAS, 2005) (Figura 13).

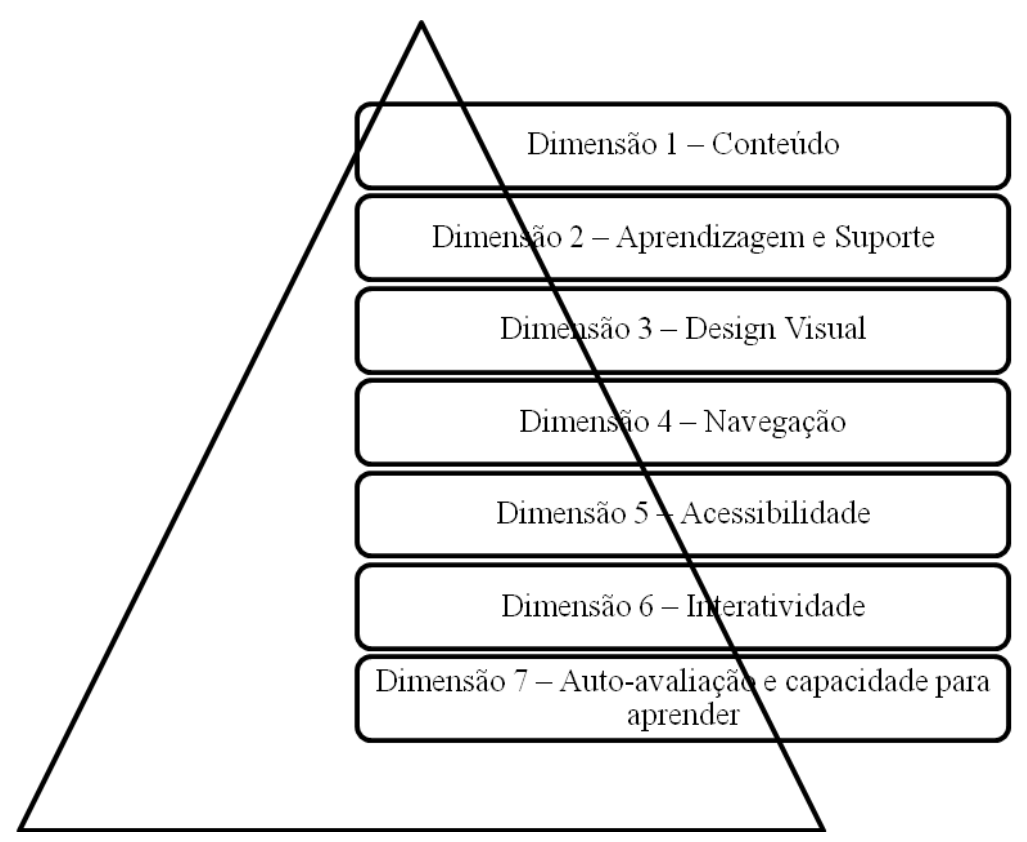

Figura 13 - Modelo de avaliação de usabilidade para aplicações e-learning, adaptado de Zaharias (2005)

Este é um modelo que, na dimensão de evidências científicas, relata que foi preparado seguindo os pressupostos da psicometria e nas aplicações já realizadas apresentou características de confiabilidade. Entretanto, não menciona elementos das dimensões relevância/utilidade e consequências. Pode ser considerado assessment. 


\subsection{Sistema Nacional de Avaliação da Educação Superior (BRASIL, 2004)}

O Sistema Nacional de Avaliação da Educação Superior (SINAES), conforme apresentado no Capítulo 2, é o sistema brasileiro para avaliação de cursos de graduação nas modalidades presencial e a distância. Este sistema é composto por três pilares: (a) avaliação institucional, (b) avaliação dos cursos de graduação e (c) avaliação do desempenho dos estudantes, e, para isso, conta com diversos instrumentos e, dentre eles, três são destinados à $\mathrm{EaD}$, conforme apresentados abaixo.

\subsubsection{Instrumento de Credenciamento Institucional para a Oferta da Modalidade de} Educação a Distância (MEC, 2009)

Os documentos de avaliação para credenciamento institucional para a modalidade de educação a distância são organizados em dois instrumentos básicos:

1) Instrumento de avaliação para Credenciamento Institucional.

2) Instrumento de avaliação para Credenciamento de Polos.

No credenciamento institucional são abordadas três dimensões com diferentes grupos de indicadores de avaliação e com seus respectivos pesos, conforme Tabela 5.

Tabela 5 - Categorias de Avaliação (Credenciamento)

\begin{tabular}{llcc}
\hline \multicolumn{1}{c}{ Dimensões } & $\mathbf{N}^{\mathbf{0}}$ de Indicadores & Pesos \\
\hline 1. Organização Institucional para Educação a Distância & 12 & 40 \\
2. Corpo Social & 11 & 35 \\
3. Instalações Físicas & 07 & 25 \\
\hline & $\mathbf{3 0}$ & $\mathbf{1 0 0}$ \\
\hline
\end{tabular}

A. Dimensão 1: Organização Institucional para Educação a Distância, a qual contempla os indicadores abaixo:

1. Missão institucional para atuação em EaD.

2. Planejamento de Programas, Projetos e Cursos a distância.

3. Plano de Gestão para a Modalidade de EaD.

4. Unidade responsável para a gestão de EaD.

5. Planejamento de Avaliação Institucional (Autoavaliação) para EaD.

6. Representação docente, tutores e discente.

7. Estudo para implantação dos polos de apoio presencial. 
8. Experiência da IES com a modalidade de educação a distância.

9. Experiência da IES com a utilização de até $20 \%$ da carga horária dos cursos superiores presenciais na modalidade de educação a distância.

10. Sistema para gestão acadêmica de EaD.

11. Sistema de controle de produção e distribuição de material didático (logística).

12. Recursos financeiros.

B. Dimensão 2: Corpo Social, a qual contempla os indicadores abaixo:

1. Programa para formação e capacitação permanente dos docentes.

2. Programa para formação e capacitação permanente dos tutores.

3. Produção científica.

4. Titulação e formação docente do coordenador de EaD da IES.

5. Regime de trabalho do coordenador de EaD da IES.

6. Corpo técnico-administrativo para atuar na gestão em EaD.

7. Corpo técnico-administrativo para atuar na área de infraestrutura tecnológica em EaD.

8. Corpo técnico-administrativo para atuar na área de produção de material didático para $\mathrm{EaD}$.

9. Corpo técnico-administrativo para atuar na gestão das bibliotecas dos polos de apoio presencial.

10. Regime de trabalho.

11. Política para formação e capacitação permanentes do corpo técnico-administrativo.

C. Dimensão 3: Instalações Físicas, a qual contempla os seguintes indicadores:

1. Instalações administrativas.

2. Infraestrutura de serviços.

3. Recursos de tecnologias de informação e comunicação (TIC) (audiovisuais e multimídia);

4. Plano de expansão e atualização de equipamentos.

5. Biblioteca: instalações para gerenciamento central das bibliotecas dos polos de apoio presencial e manipulação do acervo.

6. Biblioteca: informatização do sistema de bibliotecas (administração das bibliotecas dos polos de apoio presencial).

7. Biblioteca: política de aquisição, expansão e atualização do acervo das bibliotecas dos polos de apoio presencial. 


\section{Requisitos legais}

1. Cond ições de acesso para portadores de necessidades especiais.

2. Convênios, parcerias e acordos celebrados com outras instituições nacionais e/ou internacionais que sejam necessários à execução dos cursos de EaD.

Estes itens são essencialmente regulatórios, por isso não fazem parte do cálculo do conceito da avaliação e tem finalidade apenas informativa. Entretanto, tratando-se de disposições legais, esses itens são de atendimento obrigatório.

Ao analisar este instrumento, verifica-se que as dimensões evidências científicas, consequências e relevância/utilidade não foram mencionadas. Apenas elementos relacionados ao curso/programa, infraestrutura e recursos foram abordados na dimensão de fundamentos. Pode ser enquadrado como assessment e evaluation.

\subsubsection{Instrumento de Credenciamento de Polo de Apoio Presencial Modalidade de Educação a Distância, (MEC, 2009)}

O credenciamento de uma instituição de ensino para oferta de cursos na modalidade a distância, conforme já comentado, necessita também do credenciamento do Polo de Apoio Presencial e conta com os seguintes critérios (Quadro 6).

\begin{tabular}{|c|c|c|}
\hline \multicolumn{3}{|c|}{ Organização Institucional para Educação a Distância } \\
\hline & Planejamento e implantação do polo & \\
\hline & Justificativa para a implantação do polo & \\
\hline \multicolumn{3}{|l|}{ Cor po Social } \\
\hline & Titulação acadêmica do coordenador do polo & \\
\hline & Experiência acadêmica e adminis trativa do coordenador do & \\
\hline & Vínculo de trabalho do coordenador do polo & \\
\hline & Titulação dos tutores & \\
\hline & Qualificação e formação dos tutores de EaD & \\
\hline & Corpo técnico e ad min istrativo de apoio às atividades acadê & do polo \\
\hline \multicolumn{3}{|l|}{ Infraestrutura } \\
\hline & Instalações admin is trativas & \\
\hline & Salas de aula/tutoria & \\
\hline & Sala para a coordenação do polo & \\
\hline & Sala para tutores & \\
\hline & Auditório/Sala de conferência & \\
\hline & Instalações sanitárias & \\
\hline & Áreas de convivência & \\
\hline & Recursos de informática & \\
\hline & Recursos de TIC (audiovisuais e multimídia) & \\
\hline & Biblioteca: instalações para o acervo e funcionamento & \\
\hline & Biblioteca: instalações para estudos individuais e em grupo & Continua. \\
\hline
\end{tabular}




\begin{tabular}{|ll|}
\hline Continuação & Biblioteca: livros de bibliografia básica \\
& Biblioteca: livros de bibliografia complementar \\
& Biblioteca: periódicos especializados \\
Laboratórios especializados
\end{tabular}

Quadro 6 - Dimensões e critérios para credenciamento de polos de apoio presencial

Os instrumentos de avaliação de polos são construídos como parte inicial dedicada ao levantamento das características e informações do polo, quanto às especificidades da modalidade de $\mathrm{EaD}$, bem como a indicação dos requisitos legais pertinentes à educação superior, em especial, à modalidade de educação a distância.

Ao avaliar este instrumento, percebe-se que ele contempla somente o elemento de infraestrutura. Pode ser considerado assessment e evaluation.

\subsubsection{Instrumento de Autorização de Cursos para a Oferta na Modalidade de Educação a Distância, (MEC, 2009)}

Para a autorização de cursos são abordadas três dimensões com seus respectivos grupos de indicadores de avaliação (Tabela 6).

Tabela 6 - Categorias de Avaliação (Autorização)

\begin{tabular}{llcc}
\hline & \multicolumn{1}{c}{ Dimensões } & $\mathbf{N}^{\mathbf{0}}$ de Indicadores & Pesos \\
\hline 1. Organização Didático-Pedagógica & 23 & 40 \\
2. Corpo Social (Docentes e Tutores) & 16 & 45 \\
3. Instalações Físicas & 09 & 15 \\
\hline & $\mathbf{4 8}$ & $\mathbf{1 0 0}$ \\
\hline
\end{tabular}

\section{Dimensão 1 - Organização Didático-Pedagógica}

1. Contexto Educacional.

2. Objetivos do Curso.

3. Perfil do Egresso.

4. Número de Vagas.

5. Conteúdos Curriculares.

6. Metodologia.

7. Compatibilização entre as Tecnologias de Informação e Comunicação e o Curso 
Proposto.

8. Formação Inicial em EaD.

9. Atualização e Adequação das Ementas e Bibliografia dos Conteúdos Propostos para o Curso.

10. Material Didático Impresso.

11. Material Didático Aud iovisual para rádio, TV, computador, DVD rom, VHS, etc.

12. Material para Internet (WEB).

13. Articulação e complementaridade dos materiais impressos, materiais audiovisuais ou materiais para a Internet.

14. Materiais educacionais propiciam a abordagem interdisciplinar e contextualizada dos conteúdos.

15. Guia Geral para o Estudante.

16. Guia de Conteúdos.

17. Mecanismos para autoavaliação dos estudantes nos materiais educacionais.

18. Sistema de avaliação prévia de materiais educacionais.

19. Mecanismos gerais de interação.

20. Processo continuado de avaliação de aprendizagem, inclusive recuperação.

21. Sigilo e segurança nas avaliações.

22. Avaliação do material educacional.

23. Avaliação da infraestrutura de tecnologia.

\section{Dimensão 2 - Corpo Social (Docentes e Tutores)}

1. Titulação e Formação do Coordenador do Curso.

2. Regime de Trabalho do Coordenador do Curso.

3. Composição e funcionamento do Colegiado de Curso ou equivalente.

4. Tempo de Experiência Profissional do Coordenador de Curso.

5. Núcleo de Apoio Didático-Pedagógico aos Docentes.

6. Titulação Acadêmica dos Docentes.

7. Experiência acadêmica na educação superior e experiência profissional.

8. Qualificação/Experiência em EaD.

9. Regime de Trabalho (docentes).

10. Produção Intelectual.

11. Titulação dos Tutores.

12. Qualificação dos Tutores em EaD.

13. Regime de trabalho (tutores).

14. Equipe Docente/Tutores para atendimento dos estudantes nas atividades didáticas.

15. Relação Tutores/Estudantes para atendimento em atividades a distância.

16. Relação Tutores/Estudantes para atendimento em atividades presenciais (inclusive as obrigatórias).

\section{Dimensão 3 - Instalações Físicas}

1. Sala de professores, sala de tutores e sala de reuniões.

2. Gabinete de trabalho para professores.

3. Instalações para equipe de tutores. 
4. Recursos de Tecnologias de Informação e Comunicação (audiovisuais e multimídia).

5. Laboratórios especializados no polo para realização de atividades presenciais (inclusive as obrigatórias).

6. Livros da bibliografia básica e complementar.

7. Periód icos especializados.

8. Livros da bibliografia básica no polo.

9. Livros da bibliografia complementar no polo de apoio presencial.

\section{Requisitos legais}

Coerência dos conteúdos curriculares com as Diretrizes Curriculares Nacionais

Estágio supervisionado

Trabalho de conclusão de curso

Carga horária mínima e tempo mínimo de integralização

Disciplina optativa de Libras

Condições de acesso para portadores de necessidades especiais

Condições que garantam a realização de atividades presenciais obrigatórias nos polos de apoio presencial para os primeiros $50 \%$ do tempo de duração do curso

As escalas de atribuição do conceito utilizadas nos instrumentos são: $5=$ atende plenamente, 4 = atende adequadamente, 3 = atende suficientemente, 2 = atende insuficientemente e 1 = não atende.

Além destes instrumentos o SINAES conta, em cada um de seus três pilares, com um conjunto de outras ferramentas que possibilitam uma avaliação em sua totalidade.

Ao analisar esse instrumento percebe-se que ele pode ser enquadrado em assessment e evaluation e contempla apenas elementos relacionados ao curso, infraestrutura e recursos.

\subsection{Abordagem sistemática para avaliação, segundo Russ-Eft e Preskill (2001, 2009)}

Esta abordagem fornece uma estrutura sistemática e compreensiva da teoria e prática em avaliação, propiciando um entendimento holístico da avaliação de negócios (Figura 14). 


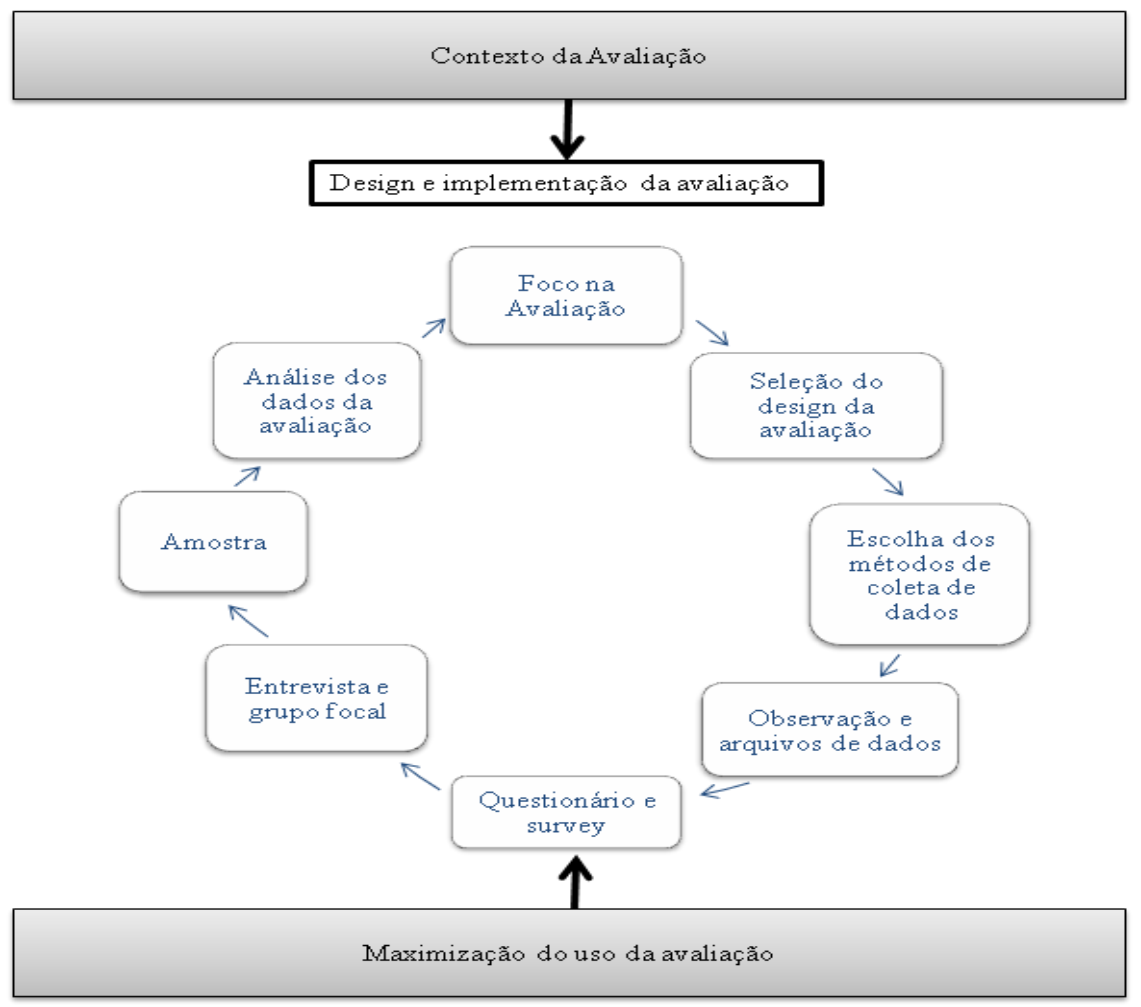

Figura 14 - Abordagem sistemática para avaliação, segundo Russ-Eft e Preskill (2001, 2009)

Na perspectiva contexto da avaliação as autoras definem a avaliação, apresentam sua evolução, discutem a avaliação como forma de aprendizagem, desempenho e mudanças de iniciativas e abordam aspectos políticos e éticos.

Em design e implementação apresentam aspectos relevantes para a avaliação, detalhando-os e associando-os a características e ameaças de confiabilidade e validade. Com isso, propiciam um rolde opções, o que facilita a escolha do avaliador/pesquisador.

Para a perspectiva maximização do uso da avaliação apresentam estratégias para relatar e divulgar os resultados e ações da avaliação; planejamento, gerenciamento e custo da avaliação, meta-avaliação e, finalmente, abordam estratégias para implementar a avaliação na organização.

Este modelo, embora focado na avaliação organizacional, pode ser adaptado para outros contextos. Ao analisar esta abordagem, observa-se diversos elementos caracterizadores das dimensões fundamentos, evidências científicas e relevância/utilidade, sinalizando maiores possibilidades de atingir confiabilidade e validade. Entretanto, não apresenta elementos caracterizadores da missão e valores da instituição, gap entre o ideal e o real, e a dimensão de consequência. Além disso, não evidencia "como fazer". Pode ser enquadrada como assessment. 
104

$\mathrm{Na}$ sequência, é apresentada uma matriz de enquadramento dos modelos no roteiro adaptado de Messick's Framework (1989) - dimensão x elemento x modelo. 
4.17. Matriz de enquadramento dos modelos no roteiro adaptado de Messick's Framework (1989) - dimensão x elementos x modelos

\begin{tabular}{|c|c|c|c|c|c|c|c|c|c|c|c|c|c|c|c|c|c|c|c|}
\hline Dim & Elementos & 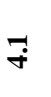 & F & $\stackrel{9}{7}$ & $\stackrel{+}{+}$ & $\stackrel{n}{q}$ & $\stackrel{0}{+}$ & 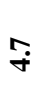 & $\stackrel{\infty}{+}$ & $\dot{q}$ & $\stackrel{f}{\rightleftarrows}$ & $\exists$ & $\stackrel{\sim}{\underset{\sim}{*}}$ & $\stackrel{m}{\rightarrow}$ & $\underset{+}{\stackrel{J}{*}}$ & $\underset{\vec{n}}{\overrightarrow{7}}$ & 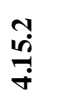 & $\stackrel{m}{\stackrel{9}{7}}$ & $\underset{7}{\ddot{r}}$ \\
\hline \multirow{19}{*}{ 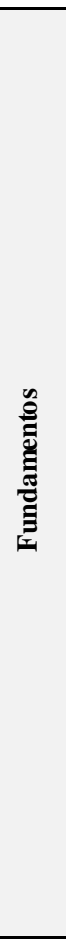 } & 1. Enquadramento em assessment ou evaluation & 1 & 1,2 & 2 & 2 & 2 & 2 & 2 & 1,2 & 1 & 2 & 1 & 1 & 1 & 1 & 1,2 & 1,2 & 1,2 & 1 \\
\hline & 2. Missão da instituição & & & & & & & & $\checkmark$ & & & & & $\checkmark$ & & $\checkmark$ & & & \\
\hline & 3. Valores institucionais & & & & & & & & $\checkmark$ & & & & & $\checkmark$ & & & & & \\
\hline & 4. Objetivos e metas do curso/programa & & & & & & & & & $\checkmark$ & & $\checkmark$ & $\checkmark$ & $\checkmark$ & & & & $\checkmark$ & \\
\hline & 5. Definição do problema existente & & & & & & $\checkmark$ & & & & & & & & & & & & \\
\hline & 6. Apresentação de gap entre o ideal e o real & & & $\checkmark$ & & $\checkmark$ & & & & & $\checkmark$ & & & & & & & & \\
\hline & 7. Lógica do assessment & & $\checkmark$ & & & & & & & & & $\checkmark$ & & & & & & & $\checkmark$ \\
\hline & 8. $\quad$ Objetivo do assessment & $\checkmark$ & & $\checkmark$ & $\checkmark$ & & $\checkmark$ & $\checkmark$ & $\checkmark$ & & & & & $\checkmark$ & & & & & $\checkmark$ \\
\hline & 9. $\quad$ Interessados no assessment (stakeholders) & $\checkmark$ & $\checkmark$ & $\checkmark$ & & & & $\checkmark$ & & & & & & & & & & & $\checkmark$ \\
\hline & 10. Modelo lógico do assessment & $\checkmark$ & $\checkmark$ & $\checkmark$ & $\checkmark$ & $\checkmark$ & $\checkmark$ & & & & & & & & & & & & \\
\hline & 11. Participantes do assessment & & $\checkmark$ & $\checkmark$ & & & & & & & & & $\checkmark$ & & & & & & \\
\hline & 12. Questões chave para o assessment & $\checkmark$ & $\checkmark$ & $\checkmark$ & & & & & & & & & & & & & & & $\checkmark$ \\
\hline & 13. Modelo/Abordagem de avaliação utilizado & $\checkmark$ & & $\checkmark$ & & & & & & & & & & & & & & & $\checkmark$ \\
\hline & 14. Método de investigação & & & & & & & & & & & & & & & & & & $\checkmark$ \\
\hline & 15. Design do assessment & & & & & & & & & & & & & & & & & & $\checkmark$ \\
\hline & 16. Natureza do assessment & $\checkmark$ & $\checkmark$ & $\checkmark$ & & & & & & & & & & & & & & & $\checkmark$ \\
\hline & 17. Recursos disponíveis & $\checkmark$ & $\checkmark$ & $\checkmark$ & & $\checkmark$ & & & $\checkmark$ & & & & & & & $\checkmark$ & & $\checkmark$ & \\
\hline & 18. Infraestrut ura & $\checkmark$ & $\checkmark$ & $\checkmark$ & & $\checkmark$ & & & $\checkmark$ & & & & $\checkmark$ & & & $\checkmark$ & $\checkmark$ & $\checkmark$ & \\
\hline & 19. Consulta a outras fontes e/ou modelos existentes & $\checkmark$ & & & & & & & & & & & & & & & & & \\
\hline \multirow{7}{*}{ 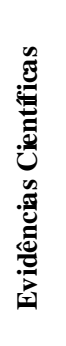 } & 1. Métodos e instrumentos para a coleta de dados & $\checkmark$ & $\checkmark$ & $\checkmark$ & $\checkmark$ & & $\checkmark$ & $\checkmark$ & $\checkmark$ & & & $\checkmark$ & & $\checkmark$ & & & & & $\checkmark$ \\
\hline & 2. $\quad$ Triangulação & $\bar{\checkmark}$ & & & & & & & & & & & & & & & & & $\checkmark$ \\
\hline & 3. Consistência interna & & & & & & & & & & & & & & & & & & $\checkmark$ \\
\hline & 4. $\quad$ Análise fatorial & & & & & & & & & & & & & & & & & & $\checkmark$ \\
\hline & 5. Análise por hipótese & & & & & & & & & & & & & & & & & & \\
\hline & 6. $\quad$ Correlação & & & & & & & & & & & & & & & & & & $\bar{\checkmark}$ \\
\hline & 7. Alfa de Cronbach & & & & & & & & & & & & & & & & & & $\checkmark$ \\
\hline
\end{tabular}




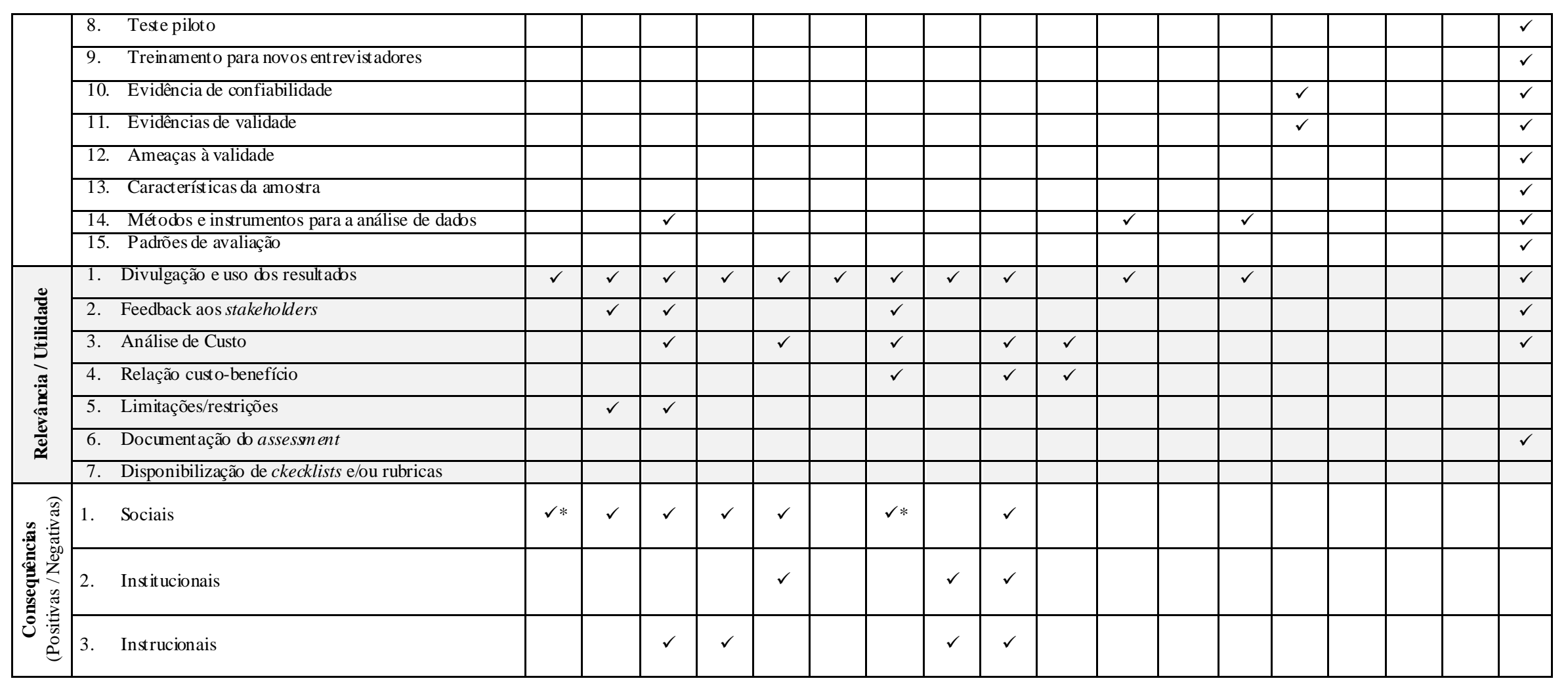


* Abordam consequências de uma forma geral, não sendo possível enquadrá-las em nenhum tipo.

\section{Legenda:}

$1=$ assessment $\quad 2$ = evaluation

4.1. Modelo Lógico de Avaliação segundo Marynowski (2006)

4.2. Modelo Sistemático para Avaliação do E-Learning, segundo Mungania e Hatcher (2004)

4.3. A Practical Framework for Evaluation Online Distance Education Program, segundo Rovai (2003)

4.4. The Kirkpatrick's Four Level of Evaluation (1959)

4.5. Kaufman's Five Level of Evaluation (1994)

4.6. CIRO (Context, Input, Reaction, Outcome) Approach

4.7. O esquema dos cinco níveis do retorno sobre investimento (1997)

4.8. Modelo de Avaliação de Van Slyke, Kittner e Belanger (1998)

4.9. Framework Belanger e Jordan (2000)

4.10. Modelo ACTION de Bates (1995)

4.11. Modelo CIAO de Scanlon et al. (2000)

4.12. Modelo E-Learning, segundo Hughes e Attwell's (2002)

4.13. Modelo e3Learning, segundo Lam \& McNaught (2005)

4.14. Modelo de avaliação de usabilidade para aplicações e-learning, segundo Zaharias (2005)

4.15.1. Instrumento de Credenciamento Institucional para a Oferta da Modalidade de Educação a Distância, (MEC, 2009)

4.15.2. Instrumento de Credenciamento de Polo de Apoio Presencial Modalidade de Educação a Distância, (MEC, 2009)

4.15.3. Instrumento de Autorização de Cursos para a Oferta na Modalidade de Educação a Distância, (MEC, 2009)

4.16. Abordagem sistemática para avaliação, segundo Russ-Eft e Preskill (2001, 2009)

Conforme observado, os vários modelos citados apresentam limitações, visto que não contemplam todos os elementos considerados essenciais no planejamento de um assessment ou evaluation. Contudo, o modelo de Russ-Eft e Preskill $(2001,2009)$ é o que congrega a maioria dos elementos, os quais estão alocados na dimensão de evidências científicas. 
Entretanto, nenhum elemento da dimensão de consequências é contemplado, bem como alguns das dimensões de fundamentos e relevância/utilidade.

Verifica-se, ainda, que os modelos descritos não apresentam uma orientação sobre as etapas a serem seguidas, bem como as ações a serem executadas; não deixam evidente o processo de realização e também não articulam a avaliação como sendo indissociável da pesquisa. Além disso, pouquíssimos modelos abordaram sobre o gap entre o ideal e o real, como forma de mapear "o que se tem e o que se quer".

Desta forma, a proposta da arquitetura de orientação, que se apresenta no capítulo seguinte, é contemplar os elementos elencados na matriz, bem como apresentar uma metodologia que conduza a construção de instrumento de forma a ficar claro o processo de realização, disponibilizando um conjunto de ações a serem realizadas à luz das escolhas, conforme especificidade de cada programa de $\mathrm{EaD}$, ou seja, um planejamento de assessment.

A arquitetura de orientação se propõe a:

- ser um processo contínuo, cuja avaliação (assessment) é customizada às necessidades de cada programa de $\mathrm{EaD}$;

- ser vista como um conjunto de ações contidas em cada etapa do ciclo, podendo ser ajustada/reajustada antes de avançar para as etapas seguintes;

- consultar fontes formais e informais e envolver os interessados e os participantes no assessment;

- apresentar um conjunto de ações denominado ponto de controle, em que as evidências de confiabilidade, validade e ameaças são aferidas antes de prosseguir para a etapa seguinte;

- fazer uma distinção sobre avaliação no sentido de assessment e evaluation;

- apresentar um plano de assessment que contemple o maior número possível de evidências de confiabilidade e validade, proporcionando, assim, um plano consistente e robusto o suficiente para realização de evaluation adequado, que gere resultados satisfatórios.

Além disso, trata a avaliação (assessment) como elemento indissociável da pesquisa e entrelaçado ao rigor científico, de forma a possibilitar evidências de confiabilidade e validade.

Diante do exposto e dando continuidade ao estudo, as figuras 15 e 16 resumem e ilustram o desenvolvimento da pesquisa até o momento. 


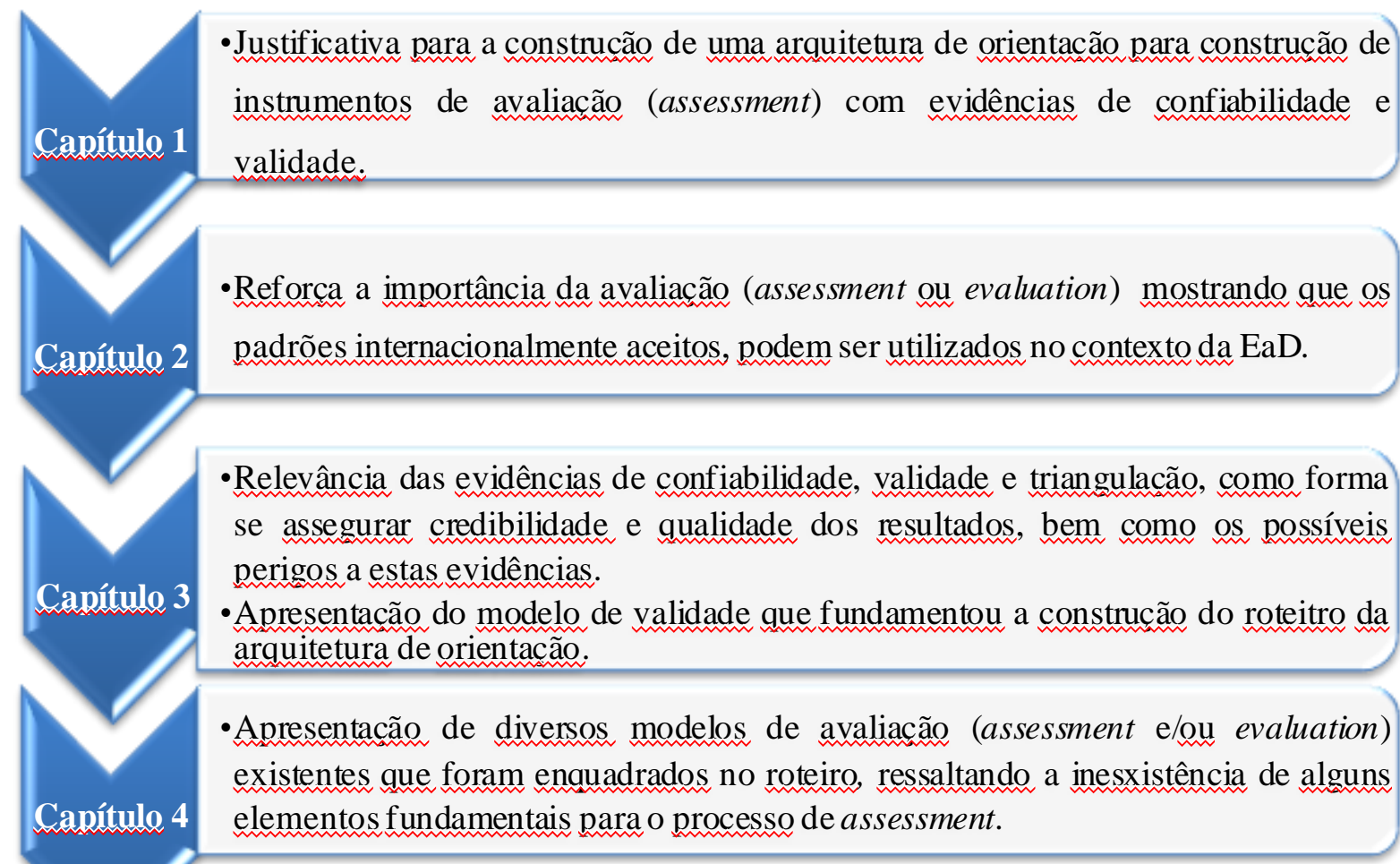

Figura 15 - Resumo dos quatro primeiros capítulos

A figura 16 sistematiza os conceitos utilizados na sustentação da tese.

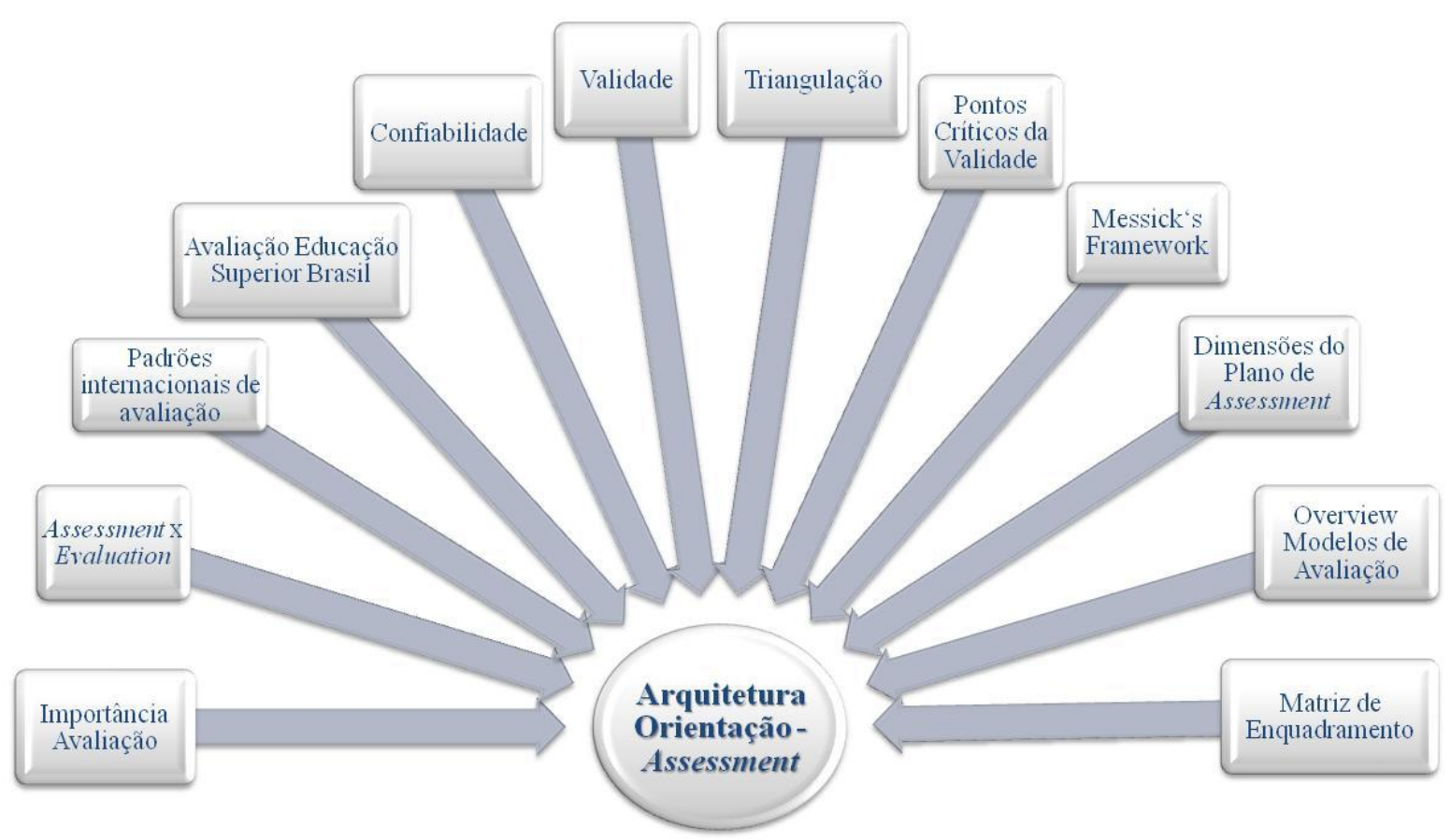

Figura 16 - Sistematização do referencial da pesquisa

Com base nas Figuras 15 e 16 é possível ter uma visão holística da investigação. 


\section{CAPÍTULO 5 - Metodologia}

Este capítulo apresenta a trajetória metodológica seguida na pesquisa, tendo em vista que esta investigação é composta por três etapas: (1) construção da arquitetura de orientação; (2) desenvolvimento de uma solução (plano de assessment), baseada na arquitetura elaborada; e (3) ap licação da solução desenvolvida.

Além disso, para atingir os objetivos propostos, os quais são apresentados abaixo, são apresentadas as estratégias utilizadas, conforme quadro 7.

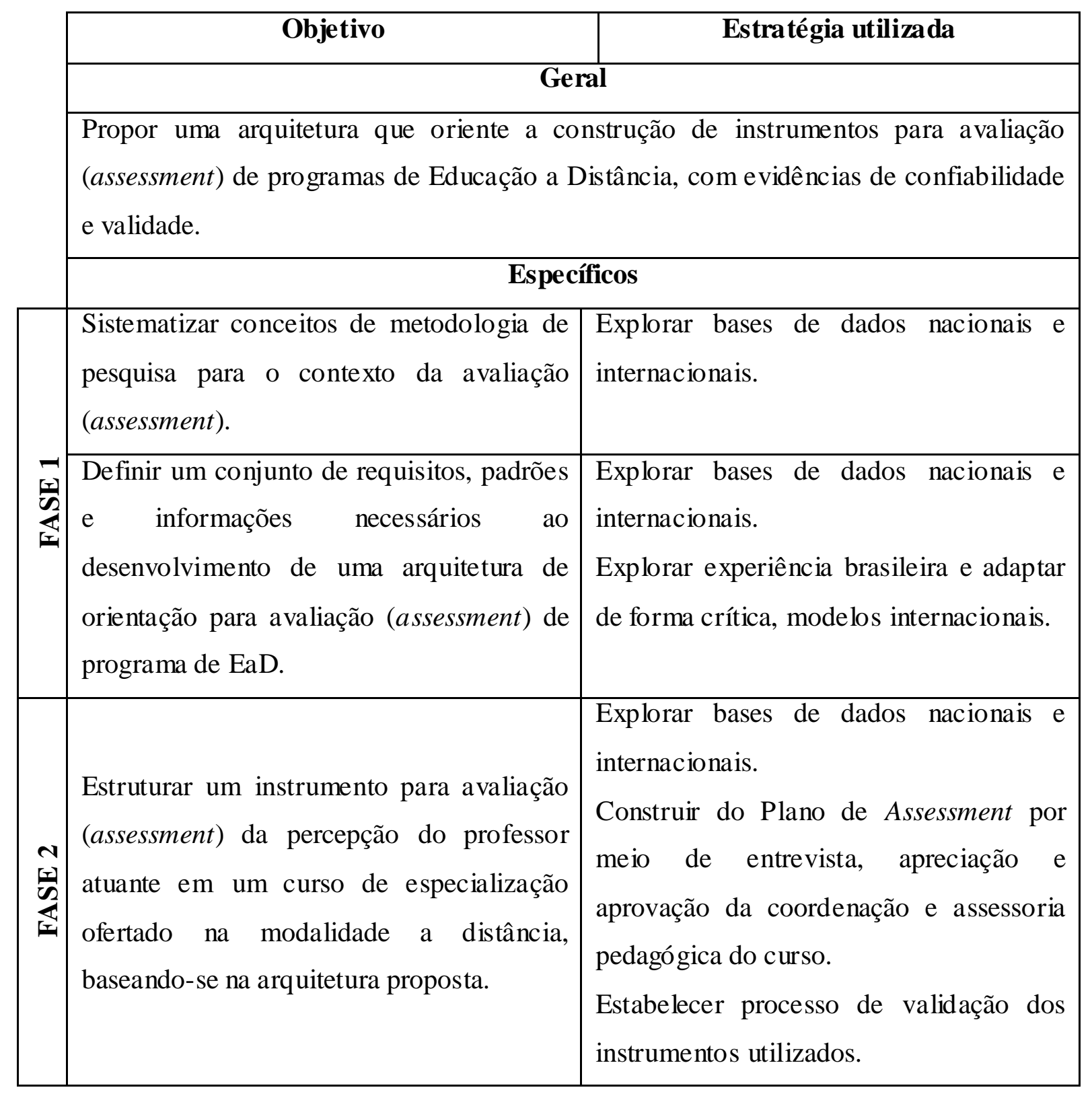




\begin{tabular}{|c|c|c|}
\hline 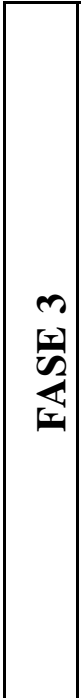 & $\begin{array}{l}\text { Aplicar o instrumento desenvolvido em } \\
\text { estudo de caso. } \\
\text { - Analisar os resultados do instrumento } \\
\text { desenvolvido quanto à percepção do } \\
\text { professor atuante em EaD. }\end{array}$ & $\begin{array}{l}\text { Convidar professores atuantes no curso } \\
\text { em estudo. } \\
\text { Utilizar termo de consentimento livre e } \\
\text { esclarecido para participação dos } \\
\text { envolvidos. } \\
\text { Analisar } \\
\text { quantitativamente os resultados obtidos } \\
\text { na aplicação dos instrumentos. } \\
\text { Analisar o processo de construção e } \\
\text { aplicação da arquitetura de orientação. }\end{array}$ \\
\hline
\end{tabular}

Quadro 7 - Estratégias utilizadas par ao alcance dos objetivos

Por meio do quadro 7 é possível verificar como e em que fase os objetivos são alcançados.

\subsection{ConteXtos Metodológicos da Pesquisa}

\subsubsection{CaracterizaÇÃo da PeSQuisa}

A pesquisa científica é concebida como um processo, com múltiplas etapas relacionadas entre si, que acontece ou não de maneira sequencial ou contínua, porém é mais rígida, organizada e cuidadosamente realizada (SAMPIERI, COLLADO e LUCIO, 2006). E este processo é utilizado para a solução de problemas.

Nesse sentido, a pesquisa aqui apresentada é de natureza aplicada, uma vez que visa sua aplicação prática para solução de problemas específicos (GIL, 1999). Esta característica pode ser observada na proposta do estudo que é a construção de uma arquitetura de orientação para avaliação de Programas de EaD.

De acordo com Gil (1999) esta pesquisa, segundo seus objetivos, é classificada como descritiva e explicativa. É descritiva por descrever as características de determinada população ou fenômeno ou o estabelecimento de relações entre variáveis. Envolve o uso de técnicas padronizadas de coleta de dados: questionário, entrevista semiestruturada e observação sistemática. Além disso, a pesquisa assume caráter explicativo quando registra, analisa, interpreta os fatos e identifica as causas.

Esta pesquisa tem como interesse aprofundar o conhecimento sobre as diferentes 
metodologias existentes para avaliação da $\mathrm{EaD}$ em seus diversos contextos, possibilitando uma contribuição metodológica, que é a construção de uma arquitetura de orientação para avaliação de programa de $\mathrm{EaD}$, além de criar uma solução baseada na arquitetura e aplicar esta solução em estudo de caso.

Nesse sentido, Gil (1999) ressalta que pesquisas explicativas visam identificar os fatores que determinam ou contribuem para a ocorrência de fenômenos. Logo, esta investigação possui um grau de estruturação que implica em seus objetivos, explorar, descrever, correlacionar ou associar o fenômeno estudado.

Sampieri, Collado e Lucio (2006) ressaltam que existem diversas premissas que sustentam os enfoques quantitativos e qualitativos, sendo que o enfoque quantitativo utiliza a coleta e análise de dados para testar hipóteses com base na medição numérica e na análise estatística, para estabelecer padrões de comportamento. Já o enfoque qualita tivo utiliza a coleta de dados sem medição numérica para descobrir ou aperfeiçoar questões de pesquisa e pode ou não provar hipóteses em seu processo de interpretação.

A partir destas colocações, entende-se que nenhum dos enfoques é melhor do que outro, podendo ser complementar, por isso esta pesquisa se estabelece como qualiquantitativa, reconhecendo que o mix entre os enfoques pode enriquecer o estudo, bem como aprimorar os resultados obtidos e, para isso, foram respeitadas as especificidades de cada enfoque.

$\mathrm{Na}$ perspectiva do enfoque qualitativo, utilizou-se entrevistas para complementar e confirmar/confrontar informações obtidas no questionário, bem como triangulação de dados, metodológica e de investigador.

Para o enfoque quantitativo são utilizadas técnicas estatísticas para análise dos dados, como forma de validar a solução (instrumento) a ser aplicados nos participantes da investigação.

O interesse central desta pesquisa foi propor uma arquitetura que orientasse a construção de instrumentos para avaliação de programas de EaD. Para atingir este objetivo, realizou-se um levantamento sobre publicações nacionais e internacionais, utilizando diferentes combinações e estratégias de busca para as palavras-chave: assessment, evaluation, avaliação, educação a distância (e/ou EaD), modelo (ou framework), metodologia e qualidade nos idiomas português e inglês, nas bases de dados de dados Web of Science, Science Direct, Scielo, ProQuest, JSTOR, SCOPUS, ERIC, Psicodoc, ABI/Inform, bem como banco de dissertações e teses nacionais e internacionais.

$\mathrm{Na}$ sequência, sistematizou-se conceitos e definições de metodologia de pesquisa, 
gerando um repositório para consultas, dentro da proposta da arquitetura de orientação. Ainda, na consecução da arquitetura, integrou-se os conceitos validade e confiabilidade, o roteiro de dimensões - adaptado de Messick (1989), e os pressupostos do Modelo de Avaliação de RussEft e Preskill (2001, 2009), os quais já foram abordados. Além desses, também se integra à arquitetura a teoria do IDEAL Model e a teoria do gap da qualidade percebida, os quais sustentarão a proposta da arquitetura (que serão abordados posteriormente).

A pesquisa iniciou com a pesquisadora realizando observações não participantes, por um período de seis meses, em uma Universidade Federal, no Departamento de EaD, para se familiarizar com a rotina e conhecer elementos que poderiam contribuir para o conhecimento sistêmico da EaD. Esta observação ocorreu junto aos profissionais envolvidos no desenvolvimento das atividades de $\mathrm{EaD}$ (equipe multidisciplinar).

A partir das anotações oriundas da observação foi possível confrontar informações obtidas na literatura.

\subsubsection{LOCALDO ESTUDO}

A pesquisa se realiza em três etapas: (1) construção da arquitetura; (2) desenvolvimento de uma solução baseada na Arquitetura proposta; e (3) aplicação da solução desenvolvida a partir da Arquitetura de Orientação.

Desta forma, a primeira etapa foi uma construção teórica. A segunda foi constituída de parte teórica e parte em campo, realizada em uma Universidade Estadual do Estado do Paraná, junto a um curso de especialização Lato Sensu em Gestão Escolar. A terceira etapa da pesquisa (aplicação - pesquisa de campo) se deu em uma Universidade Pública do interior do Estado do Paraná, no segundo semestre de 2010.

\subsubsection{POPULAÇão}

O curso pesquisado iniciou em fevereiro de 2009 com 19 professores em sete polos de apoio presencial, tais como: Apucarana, Bituruna, Engenheiro Beltrão, Itambé, Laranjeiras do Sul, Palmital e Pinhão. Entretanto, atualmente conta com 18 professores, os quais serão os sujeitos da pesquisa. 


\subsection{ETAPAS DO DESENVOLVIMENTO DA PeSQUISA}

1'. Etapa: Construção da Arquitetura de Orientação

Buscou-se realizar uma sólida investigação em trabalhos acadêmico-científicos disponíveis em bases de dados nacionais e internacionais. E a partir do material levantado, iniciou-se a construção da arquitetura, a qual foi fundamentada principalmente nos pressupostos da avaliação, da metodologia científica, da validade, da confiabilidade, do roteiro de dimensões - adaptado de Messick (1989), do modelo de avaliação de Russ-Eft e Preskill (2001, 2009); no modelo Servqual - gap da qualidade percebida e na teoria do IDEAL, além de ser permeada pelo ciclo PDCA.

$2^{\mathbf{a}}$. Etapa: Construção de uma solução baseada na arquitetura desenvolvida - Plano de Assessment.

Para execução desta etapa da pesquisa adotou-se os procedimentos de investigação abaixo relacionados.

Primeiramente reuniu-se com a coordenação e assessoria pedagógica do curso de especialização para identificar quais as necessidades/problemas do curso que precisavam ser investigadas.

Com base na entrevista realizada foram elaboradas as questões chave da pesquisa, bem como o plano de assessment. As questões chave foram apreciadas pela coordenação e assessoria pedagógica do curso e aprovadas. Na sequência, iniciou-se a pesquisa em diferentes de bases de dados (Web of Science, Science Direct, Scielo, ProQuest, JSTOR, SCOPUS, ERIC, Psicodoc, ABI/Inform, bem como banco de dissertações e teses nacionais e internacionais), para a construção de uma primeira versão dos instrumentos a serem aplicados - questionário e entre vista.

Estes instrumentos foram aprovados pela coordenação e assessoria pedagógica. Posteriormente, iniciaram-se os procedimentos de validação, tais como: (1) apreciação dos instrumentos por cinco professores que atuam na UAB e são orientadores do Curso em estudo; (2) utilização da técnica Delphi (LOO, 2002; TUROFF, 1975) para apreciação dos instrumentos por juízes; (3) pré-teste dos instrumentos; e (4) análise das evidências de confiabilidade e validade.

Após a conclusão do processo de validação, a coordenação do curso em estudo enviou um e-mail para todos os professores participantes e solicitou a colaboração na pesquisa. Posteriormente, foi agendado (via ligação te lefônica) um horário com cada professor. 
Antes de cada entrevista, a pesquisadora explicou o objetivo do estudo, bem como a finalidade dos resultados e verificou o interesse do professor em participar. Os que colaboraram, assinaram um Termo de Consentimento Livre e Esclarecido (Apêndice E).

O tempo gasto por cada professor foi de aproximadamente 30 minutos.

O Plano de Assessment foi elaborado coletivamente com a coordenação e assessoria pedagógica do curso investigado.

3. Etapa: Aplicação da solução desenvolvida a partir da Arquitetura de Orientação Plano de Assessment

Para a consecução desta etapa foi utilizado o Termo de Consentimento Livre e Esclarecido (Apêndice E) e a participação dos profes sores (respondentes) se deu por adesão, a partir do convite da coordenação do curso para participação na pesquisa.

Posteriormente, agendou-se (via ligação telefônica) um horário para cada professor e a pesquisadora realizou a aplicação do questionário e e ntre vista.

Os professores participantes foram orientados sobre o objetivo da investigação, bem como o sigilo das informações.

O detalhamento destas etapas está organizado da seguinte forma:

1. Construção de uma arquitetura de orientação para avaliação de programas de EaD: a ser descrita no Capítulo 6.

2. Construção de um Plano de Assessment a partir da arquitetura de orientação desenvolvida: a ser descrita no Capítulo 7.

3. Aplicação do Plano de Assessment: a ser descrita no Capítulo 8. 


\section{CAPÍTULO 6 - Descrição da Construção da Arquitetura de Orientação}

A arquitetura de orientação que se propõe é fundamentada nos pressupostos da avaliação, metodologia científica, validade, confiabilidade, roteiro de dimensões - adaptado de Messick (1989), modelo de avaliação de Russ-Eft e Preskill (2001, 2009); no modelo Servqual - gap da qualidade percebida e na teoria do IDEAL Model. Além disso, é permeada pelo ciclo PDCA.

Alguns desses pressupostos já foram abordados anteriormente, para que houvesse uma sequência lógica na apresentação do estudo. Assim, em cada uma das sessões é apresentado um conjunto de elementos que compõem a Arquitetura de Orientação para Avaliação de Programas de EaD (objetivo central deste estudo), e tem como propósito facilitar a escolha de um ou mais componentes em conformidade com as especificidades do Programa de Educação a Distância e/ou Instituição de Ensino, conforme segue.

\subsection{O IdEAL MODEL INTEGRANDO A ARQUITETURA de ORIENTAÇÃo PARA A AVALIAÇÃo de Programas de EduCAÇÃo a DistânCIA}

O IDEAL Model foi idealizado pelo Software Engineering Institute (SEI) da Carnegie Mellon University (1996, 2009), e é um modelo de melhoria organizacional que serve como roteiro para a inicialização, planejamento e implementação de ações de melhoria; é baseado no Capability Maturity Model Integration (CMMI). Ele é composto por cinco fases: (1) Inicialização (Initiating), (2) Diagnóstico (Diagnosting), (3) Estabelecimento (Establishing), (4) Ação (Acting) e (5) Aprendizagem (Learning).

O modelo tem suas raízes no ciclo Plan, Do, Check e Act (PDCA) de Deming (CASEY; RICHARDSON, 2002, ZAHRAN, 1998). Na primeira versão do modelo, a fase 5 era denominada Leveraging (Lição).

De acordo com McFeeley (1996); SEI (1996, 2009); Casey e Richardson (2002) a proposta deste modelo é formar uma infraestrutura para guiar as organizações no planejamento e implementação de um efetivo programa de melhoria no processo de software. O IDEAL Model permite integrar diferentes ferramentas dentro um método compreensível para gerenciamento e melhoria. Desta maneira, o referido modelo será adaptado conforme necessidades da Arquitetura de Orientação em construção.

A opção por este modelo se justifica pelo fato de que ele é originário de estudos de 
casos e não apenas de modelos conceituais e também por ter sido idealizado para qualquer esforço de melhoria, não se restringindo apenas a softwares. Além disso, apresenta um aspecto interessante que é ter um processo iterativo que permite refinamentos e aprimoramentos ao longo das fases.

Para melhor adequação à Arquitetura de Orientação as fases do modelo foram adaptadas e passam a ser denominadas: (1) Exploratória; (2) Diagnóstico, (3) Estabelecimento, (4) Implementação e (5) Aprendizagem.

Com isso, cada fase dispõe de um conjunto de atividades a serem executadas, as quais foram relacionadas no roteiro criado anteriormente e possuem um ponto de controle.

O ponto de controle é um conjunto de ações e/ou estratégias que conferem ou viabilizam confiabilidade e validade, bem como minimizam as ameaças à validade e que é aferido antes de avançar para a fase seguinte. Dessa forma, a fase seguinte só é iniciada quando um volume significativo de ações e/ou estratégias é evidenciado. As fases são descritas abaixo:

\section{(1) Exploratória}

Esta fase é crucial para as fases seguintes do modelo, uma vez que são traçadas as diretrizes para a realização bem sucedida do ciclo. Para tanto, têm-se as atividades: contexto, recursos, infraestrutura e todos os elementos da dimensão fundamentos do roteiro (apresentado nas páginas 67 e 68).

Contudo, esta fase deve ser bem sistematizada e articulada, para que o planejamento do assessment seja consistente e exequível, tendo em vista que as características do programa/curso a ser avaliado.

\section{(2) Diagnóstico}

Nesta fase o pesquisador/avaliador precisa conhecer bem o contexto do assessment, "definindo onde está e onde se deseja chegar". Para tanto, têm-se os elementos da dimensão evidências científicas (apresentada na página 68), aferição do planejamento do assessment, finalizando com as recomendações devidas.

Os resultados obtidos na fase exploratória proporcionam aferições e remetem recomendações para o alinhamento do Plano de Assessment, proporcionando uma definição clara e precis a dos elementos do plano que compõe a Fase Diagnóstico. 


\section{(3) Estabelecimento}

O propósito desta fase é a definição de prioridades, caso seja necessário, finalização do planejamento do assessment, o que pode ser considerado um plano de ação, cujas atividades devem passar pelo teste piloto, a fim de identificar quaisquer necessidades de revisão e/ou ajustes.

Todavia, deve ser atribuída atenção especial aos aspectos de confiabilidade e validade, uma vez que estas evidências são nacional e internacionalmente desejadas em programas de avaliação (assessment e/ou evaluation).

\section{(4) Implementação}

Nesta fase, com o plano de ação (assessment) criado, o qual deve ser consistente e claro o suficiente para ter respostas às seguintes perguntas: o que será avaliado? - por quê? onde? - quando? - quem? - como? - e quanto vai custar? $(5 \mathrm{~W} 2 \mathrm{H})$.

Para tanto, executa-se os refinamentos necessários oriundos do teste piloto, inicia-se a aplicação do instrumento e analisa as evidências de confiabilidade, validade e triangulação, para que se tenha um resultado confiável e válido e que permita tomada de decisão eficaz.

\section{(5) Aprendizagem}

Esta fase completa o ciclo do assessment e está focada na aprendizagem sobre o que foi realizado, além de prospectar ações futuras. Além disso, deve-se contemplar os elementos das dimensões relevância/utilidade e consequências (apresentadas nas páginas 67 e 68), para que ao retroalimentar o ciclo, possibilite novas ações que agreguem valor e incorpore conhecimento a um processo contínuo de melhorias.

\subsection{GAPS DA QUALIDADE PERCEB IDA (IDEAL X REAL)}

Ao elaborar um instrumento ou método de avaliação (sempre que possível) é interessante incorporar sentenças que possam sinalizar a expectativa do investigado, bem como sua percepção, ou seja, o que era esperado e o que foi recebido (diferença entre o ideal e o real). O conhecimento da percepção de qualidade do usuário auxilia na elaboração de estratégias efetivas para o aprimoramento do desempenho futuro de qualquer instituição, e possibilita atingir índices de satisfação que asseguram qualidade.

No entanto, a noção de qualidade percebida é muito ampla e se baseia em diferentes 
fundamentações que variam de pessoa para pessoa e está relacionada com a comparação entre as expectativas prévias e as percepções reais do serviço prestado, sendo dimensionada pela lacuna existente.

Assim, baseando-se nesta fundamentação, Parasuraman et al. (1985) desenvolveram um modelo denominado "Modelo de Qualidade em Serviços" ou Gap da Qualidade, em que descreve cinco tipos de gaps que representam as falhas do serviço (Figura 17). Esse modelo visa auxiliar a compreensão dos problemas, bem como busca soluções para melhorá-los. Além disso, é amplamente utilizado e referenciado por diversos autores (FITZSIMMONS, FITZSIMMONS (2000); GIANESI e CORRÊA (1996); GRÖNROOS (1995).

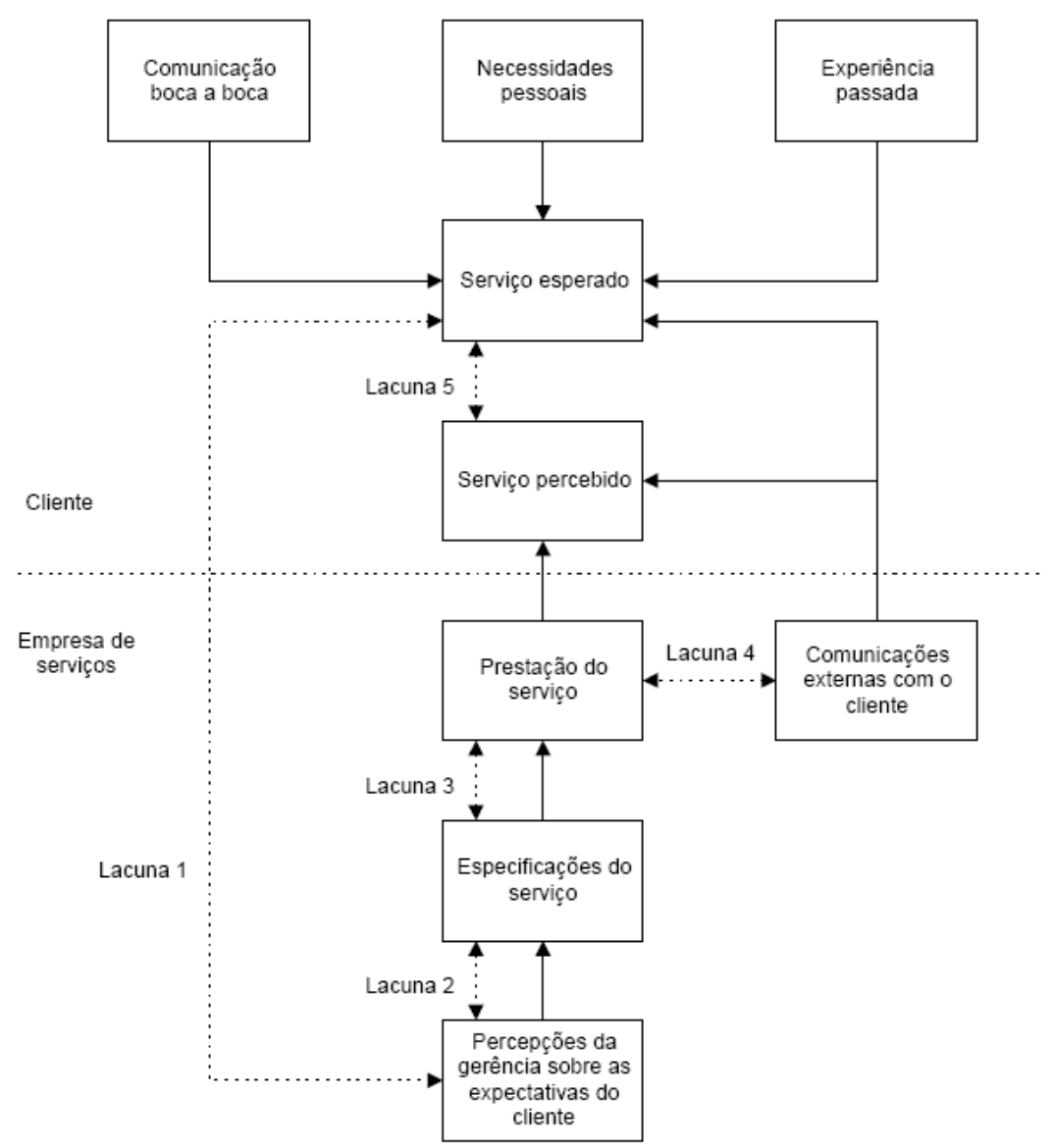

Figura 17 - Modelo de Gaps em qualidade em serviço, adaptado de Parasuraman et al. (1985)

De acordo com o modelo apresentado, Gianesi e Corrêa (1996) discutem os gaps e sugerem algumas medidas para corrigir e prevenir as falhas. 
Gap 1 - Lacuna entre expectativas do consumidor e a percepção gerencial: refere às discrepâncias que podem existir entre a percepção dos executivos e as reais expectativas dos clientes. Para corrigir e prevenir as falhas do gap 1 podem ser tomadas as seguintes medidas:

- Foco/seleção de clientes: selecionar os clientes para reduzir a amplitude das expectativas.

- Realização de pesquisas: executar pesquisas periódicas sobre qualidade dos serviços, pois as expectativas são dinâmicas estando em constantes mudanças.

- Pré-formação das expectativas dos consumidores: usar diferentes recursos para influenciar as expectativas do consumidor, como por exemplo, consistência do serviço, preço.

- Canais de comunicação: criar canais de comunicação formais e informais, estimulando as pessoas da linha de frente a prospectarem o cliente, criando centrais de atendimento para sugestões/reclamações dos clientes e aproximando as pessoas da linha de frente aos gestores, para que as informações sejam repassadas.

Um exemplo do Gap 1 em EaD: o curso tem um propósito e os alunos tem expectativas divergentes do propósito do curso.

Gap 2 - Lacuna entre percepção gerencial e as especificações da qualidade do serviço: os gestores podem não incluir nas especificações da qualidade do serviço, todos os elementos capazes de atender as expectativas dos clientes, não traduzindo corretamente suas expectativas reais. Para corrigir ou prevenir as falhas do Gap 2, pode-se realizar as seguintes ações:

- Análise do pacote de serviço: identificar como cada elemento do pacote de serviços afeta a avaliação da qualidade pelo cliente.

- Análise do ciclo de serviço: analisar as diversas etapas do ciclo de serviços, do ponto de vista do cliente.

- Análise dos momentos de verdade: projetar cada momento de verdade crítica, visando atender ou superar as expectativas dos clientes.

- Padronização: elaboração de um sistema de procedimentos e especificações adequados e exequíveis para o atendimento das expectativas dos clientes.

Um exemplo do Gap 2 em EaD: a coordenação do curso pode achar que o material didático está adequado, mas os alunos não estão satisfeitos com um ou mais aspectos dele. 
Gap 3 - Lacuna entre as especificações da qualidade do serviço e prestação do serviço: a especificação do serviço pode estar adequada, porém, podem ocorrer falhas na prestação do serviço ao cliente, pois na execução propriamente dita, os funcionários podem cometer erros, influenciando a qualidade final. Para corrigir estas falhas do Gap 3, pode-se:

- Adequar os funcionários ao trabalho: recrutamento e seleção adequados, capacitação e definição dos níveis de autonomia.

- Estabelecer padrões: elaborar padrões de operação para orientar as decisões dos funcionários, sem prejudicar a flexibilidade e autonomia.

- Estabelecer medidas para avaliação de desempenho: avaliar os funcionários com base em medidas de desempenho, baseadas nas expectativas dos clientes, para que os funcionários saibam o que se espera do seu desempenho.

- Utilizar medidas à prova de falha: desenvolvimento de mecanismos que impedem que erros sejam cometidos. Esses mecanismos são chamados de poka-yoke.

Um exemplo do Gap 3 em EaD: o curso pode ter sido muito bem planejado mas a relação dos professores e tutores com os alunos não atende ao padrão adequado, e isso compromete a efetividade do curso.

\section{Gap 4 - Lacuna entre a prestação do serviço e as comunicações externas ao consumidor:} é a lacuna entre o serviço prestado e o serviço prometido, por meio da propaganda e outras formas de comunicação. Promessas exageradas influenciam as expectativas e percepções do cliente. Deve-se procurar um equilíbrio nas comunicações externas, para gerar atratividade, porém, ser compatível com a capacidade de atendimento. Para corrigir ou prevenir as falhas do Gap 4, pode-se realizar as seguintes ações:

- Coordenação entre marketing e operações: as duas funções devem participar do projeto e acompanhamento do desempenho do serviço.

- Formação de expectativa coerente: nunca se deve prometer algo que não se pode executar.

- Comunicação durante processo: deve-se manter o cliente informado sobre todo o processo de prestação do serviço e eventuais falhas devem ser corrigidas no contato do cliente.

Um exemplo do Gap 4 em EaD: o curso pode ter sido muito bem planejado e divulgado de uma forma em que o polo de apoio presencial não tenha condições de executá-lo 
em sua totalidade. Outro exemplo é em relação ao Projeto Político Pedagógico que nem sempre é executado conforme elaborado.

Gap 5 - Lacuna entre o serviço esperado e o serviço percebido: essa lacuna é o resultado das demais quatro lacunas, só ocorrendo se uma ou mais das anteriores ocorrerem. A qualidade percebida pelo consumidor é uma função do tamanho e direção da lacuna entre o serviço esperado e o percebido.

Segundo Parasuraman et al. (1985) a qualidade percebida do serviço pelo consumidor depende do gap 5 que, por sua vez, depende das quatro demais lacunas associadas com informações do projeto, marketing e entrega do serviço. Assim, o gap 5 pode ser resumido em: a diferença entre o esperado e o recebido e é representado pela seguinte função:

$$
\text { Gap } 5 \text { = f(Gap 1, Gap 2, Gap 3, Gap 4) }
$$

Um exemplo do Gap $5 \mathrm{em} \mathrm{EaD} \mathrm{pode} \mathrm{ser} \mathrm{observada} \mathrm{quando} \mathrm{a} \mathrm{expectativa} \mathrm{dos} \mathrm{agentes}$ de $\mathrm{EaD}$ (professores, alunos, equipe multidisciplinar...) não é atendida.

Essa fundamentação de qualidade percebida em serviço pode ser associada a EaD. Com isso, ao se escolher método ou instrumento deve-se considerar a amplitude do gap 5, buscando sempre mensurar a expectativa do cliente com sua percepção.

Ao inserir este procedimento nos instrumentos (exemplo: questionário) o pesquisador/avaliador está propondo mais uma fonte de informação, propiciando ampliação do espectro da avaliação e consequentemente da validade.

Nesse sentido, a escala entre a expectativa e a percepção pode ser equacionada conforme especificidades do programa de avaliação (assessment ou evaluation). Além disso, este procedimento proporciona mais uma forma de triangular as informações (Ex. presença $\mathrm{x}$ importância; ideal x real). 


\subsection{FASES DA ARQUITETURA dE ORIENTAÇÃo}

A Arquitetura de Orientação conforme já apresentado, está fundamentada nos pressupostos teóricos da avaliação, metodologia científica, validade e confiabilidade, roteiro de dimensões - adaptado de Messick (1989), modelo de avaliação de Russ-Eft e Preskill (2001, 2009), do modelo Servqual - gap da qualidade percebida e da teoria do IDEAL Model. Além disso, é permeada pelo ciclo PDCA.

Desta forma, esta sessão apresenta detalhadamente cada uma das fases da Arquitetura que são: (1) Fase Exploratória; (2) Fase Diagnóstico; (3) Fase Estabelecimento; (4) Fase Implementação; e (5) Fase Aprendizagem.

A figura 18 ilustra o esboço das fases da arquitetura de orientação.

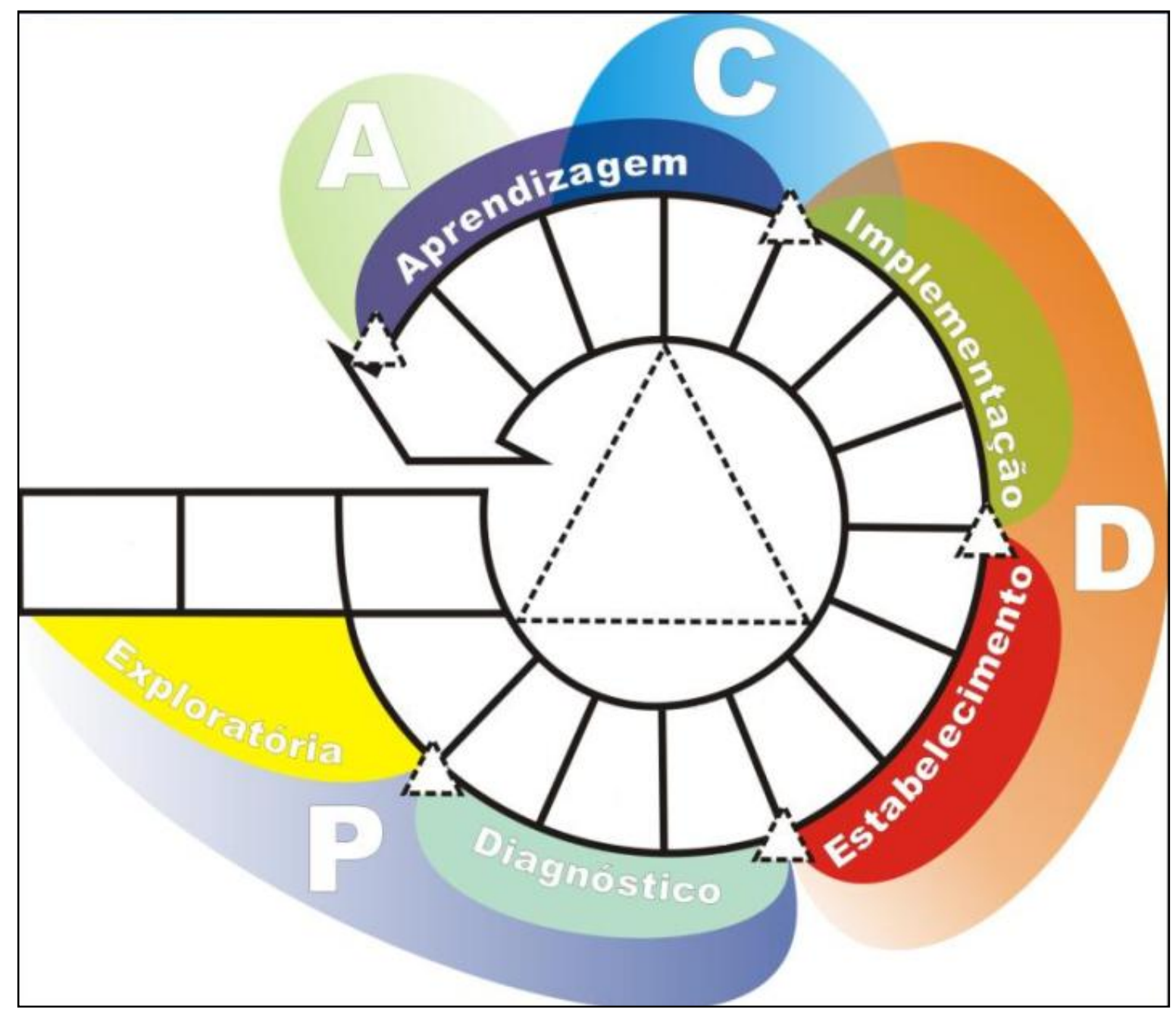

Figura 18 - Esboço das Fases da Arquitetura de Orientação 


\subsubsection{FASE EXPLORATÓRIA}

O planejamento de uma avaliação pode ser denominado plano de assessment e/ou plano de ação e é o que delineia claramente o que será avaliado, bem como responde algumas perguntas, tais como: O que? Por quê? Quando? Onde? Quem? Como? Quanto custa? $(5 \mathrm{~W} 2 \mathrm{H})$. Funciona como um contrato entre o avaliador/pesquisador e a organização/s ujeitos. Além disso, é um documento que guia todo o processo de assessment, uma vez que define as regras e responsabilidades dos envolvidos na avaliação.

Ao iniciar a construção do plano de assessment é preciso conhecer a missão e valores da instituição, os objetivos e metas do curso/programa que será avaliado. Também é preciso apresentar o problema existente ou a necessidade de investigação, seguido da identificação do gap entre o ideal e o real. Essas informações devem ser registradas no plano e poderão ser utilizadas para justificar determinadas escolhas. A fase exploratória deve conter todos os elementos da dimensão fundamentos do roteiro (apresentado nas páginas 67 e 68).

Além dis so, Russ-Eft e Preskill (2009) sugerem atenção a quatro passos do desenho do plano de assessment:

1. Lógica e propósito da avaliação.

2. Desenvolver um modelo ló gico para a avaliação.

3. Identificar os interessados na avaliação (stakeholders).

4. Determinar as questões chave da avaliação.

As autoras ressaltam que estes passos alicerçam outros. Além disso, recomendam que o grupo ou equipe de pessoas interessadas na avaliação e/ou nos seus resultados, ou serão os avaliandos (participantes), sejam convidadas a participar desse processo de construção, de forma a manifestar suas experiências e percepções sobre o que será avaliado e os resultados que esperam.

Com isso, há um envolvimento maior de todos e, consequentemente, amplia-se significativamente o entendimento do assessment, do programa avaliado e do uso dos resultados, fazendo com que se sintam mais conectados ao processo de avaliação. E isso contribui para se ter clareza sobre as necessidades e expectativas dos interessados e a partir disso discutir sobre as fronteiras da avaliação.

Abaixo, segue o detalhamento dos quatro passos sugeridos por Russ-Eft e Preskill (2009): 


\section{Descrever a lógica e propósito da avaliação}

Descreve-se o porquê da realização da avaliação, bem como do programa, produto, processo, serviço ou pessoas que estão sendo avaliadas.

As informações sobre o responsável pela avaliação e o motivo de se ter pedido a avaliação, devem ser contemplados, de forma que fique evidente o porquê, os fatores e os interesses da avaliação.

O propósito de uma avaliação é explorar as razões, objetivos e metas da investigação, deixando claro o que se pretende fazer com os resultados obtidos.

Para realização dessa tarefa, existem vários caminhos, entretanto, Russ-Eft e Preskill (2009) sugerem um diálogo franco com a equipe deixando claras as hipóteses, atividades, recursos, resultados a curto e longo prazo, bem como as necessidades e expectativas dos interessados (stakeholders) para com a avaliação.

As respostas a estas questões ajudam a explicitar o não entendido ou tácito, os objetivos e metas do programa, processo ou produto, ou o objeto a ser avaliado.

\section{Desenvolver um modelo lógico para a avaliação}

Um modelo lógico é uma representação visual de como um programa é supostamente operado, considerando os seus vários componentes. Trata-se de um processo repetitivo e colaborativo entre avaliador/pesquisador e o grupo participante (RUSS-EFT; PRESKILL, 2009).

Ao desenvolver um modelo lógico, o avaliador/pesquisador e todos os interessados e participantes compreendem a lógica e o propósito da avaliação. Além disso, o modelo lógico provê informações necessárias ao plano de assessment.

\section{Identificar os interessados na avaliação (stakeholders)}

Os interessados na avaliação são categorizados de forma clara e conforme a ordem de prioridade e interesse nos resultados a serem obtidos, podendo adotar-se a seguinte denominação:

- Primário: tipicamente, são aqueles que permitem a avaliação existir ou a fazem acontecer.

São os principais interessados no desenho, desenvolvimento, implementação e resultados da avaliação.

- Secundário: são geralmente, os interessados na parte operacional do programa de avaliação, entretanto, sofrem os reflexos do resultado da avaliação. 
- Terciário: são os que possuem algum interesse na avaliação para planejamento futuro ou tomada de decisão ou nos resultados da avaliação.

É interessante detalhar cada grupo de interessados e explanar sobre as razões do interesse nos resultados da avaliação.

A ação mais importante neste passo é a identificação de todos os potenciais stakeholders, bem como, assegurar que os resultados da avaliação serão maximizados entre os grupos de interessados.

\section{Determinar as questões chave da avaliação}

Parte-se da construção de uma lista de perguntas claras e abertas que irão focar e guiar o processo de avaliação. Estas perguntas formam as fronteiras e o escopo do processo de avaliação.

As questões-chave devem ser definidas juntamente com os interessados, as quais devem ser relacionadas ao propósito da avaliação que por sua vez está atrelada à lógica e negociação entre avaliador/pesquisador e stakeholders. Estas perguntas ajudarão a deixar claro o que a avaliação atenderá e o que não atenderá.

De acordo com Russ-Eft e Preskill (2009), não se deve ter muitas questões, assim o ideal é priorizar aquelas que necessitam de resposta rápida, podendo ter entre três e cinco questões. Contudo, ressaltam que em processos de avaliação complexos e multifacetados, pode-se requerer entre dez a doze questões chave. Além disso, recomendam que:

- $\quad$ se tenha questões gerais e não apenas questões específicas;

- que as questões sejam agrupadas por temas ou categorias;

- priorize as questões em cada categoria de acordo com o que se necessita responder "agora";

- categorize as questões de forma a determinar a ordem de importância.

As respostas às questões-chave ajudam explicitar o programa, processo, produto ou objeto que está sendo avaliado. Além disso, elas podem conduzir para um tipo de método de coleta de dados. Desta forma, para cada uma das questões-chave, devem-se considerar qual(is) o(s) método(s) mais apropriado(s) para conseguir a melhor informação necessária.

Ao decidir pelos métodos e instrumentos a serem utilizados na coleta de dados, devese atentar para a validade e a confiabilidade, as quais são aspectos importantes em um processo de assessment. 
Nesse sentido, buscando assegurar confiabilidade e validade, Russ-Eft e Preskill (2001) sugerem algumas técnicas para estabelecer validade em dados qualitativos ou quantitativos, tais como:

- Verifique cuidadosamente a precisão dos dados registrados e codificados - assegure que todos sejam lidos e disponibilizados para análise.

- Faça observações repetidas e completas - construa confiança e compreensão entre os participantes, isso possivelmente, proporcionará informações válidas.

- Verifique continuamente os dados com os participantes ou outros interessados, após as várias atividades de coleta de dados ou quando o esboço do relatório final estiver sendo escrito.

- Utilize das estratégias de triangulação como forma de obter dados confiáveis.

- Interrogação entre pares - engaje as pessoas em discussões formais ou informais sobre o que tem visto, sentido, experenciado e interpretado. Isso ajuda a explorar explicações alternativas, bem como emergem temas e padrões.

- Julgamento de auditoria - permita que um auditor determine a confiabilidade do estudo. $\mathrm{O}$ auditor pode rever guias de entrevistas, notas de campo, documentos, interrogar sobre qualquer outro documento usado ou coletado.

- Teste piloto - realizado preliminarmente em uma escala menor, ou seja, uma amostra da população. Isso servirá como orientação para a realização da pesquisa/avaliação propriamente dita, uma vez que fornecerá as devidas correções a serem realizadas antes da implementação do instrumento na amostra total ou na população.

- Explicação competitiva - observe as diversas formas de organização dos dados, uma vez que isso pode conduzir a resultados diferentes.

- Casos negativos - considere casos que não seguem um padrão. Esses casos podem produzir insights ou novas perspectivas para um problema recorrente.

Diante destas técnicas e com vistas a ampliar as possibilidades de sucesso de um programa de avaliação, buscou-se no Joint Committee on Standards for Educational Evaluation (2009) um documento derivado do The Program Evaluation Standards, no qual foram compiladas as opiniões de diversos profissionais da educação e da avaliação sobre o processo de avaliação de um programa, sendo que as funções da avaliação apresentadas são:

1. Decidir sobre o que avaliar.

2. Definir o problema da avaliação. 
3. Desenho da avaliação.

4. Coletar as informações.

5. Analisar as informações.

6. Relatar as informações.

7. Orçamento da avaliação.

8. Contratar a avaliação.

9. Gestão da avaliação.

10. Equipe para a avaliação.

Ainda de acordo com o Joint Committee e a National Science Foundation (2009), o design da avaliação deve ser orientado por diretrizes e padrões que possam propiciar sucesso. Desta forma, relacionam-se alguns elementos que o design deve abranger, buscando atrelá-los aos padrões de avaliação: utilidade $(\mathrm{U})$, viabilidade $(\mathrm{V})$, propriedade $(\mathrm{P})$ e precisão/acurácia (A), os quais foram citados no Capítulo 2 e detalhados no Apêndice A.

Além de atender aos padrões internacionais de avaliação é importante que o relatório de um plano de assessment tenha um formato adequado, para tanto, McNamara (2008) sugere um modelo, o qualé apresentado no Apêndice B.

Outrossim, o planejamento de um plano de assessment ou evaluation deve contemplar etapas de reflexão sobre o contexto e o história do programa e articular a lógica e o propósito da avaliação, mostrando como os resultados serão utilizados, quem são os potenciais interessados (stakeholders) e o público participante. Além disso, deve ter clareza sobre quais as questões-chave que nortearão a avaliação.

O desenvolvimento de um plano de assessment deixa claro o que será avaliado, bem como as respostas para os $5 \mathrm{~W} 2 \mathrm{H}$. Além disso, deve funcionar como um contrato entre o(s) pesquisador(es)/avaliador(es) (internos ou externos) e a instituição/organização, e é o documento que guia o processo de avaliação, devendo ter claramente definidos os papéis e as responsabilidades de cada um dos envolvidos na avaliação (RUSS-EFT; PRESKILL, 2009).

Além disso, algumas questões e reflexões podem ser realizadas, tais como:

- Qual a motivação para a avaliação?

- Qual o contexto para a avaliação?

- Quais os recursos disponíveis?

- Qual a infraestrutura?

Além das respostas a estas perguntas, nesta fase tambémé necessário:

- Identificar os interessados no processo de avaliação, bem como nos resultados 
oriundos da avaliação;

- Definição do escopo e seleção das informações que serão utilizadas na coleta de dados;

- Idealização da lógica, procedimentos e perspectivas da a valiação;

- Mapeamento dos procedimentos necessários para condução do processo de avaliação;

- Levantamento do custo da avaliação no programa de EaD;

- Definição formal dos papéis dos envolvidos no processo de avaliação, tais como: o que será feito, como, por quem e quando;

- Identificação dos canais de divulgação dos resultados da avaliação;

- Formas de sensibilização para o processo de avaliação;

- Averiguação das formas de avaliação;

- Descrição detalhada dos objetivos e procedimentos da avaliação;

- É interessante que se realize consultas em outros modelos/fontes de informação acerca de assessment/avaliação.

Esta fase é crucial para as fases seguintes da arquitetura, tendo em vista que são traçadas as diretrizes, de modo que sejam sistematizadas e articuladas, viabilizando um plano de assessment consistente e exequível.

Além disso, dispõe do ponto de controle, que é um arcabouço de ações que contribuem para assegurar confiabilidade e validade nos instrumentos do assessment.

A Fase Exploratória é composta pelas etapas contexto, recursos, infraestrutura e os elementos da dimensão fundamentos, bem como o ponto de controle para a fase exploratória com as seguintes ações/estratégias: rigor e critério metodológico, definição clara do conteúdo abordado, explicitação dos objetivos e consulta a diferentes fontes de informação.

A figura 19 ilustra a Fase Exploratória da Arquitetura de Orientação. 


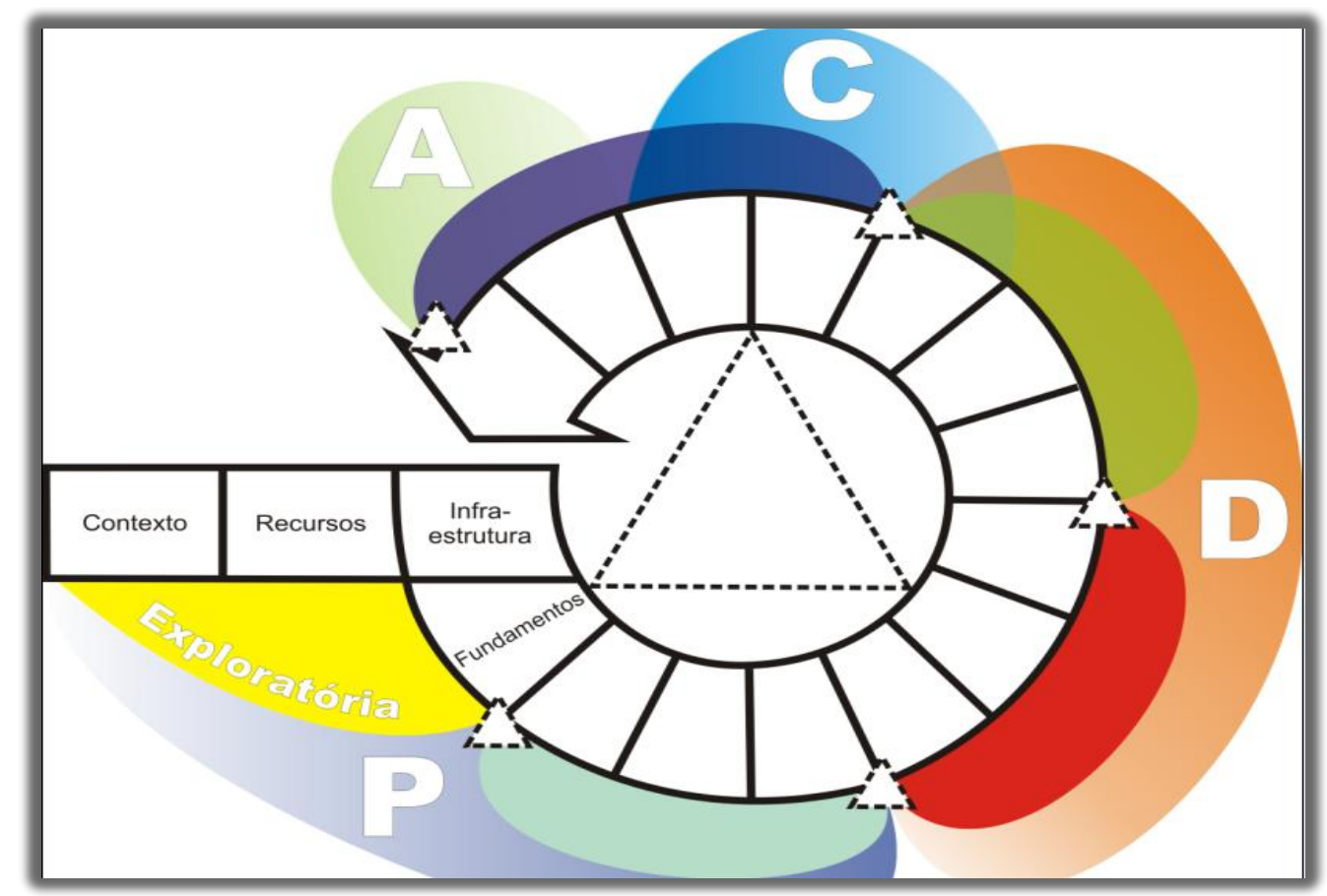

Figura 19 - Fase Exploratória da Arquitetura de Orientação

- Etapas:

\section{Contexto}

É o momento em que os condicionantes ambientais, organizacionais e comportamentais são analisados na perspectiva de que podem ter alguma influência no desenvolvimento do assessment na IES, curso e/ou disciplina investigada. Além disso, deve haver motivação para o desenvolvimento do assessment.

\section{Recursos}

São mapeados todos os recursos necessários para o desenvolvimento do assessment, principalmente os recursos de pessoal.

\section{Infraestrutura}

São levantadas as necessidades de equipamentos, materiais e pessoal. Sendo que estes podem ser distribuídos em equipes que assumirão as várias atividades ao longo da execução do assessment. 


\section{Elementos da Dimensão Fundamentos}

Neste momento, todos os elementos apresentados na Dimensão Fundamentos são elencados, definidos e preenchidos, considerando as necessidade e especificidades da IES, programa, curso ou disciplina avaliada.

Os elementos da dimensão Fundamentos são: missão e valores da instituição, objetivos e metas do curso ou programa de $\mathrm{EaD}$; definição do problema ou necessidade existente; consultas em fontes formais e informais; apresentação do gap entre o ideal e o real; lógica do assessment; objetivo do assessment; interessados no assessment (stakeholders); modelo lógico da avaliação (assessment); participantes do assessment; questões chave; modelo/abordagem de avaliação (assessment) utilizado; método de investigação; design do assessment; natureza do assessment; custo prévio do assessment e designação da equipe de avaliação.

Missão: é a razão de existir da organização. Deve responder o que a organização se propõe a fazer e para quem.

Visão: é a descrição do futuro desejado para a organização.

Estes dois elementos podem impactar o andamento do curso/programa de $\mathrm{EaD}$, haja vista a influência que os mesmos podem provocar nas ações e procedimentos existentes.

Objetivos e metas do curso/programa de EaD: identificação dos objetivos almejados pelo curso/programa como fio condutor de suas ações e procedimentos.

Além disso, tem-se: Lógica do assessment; Objetivos do assessment : definir para que a avaliação (assessment) será realizada; Interessados no assessment; Modelo lógico de assessment; Participantes do assessment: definição dos envolvidos no assessment; Questões chave do assessment; Modelo/abordagem de avaliação (assessment) utilizado: é a definição do modelo e teoria que permeiam o assessment, bem como a indicação de como os resultados serão utilizados; Método de investigação: é a definição e justificativa dos métodos e instrumentos utilizados para a coleta de dados; Natureza do assessment: com base no ciclo de vida do curso/programa de $\mathrm{EaD}$ é definido em que momento o assessment está sendo realizado, pois conforme o tempo em que está sendo realizado, poderá prover diferentes tipos de informações.

E, por fim, tem-se Custo prévio do assessment: mapeamento de todos os custos para realização do assessment (pessoal, equipamento, logística, etc).

O quadro 8 apresenta a relação de elementos da Fase Exploratória. 


\begin{tabular}{|l|l|}
\cline { 2 - 2 } \multicolumn{1}{l|}{} & \multicolumn{1}{|c|}{ Ele mentos } \\
\hline & Missão da instituição \\
\hline & Valores instituc iona is \\
\hline & Objetivos e metas do curso/programa \\
\hline & Definição do problema existente \\
\hline & Lógica do assessment \\
\hline & Objetivo do assessment \\
\hline & Interessados no assessment (stakeholders) \\
\hline & Modelo lógico da avaliação \\
\hline & Participantes do assessment \\
\hline & Questões chave para o assessment \\
\hline & Modelo/Abordagem de avaliação utilizado \\
\hline & Método de investigação \\
\hline & Natureza do assessment \\
\hline & Recursos disponíveis \\
\hline & Infraestrutura \\
\hline & Consulta a outras fontes/modelos existentes \\
\hline & Designação da equipe de a valiação \\
\hline
\end{tabular}

Quadro 8-Checklist dos Elementos da Fase Exploratória

- Ponto de Controle para a Fase Exploratória:

O ponto de controle tem como objetivo aferir determinadas ações/estratégias que contribuem para os procedimentos iniciais da confiabilidade e validade do assessment,

\section{Crité rio e Rigor Metodológico}

Estes quesitos estão atrelados à adequação entre o problema a ser investigado e a maneira de explicitá-lo, relatando sua opção metodológica e os procedimentos adotados para seu desenvolvimento. Enfim, deve-se ter uma visão crítica das diferentes estratégias metodológicas, bem como, condições de avaliar suas adequações ao(s) objetivo(s) do assessment. 


\section{Definição Clara do Conteúdo Abordado}

Todos os conceitos e definições utilizados no preenchimento dos elementos da dimensão Fundamentos devem ser claros para toda a equipe participante do assessment.

\section{Explicitação dos Objetivos}

A equipe deve ter muita clareza sobre os objetivos do assessment, bem como de suas questões-chave, tendo em vista que serão o fio condutor de todo o processo. Portanto, é de suma importância que os objetivos e as questões-chave sejam aferidos.

\section{Cons ulta a Diferentes Fontes de Informação}

O coordenador do assessment ou a equipe deve consultar diferentes modelos, fontes e outras bases de boas práticas, para o contexto em que se insere o assessment. Portanto, o benchmarking é muito útil nesta aferição.

O quadro 9 apresenta as ações/estratégias do ponto de controle para a Fase Exploratória.

\begin{tabular}{|l|l|}
\cline { 2 - 2 } \multicolumn{1}{c|}{} & \multicolumn{1}{c|}{ Ações e/ou Estratégias } \\
\hline & Rigor e critério metodológico \\
\hline & Definição clara do conteúdo abordado \\
\hline & Explicitação dos objetivos \\
\hline & Consulta a diferentes fontes de informação \\
\hline
\end{tabular}

Quadro 9 - Ponto de controle para a Fase Exploratória

A realização do Ponto de Controle assegura que estas ações/estratégias foram atendidas, o que contribuirá para uma maior garantia de robustez do Plano de Assessment. 


\subsubsection{FASE DIAGNÓSTICO}

Nesta fase, o resultado da fase anterior já propicia a visualização do escopo do assessment, restando ainda algumas informações para completar o plano. Para tanto, nesta se insere todos os elementos da dimensão evidências científicas (apresentado no roteiro da página 68), com as devidas aferições e recomendações cabíveis, ressaltando o ponto de controle.

As sessões apresentadas na sequência auxiliam na escolha/seleção de elementos que podem compor os instrumentos de assessment (avaliação), conforme objetivo do curso/programa de EaD.

\subsubsection{MÉTOdOS E INSTRUMENTOS DE COLETA DE DADOS}

Nesta etapa, um fator fundamental são as questões-chave da avaliação/pesquisa, pois certas questões podem conduzir para um tipo específico de métodos de coleta de dados. Desta forma, para cada questão deve se considerar quais os métodos de coleta de dados adequados para obter a informação necessária, considerando as escolhas anteriores (Figura 20).

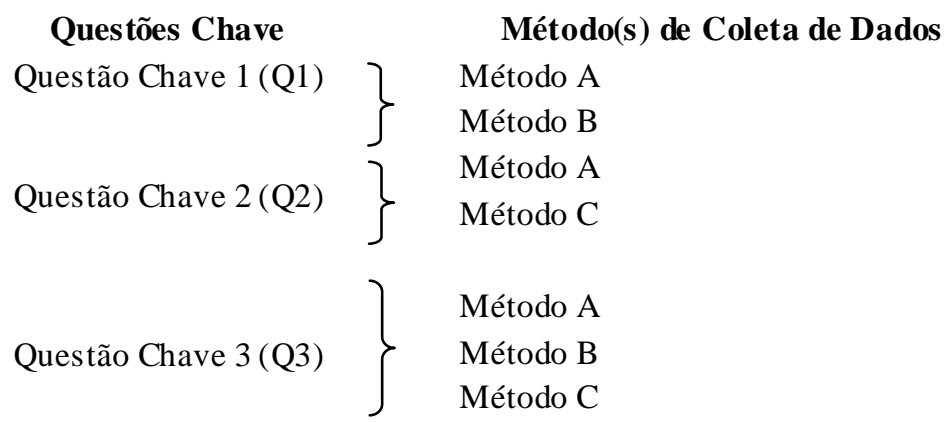

Figura 20 - Relação da questão chave com o método de coleta de dados

Logo, a elaboração de um instrumento de pesquisa (assessment) é um componente crucial no processo de avaliação, pois é nesta etapa que o avaliador/pesquisador esquematiza o instrumento de forma estruturada e sem viés.

Os métodos e as técnicas a serem empregados na pesquisa/avaliação podem ser selecionados desde a proposição do problema e da delimitação do universo ou da amostra.

Assim, deve-se selecionar o modelo de pesquisa apropriado e a amostra adequada (probabilística, não probabilística), de acordo com o enfoque escolhido (quantitativo, 
qualitativo ou misto) para coletar os dados pertinentes sobre as variáveis, acontecimentos, contextos, categorias, comunidades ou objetos envolvidos na avaliação/pesquisa. Sendo que a coleta de dados deve ser efetuada diretamente na fonte de informações, com o objeto de estudo, ou seja, com o indivíduo sobre o qual recaiu a amostragem.

Esta etapa, no processo de assessment/pesquisa pode ser extremamente trabalhosa e detalhada, pois de acordo com Sampieri, Collado e Lucio (2006), coletar os dados implica em ativid ades profundamente vinculadas entre si, tais como:

a) Selecionar um instrumento ou método de coleta dos dados entre os disponíveis na área do estudo, na qual está inserida a pesquisa. Este instrumento deve ser confiável e válido.

b) Aplicar esse instrumento ou método para coletar dados, isto é, obter observações, registros ou medições de variáveis, acontecimentos, contextos, categorias ou objetos que são de interesse para o estudo.

c) Preparar observações, registros e medições obtidas para que sejam analisadas corretamente.

No caso de enfoque qualitativo, os dados são coletados em duas etapas: durante a imersão inicial no campo ou contexto do estudo (mesmo que seja de forma inicial) e na coleta definitiva dos dados.

Ao selecionar ou desenvolver os métodos de coleta de dados, é importante determinar quais as informações necessárias já estão disponíveis ou já foram coletadas. Além disso, devese decidir se as informações adicionais podem ser facilmente reunidas ou se haveria necessidade de encontrar outros métodos de coleta de dados (RUSS-EFT; PRESKILL, 2001, 2009).

Esta fase é determinante para a validade, visto que reflete a extensão em que atinge a acurácia do instrumento ou método. Assim, ao realizar a escolha dentre os vários métodos existentes, deve-se considerar quão bem ele(s) é(são) capaz(es) de as segurar confiabilidade e validade.

Outro aspecto importante ao decidir pelo(s) método(s) é considerar a disponibilidade, acessibilidade, viabilidade e objetividade da informação a ser obtida. Além dessas características a informação deve ser atual, uma vez que ela subsidiará a tomada de decisão.

Embora existam diversas ferramentas para coleta de dados, é fundamental que a escolha seja adequada ao que se deseja obter como resultado. Nesse sentido, segue o detalhamento de alguns métodos e instrumentos, conforme abaixo. 


\section{Survey}

São ferramentas versáteis que reúnem informações sobre conhecimento, atitudes, crenças, comportamentos e características dos indivíduos. Surveys são realizadas por questionários, entrevista por telefone, internet, sendo esta última uma tecnologia recente que pode ter custo reduzido, entretanto, pode não ser representativa, pois tudo depende da amostra escolhida.

Surveys podem ser utilizadas tanto para avaliação formativa como somativa e saber quando utilizá- la ajuda na condução da investigação. Assim, Marynowski (2006), sugere que se deve usá-la para (a) reunir informações públicas ou de um grupo específico, (b) para reunir informações estatisticamente válidas que possam ser generalizadas para a população em que foi retirada a amostra e (c) coletar informações de pessoas chave para enriquecer o objeto de investigação.

Segundo a mesma autora, é importante observar também as condições que não favorecem surveys, tais como: (a) quando se tem um orçamento limitado para a realização da avaliação, (b) quando não é necessário obter uma amostra estatisticamente válida, o que favorece a utilização de outras ferramentas como entrevistas, observações, análise de conteúdo, (c) quando se necessita enriquecer as informações qualitativas sobre o objeto da avaliação e (d) quando se tem um tempo limitado para execução da investigação.

Além disso, Germuth (2010) da American Evaluation Association sugere um checklist que auxilia na construção de questões de survey mais confiáveis, tais como:

- A pergunta pode ser entendida de forma consistente?

- Será que a pergunta realizada proporciona uma boa resposta?

- Será que todos os participantes têm acesso às informações necessárias para responder a pergunta?

- É uma pergunta que todos os investigados estarão dispostos a responder?

- Aquestão pode ser sempre comunicada aos respondentes?

Independentemente do tipo de survey a ser realizado é fundamental que se evite vieses na pesquisa, de forma que as perguntas sejam claras e precisas, que seja realizado teste piloto ou pré-teste com alguns membros da população a ser investigada. Além dis so, deve-se atentar para as condições que ameaçam a validade.

\section{Entrevista}

É definida como uma conversa entre uma pessoa (o entrevistador) e outra 
(entrevistado), podendo ser também entre várias pessoas. É uma conversa que pode ser estruturada ou não estruturada, conduzida por uma pessoa (entrevistador), para o qual se exige habilidade ou treinamento para que sejam evitados vieses durante a coleta de dados.

As entrevistas enriquecem os dados qualitativos e Marynowski (2006) sugere que as mesmas sejam usadas para: (a) reunir informações que sejam significativas para a população em que a amostra representa; (b) reunir informações de grupos públicos ou específicos; (c) verificar o nível de conhecimento, entendimento ou aceitação de um programa ou assunto; (d) para clarear questões ou discrepância da coleta de dados, realizada por outras ferramentas; (e) para obter taxas de respostas mais elevadas do que em outras formas de avaliação e (f) para reunir informações de uma população espalhada geograficamente.

Ao preparar o instrumento de entrevis ta é importante observar que o mesmo é baseado no objetivo do assessment, identificando os conceitos chaves que subsidiarão a entrevista. Por natureza, pode utilizar perguntas fechadas e abertas, tendo em vista a codificação dos resultados. Além disso, caso trabalhe com entrevistadores voluntários é importante que os mesmos sejam capacitados, de forma que haja um mesmo padrão para as perguntas. $\mathrm{O}$ teste piloto ou pré-teste deve ser realizado com alguns integrantes da população.

Segundo Grinnell (1997) a entrevista pode ser classificada em estruturada, semiestruturada ou não-estruturada ou abertas. Em entrevistas estruturadas, o questionamento do entrevistador deve ser consistente para se obter resultados válidos. Já nas não estruturadas, as questões podem variar conforme o propósito do estudo. Entretanto, para qualquer um dos tipos, pode se utilizar diversas formas de questões:

- Questões gerais: partem de colocações globais para chegar ao assunto de interesse;

- Questões para exemplificar: servem como impulsos para explorações mais profundas;

- Questões de estrutura ou estruturais: o entrevistador solicita ao indivíduo uma lista de itens em forma de conjunto ou categorias.

- Questões de contraste: questiona-se o entrevistado sobre semelhanças e diferenças com relação a símbolos ou tópicos, e é solicitado que classifique símbolos em categorias;

O objetivo das entrevistas é obter respostas sobre o tema, problema ou tópico de interesse nos termos, a linguagem e a perspectiva do entrevistado ("em suas próprias palavras", portanto, o entrevistador deve ouvi-lo com atenção) (GRINNELL, 1997).

A entrevista é utilizada muitas vezes quando se tem necessidade de dados que não podem ser encontrados em registros e fontes documentárias e que podem ser fornecidos por certas pessoas. 
Cervo e Bervian (1983) e Ruiz (2006) sugerem alguns critérios para o preparo e a realização da entrevista:

- O entrevistador deve planejar a entrevista, delineando cuidadosamente o objetivo a ser alcançado.

- Obter, sempre que possível, algum conhecimento prévio acerca do entrevistado.

- Marcar com antecedência o local e o horário para a entrevista. Qualquer transtorno poderá comprometer os resultados da pesquisa.

- Criar condições, isto é, uma situação discreta para a entre vista.

- Escolher o entrevistado de acordo com a sua familiaridade ou autoridade em relação ao assunto escolhido.

- Fazer uma lista das questões, destacando as mais importantes.

- Assegurar o número suficiente de entrevistados, o que dependerá da viabilidade da informação a ser obtida.

- O entrevistador deve manter a confiança do entrevistado.

Mesmo seguindo tais critérios para a elaboração da entrevista, a mesma apresenta diversas vantagens e limitações, para as quais Marconi e Lakatos (1996) sintetizam:

Vantagens

- Pode ser utilizada com todos os segmentos da população.

- Há maior flexibilidade, podendo o entrevistador repetir ou esclarecer perguntas, formular de maneira diferente; especificar algum significado, como garantia de estar sendo compreendido.

- Oferece maior oportunidade para avaliar atitudes, conduta, podendo o entrevistador ser observado naquilo que diz e como diz: registro das reações, gestos, etc.

- Dá oportunidade para a obtenção de dados que não se encontram em fontes documentais e que sejam relevantes e significativos.

- Há possibilidade de conseguir informações mais precisas, podendo ser comprovadas, de imediato, as discordâncias.

- Permite que os dados sejam quantificados e submetidos a tratamento estatístico.

Limitações

- Dificuldade de expressão e comunicação de ambas as partes.

- Incompreensão, por parte do informante, do significado das perguntas, da pesquisa, que pode levar a uma falsa interpretação.

- Possibilidade de o entrevistador ser influenciado, consciente ou inconscientemente, pelo 
entrevistado, por suas atitudes, ideias, opiniões, etc.

- Disposição do entre vistador em dar as informações necessárias.

- Retenção de alguns dados importantes, receando que sua identidade seja revelada.

- Pequeno grau de controle sobre uma situação de coleta de dados.

- Ocupa muito tempo e é difícil de ser realizada.

Percebe-se que a entrevista além de registrar, também permite obter informações adicionais sobre o comportamento e atitude dos entrevistados.

Contudo, sempre que houver mais de uma pessoa para realizar a(s) entrevista(s) é imprescindível que haja treinamento, visto que este prevê orientação sobre o estudo, ou seja, os objetivos, o escopo, as intenções, além das questões chave da investigação. Com isso, o entrevistador poderá conduzir a(s) entrevista(s) de forma a minimizar os vieses e ampliar a possibilidade de bons resultados.

\section{Questionário}

Trata-se de um dos instrumentos mais utilizados para coletar dados e consiste em um conjunto de questões com relação a uma ou mais variáveis a serem medidas.

O conteúdo das questões de um questionário é tão variado como os aspectos que ele mede. Basicamente são consideradas em dois tipos: fechadas e abertas. As questões fechadas contêm categorias ou alternativas de respostas que foram delimitadas, isto é, são apresentadas as possibilidades de respostas aos indivíduos, os quais devem se limitar a estas. Podem ser dicotômicas ou incluir várias alternativas de respostas (SAMPIERI; COLLADO; LUCIO, 2006).

Nas questões fechadas, as categorias são definidas a priori pelo pesquisador/a valiador e são apresentadas ao respondente. As escalas de atitudes em forma de questão ficariam dentro da categoria de questões fechadas. Existem também questões fechadas nas quais os respondentes podem selecionar mais de uma opção ou categoria de resposta.

De acordo com Sampieri, Collado e Lucio (2006) cada questionário obedece a diferentes necessidades e problemas de pesquisa, o que faz que, em cada caso, o tipo de questão seja diferente. Algumas vezes estão incluídas apenas questões fechadas, outras, unicamente questões abertas e em certos casos ambos os tipos de questões. Cada tipo de questão tem suas vantagens e desvantagens, de forma que as questões fechadas são fáceis de codificar e analisar, além disso, são simples de responder e leva menos tempo completá-las. A principal desvantagem das questões fechadas é que limitam as respostas da a mostra, pois 
nenhuma das categorias descreve com exatidão os que as pessoas têm em mente. Para formular questões fechadas é necessário antecipar as possíveis alternativas de respostas, pois só assim é possível delineá-las. Além disso, é fundamental assegurar-se que os indivíduos, a quem serão aplicadas, conhecem e compreendem as categorias de respostas (SAMPIERI; COLLADO \& LUCIO, 2006).

As perguntas abertas são particularmente úteis quando não se tem informação sobre as possíveis respostas das pessoas ou quando essa informação é insuficiente. Também servem em situações em que se deseja aprofundar uma opinião ou os motivos de um comportamento. Sua maior desvantagem é que são mais difíceis de codificar, classificar e preparar para a análise.

Para Sampieri, Collado e Lucio (2006), independentemente de as questões serem abertas ou fechadas e de suas respostas estarem pré-codificadas ou não, há uma série de características que devem ser observadas, tais como:

- As questões devem ser claras e compreensivas para os indivíduos: devem ser evitados termos confusos ou ambíguos.

- As questões não devem incomodar o indivíduo: existem questões que precisam ser realizadas sutilmente, para que o indivíduo não se sinta incomodado.

- As questões devem ser de preferência, sobre um só aspecto ou uma só relação lógica.

- As questões não devem induzir as respostas: devem-se evitar questões tendenciosas ou que induzem a escolher um tipo de resposta.

- As questões não podem estar baseadas em instituições, ideias com respaldo social nem em evidência comprovada: também é uma maneira de induzir respostas.

- Nas questões com várias alternativas ou categorias de resposta e nas quais o indivíduo apenas deva escolher uma, acaba acontecendo que a ordem em que se apresentam essas alternativas, afeta as respostas dos indivíduos: é conveniente trocar a ordem de leitura das alternativas de maneira proporcional.

- A linguagem utilizada nas questões deve ser apropriada para as características do indivíduo: deve-se levar em conta o nível educacional e socioeconômico e o vocabulário do respondente.

Além dessas características, Fachin (2006) ressalta que ao elaborar um questionário é necessário ter princípios gerais e regras específicas de cada situação, o que obviamente não é tarefa fácil, assim, apresenta alguns lembretes:

- Incluir apenas questões comprovadamente essenciais, as quais devem ser ordenadas de 
forma a conduzir as respostas desde as mais simples às mais complexas;

- Evitar sistematicamente questões que não servem para a identificação do pesquisado, nem para o esclarecimento de qualquer pormenor fundamental, nem para a apuração;

- Não incluir perguntas cujas respostas serão inevitavelmente inexatas. As questões devem ser bem estruturadas;

- As questões devem ser neutras;

- Não incluir questões de juízo de valor como no caso de emprego de alguns termos, como bom, perfeito, ruim, etc.;

- Formular questões de modo que elas produzam, efetivamente, a informação desejada; o vocabulário empregado nas questões tem grande influência sobre o conteúdo das respostas;

- Incluir questões de controle, a fim de possibilitar a comprovação e a veracidade das informações, antes de sua aplicação. O questionário deve ser submetido a provas quanto à sua validade e confiabilidade.

De acordo com Hill e Hill (1998), para escrever um bom questionário é fundamental especificar em detalhe os objetivos da investigação, as hipóteses (se houverem), as escalas de resposta das perguntas do questionário e os métodos para análise dos dados.

Ao construir um "bom" questionário é importante que seja criterioso, bem como atento a todas as etapas de sua construção, de forma a assegurar um instrumento robusto e consistente. Para isso, dois esquemas sobre as etapas de construção de um questionário são apresentados, ilustrativamente, conforme figuras 21 e 22. 


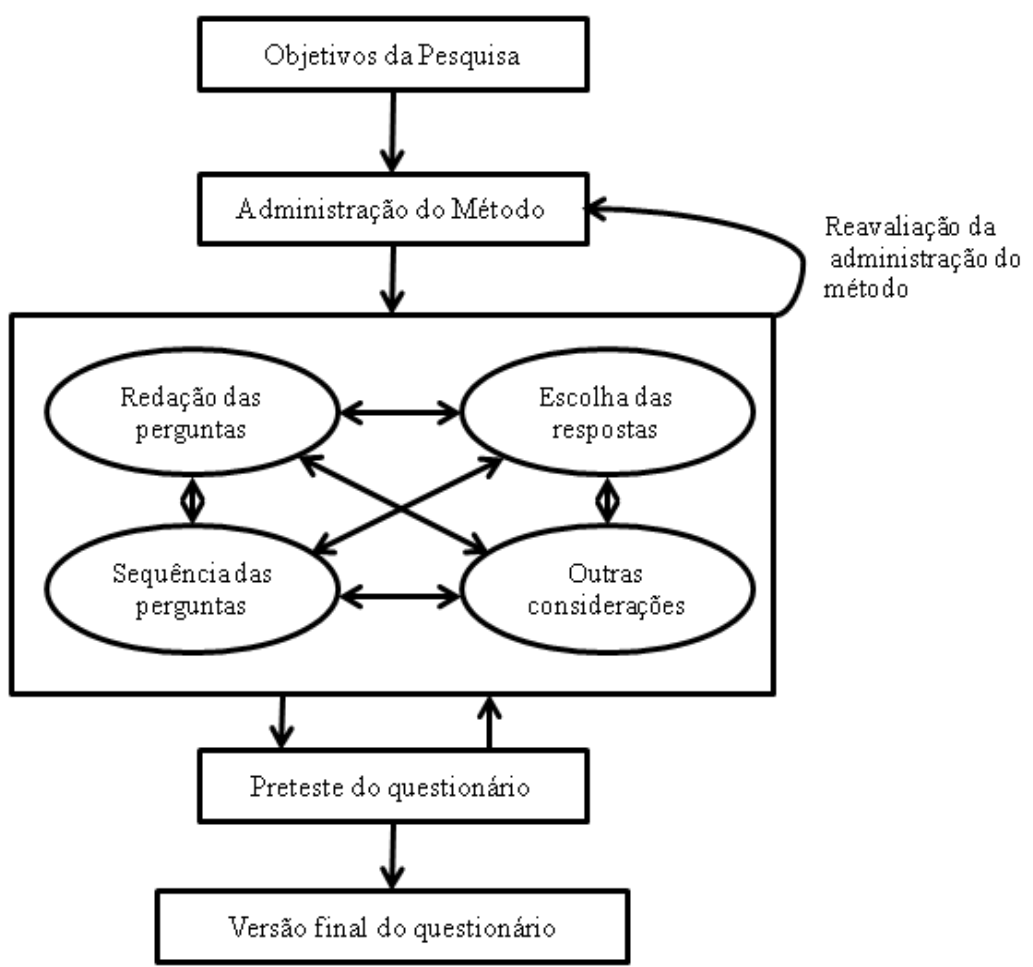

Figura 21 - Etapas da construção de um questionário, adaptado de Synodinos (2003)

O autor sugere um esquema de etapas para administração de questionários, apresenta as inter-relações e os aspectos de retroalimentação.

Por meio da figura 22 é possível observar um detalhamento maior das etapas de um questionário, mostrando que a elaboração um "bom" questionário não é tarefa fácil, entretanto, possibilita resultados confiáveis e válidos para a investigação. 


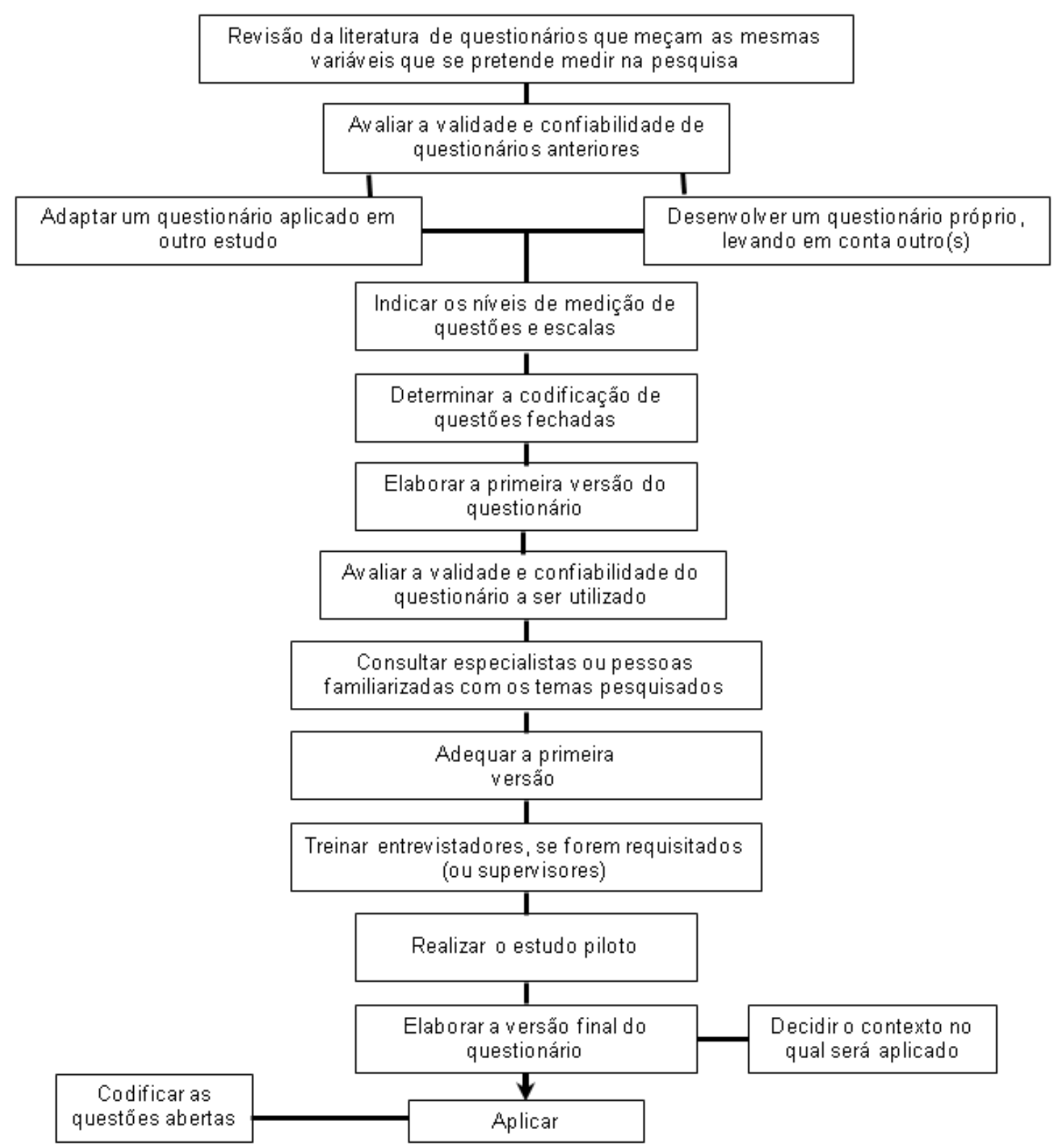

Figura 22 - Etapas da construção de um questionário

Fonte: Adaptado de Sampieri, Collado e Lucio (2006).

Diante do exposto, verifica-se que o questionário é um arranjo de questões que seguem uma ordem rigorosamente estudada, tanto no que diz respeito à ordem geral das perguntas como ao número delas. Este instrumento é amplamente utilizado em situações de pesquisa e avaliação.

\section{Brainstorming}

É uma técnica utilizada individualmente ou em grupo para capturar e generalizar um 
grande número de ideias, sendo possível encontrar grandes chances de soluções criativas e viáveis. Esta abordagem pode ser usada para gerar ideias originais e criativas para melhoria ou novo desenvolvimento de um produto ou programa, para gerar soluções alternativas para problemas difíceis, encontrar novos caminhos para melhoria de processos e gerar colaboração e discussão entre os membros da equipe.

Segundo Marynowski (2006) esta técnica deve ser evitada quando o julgamento de um expert é essencial para a tomada de decisão, pois nestes casos a brainstorming pode produzir soluções inferiores as do expert, quando há pressão para tomar uma decisão, quando o grupo precisa construir consenso e finalmente quando não tem mente aberta para novas ideias.

A técnica brainstorming pode começar com apenas uma sentença do problema ou algo mais estruturado, procurando desenvolver ideias/soluções para uma série de questões, cabendo ao facilitador o encorajamento da equipe. Trabalhar com pequenos grupos facilita a geração de boas ideias ou soluções para vários fatos que são importantes para o sucesso do programa.

\section{Focus Group}

Este método de coleta de dados, cuja popularidade tem crescido, são os grupos de discussão (ou grupo focal), o qual consiste em reuniões em que os participantes conversam sobre um ou vários assuntos, sob a coordenação de um especialista em dinâmicas de grupo.

Esta técnica fornece oportunidade para que os participantes compartilhem informações e discutam as diferentes visões e perspectivas de um programa ou assunto, pode ocorrer com pessoas internas ou externas ao objeto de estudo. Além disso, é de fácil aplicação e custo moderado (MARYNOWSKI, 2006).

O focus group é a uma boa técnica para avaliar as necessidades, atitudes e motivações de um grupo, uma vez que o entrevistador ou (equipe entrevistadora) interage diretamente com os respondentes e isso pode resultar em novos insights sobre as questões apresentadas pelo grupo, auxiliando no entendimento dos fatos que afetam os indivíduos e o objeto de estudo como um todo (RUSS-EFT; PRESKILL, 2001).

Nesse sentido, esta técnica é recomendada: (a) quando se deseja entrevistar simultaneamente um grupo de pessoas, o que assegura ganho de tempo e recursos, tendo em vista as discussões interativas, (b) para encorajar o diálogo interativo e gerar novas ideias sobre o problema ou assunto em estudo, (c) para estabelecer a ordem dos diferentes valores ou perspectivas dentro de uma comunidade sobre um determinado assunto visto pelos diferentes grupos e (d) ter oportunidade de fornecer informações e apontar questões-chaves para os 
participantes.

Embora apresente várias situações em que a técnica é apropriada, existem também circunstâncias em que não se deve usar, tais como: quando se necessita de uma amostra representativa da população; quando se tem um grupo que aprecia interações um-a-um e quando os problemas tratados são totalmente controversos para o grupo.

Ao utilizar focus group observe os propósitos do assessment, a identificação dos conceitos chaves para ser trabalhada na técnica, a definição do grupo de participantes bem como os critérios para a seleção. Normalmente tem duração de uma ou duas horas. Assim, para aumentar sua eficácia, pode se realizar diversas sessões, conforme necessidade.

Sampieri, Collado e Lucio (2006), apresentam algumas etapas para a realização de uma sessão de grupo:

- Determinar o número de grupos e sessões que deverão ser realizadas (reduzido ou ampliado de acordo com o desenvolvimento do estudo).

- Definir o perfil das pessoas que irão participar da(s) sessão(ões). O perfil pode ser modificado caso a pesquisa requeira.

- Detectar pessoas com o perfil escolhido.

- Convidar essas pessoas para participar.

- Organizar a(s) sessão(ões).

- Realizar cada sessão. O mediador deve ser capacitado para dirigir ou conduzir grupos, e deve criar um clima de confiança entre os participantes. Uma característica necessária é a paciência. O mediador deve ter muito claro a informação ou os dados que deverão ser coletados.

- Elaborar relatório da sessão.

$\mathrm{Na}$ técnica de focus group ou grupo focal o objeto de análise é a interação dentro grupo, a qual é estimulada por comentários ou questões fornecidas pelo moderador. As informações fundamentais produzidas por essa técnica são transcritas das discussões do grupo, acrescidas das anotações e reflexões do moderador e de outros observadores.

O uso do focus group é particularmente apropriado quando o objetivo é explicar como as pessoas consideram uma experiência, uma ideia ou um evento, visto que a discussão durante as reuniões é efetiva em fornecer informações sobre o que as pessoas pensam ou sentem, ou, ainda, sobre a forma como agem. 


\section{Sociometria}

É uma técnica quantitativa que procura explicar as relações pessoais entre indivíduos de um grupo. Revela a estrutura interna dos grupos, indicando as posições de cada indivíduo em relação aos demais. Permite analisar os grupos, identificar seus líderes, os subgrupos e os isolados (ANDER-EGG, 1978). Pode ser classificada em três pontos de referência: socius - o companheriro; metrum - a medida; e drama - a ação; resultando em três áreas de investigação: o grupo, a medida e a ação no campo social.

Para Xavier (1990) a sociometria é um recurso exploratório extremamente útil para estudar as estruturas sociais em um dado momento, à luz das atrações, repulsas e sentimentos manifestados no interior do grupo.

Em sua execução, o pesquisador/avaliador, por votação, tenta descobrir as atrações, indiferenças ou repulsas intergrupais, pedindo aos indivíduos que escolham três colegas, por ordem de preferência, com quem gostariam de trabalhar (ou outra ação). Posteriormente, após ter as respostas, os resultados são apresentados graficamente por meio de um diagrama denominado sociograma. O seu objetivo é dar não só uma visão rápida das relações entre os indivíduos, mas também verificar a posição de cada um no grupo.

Contudo, Alves (1964) relata que os sociogramas podem ser provenientes de dois tipos de teste: (a) do teste de projeção sociométrica - que fornece a imagem do indivíduo para o grupo e do grupo para o indivíduo; e (b) do teste de percepção sociométrica - que fornece a forma pela qual o próprio indivíduo se percebe e sente que é percebido pelo grupo. Com isso, esta técnica busca observar, descrever e medir as relações grupais.

De acordo Ander-Egg (1978), existem alguns problemas/limitações na utilização do sociograma: (a) depende da boa vontade das pessoas; (b) existe medo em saber qual será a sua posição no grupo e o receio de que descubram suas preferências ou repulsas; (c) a aplicação da técnica sociograma necessita de aceitação e compreensão do grupo; (d) ter duração passageira, pois se baseia na suposta estabilidade das relações no interior do grupo; e (e) pode criar um ambiente prejudicial ao grupo, em face dos resultados positivos ou negativos das escolhas.

Diante do exposto, percebe-se que a sociometria é uma técnica que pode ser utilizada na identificação de estruturas informais dos grupos, bem como na socialização de seus interesses.

\section{Observação}

A observação é uma técnica de coleta de dados que para obter informações, utiliza os 
sentidos na captação de determinados aspectos da realidade, não consiste apenas em ver e ouvir, mas também em examinar fatos ou fenômenos que se deseja investigar.

O método de coleta de dados denominado observação é particularmente útil, e segundo Russ-Eft e Preskill (2001) auxilia:

- Entender o nível de conhecimento de um aprendiz ou de um grupo, antes da intervenção na aprendizagem.

- Entender como e quando os participantes estão transferindo sua aprendizagem.

- Entender como a iniciativa de mudança está sendo implementada.

Além disso, também pode ser denominada observação de campo, observação direta ou observação participante ou não participante, implicando em conhecer a fundo as situações, mantendo-se muito atento aos detalhes dos fatos, eventos e interesse.

A condução desse método implica em observar o sujeito estudado em situações normais do dia-a-dia, documentando suas atividades e interações em detalhes. A relevância do método de observação é que ele envolve todos os sentidos humanos, não apenas a visão, ele permite perceber toda a experiência adquirida por meio dos sentidos, tais como: cheiro, visão, audição, sabor e toque. E, ao contrário de outros métodos de coleta de dados, a observação fornece uma compreensão mais holística do fenômeno em estudo.

Segundo Sampieri, Collado e Lucio (2006), os objetivos do método de observação são: (a) explorar ambientes, contextos, subculturas e a maioria dos aspectos da vida social (GRINNELL, 1997); (b) descrever comunidades, contextos ou ambientes, e as atividades que se desenvolvem neles, as pessoas que participam em tais atividades e os significados das atividades; (c) compreender processos, inter-relações entre pessoas e suas situações ou circunstâncias, e eventos que ocorrem com o tempo, assim como os padrões que são desenvolvidos e os contextos sociais e culturais em que acontecem as experiências humanas; (d) identificar problemas; e (e) gerar hipóteses para estudos futuros.

É necessário manter registros e fazer anotações de cada situação observada, além disso, é conveniente tirar fotos, registrar em vídeo ou áudio, elaborar mapas e esquemas sobre os contextos observados. De acordo com Grinnell (1997) as anotações podem ser de diferentes tipos, tais como: (a) anotações da observação direta - é a descrição de tudo que está sendo observado; (b) anotações interpretativas - percepções do observador; (c) anotações temáticas - observações categorizadas, com conclusões preliminares; e (d) anotações pessoais - do observador.

Entretanto, mesmo seguindo os passos para a realização de uma boa observação, sua qualidade está muito ligada à habilidade do observador de anotar e descrever precisamente e 
detalhadamente o que observou, de forma a proporcionar confiabilidade e validade aos dados da observação.

Todos os métodos de coleta de dados têm seus pontos fortes e suas limitações, assim, a escolha implica em avaliar as vantagens e desvantagens de cada um. Nesse sentido, Russ-Eft e Preskill (2001) apresentam como vantagens do método observação:

a) facilmente coletado;

b) permite desenvolver modelo e teorias;

c) destaca as discrepâncias entre os fatos e a ficção;

d) amplia o entendimento sobre o contexto do fenômeno observado;

e) permite ao observador identificar coisas que podem escapar na rotina dos participantes; e,

f) complementa outros métodos de coleta de dados.

E como desvantagens citam-se:

a) ameaças à validade;

b) ameaças à confiabilidade;

c) treinamento do observador; e,

d) custo da observação como método de coleta de dados.

O método de observação pode prover importantes informações para responder questões específicas de muitos tipos de avaliação. Assim, Russ-Eft e Preskill (2009) apresentam um guia para conduzir a observação:

- Determinar quais os comportamentos que serão observados.

- Determinar quais os aspectos do ambiente serão observados.

- Determinar quantas observações serão realizadas.

- Determinar o tamanho de cada observação.

- Determinar a locação da observação.

- Preparar as formas de relatórios das observações.

- Pedir e pegar todas as permissões necessárias para conduzir as observações.

- Treinar os observadores.

- Definir o que será dito antecipadamente para os observados, e o que será observado.

- Conduzir as observações.

- Analisar os dados.

- Integrar com outros dados da a valiação.

$\mathrm{Na}$ investigação científica são empregadas várias modalidades de observação, que variam de acordo com as circunstâncias. Assim, Ander-Egg (1978) apresenta quatro tipos: 
1. Segundo os meios utilizados:

a. Observação não estruturada (assistemática): não tem planejamento e controle previamente elaborados.

b. Observação estruturada (sistemática): tem planejamento, realiza-se em condições controladas para responder aos propósitos preestabelecidos.

2. Segundo a participação do observador:

a. Observação não-participante: o pesquisador presencia o fato, mas não participa.

b. Observação participante.

3. Segundo o número de observações:

a. Observação individual: realizada por um pesquisador.

b. Observação em equipe: feita por um grupo de pessoas.

4. Segundo o lugar onde se realiza:

a. Observação efetuada na vida real: registro de dados à medida que ocorrem.

b. Observação efetuada em laboratório: onde tudo é controlado.

Adotando tais procedimentos, ampliam-se as possibilidades de se obter resultados passíveis de serem validados e confiáveis.

\section{Dados arquivados - Relatórios, Documentos e Base de Dados}

Os dados arquivados podem trazer diversas informações, as quais são obtidas de relatórios e registros da organização, entretanto, muitas dessas informações podem ser provadas ou confidenciais. Dessa forma, antes de iniciar o processo de coleta de dados, tenha a aprovação necessária.

Segundo Russ-Eft e Preskill (2001) os relatórios tipicamente, fornecem informações quantitativas a respeito de um fenômeno avaliado, já os documentos proveem informações mais qualitativas e descritivas, mas pode também incluir dados quantitativos.

Além desses, existem também as bases de dados organizacionais, as quais podem conter os relatórios e documentos acima mencionados, sobretudo dados relacionados ao local, estado ou federação e, de acordo com Russ-Eft e Preskill (2009), estes incluem:

- Dados estatísticos

- Dados de censo

- Estatísticas educacionais

- Estatísticas trabalhistas

- Dados estatísticos relacionados à saúde 
- Websites de outras organizações

Como se observa, as bases de dados podem prover uma rica informação, que, entretanto, necessitam ser preparadas para examinar qual a informação está disponível, como está organizada e a sua precisão, bem como sua atualização.

Assim, para conduzir este processo de coleta de dados em relatórios, documentos e bases de dados, Russ-Eft e Preskill (2009) apresentam um guia:

- Determinar quais relatórios e documentos ajudarão a responder as questões da a valiação.

- Verificar se há necessidade de permissão para averiguação de algum documento e/ou relatório.

- Obter as permis sões necessárias.

- Desenvolver uma forma de coleta de dados.

- Revisar documentos - observar se há discrepância ou falta de alguma informação.

- Se possível, ter a revisão de uma segunda pessoa nos documentos, como forma de assegurar os resultados.

- Determinar em que medida os documentos, relatórios e base de dados são precisos. Considerar a extensão em que os documentos podem refletir uma agenda política particular e com isso impedir a credibilidade dos dados derivados do mesmo. Assim, ao revisar documentos, é importante restringir-se na análise do que está na página, pois nem sempre se conhece as intenções do autor.

- Observar que as amostras descritas no documento podem não ser representativas para todos os participantes.

Este método de coleta de dados, assim como os outros, tem suas vantagens e desvantagens que de acordo com Russ-Eft e Preskill (2001), são:

\section{Vantagens}

a) As informações são facilmente coletadas.

b) Podem prover dados quantitativos.

c) Podem fornecer um contexto histórico do objeto em estudo/avaliação.

d) Os documentos podem reduzir custos se os dados são facilmente coletados e estão centralizados em uma mes ma localização.

e) Podem extrair informações que não foram coletadas em entrevistas ou survey.

f) Aumenta a percepção da credibilidade dos dados.

g) Fornece a cronologia dos eventos.

h) Representa medidas discretas. 
i) Requer treinamento mínimo sobre como coletar os dados.

j) Permite a criação de novas variáveis e escalas.

\section{Desvantagens}

a) Dados inacessíveis.

b) Limitações nos retornos - relatórios e documentos podem representar somente alguma lembrança do evento e assim pode não ser preciso/seguro.

c) Pode-se encontrar documentos e relatórios incompletos.

d) Consumo de tempo - se houver muitos documentos para serem revisados, a tarefa pode ser tediosa e com custo elevando, em termos de tempo.

e) Necessidade de análise de dados sofisticada - algumas bases de dados são extremamente complexas e requerem pessoal qualificado para manipular e analisar seus dados.

f) A qualidade da redação dos documentos e relatórios pode variar, podendo não ser completamente legívele inteligível.

g) Amostras limitadas - é difícil saber o grau em que os relatórios e documentos representam tudo que existe ou que foram escritos; algum pode ter sido descartado, destruído ou não estar acessível.

h) Alguns relatórios e documentos podem ser imprecisos.

i) Amostra não representativa - a amostra descrita no documento pode não ser representativa para todos participantes.

j) Definição de termos e variáveis pode ter variação ao longo do tempo.

k) Os dados disponíveis são coletados para certa razão, e eles podem não ajudar a responder as questões chave da avaliação.

Todavia, a escolha do método requer esclarecimento acerca de suas vantagens e desvantagens, devendo estar em consonância com os objetivos propostos para a avaliação/pesquisa e os resultados esperados. Além disso, deve possibilitar respostas para as questões-chave da investigação, bem como sinalizar diagnóstico sobre as expectativas e percepções dos investigados.

Conforme verificado, existe uma variedade de métodos e instrumentos para coleta de dados. Assim, o quadro 10 sintetiza alguns métodos e resume os já apresentados. 


\begin{tabular}{|c|c|}
\hline Método de Coleta de Dados & Características Gerais \\
\hline $\begin{array}{l}\text { Documentos e relatórios arquivados } \\
\qquad \text { e disponíveis }\end{array}$ & $\begin{array}{l}\text { Nada de novo é introduzido no sistema de coleta de dados. A avaliação é } \\
\text { baseada inteiramente nos dados existentes. Eles podem ser selecionados, } \\
\text { combinados e analisados em u ma nova perspectiva. }\end{array}$ \\
\hline $\begin{array}{l}\text { Documentos e relatórios modificados } \\
\text { e arquivados }\end{array}$ & $\begin{array}{l}\text { O sistema corrente pode ser expandido para fornecer dados adicionais. A } \\
\text { avaliação é baseada em dados dis poníveis neste sistema expandido. }\end{array}$ \\
\hline Observação em situação natural & $\begin{array}{l}\text { A avaliação é baseada em descrições detalhadas do comportamento no } \\
\text { dia-a-dia que não podem ser fornecidas por relatórios arquivados. }\end{array}$ \\
\hline $\begin{array}{l}\text { Observação em situação artificial ou } \\
\text { simu lada }\end{array}$ & $\begin{array}{l}\text { Estímu lo especial ou situações são introduzidos e um observador não- } \\
\text { participante anota as reações ou comportamentos do respondente. Uma } \\
\text { avaliação dos me mbros da equipe reúne os dados. }\end{array}$ \\
\hline Survey e/ou Questionários & $\begin{array}{l}\text { Instrumentos especiais são desenvolvidos para os respondentes } \\
\text { completá-los. A avaliação é baseada nos dados gerados por este } \\
\text { instrumento. }\end{array}$ \\
\hline Testes baseados em computador & $\begin{array}{l}\text { São testes comercialmente produzidos ou especialmente desenvolvidos } \\
\text { para avaliar o conhecimento ou habilidades. A avaliação é baseada nos } \\
\text { dados gerados por estes exames. }\end{array}$ \\
\hline Entrevistas individuais & $\begin{array}{l}\text { Guias de entrevistas são desenvolvidos e conduzidos por um } \\
\text { entrevistador habilitado. A avaliação é baseada nos dados gerados por } \\
\text { esta interação. }\end{array}$ \\
\hline Foct & $\begin{array}{l}\text { Explora um tópico em profundidade por meio de debates (exemplos: } \\
\text { reações, experiências, sugestão, compreensão ou reclamação). } \\
\text { Proporciona impressões rápidas e confiáveis, além de transmitir } \\
\text { informações chaves do objeto investigado. }\end{array}$ \\
\hline Revisão de documentos & $\begin{array}{l}\text { Quando se deseja saber como um programa funciona sem ter que } \\
\text { interrompê-lo, realizando análise dos pedidos, finanças, memorandos, } \\
\text { etc. Este procedimento possibilita uma informação compreensiva e } \\
\text { histórica, semvieses. }\end{array}$ \\
\hline Braintorming & $\begin{array}{l}\text { Técnica utilizada individualmente ou em grupo para um grande número } \\
\text { de ideias - "Tempestade de ideias". }\end{array}$ \\
\hline Sociometria & $\begin{array}{l}\text { Recurso utilizado para estudar as estruturas sociais em um dado } \\
\text { mo mento, à luz das atrações, repulsas e sentimentos manifestados no } \\
\text { grupo. }\end{array}$ \\
\hline
\end{tabular}

Quadro 10 - Síntese de alguns métodos de coleta de dados, adaptado de Russ-Eft; Preskill (2001) e McNamara (2008) 


\subsubsection{Pré-teste ou teste piloto}

Após a preparação do instrumento, visando assegurar os objetivos e metas do estudo, é importante efetuar um teste prévio do referido instrumento em condições reais da pesquisa. Assim, o pré-teste ou teste piloto é a testagem antecipada de um instrumento de pesquisa, com o objetivo de simular a aplicação definitiva.

Nesse sentido, é relevante aplicar o instrumento em uma amostra com perfil semelhante ao grupo a ser pesquisado, a fim de evidenciar possíveis dificuldades e ambiguidades no instrumento.

A aplicação do pré-teste ou teste piloto possibilita avaliar fatores críticos, conforme apontados por Rea e Parker (2002):

- Clareza do instrumento: pode-se constatar pequenas ambiguidades. As opções de resposta são claras o suficiente para extrair as informações desejadas?

- Abrangência do instrumento: as perguntas e opções de resposta são abrangentes o suficiente para cobrir uma gama razoavelmente completa de alternativas? Pode-se constatar perguntas irrelevantes, incompletas ou redundantes que não geram informações importantes para o estudo.

- Aceitabilidade do instrumento: problemas em potencial como extensão excessiva do instrumento, bem como perguntas invasivas à privacidade dos entrevistados, assim como as que podem resumir padrões éticos ou morais, devem ser identificadas e corrigidas pelos avaliadores/pesquisadores.

Nesse momento, o avaliador/pesquisador não está interessado na precisão estatística do instrumento, mas sim nas informações referentes à qualidade geral do instrumento.

\subsubsection{DESIGN DAAVALIAÇÃO}

O design indica elementos importantes no processo de avaliação, linkando uns aos outros de modo a trabalharem juntos de maneira estruturada. Existe uma variedade, entretanto, é importante encontrar dentre os diferentes tipos o mais apropriado para o assessment que se pretende realizar, tendo em vista o tempo e os recursos disponíveis. Logo, seu propósito é identificar relações de causa-e-efeito e descobrir as leis que conduzem estas relações, tendo em vista que esses fatores influenciam as questões chave da avaliação, o design, bem como a escolha dos métodos de coleta de dados.

De acordo com o Meera (2009) da University of Michigan e Russ-Eft e Preskill 
(2009), os tipos de design podem ser:

1) Pós-teste apenas.

2) Pré-teste retrospectivo e pós-teste.

3) Pré e pós-teste.

4) Pré e pós-teste com comparação entre grupos.

5) Pré e pós-teste com acompanhamento.

6) Testes intermediários e pós-testes.

7) Regressão-Descontinuidade.

8) "Solomon" em quatro grupos.

9) Estudo de caso.

10) Mix métodos.

1) Pós-teste apenas: quando o teste é aplicado no final do programa.

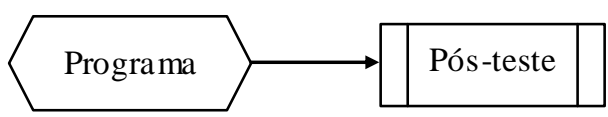

Figura 23 - Design pós-teste apenas

\section{Vantagens:}

- Este tipo de design da avaliação é útil quando o tempo é escasso ou os participantes não estão disponíveis antes de iniciar o programa.

- Simples e de baixo custo.

- Reduz o tempo de coleta e análise de dados.

- Produzem dados que podem ser analisados de forma oportuna e rentável.

\section{Desvantagens:}

- Os dados são coletados apenas uma vez.

- Porque não há nenhum pré-teste ou grupo de comparação, é difícil determinar a magnitude dos resultados (exemplo: mensurar o aumento do conhecimento em relação ao que os participaram tinham antes); e se os resultados se devem ao programa ou a outras causas.

- Os resultados não podem ser necessariamente generalizados para outras populações.

- Assumem que reações positivas e testes de conhecimentos conduzem à mudança de comportamento. 
2) Pré-teste retrospectivo e pós-teste: Os dados são coletados no final do programa. Os participantes são convidados a avaliar o seu nível atual de conhecimento / atitudes / habilidades / intenções depois de experenciar o programa e para refletir seu nível anterior de conhecimento / atitudes / habilidades / intenções antes do programa de avaliação.

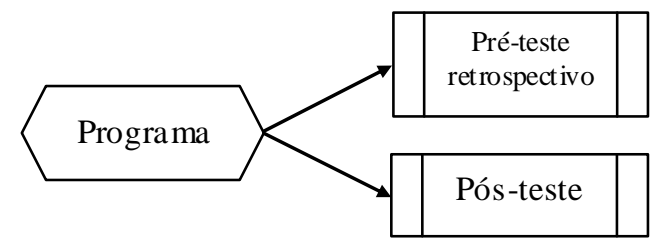

Figura 24 - Design pré-teste retrospectivo e pós-teste

\section{Vantagem:}

- Útil quando a realização de um pré-teste é impossível.

- É simples e de baixo custo.

- Compara os dados do pós-teste com os dados do pré-teste retrospectivo.

\section{Desvantagem:}

- Alguns podem sentir dificuldade para lembrar como pensavam e/ou comportaram antes da realização do programa de avaliação.

3) Pré e pós-teste: o mesmo instrumento é utilizado para a coleta de dados antes do programa iniciar e repetido após o seu término.

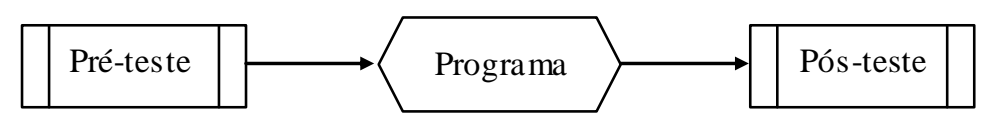

Figura 25 - Design pré e pós-teste

\section{Vantagens:}

- Relativamente simples de implementar.

- Controle do conhecimento / atitudes / habilidades / intenções dos participantes antes da realização do programa de avaliação.

- Fornece melhores evidências de efetividade do programa se comparado com programas anteriores. 
Desvantagens:

- Não se podem considerar as influências do não-resposta nos resultados.

- Se o autorelato é usado em vez de medidas objetivas, a pontuação do pós-teste pode ser inferior a do pré-teste. Isso ocorre quando os participantes superestimam seus conhecimentos, atitudes e/ou habilidades em um pré-teste, entretanto, precisam avaliar os mesmos atributos no pós-teste.

4) Pré e pós-teste com comparação entre grupos: os dados são coletados em dois grupos antes do início do programa. Um dos grupos participa do programa e o outro não. Ao término do programa, os dados são novamente coletados nos dois grupos.

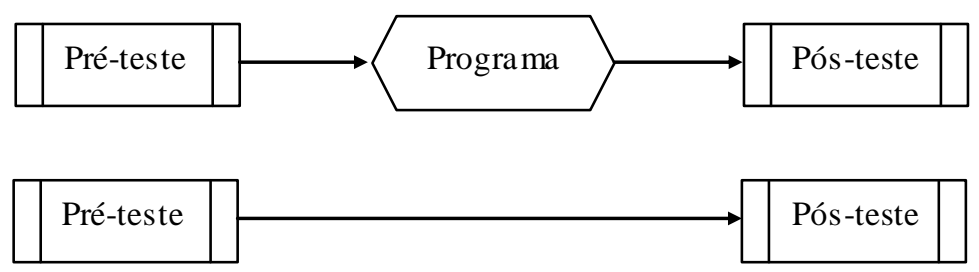

Figura 26 - Design pré e pós-teste com comparação entre grupos

Vantagens:

- Fornece a garantia de que os resultados são atualmente os resultados do programa.

- Permite uma avaliação mais precisa sobre os efeitos do programa.

Desvantagens:

- Pode demandar mais tempo e recursos.

- Requer acesso ao menos a dois grupos similares.

5) Pré e pós-teste com comparação e com acompanhamento: os dados são coletados antes de o programa iniciar, no seu término e em algum momento no futuro.

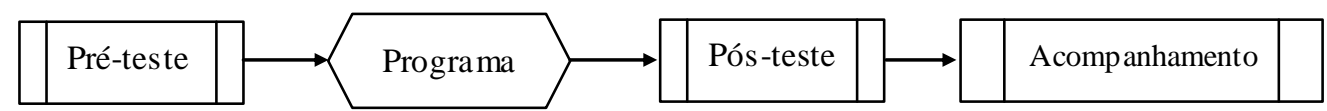

Figura 27 - Design pré e pós-teste com comparação e com acompanhamento

\section{Vantagens:}

- Permite verificar se o programa de avaliação terá resultados duradouros. 
- Pode fornecer informações valiosas sobre os impactos do programa a longo prazo.

Desvantagens:

- Contatar e monitorar os participantes exige tempo e recursos.

- Não se podem considerar as influências do não-resposta a menos que um grupo de comparação seja também monitorado.

6) Testes intermediários e pós-teste: os testes são aplicados em diferentes momentos $\left(\mathrm{t}_{1}, \mathrm{t}_{2}\right.$, $t_{n}$ ) e ao término do programa.

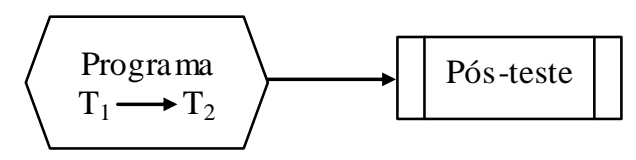

Figura 28 - Design testes intermediários e pós-teste

\section{Vantagem:}

- Permite que haja um acompanhamento do progresso do participante, verificando seu andamento ao longo do programa de avaliação.

- Fornece informações diversas ao longo do tempo.

\section{Desvantagens:}

- Mais adequado para programas.

- Não se podem considerar as influências do não-resposta.

- Requer mais recursos devido às repetidas coletas de dados.

- Podem ocorrer mudanças nos resultados, tendo em vista os efeitos dos testes ou instrumentos nas repetidas coletas de dados.

7. Regressão-Descontinuidade: assim como o pré e pós-teste, este design requer dois grupos, um que recebe treinamento ou intervenção e outro que não recebe. A diferenciação está no processo, visto que os indivíduos são a valiados baseados nos resultados obtidos no pré-teste. Os demais participantes são alocados no grupo controle.

Tanto o pré como o pós-teste exigem continuidade e análise quantitativa, utilizando técnica estatística conhecida como regressão. Os resultados são apresentados por meio de gráfico de dispersão, utilizando os escores do pré e pós-teste. Assim, utiliza-se a linha da 
regressão para comparar os dois grupos.

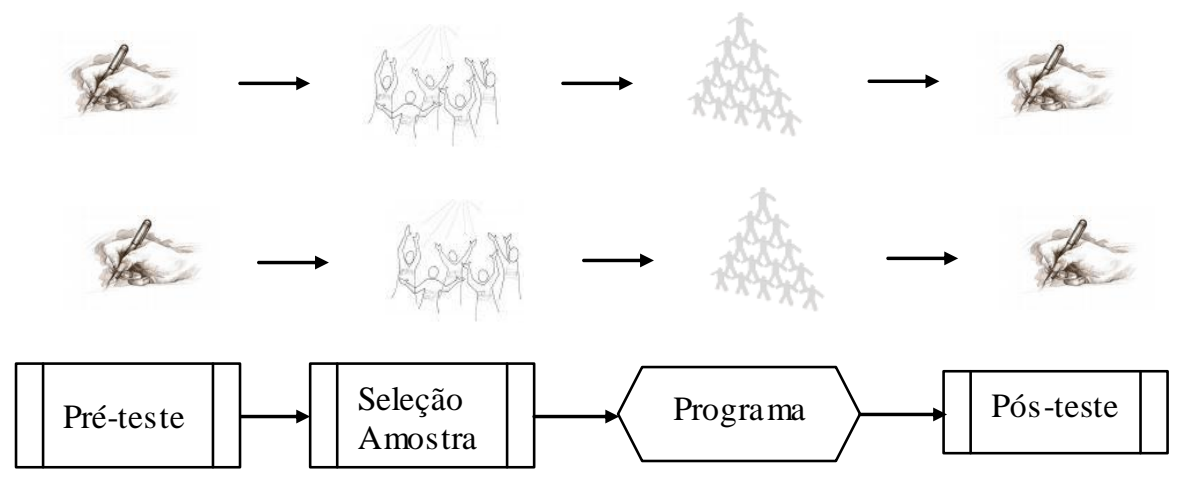

Figura 29 - Design regressão-descontinuidade

\section{Vantagens:}

- Provê controle sobre os efeitos históricos, de maturação e pré-teste.

- Reúne evidências ao longo do tempo.

- Possibilita identificar os elementos mais necessitados de intervenção.

- Pode usar medidas já disponíveis para determinar os escores.

- Permite o uso de diferentes medidas de pré e pós-testes.

- Melhora a capacidade de generalizações.

\section{Desvantagens:}

- Pode requerer mais recursos, tendo em vista as repetidas coletas de dados.

- Resultados diferentes podem ser obtidos nas diferentes coletas de dados.

- Pode haver desistências na amostra dos grupos.

- Pode ser difícil ou mesmo impossível avaliar os indivíduos somente com medidas quantitativas.

- Requer familiaridade com os processos e procedimentos para a análise de regressão.

8. Solomon em quatro grupos: este design provê uma abordagem de controle dos efeitos do pré-teste. Provavelmente este é o mais rigoroso em termos de validade interna e externa. É um design em que quatro grupos são selecionados aleatoriamente e avaliados. Este design inclui todos os benefícios do pré e pós-teste com acompanhamento. Além disso, incluem dois grupos que não participaram do pré-teste e is so controla qualquer efeito do pré-teste, o que propicia generalizações, bem como estende o resultado aos grupos não participantes do pré-teste. 
Este design oferece as mesmas vantagens e desvantagens do pré e pós-teste. Entretanto, a maior desvantagem é a sua complexidade.

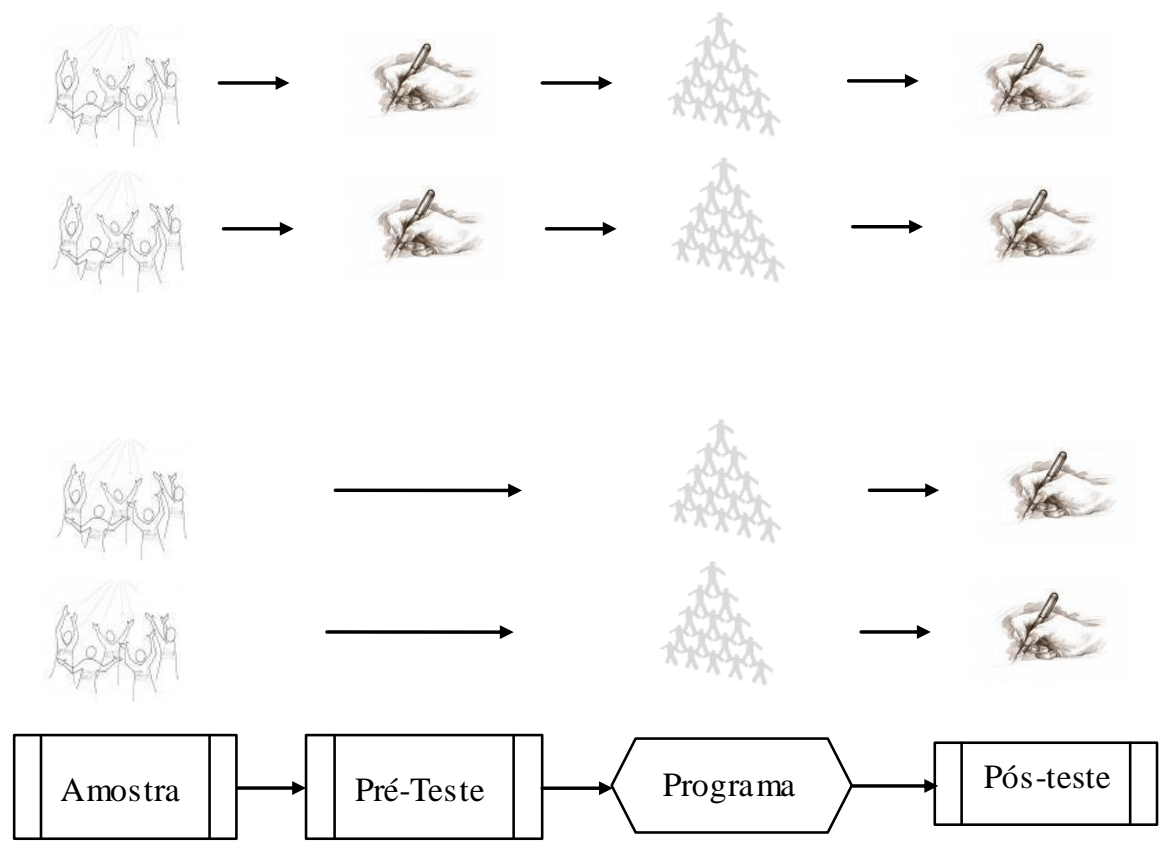

Figura 30 - Design Solomon em quatro grupos

\section{Vantagens:}

- Provê evidências ao longo do tempo.

- Melhora a capacidade de generalização.

- Provê controle sobre os diferentes efeitos.

\section{Desvantagens:}

- Pode requerer mais recursos tendo em vista as repetidas coletas de dados.

- Pode ter um custo mais elevado, considerando as diferentes coletas de dados.

- Os resultados podem se alterar nas diferentes coletas de dados.

- Pode haver desistência dos participantes, deixando grupos não comparáveis.

- Pode ser difícil encontrar dois grupos de controle.

- Requer uma amostra significativa.

9. Estudo de Caso: de acordo com Yin (2001) é uma investigação empírica que investiga um fenômeno contemporâneo dentro de seu contexto da vida real, especialmente quando os limites entre o fenômeno e o contexto não estão claramente definidos. Envolve a descrição em profundidade da coleta e análise de dados de indivíduos, grupos, sistemas, 
processos ou organizações. Este design é o mais utilizado quando se quer responder questões do tipo “por que?" e "como?", e o pesquisador/avaliador tem pouco ou nenhum controle sobre os eventos e quando há necessidade de entender particularidades, singularidades e diversidades (YIN, 2003).

O estudo de caso pode ser tanto quantitativo como qualitativo ou inclusive misto, podem ser realizados do ponto de vista de qualquer modelo: experimental, não experimental, transversal ou longitudinal (S AMPIERI, COLLADO e LUCIO, 2006).

Stake (2000) identificou três diferentes tipos de estudos de caso: intrínsecos, instrumentais e coletivos. $\mathrm{O}$ objetivo do primeiro não é elaborar uma teoria, mas sim, que o próprio caso seja interessante. Os estudos de caso instrumentais são examinados para fornecer material de conhecimento para algum tema ou problema de pesquisa, refinar uma teoria ou aprender a trabalhar com outros casos similares. Por sua vez, os coletivos servem para construir um corpo teórico (somando descobertas, encontrando elementos comuns e diferenças, acumulando informações).

$\mathrm{O}$ avaliador utilizando o estudo de caso não controla ou manipula o ambiente ou qualquer variável, logo, a avaliação apresenta realmente o que é.

\section{Vantagens:}

- Fornece dados descritivos.

- Não requer controle ou manipulação dos indivíduos ou grupo.

- Permite grande entendimento do contexto a valiado.

- Tende a reunir dados utilizando múltiplos métodos (triangulação).

- Captura o que é importante para os participantes.

- Abarca a diversidade de perspectivas e experiências dos participantes.

- Permite o avaliador coletar informações de que não conhecia.

\section{Desvantagens:}

- Os resultados não permitem generalizações científicas.

- O viés do pesquisador/a valiador pode interferir na validade dos resultados.

- Pode consumir muito tempo.

10. Mix Métodos: melhor que confiar somente em métodos qualitativos ou quantitativos, os pesquisadores/avaliadores são motivados a utilizar um mix de métodos, ou seja, 
quantitativos e qualitativos para responder suas questões chave. Assim, mix métodos é quando o pesquisador/avaliador coleta e analisa dados, integrando os resultados com inferências que utilizaram abordagens qualitativas e quantitativa (TASHAKKORI; CRESWELL, 2007).

Desta forma, percebe-se que esta abordagem amplia as fronteiras da avaliação/pesquisa, possibilitando resultados mais consistentes, que perpassam pela esfera sociale ambiente físico.

O melhor design da avaliação é aquele que melhor se adéqua ao seu plano de assessment, bem como responde suas questões chave, podendo ser um ou mais. Além disso, a escolha deve possibilitar evidências de validade interna e externa.

Diante da diversidade de instrumentos e métodos apresentados, a escolha de um ou mais deve estar atrelada às questões chaves e ao objetivo do assessment. Além disso, percebese que todos os métodos apresentados podem ser amplamente aplicados em EaD, desde que respeitadas as especificidades.

\subsubsection{SELEÇÃO DA AMOSTRA}

Dando continuidade na apresentação dos elementos da Arquitetura, segue a seleção da amostra, que, na maioria das vezes, é muito difícil investigar na população, pois isso demanda tempo, recurso de pessoal e financeiro, o que nem sempre se tem em disponibilidade. Desta forma, a alternativa é utilizar a amostragem, que é um processo pelo qual se obtém informações de um todo (população), examinando apenas uma parte des se todo (amostra).

A amostra é utilizada quando é difícil ou não é viável envolver toda a população na avaliação ou pesquisa e esta pode afetar diretamente a validade interna e externa dos dados. Desta forma, Russ-Eft e Preskill (2001) ressaltam algumas razões para se utilizar a a mostra:

- Quando não se tem tempo para entrevistar um grande número de indivíduos (Tempo).

- Quando não se tem recursos para visitar vários lugares para a coleta de dados (Custo).

- Quando algumas pessoas dentro da população são de difícil acesso (Acessibilidade limitada).

- Quando não se tem entrevistador qualificado para conduzir todas as entrevistas, a qualidade dos dados pode ser prejudicada (a precisão pode ser comprometida).

Com estas razões, pode-se obter maior velocidade, precisão controlada, necessidades especializadas e redução da carga de coleta sobre as unidades da população. 
Para selecionar uma amostra, o primeiro passo é definir a unidade de análise (pessoas, organizações, jornais, comunidades, situações, eventos, etc). Sobre o que ou quem serão coletados os dados, depende do enfoque escolhido (quantitativo, qualitativo ou misto), da formulação do problema a ser investigado e dos tipos de estudo. Para o enfoque quantitativo, a amostra é um subgrupo da população de interesse e deve ser estatisticamente representativa. Já no enfoque qualitativo, amostra é uma unidade de análise, sem que necessariamente seja representativa da população ou universo de estudo (S AMPIERI; COLLADO; LUCIO, 2006).

Assim, antes de selecionar uma amostra, deve-se ter resposta para a seguinte pergunta: "Os resultados obtidos a partir da amostra selecionada, devem permitir generalizações para a população? Pois a resposta para esta pergunta influenciará o tipo de amostragem a ser escolhido e trabalhado, conforme descrito abaixo:

As amostras podem ser divididas em dois grandes grupos: (1) amostras nãoprobabilísticas e (2) amostras probabilísticas. Nas amostras não-probabilísticas: a escolha dos elementos não depende da probabilidade, mas sim de causas relacionadas com as características da pesquisa ou da amostra, sendo que o procedimento não é mecânico nem com base em fórmulas de probabilidade, e sim, depende do processo de tomada de decisões, obedecendo a outros critérios da pesquisa.

Para as amostras probabilísticas todos os elementos da população possuem a mesma possibilidade de serem escolhidos. Isso é obtido definindo as características da população, o tamanho da amostra e por meio de uma seleção aleatória ou mecânica das unidades de análise (SAMPIERI; COLLADO; LUCIO, 2006).

De acordo com Bussab e Morettin (2004), a amostra não probabilística pode ser classificada em:

- Amostragem a esmo: a escolha dos elementos é feito sem critérios, ou seja, seleciona-se quem chegar. Por exemplo, participa do estudo quem chegar para ser atendido numa clínica.

- Amostragem intencional: a escolha é feita a partir de alguns critérios que o sujeito tem, como, características físicas ou psicológicas. Geralmente é utilizada por especialistas que conhece muito bem a população que trabalha.

- Amostragem por cotas: a seleção é feita a partir de variáveis auxiliares que estratificam a amostra segundo essas variáveis.

- Amostragem por áreas: a seleção é feita a partir de segmentos de áreas contíguas que exibem características semelhantes, como por exemplo, regiões da cidade com maior 
similaridade entre si.

Em relação aos Métodos de Amostragem Probabilística, pode-se classificar:

- Amostragem Casual Simples (ACS):

- Todos os elementos da população tem igual probabilidade de estar na amostra.

- Ideal para informações mais homogêneas.

- Método mais simples.

- Existência de uma lista com todos os elementos da população - difícil de ser conseguida.

- Fornece estimativas com precisão determinada.

- Amostragem Sistemática (AS) - equivalente a ACS :

- Divide-se os elementos da população em $\underline{\text { n }}$ partes iguais e consecutivas.

- Enumera-se os elementos em cada parte de forma consecutiva.

- De cada parte sorteia-se aleatoriamente um elemento. A ordem deste elemento sorteado determina a posição dos próximos elementos em cada parte.

- A amostra final é constituída pelos n elementos, cada um de uma parte.

- Este método é muito fácil de ser aplicado.

- Problemas:

- Existência de alguma periodicidade na lista.

- Estimativas com a mesma precisão que a ACS.

- Amostragem Estratificada (AE):

- A população é dividida em partes homogêneas internamente e mais heterogênea externamente.

- Cada parte é chamada de estrato.

- De cada estrato, uma amostra casual simples é selecionada.

- A amostra final é constituída com a junção dos dados de todos os estratos e as estimativas ponderadas pelos tamanhos dos estratos.

- É uma amostragem bem próxima do conceito de representatividade.

- Pode aumentar a precisão em até $40 \%$ se comparada com a ACS.

- Amostragem por Conglomerados (Cluster):

- A população é dividida em partes, sendo que cada parte é um réplica o mais próximo possível da população.

- Cada uma das partes é denominada Cluster.

- Seleciona-se por meio de uma ACS, uma amostra de clusters. 
- Pode-se também sortear alguns elementos dentro de cada cluster selecionado (amostragem em 2 estágios).

- A amostra final é constituída de todos os elementos dos clusters selecionados (ou dos elementos sorteados nos cluster).

- Método prático, uma vez que não há necessidades de se conhecer toda a população, apenas a parte selecionada no final do processo.

- É necessária uma amostra maior para se ter a mesma precisão.

- Mais econômica.

- Amostragem em Estágios Múltiplos:

- Vários tipos de amostragem são utilizados até se chegar à amostra final.

- Geralmente a ACS é o método final.

- Utilizado em grandes regiões.

Para Pádua (1997), a amostra probabilística estratificada também denominada seleção aleatória estratificada, inclui o acaso, cuja população é heterogênea ou multiforme, entretanto, requer homogeneidade nos estratos, ou seja, estratos compactos, como subgrupos (estratos), os quais precisam ser representados na amostra. Além disso, ressalta que a amostragem probabilística por conglomerado possui população considerada homogênea, cuja divisão em subgrupos é semelhante aos clusters. Nesse tipo de amostra considera-se que as unidades de análise encontram-se encapsuladas em determinados lugares físicos ou geográficos, reduzindo assim, os custos, tempo e energia. Esta amostragem é feita em duas etapas, primeiro seleciona os conglomerados, em seguida, dentro desses conglomerados, selecionam-se os indivíduos ou objetos que serão medidos. Para isso é feita uma seleção que garanta que todos os elementos do conglomerado possuam a mesma probabilidade de ser escolhidos (SAMPIERI; COLLADO; LUCIO, 2006).

Ainda de acordo com Sampieri, Collado e Lucio (2006), as amostras nãoprobabilísticas, também chamadas amostras por conveniência, supõem um procedimento de seleção informal e isso implica em algumas desvantagens como, não é possível calcular com precisão o erro-padrão, e isso é um grave problema, pois a estatística inferencial está baseada na teoria da probabilidade, de modo que os testes estatísticos em amostras não-probabilísticas possuem um valor limitado em relação a si, mas não à população, ou seja, os dados não podem ser generalizados.

Para o enfoque qualitativo que não exige tanto a generalização de resultados, as 
amostras não-probabilísticas são de grande valor, pois conseguem oferecer grande riqueza para a coleta de dados.

Ao delinear um estudo deve sempre refletir que conforme o tipo de amostra escolhido pode-se definir as técnicas estatísticas adequadas e possíveis.

Nessa perspectiva, verifica-se que em $\mathrm{EaD}$, a amostragem será constantemente utilizada, tendo em vista que a população, principalmente no que se refere aos estudantes, é normalmente em grande número. Assim, o uso de técnicas amostrais adequadas facilita, agiliza e reduz custos na investigação.

\subsubsection{OPERACIONALIZAÇÃO DA COLETA DE DADOS}

Após o delineamento do plano de avaliação, seleção do instrumento ou método de coleta de dados apropriado, a amostra adequada (probabilística ou não-probabilística), ou estudo de caso; de acordo com o enfoque escolhido (quantitativo, qualitativo ou misto), a etapa seguinte consiste em coletar os dados pertinentes às variáveis, acontecimentos, contextos, categorias, comunidades ou objetivos envolvidos na pesquisa.

Para isso, a coleta dos dados implica em três atividades profundamente vinculadas, que segundo Sampieri, Collado e Lucio (2006) são:

a) Selecionar um instrumento ou método de coleta de dados entre os disponíveis na área do estudo, na qual está inserida a pesquisa, ou desenvolver um. Esse instrumento deve ser confiávele válido, do contrário, não poderá basear-se em seus resultados.

b) Aplicar esse instrumento ou método para coletar dados, isto é, obter observações, registros ou medições de variáveis, acontecimentos, contextos, categorias ou objetos que são de interesse do estudo.

c) Preparar observações, registros e medições obtidas para que sejam analisadas corretamente.

É sempre relevante destacar a necessidade de se ter critérios, os quais devem ser perseguidos em todas as etapas da pesquisa, independentemente do enfoque escolhido, havendo também a possibilidade de utilizar diferentes instrumentos de medição para registrar informações sobre as variáveis que se tem em mente. Esse procedimento ajuda aproximar o máximo possível da representação fiel das variáveis a serem observadas, e is so contribui para confiabilidade e validade. 


\subsubsection{MÉTODOS E INSTRUMENTOS PARAA ANÁLISE E INTERPRETAÇÃo DE DADOS}

Após a coleta dos dados julgados pertinentes e relevantes, inicia-se o processo de análise, classificação e interpretação das informações coletadas.

A análise dos dados pode assumir enfoque quantitativo, qualitativo ou um mix dos dois. Além disso, as questões chave da avaliação e os objetivos devem ser o guia dessa análise.

O enfoque quantitativo utiliza dados numéricos para criar senso de informação, já o qualitativo, usa formas narrativas, bem como a percepção do pesquisador/avaliador para descrever o que está sendo avaliado. Contudo, o mix métodos, é a combinação de enfoque qualitativo e quantitativo ou vice-versa na análise dos dados.

Segundo Sampieri, Collado e Lucio (2006), as análises dependem de três fatores:

a) O nível de medição das variáveis.

b) A forma como foram elaboradas as hipóteses.

c) $\mathrm{O}$ interesse do pesquisador.

Além disso, a análise dos dados é uma etapa que se exige criatividade, pois caso contrário, a pesquisa não ultrapassa o nível de simples compilação de dados. De acordo com Pádua (1997) esta etapa envolve:

- Clas sificação e organização das informações coletadas, levando-se em consideração:

○ Pertinência.

○ Relevância.

○ Autenticidade.

- Estabelecimento das relações existentes entre os dados:

○ Pontos de divergência.

○ Pontos de convergências.

○ Tendências.

○ Regularidades.

○ Princípios de causalidade.

○ Possibilidades de generalizações.

- Tratamento estatístico dos dados (quando necessário).

Esta etapa de análise dos dados apresenta-se como uma possibilidade de estabelecimento de novas relações entre os dados coletados, possibilitando diferentes olhares para os mesmos dados, pois se trabalha em um contexto interpretativo. 
Para orientar o desenvolvimento desta etapa de análise de dados, Dusilek (1986) sugere um roteiro para auxiliar na interpretação e verificação dos dados:

1. Verificar os fatos.

2. Verificar os pressupostos.

3. Verificar os materiais ou fontes utilizadas.

4. Verificar as técnicas utilizadas.

5. Verificar o esquema de referência teórico e as categorias utilizadas.

6. Procurar erros lógicos.

7. Verificar erros lógicos.

8. Verificar a inter-relação entre a hipótese (se houver), a teoria e o esquema proposto.

Complementando as sugestões apresentadas, um quadro pode ser elaborado, relacionando questões chave/ objetivos/ instrumento(s) utilizados/ variáveis/ técnica estatística, conforme modelo abaixo: (Quadro 11)

\begin{tabular}{|c|c|c|c|c|}
\hline $\begin{array}{c}\text { Questões chave da } \\
\text { pesquisa }\end{array}$ & $\begin{array}{c}\text { Objetivo do plano de } \\
\text { assessment }\end{array}$ & $\begin{array}{c}\text { Instrumentos } \\
\text { utilizados }\end{array}$ & Variáveis & Técnica estatística \\
\hline & & & & \\
\cline { 3 - 5 } & & & & \\
\hline
\end{tabular}

Quadro 11 - Modelo de Planejamento de Análise de Dados

A utilização do quadro pode facilitar a organização e visualização das informações em uso.

Conforme observado, esta etapa de análise dos dados é um processo complexo, que exige muita atenção do pesquisador ou avaliador para que não se distancie do significado do próprio projeto.

\section{Análise Quantitativa dos Dados}

Geralmente a análise quantitativa dos dados é realizada por meio do computador, utilizando softwares específicos para análise estatística (exemplo, SPSS, Minitab, Statistica). Além disso, esta etapa da pesquisa pode ser realizada pelo próprio pesquisador ou contar com a assessoria de um especialista da área de estatística.

Geralmente o pesquisador procura, em primeiro lugar, descrever seus dados e, posteriormente efetua as análises estatísticas para relacionar suas variáveis, isto é, realiza análise de estatística descritiva para cada uma de suas variáveis e depois descreve a relação 
entre elas. Existem diversos tipos de métodos de análise quantitativa ou estatística, porém, cabe ressaltar que a análise não é indiscriminada, cada método possui uma razão de existir e um objetivo específico; não devem ser feitas mais análises do que o necessário, pois a estatística não é um fim em si mesma, mas uma ferramenta para analisar os dados (SAMPIERI; COLLADO; LUCIO, 2006).

Para maior detalhamento da análise quantitativa de dados, verificar Apêndice D.

\section{Análise Qualitativa dos Dados}

$\mathrm{Na}$ análise qualitativa, normalmente o pesquisador se depara com um volume enorme de dados de toda espécie, por isso é necessário que o material esteja organizado e separado, que seja de fácil acesso e busca, e que esteja ordenado para o pesquisador.

Tendo em vista o grande volume de informações a serem trabalhadas, tomou-se como referência a obra de Sampieri, Collado e Lucio (2006), da qual foram realizados alguns recortes para compor um repositório de definições (observações) úteis para a etapa de análise qualitativa de dados:

- Nos estudos qualitativos, a análise dos dados não está totalmente determinada, mas sim é "pré-configurada ou esboçada", ou seja, começa-se a efetuar sob um plano geral, entretanto, seu desenvolvimento vai sofrendo modificações de acordo com os resultados.

- A análise qualitativa possui como objetivos centrais:

○ Organizar os dados.

- Organizar as unidades, as categorias, os temas e os padrões.

- Compreender profundamente o contexto dos dados.

- Descrever experiências das pessoas estudadas de sua ótica, em sua linguagem e com suas expressões.

- Interpretar e avaliar unidades, categorias, temas e padrões.

○ Explicar contextos, situações, fatos e fenômenos.

- Gerar questões de pesquisa e hipótese.

- Reconstruir histórias.

- Relacionar os resultados da análise com teoria fundamentada ou construir teorias.

- A análise qualitativa não é sinônima de pura descrição de casos, é preciso ter um plano de análise. Entretanto, não se pode perder de vista que a abordagem qualitativa requer flexibilidade (HAGUETTE, 2003). 
- Na análise qualitativa existe uma diversidade de estratégias. Contudo, Sampieri, Collado e Lucio (2006) propuseram um esboço desse processo, conforme figura 31.

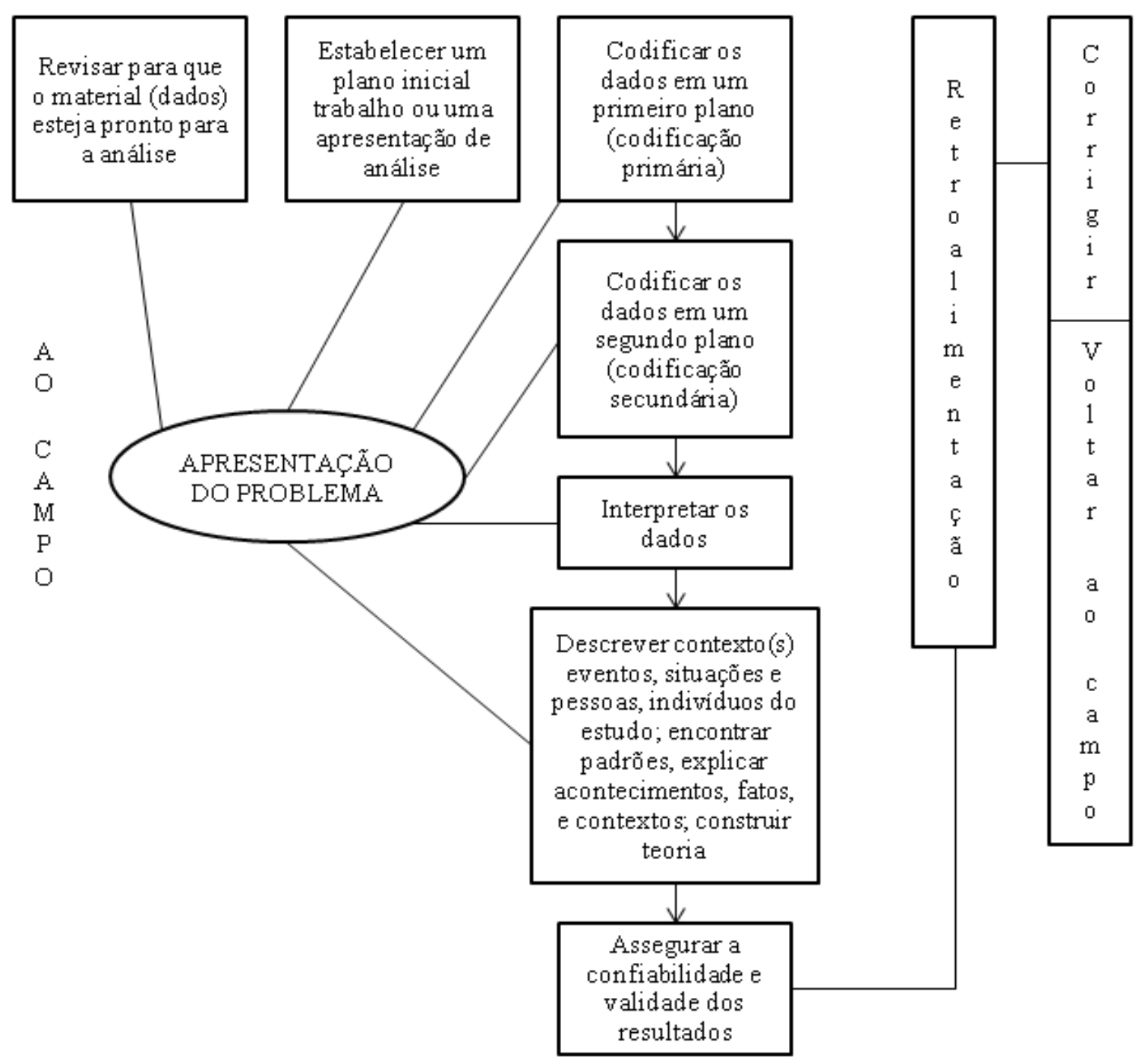

Figura 31 - Processo de análise qualitativa de dados, adaptado de Sampieri, Collado e Lucio (2006)

Esse processo é derivado em:

1. Revisar o material: consiste em revisar os dados preparados de maneira adequada para a análise, is to é, que estejam organizados e classificados por um critério lógico.

2. Estabelecer um plano de trabalho inicial (apresentação), o qual inclui: (a) revisar todos os materiais; (b) revisar o registro elaborado durante a etapa de coleta de dados; (c) estabelecer um sistema de codificação de dados; (d) definir o método para analisar os dados; (e) estabelecer datas prováveis para a realização da análise.

3. Codificar os dados em um primeiro nível ou plano: codificam-se os dados para se ter uma descrição mais completa, resumi-los, eliminar informação irrelevante, realizar análise 
quantitativa e gerar maior sentido de entendimento do material analisado. A codificação possui dois níveis ou planos: primeiro, codificam-se as unidades em categorias; no segundo, comparam-se categorias entre si para agrupá-las em temas e procurar possíveis vinculações.

4. Codificar os dados em segundo nível: implica em refinar a codificação e envolve a interpretação do significado das categorias obtidas no primeiro nível. Inicia-se pela identificação das diferenças e semelhanças entre categorias.

5. Interpretar os dados: é fundamental dar sentido (a) as descrições de cada categoria; (b) aos significados de cada categoria; (c) a presença de cada categoria; (d) as relações entre categorias, sendo as mais comuns: temporais, causais e de conjunto e subconjunto.

6. Descrever contexto(s), eventos, situações e pessoas, indivíduos de estudo, encontrar padrões, explicar fatos, acontecimentos e construir teoria.

7. Assegurar confiabilidade e validade aos resultados: na análise qualitativa não há coeficientes, portanto, deverá ser efetuada uma valorização do processo de análise, (a) avaliar se obteve informações suficientes de acordo com o problema, ou seja, na coleta de dados; (b) é recomendável realizar um exercício de triangulação da análise; (c) consiste em obter retroalimentação direta dos indivíduos da pesquisa (pelo menos uma amostra deles), o que significa pedir-lhes que confirmem ou contestem as interpretações.

8. Responder, corrigir e voltar a campo: como resultado da avaliação para a obtenção de retroalimentação, detecta-se deficiências, erros, falta de dados, etc. isso implica desde realizar mais entrevistas, sessões, estudos de caso ou observações até a necessidade de procurar mais maneiras, recodificar, adicionar novos esquemas ou elaborar outras análises.

Outra ferramenta relevante é a Análise de Conteúdo, a qual investiga o conteúdo das comunicações, mediante a classificação em categorias dos elementos da comunicação. Esta técnica tem grande utilidade na análise de entrevistas e focus group. Maior detalhamento pode ser verificado no Apêndice C.

Tanto a análise quantitativa como a qualitativa são ferramentas muito úteis, sendo que nenhuma é superior à outra, simplesmente comtemplam diferentes caminhos para se chegar a um mesmo fim, ou seja, ao objetivo da pesquisa e também para responder às questões do estudo e gerar conhecimento (SAMPIERI; COLLADO; LUCIO, 2006).

Enfim, a análise dos dados envolve uma revisão dos propósitos e das questões-chave do processo de avaliação. Entretanto, ao escolher os métodos de análise dos dados é 
importante se atentar para o conhecimento técnico das categorias de interessados, para que possam entender a análise qualitativa e/ou quantitativa dos resultados.

Esta fase tem também a finalidade de assegurar qualidade ao projeto, uma vez que define as necessidades e os caminhos a serem trilhados. Para isso, algumas perguntas precisam ser respondidas, tais como:

- Qual a necessidade de avaliação?

- Quais as medidas de efetividade?

- Qual a necessidade de aprendizagem?

Além das respostas a estas perguntas, nesta fase também é necessário:

- Mapear os procedimentos necessários para condução do processo de avaliação.

- Prospectar formas de utilização dos resultados obtidos na avaliação.

- Levantar o custo da avaliação no programa de EaD.

- Identificar os canais de divulgação dos resultados da avaliação.

- Descrever detalhadamente os objetivos e procedimentos da avaliação.

- Identificar as fontes e procedimentos (confiáveis e válidos) para a coleta e análise de informações.

- Prospectar as formas de análise das informações obtidas no processo de avaliação.

- Analisar os instrumentos e métodos de coleta de dados mais adequados à investigação.

- Verificar qual a amostra a ser investigada.

- Efetuar todas as aferições necessárias e caso identifique alguma incongruência, realizar as recomendações devidas.

Nesta fase, o plano de assessment está montado. Portanto, é fundamental que o avaliador/pesquisador saiba "onde está e onde se deseja chegar".

Para isso, a fase é composta pelos elementos da dimensão de evidências científicas (conforme roteiro apresentado na página 68), aferição e recomendações, bem como o ponto de controle, o qual afere as seguintes ações/estratégias: utilização de aspectos qualitativos e quantitativos, elaboração de instrumentos com agrupamento de itens por dimensão, associação dos itens do instrumento com as questões chave do plano de assessment.

A figura 32 ilustra a Fase Diagnóstico. 


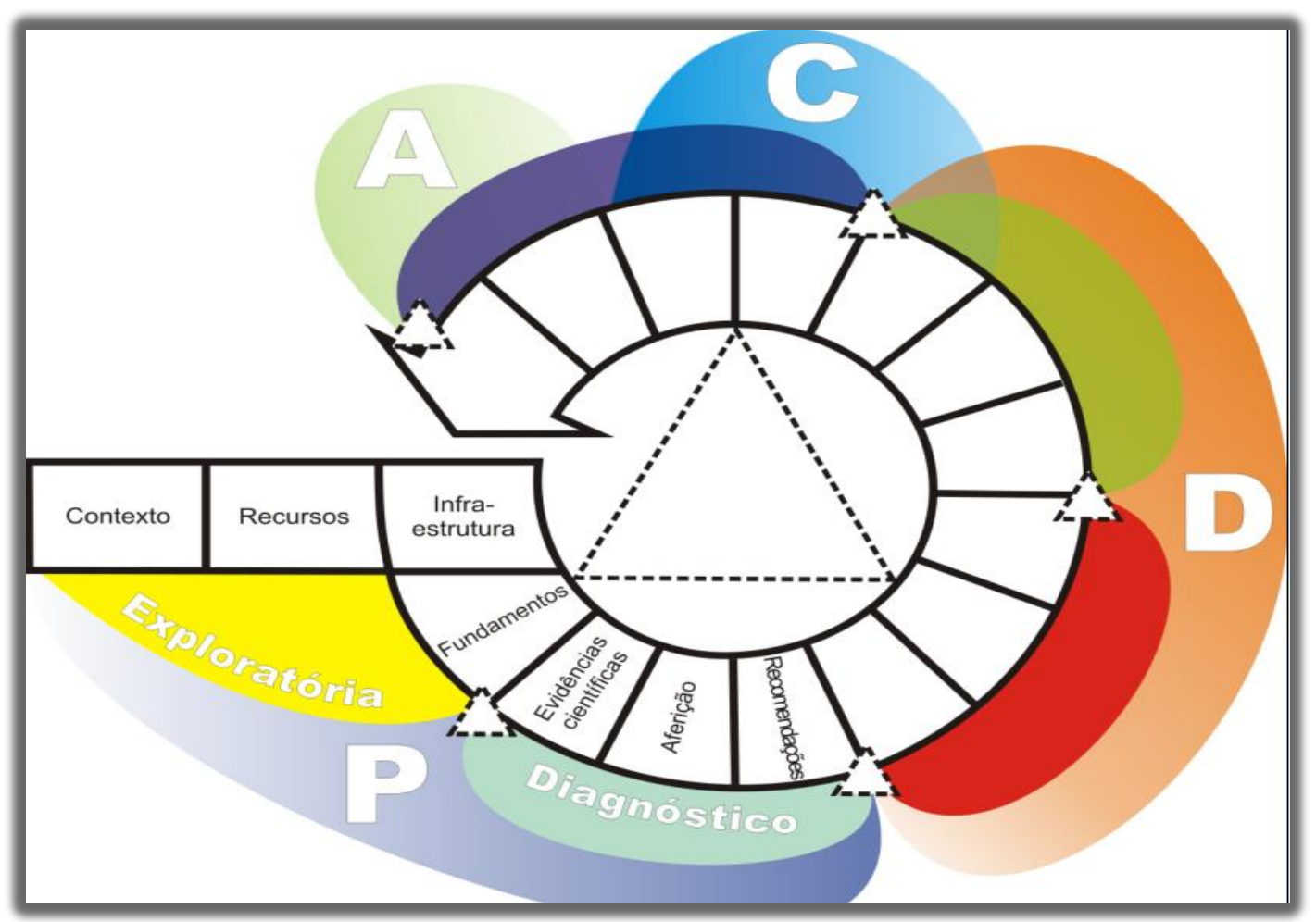

Figura 32 - Fase Diagnóstico da Arquitetura de Orientação

\section{- Etapas:}

\section{Evidências Científicas}

Trata-se da observância e definição de como os elementos da dimensão evidências científicas poderão ser utilizados.

Os elementos da dimensão evidências científicas são: métodos e instrumento para a coleta de dados; triangulação, análise de confiabilidade e análise de validade - que sintetizam consistência interna, análise fatorial, análise por hipótese, correlação e alfa de Cronbach; teste piloto; treinamento para novos entrevistadores; evidência de confiabilidade, evidência de validade; características da amostra; métodos e instrumentos para análise de dados e padrões de avaliação.

Treinamento para novos entrevistadores: é a formação de outros entrevistadores com o intuito de evitar qualquer distorção do objetivo do assessment. É a ocasião para apresentar todas as nuances da investigação para o que o futuro entrevistador esteja embasado e consiga extrair o máximo em suas ações.

Evidências de confiabilidade e validade: é a confirmação qualitativa e quantitativa dos indicativos de confiabilidade e validade.

Os demais elementos já foram abordados e constam no quadro 12 (abaixo) com indicação da página onde são localizados. 


\section{Aferição}

Com base nos resultados obtidos na fase exploratória é possível realizar aferições para que o plano de assessment seja adequado, consistente e exequível.

\section{Recomendações}

Com base nas aferições realizadas de todo o plano de assessment, é possível efetuar recomendações, tendo em vista o contexto, os recursos e a infraestrutura disponíveis para a investigação.

O quadro 12 apresenta os elementos da Fase Diagnóstico.

\begin{tabular}{|c|c|}
\hline Ele mentos & Onde encontrar \\
\hline Apresentação de gap entre o ideal e o real & Página 118 \\
\hline Design do a ssessment & Página 153 \\
\hline Métodos e instrumentos para a coleta de dados & Página 134 \\
\hline Triangulação & Página 63 \\
\hline Análise da confiabilidade & Página 52 \\
\hline Análise da validade & Página 56 \\
\hline Teste piloto ou pré-teste & Página 153 \\
\hline Análise dos pontos críticos da validade & Página 69 \\
\hline Características da amostra & Página 161 \\
\hline Métodos e instrumentos para a análise de dados & Página 166 \\
\hline Padrões de avaliação & Página 34, 242 (Apênd ice A) \\
\hline \multicolumn{2}{|l|}{ Treinamento para novos entrevistadores } \\
\hline \multicolumn{2}{|l|}{ Evidência de confiabilidade } \\
\hline Evidências de validade & \\
\hline
\end{tabular}

Quadro 12 - Checklist dos Elementos da Fase Diagnóstico

\section{- Ponto de Controle}

Tem como objetivo aferir ações/estratégias que asseguram os procedimentos conceituais de confiabilidade e validade. Portanto, as ações abaixo devem ser conferidas. 


\section{Utilização de aspectos qualitativos e quantitativos}

$\mathrm{O}$ plano de assessment deve privilegiar tanto o enfoque qualitativo como o quantitativo, de uma forma que um complemente o outro. Podendo ser utilizado também para triangular informações.

\section{Elaboração de Instrumentos com Agrupamento de Itens por Dimensão}

Ao elaborar qualquer instrumento de assessment deve-se ter o cuidado de agrupar os itens/perguntas/questões por temática/assunto, de modo que facilite o entendimento e preenchimento pelo respondente.

\section{Associação dos Itens do Instrumento com as Questões Chave do Plano de Assessment}

A cada item construído no instrumento deve-se associá-lo a uma ou mais questão chave do assessment, para que se saiba antecipadamente quais itens respondem e quais questões.

\section{Mecanismos de Triangulação}

São utilizados os diferentes tipos de triangulação (teoria, metodológica, investigador/a valiador, dados e ambiental) com o objetivo de confirmar as impressões e dados obtidos, assegurando assim, confiabilidade às informações.

O quadro 13 sintetiza as ações/estratégias para o Ponto de Controle da Fase Diagnóstico.

\begin{tabular}{|l|l|}
\cline { 2 - 3 } \multicolumn{1}{c|}{ Ações e/ou Estratégias } \\
\hline & Utilização de aspectos qualitativos e quantitativos \\
\hline & Elaboração de instrumentos com agrupamento de itens por dimensão \\
\hline & Associação dos itens do instrumento com as questões chave do plano de assessment \\
\hline Mecanismos de triangulação
\end{tabular}

Quadro 13 - Ponto de controle para a Fase Diagnóstico

O ponto de controle desta fase é voltado para os procedimentos conceituais da confiabilidade e da validade e ao ser aferido confere maior precisão aos resultados, favorecendo a tomada de decisão. 


\subsubsection{FASE ESTABELECIMENTO}

Nesta fase, o plano de assessment está praticamente concluído, restando apenas a definição de prioridades (caso necessário), em função dos recursos disponíveis, da infraestrutura existente e do gap entre a situação ideal e a real; podendo assim, traçar as recomendações do programa.

Posteriormente com o plano finalizado, passa-se ao teste piloto, buscando pré-testar todos os instrumentos que serão utilizados na avaliação.

O teste piloto deve seguir todo o rigor científico, para que realmente possa conferir confiabilidade ao(s) instrumento(s) utilizado(s).

Além disso, a seleção da amostra deve ser um processo cuidados para que se assegure representatividade da população.

Todavia, os instrumentos utilizados devem ser claros, objetivos e precisos de forma que não gerem ambiguidade de nenhuma forma.

A figura 33 ilustra a Fase Estabelecimento da Arquitetura de Orientação.

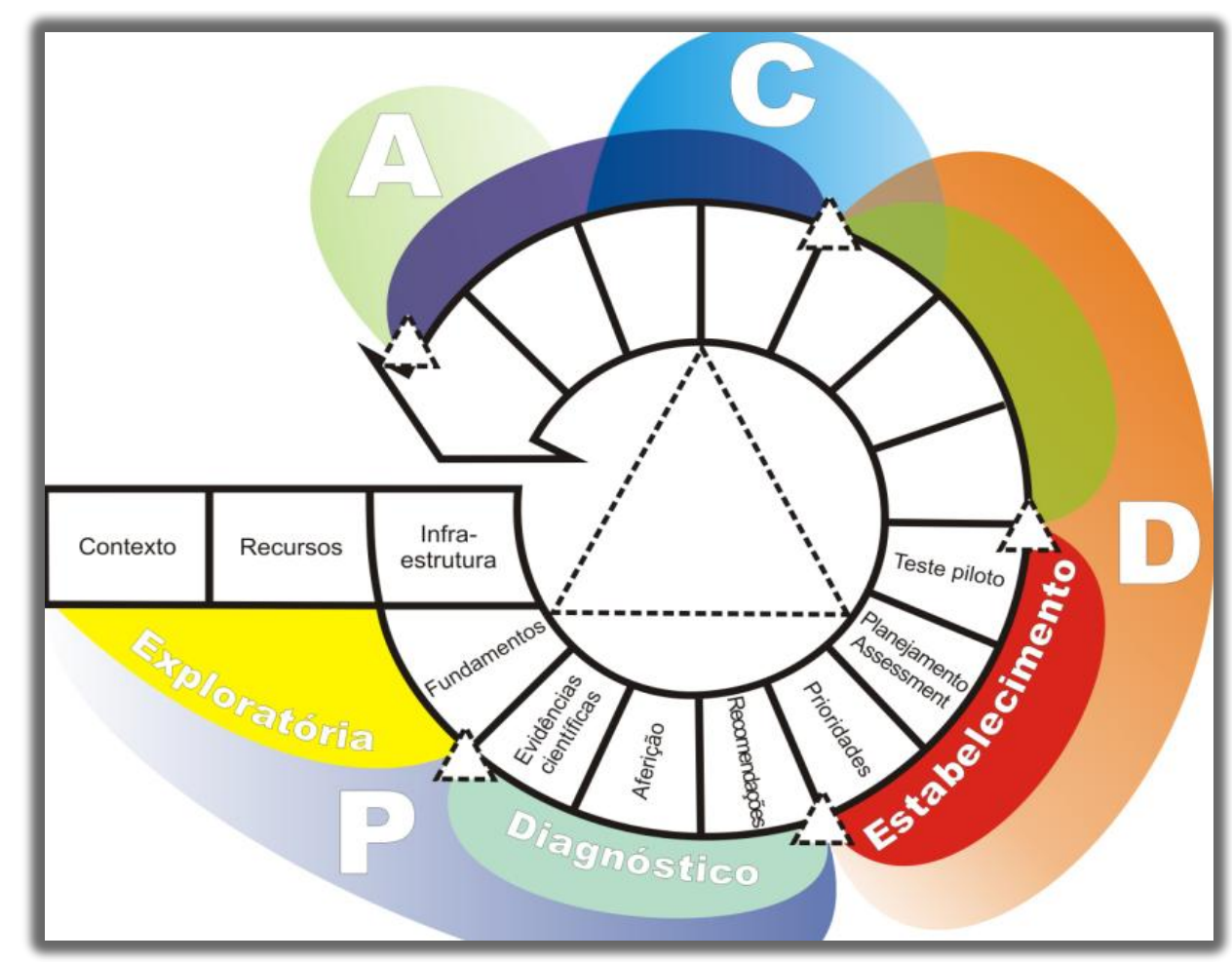

Figura 33 - Fase Estabelecimento da Arquitetura de Orientação

Outrossim, o quadro 14 sintetiza as ações e/ou estratégias que devem ser aferidas em seu ponto de controle. 


\begin{tabular}{|l|l|}
\cline { 2 - 2 } \multicolumn{1}{c|}{} & \multicolumn{1}{c|}{ Ações e/ou Estratégias } \\
\hline & Aplicação de teste piloto \\
\hline & Seleção de amostra significativa \\
\hline & Instrumento(s) claro(s), objetivo(s) e preciso(s) \\
\hline
\end{tabular}

Quadro 14 - Ponto de controle para a Fase Estabelecimento

O ponto de controle da Fase Estabelecimento é voltado para os procedimentos técnicos da confiabilidade e validade. 


\subsubsection{FASE IMPLEMENTAÇÃ̃}

Os resultados da fase anterior indicarão quais os ajustes necessários. Portanto, é nesta fase que se realiza os refinamentos, os quais são elencados com base nos resultados do teste piloto. Este procedimento deve ser realizado para analisar os níveis atingidos de confiabilidade e validade, e na sequência realizar a aplicação definitiva do(s) instrumento(s) utilizado(s).

A figura 34 ilustra a Fase Implementação da Arquitetura de Orientação.

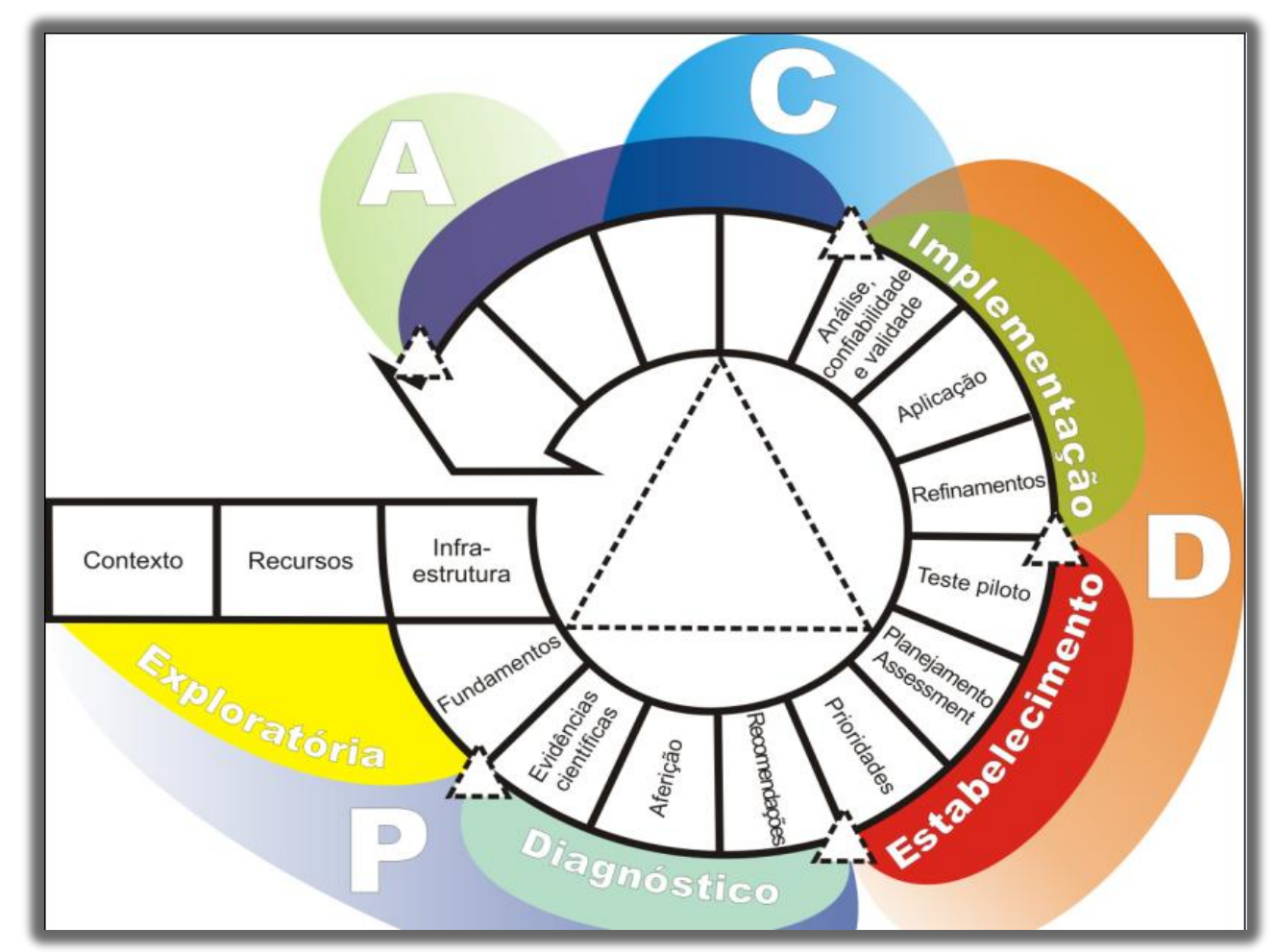

Figura 34 - Fase Implementação da Arquitetura de Orientação

Nesta fase, o plano de assessment deve ser dispor de respostas para os 5W2H, ou seja, o que será avaliado? - por quê? - quando? - onde - quem? - como? - e quanto vai custar?

Após esta finalização, o plano de assessment está adequado à aplicação definitiva, para na sequência, iniciar a análise da confiabilidade, validade e triangulação, utilizando as técnicas adequadas.

Assim, como ponto de controle, as seguintes ações e/ou estratégias devem ser aferidas (Quadro 15). 


\begin{tabular}{|l|l|}
\cline { 2 - 2 } \multicolumn{1}{c|}{} & \multicolumn{1}{c|}{ Ações e/ou Estratégias } \\
\hline & Ambiente adequado para aplicação do(s) instrumento(s) \\
\hline & Rigor metodológico \\
\hline & Aceitação dos participantes \\
\hline
\end{tabular}

Quadro 15 - Ponto de controle para a Fase Implementação

- Ponto de Controle

O ponto de controle desta fase tem como finalidade, aferir ações e/ou estratégias relacionadas aos procedimentos práticos para aquisição de confiabilidade e validade.

\section{Ambiente ade quado para aplicação do(s) instrumento(s)}

Qualquer que seja o(s) instrumento(s) utilizado(s), o ambiente onde ele(s) será(ão) disponibilizado(s) deve ser o mais adequado possível, bem como organizado e de fácil acesso, de modo a facilitar a sua aplicação e ampliar a taxa de retorno.

\section{Rigor metodológico}

É clareza e o detalhamento dos procedimentos executados em cada uma das etapas da pesquisa, de modo a ampliar a excelência da investigação.

\section{Aceitação dos participantes}

Para toda a aplicação de um plano de assessment é imprescindível a aceitação dos participantes, os quais devem ser informados sobre os objetivos da investigação, bem como assinar o termo de aceitação em participar do estudo, atendendo os pressupostos da ética em pesquisa.

É de suma importância realizar tais ações/estratégias, tendo em vista que sem os participantes, a viabilidade do plano é nula. 


\subsubsection{FASE APR ENDIZA GEM}

Esta fase possibilita a conclusão do ciclo de melhoria e foca na aprendizagem ao longo do processo. Para concluir o ciclo de assessment os elementos das dimensões relevância/utilidade e consequências (conforme roteiro da página 68) são tratados.

Assim, neste momento, é possível fornecer feedback aos participantes, bem como propor ações futuras, identificando o impacto e as medidas de desempenho obtidas em todo o processo. Além disso, deve ter ciência sobre a relação custo-benefício do assessment o que também pode impactar a tomada de decisão.

Nesse sentido, Russ-Eft e Preskill (2009) ressaltam que a análise de custo consiste em identificar todos os componentes que contribuem para formar o custo total do programa, que pode incluir custo fixo e variável. Em relação aos benefícios, talvez não seja muito fácil determinar o valor monetário, pois muitas vezes são intangíveis a curto prazo, aparecendo somente a médio/longo período depois de sua realização. Portanto, é importante utilizar projeção e prospecção de cenários.

Além disso, esta etapa proporciona avaliar a aprendizagem adquirida ao longo do processo de avaliação, bem como formar expertise em avaliação (assessment).

A figura 35 ilustra a Fase Aprendizagem da Arquitetura de Orientação.

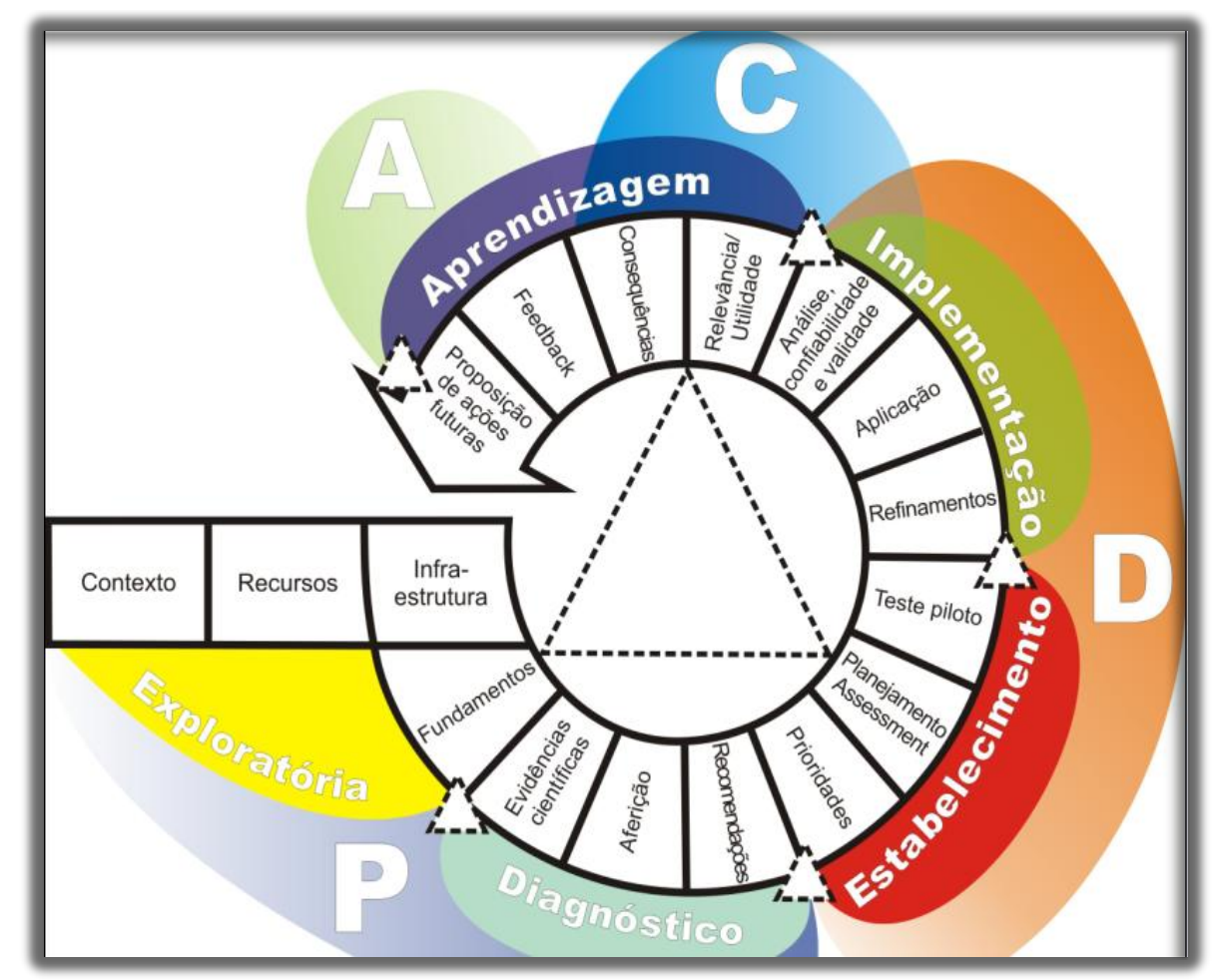

Figura 35 - Fase Aprendizagem da Arquitetura de Orientação 
Esta fase contempla também a documentação do assessment, na qual é imprescindível a apresentação das limitações/restrições encontradas ao longo do processo, bem como as consequências (sociais, institucionais e instrucionais) que o assessment pode ter provocado, tanto no aspecto positivo como negativo.

A fase aprendizagem sugere um checklist com os seguintes elementos (Quadro 16).

\begin{tabular}{|l|l|}
\cline { 2 - 2 } \multicolumn{1}{c|}{} & \multicolumn{1}{c|}{ Ele mentos } \\
\hline & Divulgação e uso dos resultados \\
\hline & Feedback aos stakeholders \\
\hline & Relação custo-benefício \\
\hline & Limitações/restrições \\
\hline & Impactontação do medidas de desempenho \\
\hline & Consequências Sociais \\
\hline & Consequências Institucionais \\
\hline & Consequências Instrucionais \\
\hline
\end{tabular}

Quadro 16-Checklist com os elementos da Fase Aprendizagem

A Fase Aprendizagem da Arquitetura de Orientação apresenta o seu ponto de controle, conforme quadro 17.

\begin{tabular}{|l|l|}
\cline { 2 - 3 } \multicolumn{1}{c|}{} & \multicolumn{1}{c|}{ Ações e/ou Estratégias } \\
\hline & Feedback aos interessados e participantes do assessment \\
\hline & Disseminação dos resultados \\
\hline & Análise geral do processo \\
\hline
\end{tabular}

Quadro 17 - Ponto de controle para a Fase Aprendizagem

\section{- Ponto de Controle}

O papel do ponto de controle nesta fase é verificar os procedimentos avaliativos relacionados à confiabilidade e validade. Para tanto, dispõe das ações e/ou estratégias, conforme apresentadas abaixo.

\section{Feedback aos interessados e participantes do assessment}

Todo e qualquer resultado obtido com a aplicação do plano de assessment deve ser 
apresentado aos interessados (stakeholders) e participantes (respondentes, colaboradores e outros).

\section{Disseminação dos resultados}

Os resultados obtidos com a aplicação do plano de assessment deve ser disseminado na tanto na instituição como na comunidade científica, por meio de publicações, tendo em vista a importância da consolidação do corpus teórico da $\mathrm{EaD}$, principalmente na realidade brasileira.

\section{Análise geral do processo}

Discutir e analisar junto aos pares e colaboradores as ações, estratégias e procedimentos adotados para consecução do plano de assessment, bem como elaborar relatório circuns tanciado sobre o processo avaliativo.

\section{Prospecção futura de melhoria}

A partir do panorama obtido pela investigação e considerando os objetivos do Programa de EaD, realiza-se a prospecção futura de melhorias.

A arquitetura de orientação se apresenta como um modelo flexível e robusto de forma que os pontos de controles sinalizam um conjunto de procedimentos que devem ser aferidos antes de avançar para a fase seguinte, os quais são: procedimentos iniciais, conceituais, técnicos, práticos e avaliativos. Estes pontos de controle são mais uma forma de assegurar evidências de confiabilidade e validade ao instrumento.

Além disso, a estruturação em fases, dos pressupostos de metodologia científica, avaliação modelo de Russ-Eft e Preskill (2001, 2009), roteiro de dimensões - adaptado de Messick (1989), modelo Servqual (gap de qualidade) e IDEAL Model, a Arquitetura de Orientação para Avaliação de Programas de $\mathrm{EaD}$ é permeada pela filosofia do ciclo PDCA, o qual envolve o estabelecimento dos objetivos e processos necessários para atingir os resultados, de acordo com a missão e valores institucionais (Plan). Contempla ainda, a implementação (Do), o monitoramento e medição dos requisitos de confiabilidade e validade, em conformidade com os objetivos, questões chave, recursos e infraestrutura para relatar os resultados (Check) e, por fim, envolve a execução de ações para melhorar continuamente a arquitetura de orientação, bem como o plano de assessment (Action).

Entende-se que o ciclo PDCA confere dinamicidade e flexibilidade à Arquitetura de Orientação, sobretudo em ações que lastreiam qualidade ao produto final. Nesse sentido, a 
natureza cíclica e repetida do método pode proporcionar melhorias às atividades desenvolvidas, propiciando uma reflexão e análise ao longo da construção de instrumentos avaliativos.

Outrossim, a Arquitetura de Orientação para Construção de Instrumentos de Avaliação de Programa de $\mathrm{EaD}$, conforme verificado, parte do pressuposto de um sistema integrado, cujos módulos atendem às necessidades de informação, sempre visando indicativos de confiabilidade e validade. Com isso, a arquitetura pretende desenvolver o máximo de funcionalidades, para se atender ao maior número possível de necessidades dentro de um amplo espectro de situações, obtendo resultados que facilitam a tomada de decisão. 


\subsubsection{Síntese dos Componentes da Arquitetura de Orientação}

Com o objetivo de facilitar a compreensão e visualização da Arquitetura de Orientação, segue uma síntese dos elementos utilizados.

\section{Checklist dos Elementos da Fase Exploratória:}

$\checkmark$ Missão da instituição

$\checkmark$ Valores institucionais

$\checkmark$ Contexto

$\checkmark$ Objetivos e metas do curso/programa

$\checkmark$ Definição do problema existente

$\checkmark$ Lógica do assessment

$\checkmark$ Objetivo do assessment

$\checkmark$ Interessados no assessment (stakeholders)

$\checkmark$ Modelo lógico da avaliação

$\checkmark$ Participantes do assessment

$\checkmark$ Questões chave para o assessment

$\checkmark$ Modelo/Abordagem de avaliação utilizado

$\checkmark$ Método de investigação

$\checkmark$ Natureza do assessment

$\checkmark$ Recursos disponíveis

$\checkmark$ Infraestrutura

$\checkmark$ Consulta a outras fontes/modelos existentes

$\checkmark$ Custo prévio da avaliação

$\checkmark$ Designação da equipe de avaliação

Checklist das ações/estratégias do Ponto de Controle para a Fase Exploratória:

$\checkmark$ Rigor e critério metodológico

$\checkmark$ Definição clara do conteúdo abordado

$\checkmark$ Explicitação dos objetivos

$\checkmark$ Consulta a diferentes fontes de informação

\section{Checklist dos Elementos da Fase Diagnóstico:}

$\checkmark$ Apresentação de gap entre o ideal e o real

$\checkmark$ Design do assessment

$\checkmark$ Métodos e instrumentos para a coleta de dados 
$\checkmark$ Triangulação

$\checkmark$ Análise da confiabilidade

$\checkmark$ Análise da validade

$\checkmark$ Teste piloto

$\checkmark$ Treinamento para novos entre vistadores

$\checkmark$ Evidência de confiabilidade

$\checkmark$ Evidências de validade

$\checkmark$ Análise dos pontos críticos da validade

$\checkmark$ Características da amostra

$\checkmark$ Métodos e instrumentos para a análise de dados

$\checkmark$ Padrões de avaliação

$\checkmark$ Aferição

$\checkmark$ Recomendações

Checklist das ações/estratégias para o Ponto de Controle da Fase Diagnóstico:

$\checkmark$ Utilização de aspectos qualitativos e quantitativos

$\checkmark$ Elaboração de instrumentos com agrupamento de itens por dimensão

$\checkmark$ Associação dos itens do instrumento com as questões chave do plano de assessment

$\checkmark$ Mecanismos de triangulação

\section{Checklist dos Elementos da Fase Estabelecimento:}

$\checkmark$ Definição de Prioridade (se necessário)

$\checkmark$ Planejamento do assessment

$\checkmark$ Teste piloto

Checklist das ações/estratégias para o Ponto de Controle da Fase Estabelecimento:

$\checkmark$ Aplicação de teste piloto

$\checkmark$ Seleção de amostra significativa

$\checkmark$ Instrumento(s) claro(s), objetivo(s) e preciso(s)

Checklist dos Elementos da Fase Implementação:

$\checkmark$ Refinamentos

$\checkmark$ Aplicação

$\checkmark$ Análise da confiabilidade e validade

Checklist das Ações e/ou Estratégias do Ponto de Controle para a Fase Implementação:

$\checkmark$ Ambiente adequado para aplicação do(s) instrumento(s) 
$\checkmark$ Rigor metodológico

$\checkmark$ Aceitação dos participantes

\section{Checklist dos Elementos da Fase Aprendizagem:}

$\checkmark$ Divulgação e uso dos resultados

$\checkmark$ Feedback aos stakeholders

$\checkmark$ Relação custo-benefício

$\checkmark$ Limitações/restrições

$\checkmark$ Proposição de ações futuras

$\checkmark$ Documentação do assessment

$\checkmark$ Impactos e medidas de desempenho

$\checkmark$ Consequências Sociais

$\checkmark$ Consequências Institucionais

$\checkmark$ Consequências Instrucionais

Checklist das Ações e/ou Estratégias Ponto de controle para a Fase Aprendizagem:

$\checkmark$ Feedback aos interessados e participantes do assessment

$\checkmark$ Disseminação dos resultados

$\checkmark$ Análise geral do processo

$\checkmark$ Prospecção futura de melhoria

A apresentação dos checklists das fases do modelo proporciona uma visão sistêmica da Arquitetura de Orientação, bem como facilita a sua utilização. 
CAPÍTULO 7 - Desenvolvimento de uma solução baseada na arquitetura de orientação para Assessment de Programas de Educação a Distância

Neste capítulo será desenvolvida uma solução baseada nos pressupostos da Arquitetura de Orientação (Plano de Assessment), que caracteriza a segunda etapa da pesquisa. Esta solução tem como finalidade analisar a percepção do professor em relação à participação em curso de especialização ofertado na modalidade a distância.

\subsection{Construção do Plano de Assessment para analisar a Percepção do Professor EM RELAÇÃo À PARTICIPAÇÃo EM UM CURSO de ESPECIALIZAÇÃo OFERTAdo NAMODALIDADE A D ISTÂNCIA}

O plano de assessment é um roteiro (planejamento), o qual deve conter todas as informações relevantes para o processo a valiativo.

Para esta situação problema, foram definidas as seguintes informações como necessárias: contexto; recursos; infraestrutura; missão e visão institucionais; objetivos e metas do curso; definição do problema existente; apresentação do gap entre o ideal e o real; lógica; objetivo(s) do assessment; interessados; modelo lógico; participantes; questões chave; modelo/abordagem utilizada; método de investigação; design da pesquisa; natureza do assessment; métodos e instrumentos para coleta de dados; protocolos utilizados para os instrumentos de coleta de dados; métodos e instrumentos para análise de dados; divulgação e uso dos resultados; feedback aos interessados e participantes do assessment; relação custobenefício; limitações/restrições observadas no assessment; documentação do assessment e por fim, consequências. As demais informações serão apresentadas após a aplicação do plano de assessment.

\section{Missão da Ins tituição}

Produzir, disseminar e propiciar a guarda e o acesso do Conhecimento Científico, da Cultura, da Arte e da Tecnologia, formando cidadãos, profissionais éticos, agentes atuantes e transformadores da realidade socioeconômica e política com enfoque local/regional, contribuintes para a realidade nacional e mundial. 


\section{Visão}

Referência em termos de qualidade em Universidade Pública, Democrática e Autônoma com gratuidade em sua oferta de cursos de Graduação e Stric to sensu, com atuação nos cenários local/regional e, contribuinte no âmbito nacional e internacional, alicerçada em Setores de Conhecimento de excelência, cooperativos e integrados com o dinamismo socioeconômico e político local, regional, nacional e mundial.

\section{Recursos e infraestrutura disponíveis}

O Curso de Especialização em estudo foi beneficiado por um Edital da CAPES/UAB e dispõe de recursos financeiros considerados suficientes para a aquisição de materiais, bem como contratação de pessoal para oferecimento do curso.

A coordenação considera que o curso dispõe de uma boa infraestratura de equipamentos e de pessoal. Entretanto, ressalta algumas dificuldades em relação à biblioteca de certos polos, tendo em vista que em alguns destes os livros ainda não chegaram e o curso já está sendo finalizado.

\section{Objetivos do curso}

O objetivo principal do curso é contribuir para reflexões críticas a respeito do trabalho do Gestor da Educação e das políticas educacionais vigentes no cenário atual.

Os objetivos específicos são:

- Proporcionar educação continuada aos alunos recém graduados.

- Aprofundar e discutir a Gestão Escolar, bem como as relações interpessoais.

- Fornecer subsídios teóricos para a compreensão do meio educacional no qual as escolas estão inseridas, tendo em vista a ética e os princípios democráticos.

- Possibilitar aos participantes do curso um espaço para a problematização, construção de novos desafios que se colocam para a escola e para a educação em geral.

- Promover a reflexão e a discussão sobre o desenvolvimento da Gestão Escolar brasileira em seus diferentes níveis, face ao contexto de globalização excludente. 
- Propiciar a reflexão e a discussão sobre a função social da escola brasileira e as suas perspectivas para uma formação fundamentada na competência, na ética, na cidadania e na autonomia.

- Propiciar condições de aprofundamento e de atualização acerca do referencial teórico que embasa a prática dos profissionais da educação.

- Apresentar aos profissionais da educação, metodologias alternativas para as necessidades do cotidiano escolar.

- Oportunizar aos profissionais da educação o intercâmbio entre suas experiências didáticopedagógicas e as suas possibilidades como gestores.

- Propiciar ao gestor educacional, o conhecimento sobre a gestão financeira, física e patrimonial das instituições escolares.

- Desenvolver competências no uso do sistema de informações tecnológicas para utilização da tecnologia no ambiente escolar.

- Oportunizar conhecimento sobre o planejamento estratégico e sobre os projetos pedagógicos para eficácia no ambiente escolar.

\section{Definição do problema existente ou necessidade de investigação}

Segundo a coordenadora do curso, havia a necessidade de investigar qual a percepção do professor com relação à sua participação em um Curso de Especialização ofertado na modalidade a distância.

\section{Gap entre o ideal e real}

Segundo a coordenação do curso de especialização em Gestão Escolar, o ideal seria que todos os professores participantes do Curso de Especialização em estudo fossem comprometidos, envolvidos, participativos e que fornecessem feedback tanto à coordenação como aos estudantes do curso. Entretanto, houve alguns casos em que ficou evidente o descompromisso e falta de interesse pelo curso, bem como a falta de adaptação à modalidade a distância. 


\section{Fundame nto e Lógica da Avaliação}

A avaliação em muitos casos é realizada como uma forma de mensuração da qualidade de diferentes aspectos. E a educação a partir do contexto da $\mathrm{EaD}$ requer princípios, diretrizes e critérios que possam assegurar qualidade na aprendizagem e nos processos produtivos da $\mathrm{EaD}$, sobretudo no que diz respeito ao desenvolvimento do curso, formação dos professores, atendimentos das necessidades dos estudantes, infraestrutura, recursos para a aprendizagem, adequação da tecnologia, bem como a autoavaliação.

Neste sentido, as universidades vêm buscando novas formas de gerenciamento das mudanças ocorridas neste cenário, haja vista a relevância de se ter capacidade para prever, antecipar e estabelecer estratégias para possíveis fatos que possam ocorrer. E para se ter esta flexibilidade de gerenciamento as Instituições de Ensino recorrem à avaliação como um instrumento de mensuração de resultados, para que a partir desses, tenham elementos que possam propiciar uma prospecção de cenários, estando preparada para possíveis mudanças ou adequações. Além disso, a realização de avaliação propicia informações relevantes para a busca de excelência e maturidade de atuação. Entretanto, para que isso aconteça é necessário um "bom" plano de assessment.

Atualmente, existem no Brasil inúmeras Instituições de Ensino formal e não formal que ofertam cursos na modalidade a distância. Recentemente, a partir de 2005 se iniciou o Sistema Universidade Aberta do Brasil (UAB), a partir de um consórcio entre as Instituições de Ensino Superior Públicas, com foco de atuação em cinco eixos fundamentais, conforme CAPES (2009):

1. Expansão pública da educação superior, considerando os processos de democratização e acesso.

2. Aperfeiçoamento dos processos de gestão das instituições de ensino superior, possibilitando sua expansão em consonância com as propostas educacionais dos estados e municípios.

3. A avaliação da educação superior a distância tendo por base os processos de flexibilização e regulação, em implementação pelo MEC.

4. As contribuições para a investigação em educação superior a distância no país.

5. O financiamento dos processos de implantação, execução e formação de recursos humanos em educação superior a distância.

Tendo como base o aprimoramento da educação a distância, o Sistema UAB visa expandir e interiorizar a oferta de cursos e programas de educação superior. Para isso, o 
sistema busca fortalecer parcerias entre as esferas federais, estaduais e municipais do governo.

A partir dessa realidade, alguns instrumentos têm surgido com o objetivo de avaliar a qualidade da educação a distância oferecida por estas IES's. Entretanto, observa-se ainda carência de instrumentos que possam avaliar de forma qualitativa e quantitativa os diversos elementos e agentes envolvidos na EaD.

Nesse sentido, avaliar a percepção do professor em relação à sua participação em um curso de especialização ofertado na modalidade a distância contribuirá para que a IES tenha elementos adequados para antecipar, prever e estar preparada para mudanças e/ou adequações que se façam necessárias para atingir a excelência na oferta de seus cursos.

\section{Objetivo do Assessment}

O propósito deste assessment é criar um plano de ação adequado às necessidades da IES, bem como aplicar este plano como forma de analisar a percepção do professor atuante em um curso de especialização a distância.

Os resultados desta avaliação serão utilizados como indicadores para o planejamento e implementação de estratégias que possam assegurar melhoria e efetividade do curso em novas edições.

\section{Audiência (stakeholders) do Assessment}

\section{Interessados primários (stakeholders primários)}

Os interessados primários são os coordenadores e assessores pedagógicos do curso, para os quais conhecer a percepção do professor acerca de sua atuação em um curso de especialização a distância contribui significativamente para o planejamento de estratégias de melhoria do curso para edições futuras.

Interessados secundários (stakeholders secundários)

O interessado nesta esfera é a coordenação da UAB na IES, que ao conhecer a percepção de $\mathrm{EaD}$ dos professores atuantes, terá elementos que favorecem a tomada de decisão.

Interessados terciários (stakeholders terciários)

Professores atuantes no curso de especialização, os quais terão oportunidade de relatar sua percepção, bem como compará-las às de seus pares. 


\section{Questões-Chave para o Assessment}

1. As experiências adquiridas a partir da atuação no Curso de Especialização a distância contribuíram para sua prática docente?

2. Quais os pontos fortes do curso?

3. Quais os pontos a melhorar do curso?

4. Quais as suas sugestões para melhoria do curso em sua $2^{\mathrm{a}}$ Edição?

5. Como foi a relação entre professor e tutor durante a participação no curso?

6. Quais as competências e habilidades julga necessárias para a atuação de um docente em um curso de $\mathrm{EaD}$ ?

\section{Abordagem}

Esta avaliação utilizará uma abordagem orientada aos objetivos, a qual é altamente adequada para o programa de educação a distância, os quais tem os objetivos muito bem definidos e o propósito da avaliação é determinar em que medida estes objetivos foram cumpridos. Além disso, será atrelada a esta a abordagem colaborativa e participativa, que segundo Russ-Eft e Preskill (2001) é adequada quando se deseja: (a) criar capacidade interna de avaliação; (b) ampliar as possibilidades de utilização dos resultados para a tomada de decisão; e (c) envolver todos os interessados nos resultados da avaliação.

Neste estudo, todas as categorias de interessados participarão direta ou indiretamente no processo, tendo em vista que os resultados da avaliação serão utilizados para recomendar e/ou implementar planos de ação. O propósito é que todos conheçam a percepção dos professores em relação à atuação em um curso de especialização a distância, o que fundamentalmente implicará em retroalimentação para o processo de avaliação, bem como delineará as ações de melhoria que devem ser tomadas para edições futuras do curso.

\section{Método de Investigação}

Para se ter um pleno entendimento das percepções dos professores, e para que se possam planejar estratégias de melhoria é importante conhecer a abrangência do fenômeno. Portanto, serão utilizados mix métodos (quanti-quali), seguido de estudo de caso.

Desta forma, será realizado um survey para examinar a percepção dos professores. Atrelado ao survey, serão realizadas entrevistas para complementar e aprofundar a 
investigação, proporcionando respostas às questões chave.

A necessidade de se utilizar um recorte qualitativo se dá pelo fato de que as questõeschave dessa investigação são permeadas por aspectos subjetivos, de forma que a análise qualitativa traduzirá mais adequadamente as percepções dos atores da pesquisa. Nesse sentido, a abordagem qualitativa será realizada para que se possa relacionar diferentes variáveis, cujo resultado seja categorizado e quantificado, por meio da utilização de técnicas estatísticas, o que caracterizará a abordagem quantitativa da investigação. Além disso, a análise quantitativa será realizada para validação do instrumento utilizado para mensurar a percepção do professor em relação à participação em um curso de especialização ofertado na modalidade a distância.

\section{Design da Pesquisa}

Este assessment se caracteriza por estudo caso, comumente usado para responder a perguntas do tipo "como" e "por que", envolve análise em profundidade sobre determinado fenômeno, de forma a compreender as particularidades, exclusividades e diversidade dos casos. Além disso, envolve a coleta e análise descritiva dos dados referentes às percepções dos professores, o que propiciará elementos para o planejamento de estratégias de melhoria contínua.

\section{Natureza do Assessment}

Considerando que o Curso de Especialização ora referido está em fase final de realização ( $1^{\mathrm{a}}$ edição), a natureza do assessment é somativa. Entretanto, as informações identificadas na investigação serão utilizadas na próxima edição do curso que está sendo planejada.

\section{Seleção da Amostra}

A população atuante no curso é de 18 (dezoito) professores. Entretanto serão considerados apenas 17 (dezessete), pois um é coordenador do curso e participou da construção deste plano de assessment. Neste sentido, a intenção é realizar um censo, cuja participação será por adesão, a partir da explicitação dos objetivos de modo evitar a interferência de tratamento. 
$\mathrm{Na}$ tentativa de minimizar os pontos críticos da validade interna, será assegurado rigor científico na construção do instrumento, como forma de manter a instrumentação adequada para o assessment.

As especificidades das variáveis serão contornadas com o rigor científico adotado na cons trução e apreciação das questões do questionário.

\section{Modelo Lógico do Assessment}

A visão sistêmica do assessment é visualizada na figura 36.

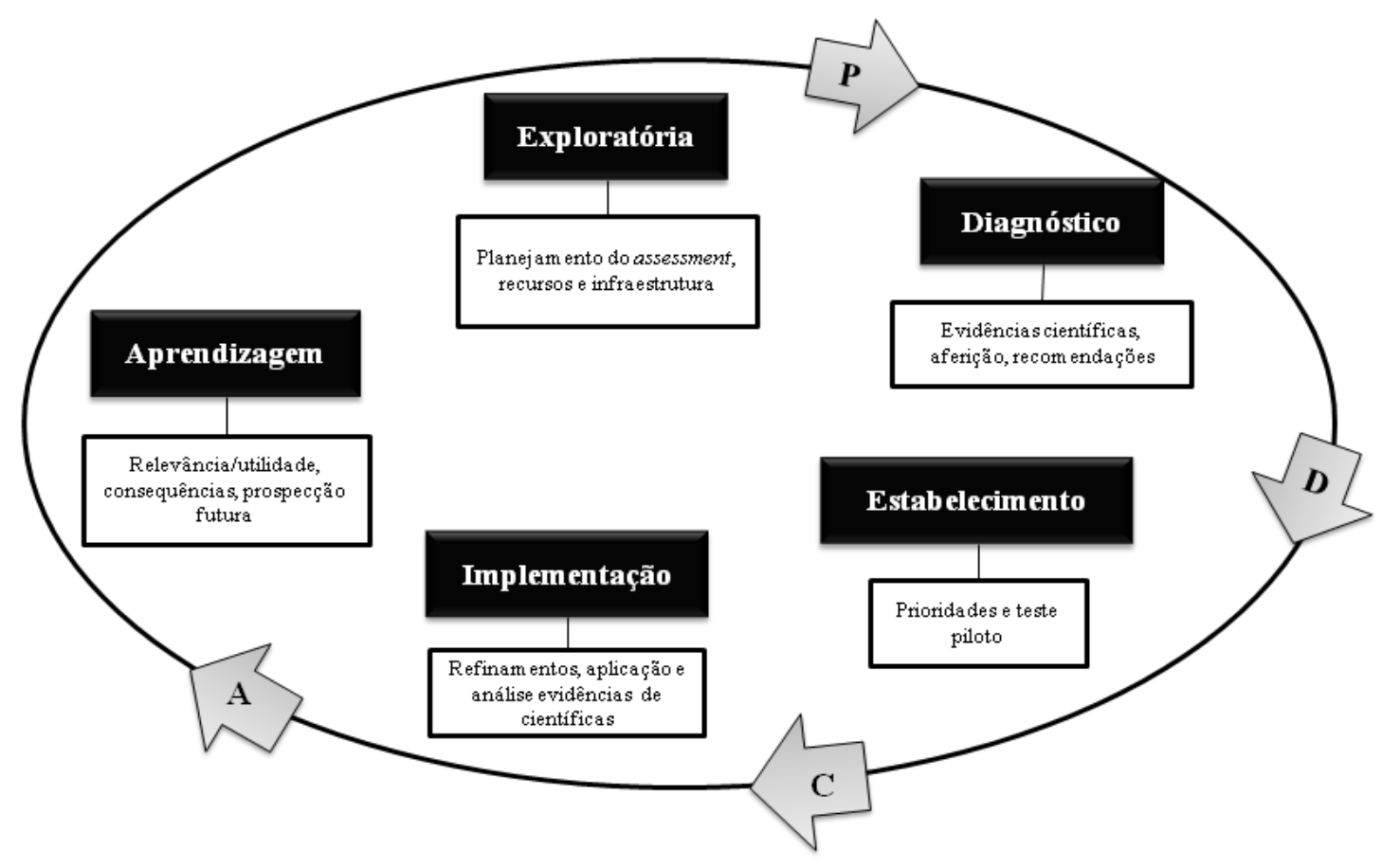

Figura 36 - Modelo lógico do assessment

\section{Métodos e Instrumentos para a Coleta de Dados}

Tendo em vista a natureza somativa da avaliação, a investigação será realizada por meio de estudo de caso e utilizará survey/questionário e entre vista individual.

\section{Survey/Questionário}

Será utilizado para se conhecer qual a percepção do professor sobre a sua participação no Curso de Especialização a distância.

$\mathrm{Na}$ tentativa de minimizar os pontos críticos da validade, o questionário será aplicado pela pesquisadora, com preservação da identidade do docente respondente. 
Além disso, será utilizada escala de Likert (1932) com cinco pontos sendo, 1 para concordo totalmente e 5 para discordo totalmente. A razão para utilizar escala ímpar é justificada pelo fato de que quando se avalia opiniões, atitudes, percepções deve-se permitir a neutralidade (HILL; HILL, 1998; S YNODINOS, 2003).

Para cada questão o respondente deverá marcar sua opinião sobre a importância e presença do conteúdo da sentença. Este procedimento favorece a triangulação de informações muito divergentes, além de verificar a existência de gap, contribuindo para a manifestação de validade.

Esta fase ocorrerá em três etapas, sendo a primeira a construção do questionário e do protocolo de entrevista, que foram realizadas a partir da sistematização da literatura. A mesma gerou um esboço que foi apreciado pela coordenação e assessoria pedagógica do curso, resultando em uma proposta de questionário e entrevista que contemplava todos os requisitos considerados relevantes sob a perspectiva da coordenação.

Na segunda etapa, o questionário e protocolo de entrevista foram apresentados a um grupo de cinco professores que trabalhavam com $\mathrm{EaD}$ na IES pesquisada.

A terceira etapa foi a apreciação do questionário e da entrevista por cinco pesquisadores sobre $\mathrm{EaD}$, considerando especialistas, para que julgassem se as questões propostas mensuravam a percepção dos professores acerca da atuação em EaD, bem como no curso de especialização em estudo (técnica Delphi segundo Turoff (1975); Loo (2002)). Foram necessárias duas sessões para atingir consenso.

O questionário, bem como, a entrevista apresenta itens que respondem a todas as questões chave do assessment, as quais foram organizadas conforme sugestões dos especialistas.

Dando continuidade à pesquisa, o questionário e o protocolo de entrevista obtido após consenso entre os juízes, serão aplicados a um grupo de cinco professores como pré-teste da avaliação.

O gerenciamento do banco de dados será realizado pela pesquisadora, não exigindo treinamento de pessoa externa à pesquisa.

\section{Entrevista individual}

As respostas às questões da entrevista serão analisadas utilizando-se a técnica análise de conteúdo (Bardin, 2002; 2004).

De posse dos resultados obtidos pela aplicação dos questionários, serão observadas questões que apresentam divergência entre o nível de presença e importância, para que as 
mesmas sejam confirmadas/confrontadas, por meio de uma nova entrevista individual e/ou verificação in loco.

Todas as entrevistas serão realizadas pela pesquisadora, descartando a necessidade de treinamento de novos entrevistadores. Além disso, as respostas serão registradas de forma literal, porém, com validação do entrevistado. Na sequência, as respostas serão tabuladas e categorizadas.

Esse procedimento enriquecerá as informações e minimizará as ameaças à validade, uma vez que neutraliza os efeitos resultantes do investigador.

O quadro 18 apresenta a relação entre os métodos de coleta de dados e as questões chaves.

\begin{tabular}{|l|c|c|}
\hline \multicolumn{1}{|c|}{ Questões Chaves } & $\begin{array}{c}\text { Survey/ } \\
\text { Questionário }\end{array}$ & $\begin{array}{c}\text { Entrevista } \\
\text { Individual }\end{array}$ \\
\hline $\begin{array}{l}\text { Q1. As experiências adquiridas a partir da atuação no } \\
\text { Curso de Especialização a distância contribuíram para } \\
\text { sua prática docente? }\end{array}$ & $\mathrm{X}$ & $\mathrm{X}$ \\
\hline Q2. Quais os pontos fortes do curso? & $\mathrm{X}$ & $\mathrm{X}$ \\
\hline $\begin{array}{l}\text { Q3. Quais os pontos francos do curso? } \\
\text { Q4. Quais as sugestões dos docentes para a melhoria do } \\
\text { curso, em sua 2 }{ }^{\text {a }} \text { Edição? }\end{array}$ & $\mathrm{X}$ \\
\hline $\begin{array}{l}\text { Q5. Como foi a relação entre professor-tutor e equipe } \\
\text { multidisciplinar durante a participação no curso? }\end{array}$ & $\mathrm{X}$ & \\
\hline $\begin{array}{l}\text { Q6. Quais as competências e habilidades considera } \\
\text { necessárias para a atuação de um docente em um curso } \\
\text { de EaD? }\end{array}$ & $\mathrm{X}$ & \\
\hline
\end{tabular}

Quadro 18 - Relação entre os métodos de coleta de dados e as questões chave da avaliação 


\section{Protocolos Para Coleta dedados}

\section{Questionário}

Idade: anos

Se xo: [ ] Masculino

[ ] Feminino

Curso(s) no(s) qual(is) é docente:

É docente de qual Departamento da UNICENTRO:

Discip lina(s) na EaD sob sua responsabilidade:

Você te mexperiência em educação a distância? [ ] Sim [ ] Não

Se sim, quanto tempo?

Você está desenvolvendo alguma pesquisa na área de EaD? [ ] Sim [ ] Não

Você já publicou algu m resultado de pesquis a no campo de EaD? [ ] Sim [ ] Não

\begin{tabular}{|c|c|c|c|c|c|c|}
\hline & Impor tância que você dá para esta ação & \begin{tabular}{|l|l|l}
1 & 2
\end{tabular} & 3 & 4 & 5 \\
\hline & & Ocorrência efeti va na sua prática & \begin{tabular}{l|l|l}
1 & 2
\end{tabular} & 3 & 4 & 5 \\
\hline \multirow[t]{2}{*}{1.} & \multirow[t]{2}{*}{ Q5 } & \multirow{2}{*}{$\begin{array}{l}\text { Trabalhar cooperativamente com designers instrucionais, suporte técnico, equipe de } \\
\text { produção de materiais didático e tutores }\end{array}$} & & & & \\
\hline & & & & & & \\
\hline 2. & Q5 & Estabelecer objetivos e resultados de aprendizagem & & & & \\
\hline \multirow{2}{*}{3.} & Q5 & \multirow{2}{*}{ Responder às questões e problemas dos usuários } & & & & \\
\hline & Q6 & & & & & \\
\hline 4. & Q5 & $\begin{array}{l}\text { Adequar o plano de ensino conforme as sugestões dos Projetistas Instrucionais } \\
\text { especializados em EaD }\end{array}$ & & & & \\
\hline \multirow{2}{*}{5.} & Q5 & \multirow{2}{*}{ Iniciar e fomentar as discussões nos fóruns } & & & & \\
\hline & & & & & & \\
\hline \multirow[b]{2}{*}{6.} & Q5 & \multirow{2}{*}{$\begin{array}{l}\text { Desenvolver atividades com a visão da modalidade de Educação a Distância e de } \\
\text { acordo com as orientações da coordenação do curso, projetistas instrucionais e equipe } \\
\text { técnica. }\end{array}$} & & & & \\
\hline & Q6 & & & & & \\
\hline \multirow{2}{*}{7.} & 05 & \multirow{2}{*}{$\begin{array}{l}\text { Auxiliar a equipe técnica na formatação do seu ambiente virtual, dando diretrizes e } \\
\text { fazendo avaliação do trabalho realizado. }\end{array}$} & & & & \\
\hline & Q & & & & & \\
\hline \multirow{2}{*}{8.} & \multirow{2}{*}{ Q5 } & \multirow{2}{*}{$\begin{array}{l}\text { Avalizar a formatação final de seu material impresso e virtual após o trabalho da equipe } \\
\text { técnica e linguística. }\end{array}$} & & & & \\
\hline & & & & & & \\
\hline \multirow{2}{*}{9.} & 05 & \multirow{2}{*}{$\begin{array}{l}\text { Responder às necessidades da coordenação do curso para o desenvolvimento de sua } \\
\text { disciplina. }\end{array}$} & & & & \\
\hline & Q & & & & & \\
\hline 10. & Q5 & $\begin{array}{l}\text { Gerenciar os tutores sob sua responsabilidade, dando-lhes feedback e verificando sua } \\
\text { assiduidade no ambiente virtual. }\end{array}$ & & & & \\
\hline \multirow{2}{*}{11.} & & \multirow{2}{*}{$\begin{array}{l}\text { Reunir periodicamente com os tutores sob sua responsabilidade (presencial e/ou } \\
\text { virtualmente) para orientação pedagógica sobre seus conteúdos e sobre seu sistema de } \\
\text { avaliação. }\end{array}$} & & & & \\
\hline & Q5 & & & & & \\
\hline \multirow[b]{2}{*}{12.} & Q5 & \multirow{2}{*}{$\begin{array}{l}\text { Fazer relatórios de final de ciclo/unidade, em um texto síntese, dando feedback para } \\
\text { todos os alunos sobre o resultado obtido, esclarecendo quaisquer pontos que necessitem } \\
\text { ser explicitados. }\end{array}$} & & & & \\
\hline & Q6 & & & & & \\
\hline \multirow[b]{2}{*}{13.} & Q5 & \multirow{2}{*}{$\begin{array}{l}\text { Dedicar-se semanalmente, após o início da disciplina, pelo menos o mes mo tempo que } \\
\text { se dedica a uma disciplina presencial, organizando seu tempo para gerenciar o } \\
\text { ambiente, os tutores e os alunos. }\end{array}$} & & & & \\
\hline & Q6 & & & & & \\
\hline \multirow[b]{2}{*}{14.} & & \multirow{2}{*}{$\begin{array}{l}\text { Manter contato com o supervis or de tutoria de seu curso para substituição ou } \\
\text { acompanhamento de tutores sob sua responsabilidade caso haja algum tipo de proble ma } \\
\text { e o tutor tenha que se ausente por um curto período. }\end{array}$} & & & & \\
\hline & Q5 & & & & & \\
\hline
\end{tabular}




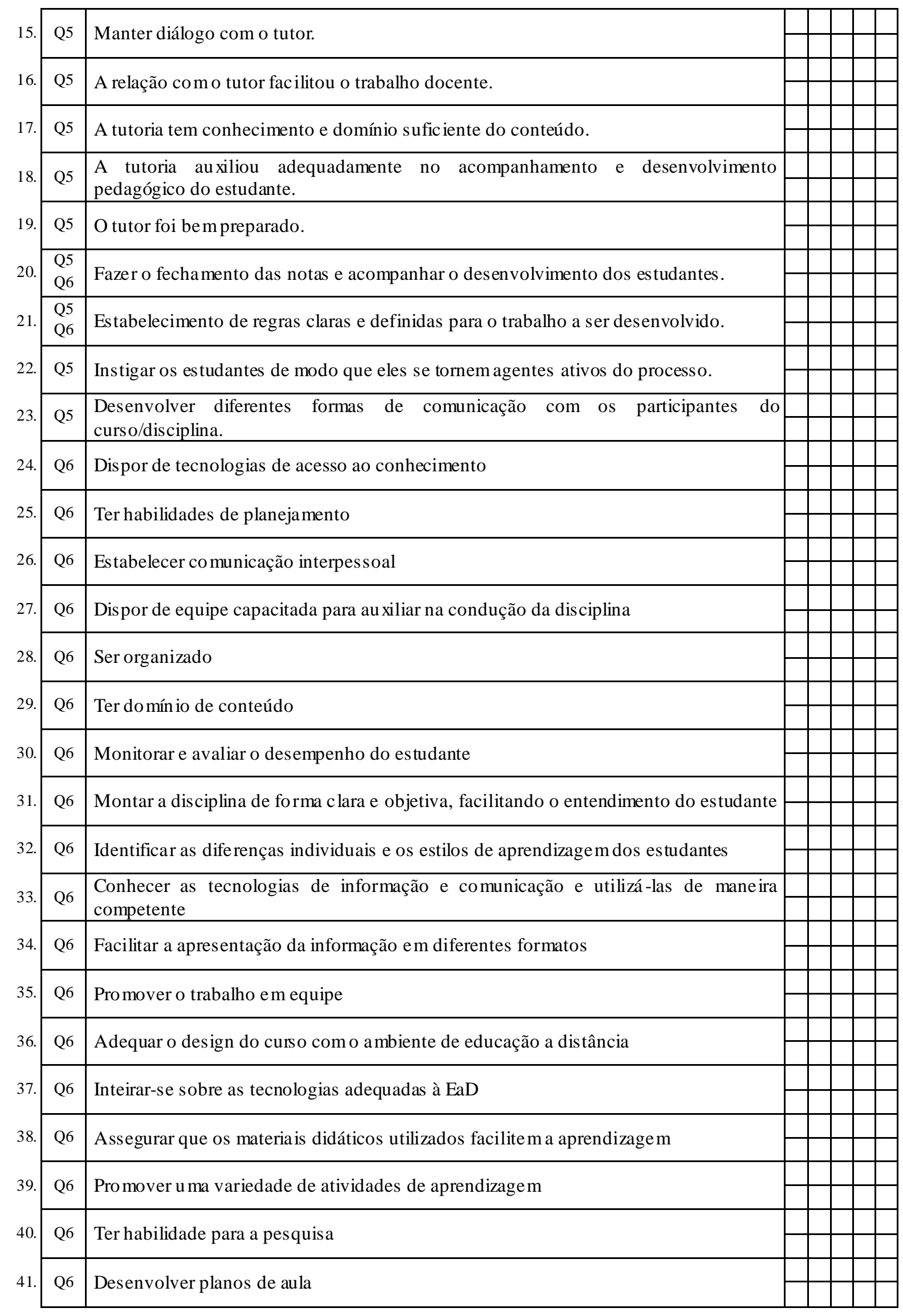




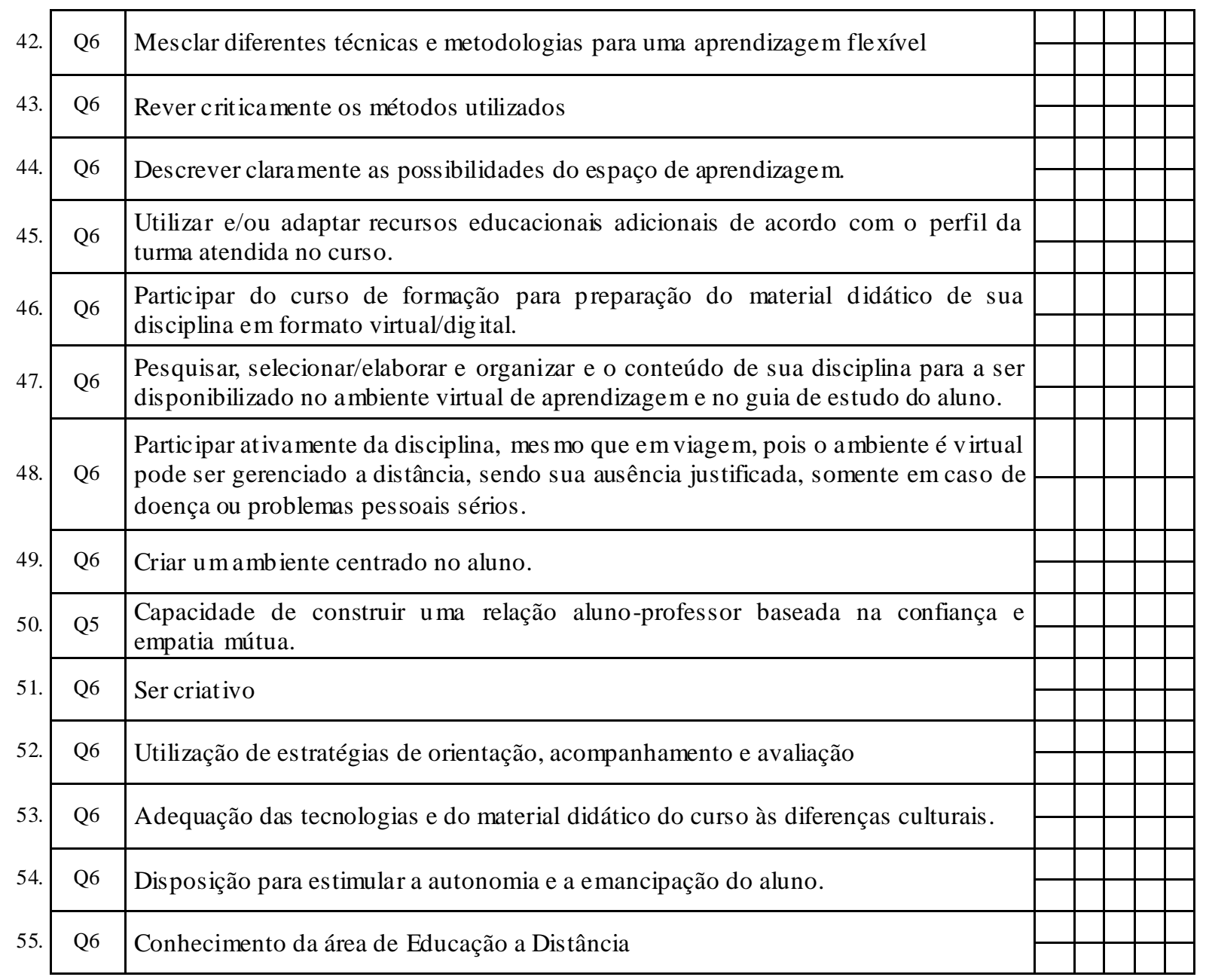

\section{LEGENDA:}

\section{Impor tância que você dá para esta ação:}

1- Mu ito importante, 2-Importante, 3- Neutro, 4- Pouco Importante, 5- Nada importante

\section{Ocorrência efetiva na sua prática:}

1- Concordo Totalmente, 2- Concordo, 3- Neutro, 4- Discordo, 5- Discordo Totalmente 
Entrevista (Q1, Q2, Q3, Q4)

Entrevistado(a)

\section{Questões-Chave da Avaliação}

1. As experiências adquiridas a partir da atuação no Curso de Especialização em Gestão Escolar contribuíram para sua prática docente?

2. Quais os pontos fortes do curso?

3. Quais os pontos a melhorar do curso?

4. Quais as suas sugestões para melhoria do curso em sua $2^{\mathrm{a}}$ Ed ição?

5. Como foi a relação entre professor e tutor durante a participação no curso?

6. Quais as competências e habilidades julga necessárias para a atuação de um docente em um curso de EaD?

\section{Guia de Entrevista}

1. Quais eram suas expectativas quando iniciou seu trabalho em um curso a distância?

2. Como você descreve sua experiência no curso a distância?

3. A atuação em um curso a distância trouxe algum benefício para sua prática no ensino presencial?

4. Em sua opinião, quais foram os pontos fortes e os pontos a melhorar do curso que atuou?

5. Quais suas sugestões para melhoria do curso?

6. Qual o grau de satisfação que você tem para com o curso que atuou?

$\begin{array}{llllllllll}\longleftrightarrow & 2 & 3 & 4 & 5 & 6 & 7 & 8 & 9 & 10\end{array}$

\section{Comentários/Observações do entrevistador/pesquisador}




\section{Métodos e Instrumentos para a Análise dos Dados}

De acordo com os instrumentos utilizados, métodos de análises serão aplicados, tais como:

\section{Questionário/ Survey}

$1^{a}$ Fase: Validação do questionário

- O questionário foi elaborado a partir da literatura científica selecionada em bases de dados (Web of Science, Science Direct, Scielo, ProQuest, JSTOR, SCOPUS, ERIC, Psicodoc, $\mathrm{ABI} /$ Inform, bem como banco de dissertações e teses nacionais e internacionais), utilizando estratégias de busca baseadas nos temas da investigação, resultando em uma sistematização de publicações referentes ao estudo.

- O primeiro esboço será apresentado à coordenação e assessoria pedagó gica do curso para apreciação e aprovação.

- Após aprovação, o questionário será apreciado por 5 professores que trabalham com EaD na IES pesquisada, para análise e sugestões.

- Na sequência, o questionário será avaliado por 5 pesquisadores sobre EaD que farão a análise de juízes.

- Após consenso entre os juízes, o questionário será pré-testado por 5 professores que atuam em EaD.

\section{$2^{a}$ Fase: Aplicação do questionário}

- O questionário será aplicado pela pesquisadora, mediante agendamento prévio com os respondentes.

- Serão explicitados os objetivos do estudo e destacada a importância de se responder a todas as questões do questionário. Entretanto, as questões não serão de preenchimento obrigatório para seu prosseguimento.

- Será solicitada a assinatura dos respondentes no Termo de Consentimento Livre e Esclarecido.

\section{Entrevista Individual}

As entrevistas serão categorizadas, utilizando a técnica de análise de conteúdo, para que se tenha um panorama sobre as percepções dos professores que atuaram no Curso de Especialização em Gestão Escolar. Além disso, será possível confirmar as respostas que se 
destoaram no questionário/survey, as quais serão destacadas com base na triangulação.

O quadro 19 apresenta uma síntese entre os métodos de coleta de dados e os métodos de triangulação utilizados.

\begin{tabular}{|c|c|}
\hline Instrumento de Coleta de Dados & Métodos de Triangulação \\
\hline Entrevista & $\begin{array}{l}\text { - } \text { Triangulação metodológica } \\
\text { - Triangulação de dados } \\
\text { - } \quad \text { Triangulação de investigador }\end{array}$ \\
\hline Questionário & $\begin{array}{ll}\text { - } & \text { Triangulação metodológica } \\
\text { - } & \text { Triangulação de dados } \\
\text { - } & \text { Triangulação de investigador }\end{array}$ \\
\hline
\end{tabular}

Quadro 19 - Relação entre os métodos de coleta de dados e os métodos de triangulação

\section{Cronograma para a Avaliação}

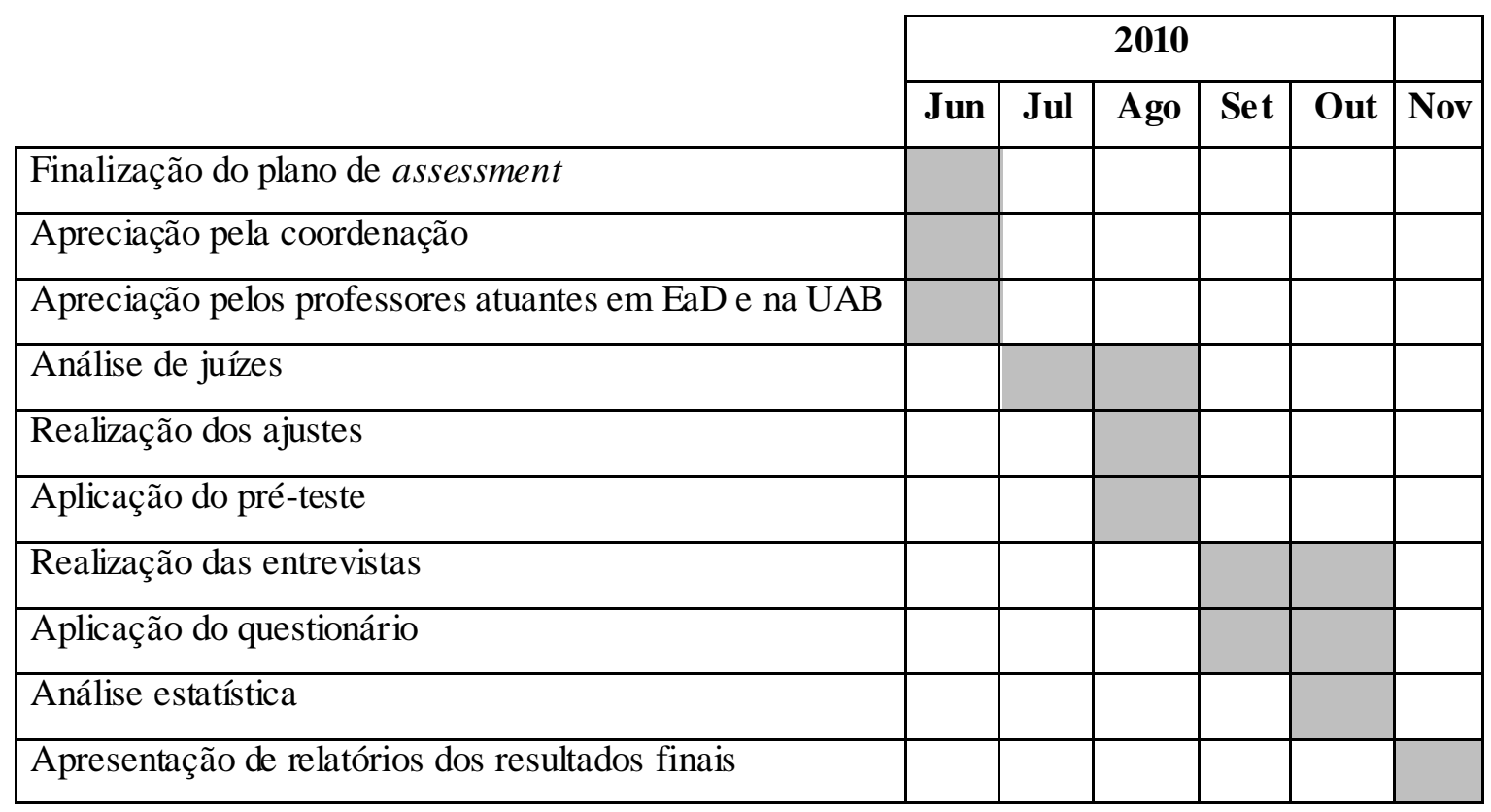

\section{Divulgação e uso dos resultados do assessment}

A partir dos resultados será elaborado um relatório circunstanciado para a coordenação do curso, bem como a redação final da tese de doutorado para defesa pública. Ficará a cargo da coordenação do curso investigado o repasse dos resultados aos interessados.

Será encaminhado aos professores participantes da pesquisa um relatório sintético dos 
resultados obtidos.

Além disso, será elaborado um artigo científico para submissão em periódico, com vista à disseminação do conhecimento gerado, na comunidade científica, contribuindo para cons trução de uma base de benchmark.

\section{Relação Custo x Benefício}

Será elaborada uma planilha com os custos prováveis, bem como a justificativa de cada investimento, justificando a relação custo x benefício.

\section{Restrições/Limitações}

Mesmo utilizando diferentes ferramentas para a coleta de dados, é possível que haja subjetividade da pesquisa, uma vez que se trata de uma aplicação em pessoas. Assim, após a análise e discussão dos resultados obtidos, será possível tecer comentários acerca das restrições/limitações da investigação.

\section{Documentação do assessment}

Este plano de assessment será entregue a coordenação do curso e será guardado com a pesquisadora, bem como os resultados obtidos com a aplicação que acontecerá posteriormente.

\section{Consequências}

Após a aplicação do instrumento será possível identificar as possíveis consequências sociais, institucionais e instrucionais, tanto no aspecto positivo como negativo, o que corrobora com a prospecção de cenário futuro. 
CAPÍTULO 8 - Aplicação da solução desenvolvida a partir da Arquitetura de Orientação para Assessment de Programas de Educação a Distância

Neste capítulo será apresentada a aplicação da solução desenvolvida a partir dos pressupostos da Arquitetura de Orientação (Plano de Assessment). Esta aplicação tem como finalidade apresentar e discutir os resultados obtidos com os instrumentos utilizados questionário, entrevista e confirmação in loco, para mapeamento da percepção do professor em relação à participação em curso de especialização ofertado na modalidade a distância. Este capítulo se caracteriza como a terceira etapa da pesquisa.

A aplicação da solução se deu em treze participantes, sendo oito do gênero masculino e cinco do feminino, isso mostra que houve uma proporcionalidade entre os respondentes.

Em relação às idades, verificou-se que o corpo docente do curso pesquisado é formado em sua maioria por professores jovens, conforme gráfico 1 .

Gráfico 1- Idades dos participantes

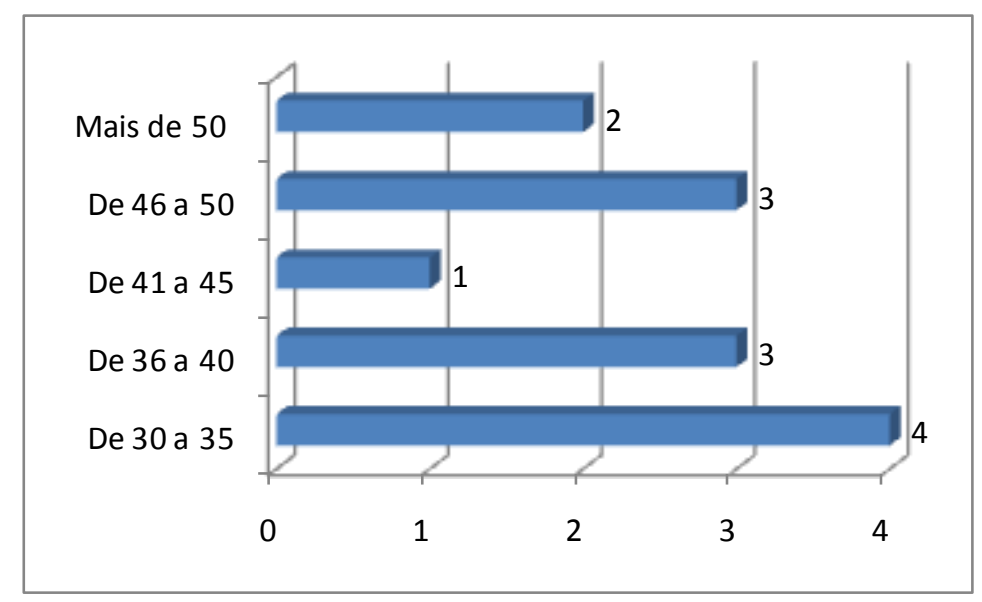

Ao analisar a experiência dos respondentes com a Educação a Distância, dez professores alegaram não ter experiência, conforme gráfico 2 . 
Gráfico 2 - Experiência dos professores em EaD

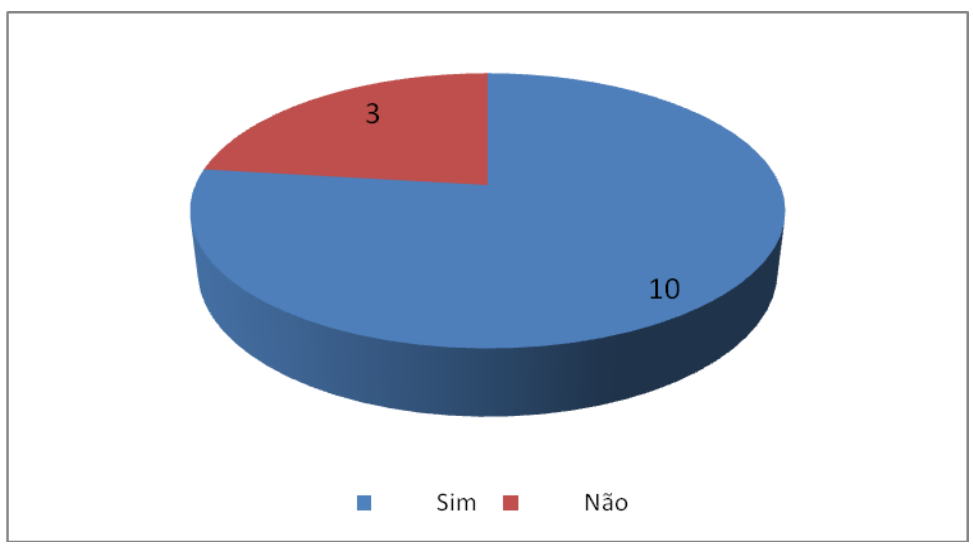

Este resultado era esperando tendo em vista que a adesão da Universidade pesquisada pela $\mathrm{EaD}$ é recente, datada de 2006, e a participação na UAB foi a partir de 2009. Dentre os que responderam que tinham experiência na área, quatro era de até um ano e cinco entre um e três anos. Com isso, pode-se inferir que este é um processo natural, que na medida em que a $\mathrm{EaD}$ cresce na IES mais professores serão engajados no processo.

Atrelado a este resultado tem-se o pouco desenvolvimento e publicação de pesquisas na área de $\mathrm{EaD}$. Somente dois professores respondentes já desenvolveram e/ou publicaram alguma pesquisa na área de $\mathrm{EaD}$.

\subsection{Análise Qualitativa}

As entrevistas aconteceram com o objetivo de ampliar a profundidade das respostas, bem como mapear o comportamento do professor que atua em um curso ofertado na modalidade a distância. O tempo gasto para cada entrevista variou entre vinte a quarenta minutos.

As respostas das questões abertas (entrevistas) foram analisadas sob a perspectiva da análise de conteúdo apregoado por Bardin (2002; 2004). Para tal, adotou-se da técnica a unidade de análise, sendo análises de registro e contexto, bem como as categorias de análises, as quais foram estabelecidas a partir da matéria - assuntos abordados e forma fatos e comentários.

Nesse sentido, foram definidas as unidades de análise, bem como as categorias de análise para cada uma das questões abordadas nas entrevistas, conforme apresentadas abaixo. Questão 01: Quais eram suas expectativas quando iniciou seu trabalho em um curso a 
distância?

$\underline{\text { Unidades de análise }}$

- Desafio

- Conhecimento

- Aprimoramento

- Avaliação

- Apreciação

- Potencial

- Contribuição

Categorias de análise

- Conhecimento/aprimoramento em EaD.

- Oportunidade para inovar em novas metodologias e procedimentos.

- Oportunidade para avaliar e analisar o potencial da EaD.

A partir deste resultado, observou-se a existência de um forte interesse em conhecer melhor a $\mathrm{EaD}$, bem como ter a oportunidade para inovar os procedimentos didáticos, metodológicos e pedagógicos. Além disso, notou-se grande interesse em analisar e avaliar criticamente os procedimentos adotados na $\mathrm{EaD}$, bem como o seu potencial.

Este resultado está em conformidade com o momento histórico que a EaD vive na Instituição de Ensino, pois em 2009 iniciou suas atividades no consórcio da Universidade Aberta do Brasil (UAB) e tem aumentado significativamente a oferta de cursos na modalidade a distância. Portanto, entende-se que o interesse do professor está muito relacionado a este fato, pois se sabe que a EaD é algo que não tem mais volta, assim, todos "precisam" conhecer e se preparar para esta modalidade de ensino.

Questão 02: Como você descreve sua experiência no curso a distância?

Unidades de análise

- Desafiadora

- Interessante

- Gratificante

- Positiva

- Inovadora 
Categorias de análise

- Envolvimento e participação dos estudantes.

- Desenvolvimento de atividades inovadoras em diferentes formatos.

- Aprimoramento da prática - aprender a aprender.

Analisando as respostas dos professores participantes da pesquisa, percebeu-se que a atuação em um curso na modalidade a distância foi muito válida, tendo em vista que tiveram a oportunidade de testar, bem como conhecer diferentes metodologias que julgaram adequadas à EaD. Além disso, o fato de terem a oportunidade de aprimorar a prática docente nesta modalidade, utilizando variadas ferramentas (tecnologias) para a construção das respectivas disciplinas, foi algo considerado por eles como instigante, pois fomentava o aprender a aprender na visão do professor.

Com isso, pode-se aferir que o curso no qual atuaram proporcionou um espaço de cons trução do conhecimento e aprimoramento da prática pedagógica.

Questão 03: A atuação em um curso a distância trouxe algum benefício para sua prática no ensino presencial?

$\underline{\text { Unidades de análise }}$

- Material didático

- Tecnologia

- Moodle

Categorias de análise

- Aprimoramento na elaboração de material didático para a modalidade EaD.

- Oportunidade de conhecer/aprimorar o uso da tecnologia (recursos multimeios).

- Apropriação e domínio do Ambiente Virtual Moodle.

A partir dos resultados obtidos, percebeu-se uma grande satisfação dos professores em relação à elaboração do material didático para a $\mathrm{EaD}$, pois embora desafiador e muitas vezes com o tempo apertado para a entrega, foi um momento especial para o docente, no qual necessitou romper com o paradigma do ensino presencial e elaborar um material adequado e interessante para a modalidade a distância. 
Também observou-se que a oportunidade de utilização de diferentes tecnologias (multimeios) contribuiu significativamente para ampliar o conhecimento dos professores nesta área. Consequentemente, oportunizou a apropriação e domínio do Moodle, fato este unânime entre todos os respondentes.

Com isso, verificou-se que embora o Moodle estivesse disponível na Instituição para uso dos professores desde 2007, muitos não o adotavam como apoio no ensino presencial e só passaram a fazer uso dele a partir da atuação no curso a distância.

Neste sentido, pode-se inferir que a atuação dos professores no curso de especialização a distância estimulou e proporcionou a utilização de diferentes tecnologias na construção de suas disciplinas, tanto na modalidade a distância como na presencial.

Questão 04: Em sua opinião, quais foram os pontos fortes e pontos a melhorar do curso em que atuou?

\section{- Pontos Fortes}

\section{$\underline{\text { Unidades de análise }}$}

- Processo

- Avaliação

- Envolvimento

- Coordenação

\section{$\underline{\text { Categorias de análise }}$}

- Qualidade do processo.

- Procedimentos de avaliação.

- Comprometimento e envolvimento da equipe de coordenação do curso.

Diante das colocações dos participantes, as respostas convergiram fortemente para as três categorias acima citadas, com destaque para a coordenação do curso, a qual obteve grande reconhecimento pela dedicação, envolvimento e comprometimento da equipe.

Além disso, os procedimentos de avaliação (tanto no AVA como presencial) foram bastante relacionados pela confiabilidade e participação dos envolvidos, pois em todas as avaliações presenciais havia a participação do professor responsável pela disciplina.

Outro aspecto ressaltado pelos respondentes foi a qualidade do processo de gestão do curso, haja vista o reconhecimento do trabalho da coordenação. 


\section{- Pontos A Melhorar}

Unidades de análise

- Capacitação.

- Logística/estrutura UAB.

- Acervo bibliográfico.

- Material impresso.

\section{$\underline{\text { Categorias de análise }}$}

- Capacitação dos professores e tutores.

- Logística interna e estrutura da UAB da instituição.

- Qualidade do material impresso.

- Acervo bibliográfico dos polos.

Uma questão bastante ressaltada pelos professores foi a capacitação docente e dos tutores, a qual, segundo eles, foi bastante limitada. Desta forma, julgaram como algo extremamente urgente para alteração.

Diante da unanimidade das respostas, a pesquisadora foi verificar in loco e aprofundarse sobre este problema e observou-se que a capacitação era ministrada de forma aligeirada, com poucas horas de prática. Além disso, a modalidade EaD é nova na IES e poucos professores tinham experiência na área. Logo, exigia-se uma formação mais abrangente e pausada para os professores.

Em relação aos tutores, algo semelhante foi relatado pelos professores pesquisados, somado ao fato de que muitos alegaram que os tutores não tinham competência adequada para atuar na EaD e acabam não contribuindo para o bom andamento da disciplina.

Para averiguar tal situação, a pesquisadora foi in loco conhecer como se dá a formação dos tutores, e verificou que a capacitação acontece em um dia, no qual se trabalha a utilização do Moodle, pois o uso da informática já é pré-requisito na seleção dos mesmos. Além disso, não existe uma discussão sobre a Educação a Distância e seus pressupostos.

Em conversa com a coordenação da $\mathrm{UAB}$, a pesquisadora foi informada que a Instituição teve o Programa Anual de Capacitação aprovado pelo MEC e que já estava providenciando a oferta de cursos de formação para todos os envolvidos (professores conteudistas/formadores, tutores e coordenadores de polo). 
Desta forma, pode-se aferir que este problema foi algo pontual para este curso pesquisado, haja vista que foi a primeira oferta de especialização a distância dentro do consórcio UAB da IES e que providências já estão sendo tomadas para corrigir tal situação.

Questão 05: Quais suas sugestões para melhoria do curso?

$\underline{\text { Unidades de análise }}$

- Capacitação.

- Acervo bibliográfico.

- Logística/es trutura.

- Número de alunos.

\section{Categorias de análise}

- Ampliar e aprimorar a capacitação dos docentes e dos tutores.

- Ampliar o acervo bibliográfico nos polos.

- Melhorar a estrutura e logística interna da UAB.

- Reduzir o número de alunos do curso.

Estes resultados mostram que as sugestões propostas vão ao encontro dos pontos a melhorar. Com isso, a partir da verificação in loco teve-se mais clareza sobre a forma como acontece a capacitação dos professores e tutores, conforme relatado anteriormente. Sendo possível afirmar, que conforme relato da coordenação da UAB esta situação será brevemente revertida.

Diante das várias sugestões e problemas abordados sobre o acervo bibliográfico dos polos, fez-se uma verificação in loco para saber as razões destas manifestações. Verificou-se que tal situação ocorre em função do processo licitatório, pois mesmo realizando o pedido antes do início do curso, a IES (por força de lei) só pode realizar as compras por meio de lotes e/ou pregões, o que acaba atrasando a entrega dos livros, o que aconteceu especificamente neste curso pesquisado.

Em relação à estrutura e logística da UAB na Instituição, este é um problema que foge da competência da coordenação do curso pesquisado. Entretanto, mediante uma verificação in loco na coordenação da $\mathrm{UAB}$, obteve-se que isso se dá pelo fato de que a $\mathrm{EaD}$ teve grande crescimento; ampliando consideravelmente o número de cursos ofertados o que acabou exigindo uma estrutura que a IES não dispunha. Portanto, esta situação está sendo ajustada na 
medida em que é liberado espaço físico, bem como pessoal. Para a questão da logística, verificou-se que o principal problema ocorre nas aplicações das avaliações presenciais, pois como os professores acompanham, exige-se grande disponibilidade de veículos, envolvendo praticamente toda a frota da universidade, o que consequentemente altera a rotina da mesma, provocando, muitas vezes, transtornos e imprevistos.

Para a categoria "Reduzir o número de aluno", foi-se verificar in loco o porquê desta colocação e encontrou-se, mediante observação no Moodle, que todos os alunos $( \pm 800)$ estavam em uma mesma sala, separados por grupos, o que dificultava o gerenciamento da disciplina. Assim, sugeriu-se à coordenação que criasse um espaço coletivo e várias salas com no máximo 30 alunos cada, pois isso facilitaria a organização e acompanhamento de cada disciplina, reduzindo o problema apontado.

Questão 06: Qual o grau de satisfação que você tem com o curso que atuou?

Conforme gráfico 3 é possível observar o grau de satisfação dos professores para com o curso.

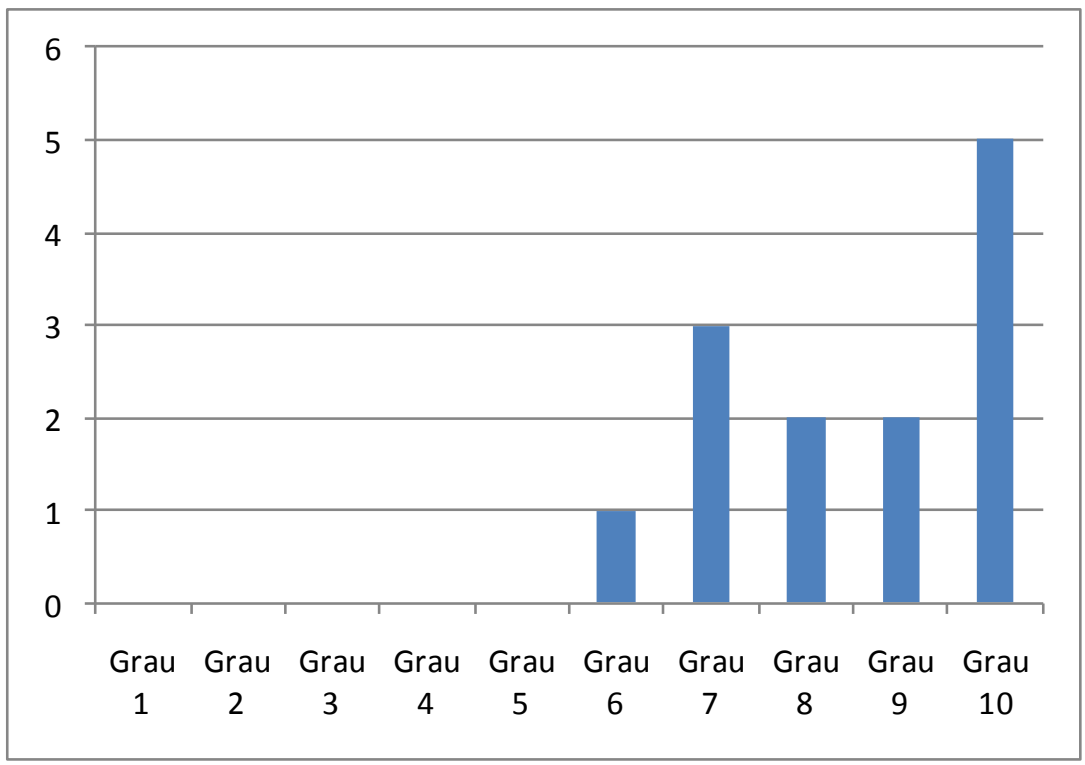

Gráfico 3 - Grau de satisfação dos professores com o curso que atuaram

De maneira geral, observou que os pontos positivos foram superiores aos pontos a melhorar do curso, proporcionando um bom nível de satisfação entre os professores pesquisados, dos quais, cinco alegaram satis fação total com o curso.

Ao término de cada entrevista abria-se um espaço para que o professor pudesse tecer seus comentários, observações, enfim, complementar a entrevista, caso julgasse necessário. Assim, com a sistematização e categorização, obteve-se: 
- O docente deve ser melhor esclarecido sobre o funcionamento da UAB (bolsas, prazos, regras, etc...).

- As pessoas precisam adaptar-se à EaD.

- Reconheceu-se esta experiência como oportunidade de aprender, sobretudo, na elaboração de material didático.

- Reconheceu-se nesta experiência a oportunidade de estabelecer uma linguagem mais coloquial sem perder de vista o caráter científico que o processo exige.

- Houve melhores resultados em polos pequenos.

- Identificou-se que se o aluno é bom, independe a modalidade.

Estas considerações sinalizam algumas melhorias que podem ser incorporadas em edições futuras do curso.

\subsection{Análise Quantitativa}

Os dados resultantes da aplicação do questionário que foram utilizados na análise possuem as seguintes características:

1) é um conjunto composto por 55 variáveis (questões do questionário) avaliadas duas vezes, quanto a importância dada a ação e quanto a ocorrência efetiva na prática (frequência de uso);

2) cada uma das variáveis foi avaliada por um conjunto de 13 sujeitos (Docentes);

3) as respostas foram dadas de acordo com uma escala de Likert (1932) variando de 1 a 5 , sendo a escala 1 correspondente a maior escala e 5 a menor escala, ou seja, Importância: $1=$ muito importante, $2=$ importante, $3=$ neutro $; 4=$ pouco importante, $5=$ nada importante. Ocorrência: $1=$ concordo totalmente, $2=$ concordo, $3=$ neutro, $4=$ discordo, $5=$ discordo totalmente.

Diante das características acima, optou-se por uma análise inferencial não-paramétrica para subsidiar a análise descritiva dos dados, que será elaborada por meio de índices construídos especialmente para estes dados.

\subsubsection{Abordage m Descritiva}

Para efetuar a abordagem descritiva, partiu-se do seguinte pressuposto de que se o 
docente julga uma determinada prática como MUITO IMPORTANTE (Escala 1) (IMPORTÂNCIA) é de se esperar que ele CONCORDE PLENAMENTE (Escala 1) (FREQUÊNCIA DE USO). Nesse sentido, pode-se prospectar um cenário mais geral que as escalas de IMPORTÂNCIA e de OCORRÊNCIA sejam iguais, ou seja, a frequência de OCORRÊNCIA sendo proporcional a sua IMPORTÂNCIA. Logo, pode-se considerar aquela determinada prática como um bom instrumento para avaliar a prática docente, visto que a não ocorrência de sua aplicação está atrelada a falta de importância dada pelo docente e sua ocorrência é devida a importância estabelecida para a prática, ou seja, possui uma importante identidade.

Nessa linha de raciocínio, tem-se três situações diferentes:

Situação $1 \rightarrow$ A escala de IMPORTÂNCIA igual à de OCORRÊNCIA.

Situação $2 \rightarrow$ A escala de IMPORTÂNCIA ser menor que a de OCORRÊNCIA.

Situação $3 \rightarrow$ A escala de IMPORTÂNCIA ser maior que a de OCORRÊNCIA.

Na Situação 2, tem-se um cenário em que o grau de IMPORTÂNCIA é maior que a frequência de OCORRÊNCIA da prática, ou seja, mesmo considerando importante, o docente não faz uso dessa prática na mesma escala. Essa não é uma boa situação, pois embora, considere a ação importante, o uso não ocorre.

Já na Situação 3, tem-se um cenário em que o grau de IMPORTÂNCIAé menor que a frequência de OCORRÊNCIA da prática, ou seja, mesmo considerando não tão importante, o docente faz uso dessa prática em uma maior escala. Essa situação é melhor que a anterior, pois o uso ocorre, mesmo sem ser considerado importante.

Para investigar tais situações, criou-se dois indicadores baseados na diferença absoluta entre as escalas de IMPORTÂNCIA (EI) e OCORRÊNCIA (EO), que será utilizado como Indicador de Diferença (ID):

$$
\text { ID }=\mathbf{E I}-\mathbf{E O}
$$

Note que se o indicador apresenta valor zero, significa que há uma Situação 1 de equilíbrio. Se o valor for negativo predomina a Situação 2 e se for positivo sinaliza a Situação 3.

Desta forma, considerando que as escalas variam de 1 a 5 , tem-se que os valores de ID poderão variar no intervalo de -4 a +4 . Assim, o Quadro 20, apresenta a distribuição dos valores de ID para cada uma das 55 questões, para cada um dos 13 Docentes. 


\begin{tabular}{|c|c|c|c|c|c|c|c|c|c|}
\hline Questão & -4 & -3 & -2 & -1 & 0 & +1 & +2 & +3 & +4 \\
\hline 1 & 0 & 1 & 8 & 0 & 4 & 0 & 0 & 0 & 0 \\
\hline 2 & 0 & 2 & 2 & 5 & 4 & 0 & 0 & 0 & 0 \\
\hline 3 & 0 & 2 & 4 & 1 & 5 & 0 & 0 & 0 & 1 \\
\hline 4 & 0 & 0 & 2 & 4 & 5 & 0 & 0 & 0 & 2 \\
\hline 5 & 0 & 1 & 4 & 2 & 5 & 0 & 0 & 0 & 1 \\
\hline 6 & 0 & 0 & 4 & 2 & 6 & 0 & 0 & 0 & 1 \\
\hline 7 & 1 & 5 & 0 & 2 & 4 & 0 & 0 & 0 & 1 \\
\hline 8 & 4 & 1 & 4 & 1 & 3 & 0 & 0 & 0 & 0 \\
\hline 9 & 0 & 0 & 1 & 2 & 8 & 0 & 0 & 0 & 2 \\
\hline 10 & 1 & 2 & 0 & 2 & 4 & 0 & 0 & 1 & 3 \\
\hline 11 & 1 & 2 & 1 & 3 & 6 & 0 & 0 & 0 & 0 \\
\hline 12 & 0 & 3 & 2 & 2 & 6 & 0 & 0 & 0 & 0 \\
\hline 13 & 1 & 0 & 2 & 1 & 7 & 0 & 0 & 0 & 2 \\
\hline 14 & 3 & 0 & 1 & 0 & 9 & 0 & 0 & 0 & 0 \\
\hline 15 & 1 & 0 & 0 & 6 & 6 & 0 & 0 & 0 & 0 \\
\hline 16 & 1 & 0 & 1 & 0 & 11 & 0 & 0 & 0 & 0 \\
\hline 17 & 0 & 3 & 4 & 3 & 3 & 0 & 0 & 0 & 0 \\
\hline 18 & 0 & 2 & 0 & 4 & 5 & 0 & 0 & 0 & 2 \\
\hline 19 & 1 & 2 & 1 & 4 & 5 & 0 & 0 & 0 & 0 \\
\hline 20 & 1 & 1 & 1 & 2 & 7 & 0 & 1 & 0 & 0 \\
\hline 21 & 0 & 2 & 0 & 2 & 9 & 0 & 0 & 0 & 0 \\
\hline 22 & 0 & 1 & 1 & 2 & 9 & 0 & 0 & 0 & 0 \\
\hline 23 & 0 & 0 & 3 & 2 & 8 & 0 & 0 & 0 & 0 \\
\hline 24 & 0 & 0 & 3 & 1 & 9 & 0 & 0 & 0 & 0 \\
\hline 25 & 0 & 0 & 2 & 1 & 10 & 0 & 0 & 0 & 0 \\
\hline 26 & 0 & 0 & 3 & 3 & 7 & 0 & 0 & 0 & 0 \\
\hline 27 & 0 & 1 & 3 & 3 & 6 & 0 & 0 & 0 & 0 \\
\hline 28 & 0 & 0 & 2 & 2 & 9 & 0 & 0 & 0 & 0 \\
\hline 29 & 0 & 0 & 0 & 2 & 11 & 0 & 0 & 0 & 0 \\
\hline 30 & 1 & 1 & 0 & 3 & 6 & 0 & 0 & 1 & 1 \\
\hline 31 & 0 & 1 & 0 & 1 & 11 & 0 & 0 & 0 & 0 \\
\hline 32 & 1 & 3 & 2 & 2 & 4 & 0 & 0 & 0 & 1 \\
\hline 33 & 1 & 0 & 2 & 2 & 8 & 0 & 0 & 0 & 0 \\
\hline 34 & 1 & 0 & 1 & 3 & 7 & 0 & 0 & 0 & 1 \\
\hline 35 & 0 & 0 & 3 & 1 & 8 & 0 & 0 & 1 & 0 \\
\hline 36 & 0 & 0 & 3 & 3 & 7 & 0 & 0 & 0 & 0 \\
\hline 37 & 0 & 2 & 2 & 5 & 4 & 0 & 0 & 0 & 0 \\
\hline 38 & 0 & 0 & 2 & 5 & 6 & 0 & 0 & 0 & 0 \\
\hline 39 & 0 & 1 & 1 & 2 & 9 & 0 & 0 & 0 & 0 \\
\hline 40 & 0 & 0 & 2 & 1 & 8 & 0 & 0 & 0 & 2 \\
\hline 41 & 0 & 0 & 1 & 2 & 10 & 0 & 0 & 0 & 0 \\
\hline 42 & 0 & 0 & 1 & 5 & 7 & 0 & 0 & 0 & 0 \\
\hline 43 & 0 & 2 & 1 & 2 & 8 & 0 & 0 & 0 & 0 \\
\hline 44 & 0 & 0 & 2 & 2 & 9 & 0 & 0 & 0 & 0 \\
\hline 45 & 0 & 2 & 0 & 3 & 8 & 0 & 0 & 0 & 0 \\
\hline 46 & 0 & 1 & 0 & 2 & 10 & 0 & 0 & 0 & 0 \\
\hline 47 & 0 & 1 & 1 & 2 & 9 & 0 & 0 & 0 & 0 \\
\hline 48 & 0 & 1 & 3 & 1 & 8 & 0 & 0 & 0 & 0 \\
\hline 49 & 0 & 0 & 3 & 0 & 8 & 0 & 0 & 0 & 2 \\
\hline 50 & 2 & 0 & 3 & 4 & 3 & 0 & 0 & 0 & 1 \\
\hline 51 & 0 & 0 & 1 & 2 & 10 & 0 & 0 & 0 & 0 \\
\hline 52 & 1 & 2 & 1 & 1 & 7 & 0 & 0 & 0 & 1 \\
\hline 53 & 0 & 4 & 5 & 1 & 3 & 0 & 0 & 0 & 0 \\
\hline 54 & 0 & 0 & 1 & 4 & 8 & 0 & 0 & 0 & 0 \\
\hline 55 & 0 & 1 & 2 & 4 & 5 & 0 & 0 & 0 & 1 \\
\hline
\end{tabular}


Quadro 20 - Distribuição dos Indicadores de Diferença para todas as questões do questionário

Analisando o quadro 20, percebe-se que o maior número de professores concentra-se no $\mathrm{ID}=0$, ou seja, equilíbrio entre importância e ocorrência. Com isso, verifica-se que dentre as 55 questões apresentadas, em $46(83,64 \%)$ existe uma predominância maior de respondentes, o que denota que nestas questões, o professor as considera importantes e também há ocorrência efetiva em sua prática.

Da mesma forma, avaliando o Quadro 21, pode-se estabelecer a seguinte análise descritiva:

\begin{tabular}{|c|c|c|c|c|c|c|c|c|c|}
\hline $\mathrm{ID}=0$ & Questão & $\mathrm{ID}=0$ & Questão & $\mathrm{ID}=0$ & Questão & $\mathrm{ID}=0$ & Questão & $\mathrm{ID}=0$ & Questão \\
\hline 11 & 16 & 9 & 28 & 8 & 48 & 6 & 11 & 5 & 55 \\
\hline 11 & 29 & 9 & 39 & 8 & 49 & 6 & 12 & 4 & 1 \\
\hline 11 & 31 & 9 & 44 & 8 & 54 & 6 & 15 & 4 & 2 \\
\hline 10 & 25 & 9 & 47 & 7 & 13 & 6 & 27 & 4 & 7 \\
\hline 10 & 41 & 8 & 9 & 7 & 20 & 6 & 30 & 4 & 10 \\
\hline 10 & 46 & 8 & 23 & 7 & 26 & 6 & 38 & 4 & 32 \\
\hline 10 & 51 & 8 & 33 & 7 & 34 & 5 & 3 & 4 & 37 \\
\hline 9 & 14 & 8 & 35 & 7 & 36 & 5 & 4 & 3 & 8 \\
\hline 9 & 21 & 8 & 40 & 7 & 42 & 5 & 5 & 3 & 17 \\
\hline 9 & 22 & 8 & 43 & 7 & 52 & 5 & 18 & 3 & 50 \\
\hline 9 & 24 & 8 & 45 & 6 & 6 & 5 & 19 & 3 & 53 \\
\hline
\end{tabular}

Quadro 21 - Indicador de diferença para todas as questões

Nota-se que as Questões 16, 29 e 31 foram as que apresentaram maior equilíbrio e coerência entre as duas medidas (foram as que mais apresentaram $\mathrm{ID}=0$, ou seja, para 11 docentes). Enquanto isso, as questões $08,17,50$ e 53 foram as que mais apresentaram discordância entre as duas medidas. Estas questões são:

Questão 8

- Avalizar a formatação final de seu material impresso e virtual após o trabalho da equipe técnica e linguística.

Questão 17

- A tutoria tem conhecimento e domínio do conteúdo.

Questão 50

- Capacidade de construir uma relação aluno-professor baseada na confiança e empatia mútua.

Questão 53

- Adequação das tecnologias e do material didático do curso às diferenças culturais.

Estas questões mostram um cenário em que os docentes as julgam importantes ou muito importantes, entretanto, elas não acontecem na prática. Resgatando a análise qualitativa, verifica-se que a questão 17 (capacitação) foi um ponto a melhorar indicado pelos respondentes.

Um segundo indicador que foi considerado, relaciona de forma ponderada a frequência 
de ocorrência de cada tipo de ID com o valor absoluto do ID, o qual é apresentado por IDP (Indicador de Diferença Ponderada). Considerando que o indicador ID varia de -4 a +4 , e que se tem 13 sujeitos, se considerar as situações extremas, observará que IDP terá seus valores variando de -52 até +52 . O quadro 22 dispõe todos os valores de IDP para as 55 questões.

\begin{tabular}{|c|c|}
\hline Questão & Indicador 2 \\
\hline 1 & -19 \\
\hline 2 & -15 \\
\hline 3 & -14 \\
\hline 4 & -6 \\
\hline 5 & -12 \\
\hline 6 & -9 \\
\hline 7 & -20 \\
\hline 8 & -28 \\
\hline 9 & -2 \\
\hline 10 & -7 \\
\hline 11 & -15 \\
\hline 12 & -15 \\
\hline 13 & -7 \\
\hline 14 & -14 \\
\hline 15 & -10 \\
\hline 16 & -6 \\
\hline 17 & -20 \\
\hline 18 & -8 \\
\hline 19 & -16 \\
\hline 20 & -8 \\
\hline 21 & -8 \\
\hline 22 & -7 \\
\hline 23 & -8 \\
\hline 24 & -7 \\
\hline 25 & -5 \\
\hline 26 & -9 \\
\hline 27 & -12 \\
\hline 28 & -6 \\
\hline 29 & -2 \\
\hline 30 & -7 \\
\hline 31 & -4 \\
\hline 32 & -18 \\
\hline 33 & -10 \\
\hline 34 & -8 \\
\hline 35 & -5 \\
\hline 36 & -9 \\
\hline 37 & -15 \\
\hline 38 & -9 \\
\hline 39 & -7 \\
\hline 40 & -3 \\
\hline 41 & -4 \\
\hline 42 & -7 \\
\hline 43 & -10 \\
\hline 44 & -6 \\
\hline 45 & -9 \\
\hline 46 & -5 \\
\hline 47 & -7 \\
\hline 48 & -10 \\
\hline 49 & -4 \\
\hline 50 & -17 \\
\hline 51 & -4 \\
\hline 52 & -12 \\
\hline 53 & -23 \\
\hline 54 & -6 \\
\hline 55 & -10 \\
\hline
\end{tabular}


Quadro 22 - Indicador de Diferença Ponderada para as 55 questões

Em função de sua construção, quanto mais positivo for o valor de IDP, maior a representatividade dos valores positivos (Situação 3), e quanto mais negativo for o valor de IDP maior a representatividade dos valores negativos (Situação 2).

Avaliando o Quadro 22, de imediato constata-se que para as 55 questões o indicador ficou negativo, representando uma significância maior dos valores de ID negativos, ou seja, uma supremacia da situação em que a escala apontada para a Importância é menor que a apontada para a Ocorrência; ou seja, isso representa uma frequência de ocorrência das situações abaixo de sua importância, ou ainda, apesar da importância destacada pelos docentes, a ocorrência de fato não segue na mesma proporção.

Deve-se avaliar também que quanto mais próximo de zero estiver o valor de IDP, mais significativo é o equilíbrio entre as duas medidas.

Assim, ordenando os valores de IDP (Quadro 23), tem-se:

\begin{tabular}{|c|c|c|c|c|c|c|c|c|c|}
\hline IDP & Questão & IDP & Questão & IDP & Questão & IDP & Questão & IDP & Questão \\
\hline-2 & 9 & -6 & 16 & -7 & 47 & -10 & 15 & -15 & 11 \\
\hline-2 & 29 & -6 & 28 & -8 & 18 & -10 & 33 & -15 & 12 \\
\hline-3 & 40 & -6 & 44 & -8 & 20 & -10 & 43 & -15 & 37 \\
\hline-4 & 31 & -6 & 54 & -8 & 21 & -10 & 48 & -16 & 19 \\
\hline-4 & 41 & -7 & 10 & -8 & 23 & -10 & 55 & -17 & 50 \\
\hline-4 & 49 & -7 & 13 & -8 & 34 & -12 & 5 & -18 & 32 \\
\hline-4 & 51 & -7 & 22 & -9 & 6 & -12 & 27 & -19 & 1 \\
\hline-5 & 25 & -7 & 24 & -9 & 26 & -12 & 52 & -20 & 7 \\
\hline-5 & 35 & -7 & 30 & -9 & 36 & -14 & 3 & -20 & 17 \\
\hline-5 & 46 & -7 & 39 & -9 & 38 & -14 & 14 & -23 & 53 \\
\hline-6 & 4 & -7 & 42 & -9 & 45 & -15 & 2 & -28 & 8 \\
\hline
\end{tabular}

Quadro 23 - Ordenação crescente de IDP

Nota-se que as Questões 09 e 29 foram as que mais se aproximaram de 0 e, portanto, possuem maior equilíbrio e coerência entre as duas medidas. Enquanto isso, as questões 08 e 53 foram as que mais apresentaram discordância entre as duas medidas.

Analisando comparativamente as duas abordagens, pôde-se identificar alguns padrões de comportamento, tais como:

1. As 10 questões com maior equilíbrio entre as duas medidas, considerando os dois indicadores construídos são: $09-16$ - 25 - 28 - 29-31-41-44-46-51.

Questão 9 - Responder necessidades da coordenação.

Questão 16 - A relação com o tutor facilitou o trabalho docente.

Questão 25 - Ter habilidades de planejamento. 
Questão 28 - Ser organizado.

Questão 29 • Ter domínio de conteúdo.

Questão 31 - Montar a disciplina de forma clara e objetiva.

Questão 41 - Desenvolver planos de aula.

Questão 44 - Descrever as possibilidades do espaço de aprendizagem.

Questão 46 - Participar do curso de formação para preparação do material.

Questão 51 - Ser criativo.

2. As 10 questões com pior equilíbrio entre as duas medidas, considerando os dois indicadores construídos são: $01-02-07-08-17-19-32-37-50-53$.

Questão 1 • Trabalhar cooperativamente com designers.

Questão 2 - Estabelecer objetivos e resultados de aprendizagem.

Questão 7 - Auxiliar a equipe técnica na formatação do seu ambiente virtual.

Questão 8 - Avalizar a formatação final de seu material impresso e virtual.

Questão 17 - A tutoria tem conhecimento e domínio suficiente do conteúdo.

Questão 19 - O tutor foi bem preparado.

Questão 32 - Identificar diferenças individuais dos estudantes.

Questão 37 - Inteirar-se sobre as tecnologias adequadas à EaD.

Questão 50 - Capacidade de construir uma relação aluno-professor baseada na confiança.

Questão 53 - Adequação das tecnologias e do material às diferenças culturais. 
O gráfico 4 ilustra o cruzamento entre os indicadores IDP x ID.

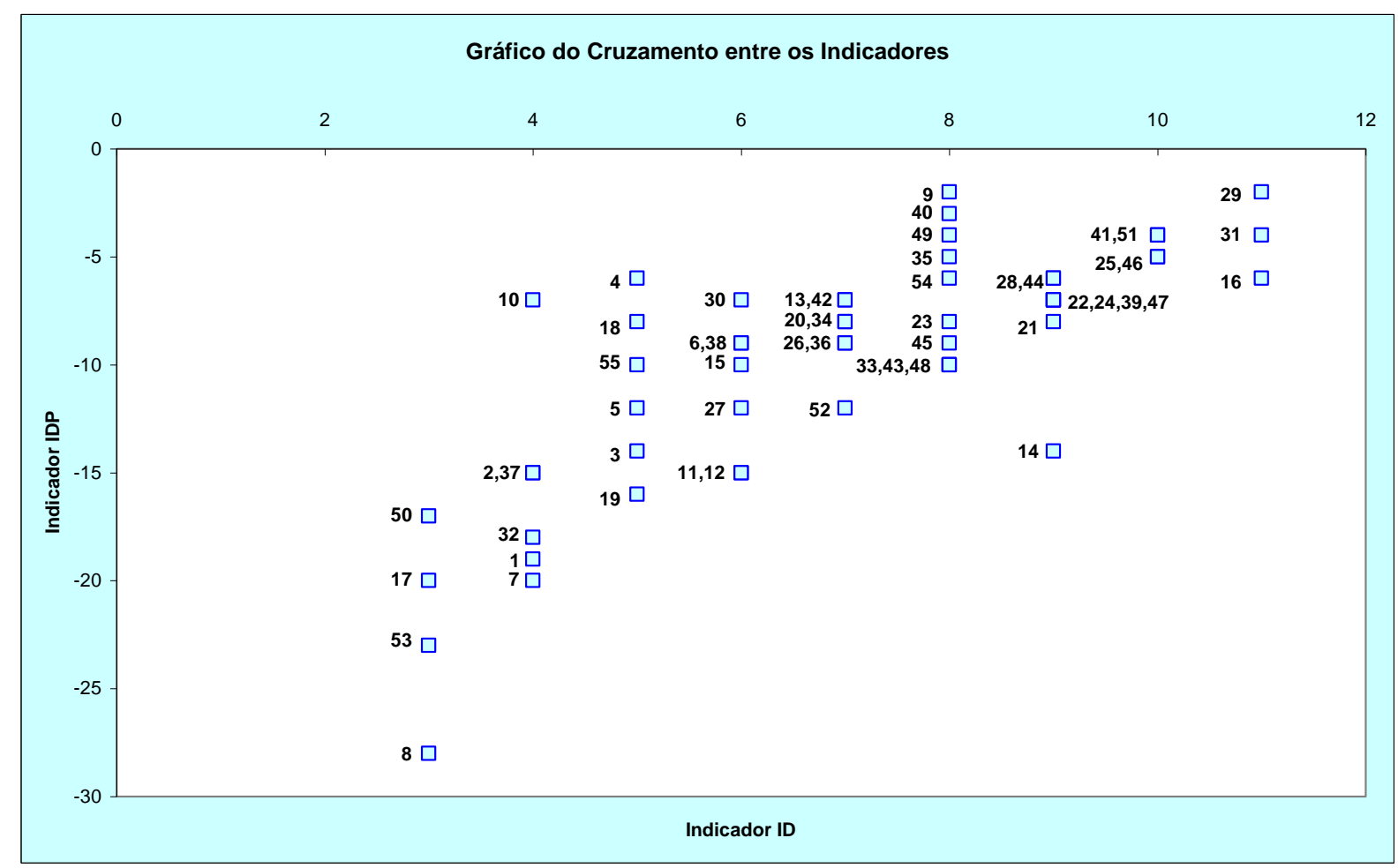

Gráfico 4: Cruzamento IDP x ID

As análises anteriores foram utilizadas com a finalidade de levantar alguns questionamentos sobre as questões, bem como o ponto de vista dos respondentes (professores). Estas apontam algumas possíveis tendências sobre a percepção do docente que atuou em um curso de espacialização na modalidade a distância. Além disso, sinaliza possíveis estratégias que a coordenação poderá adotar para minimizar/eliminar situações problema.

Outrossim, uma análise mais apurada das questões, a fim de comparar as escalas entre as duas medidas, de forma a se comprovar as divergências relatadas nas análises descritivas, será feita mediante um teste não-paramétrico.

\subsubsection{Abordage $m$ Inferencial Não-Paramétrica}

A análise não-paramétrica realizada considera as duas medidas não pareadas, 
admitindo o resultado global para os 13 docentes. A análise seguirá a proposição apresentada anteriormente, ou seja, testar-se-á a igualdade das escalas entre as duas medidas (que representa o equilíbrio da Situação 1) versus uma diferença estatística entre as escalas (como os valores de IDP foram todos negativos, a proposição alternativa é que a escala da importância é menor que a da ocorrência).

Os testes serão feitos com um nível de significância de $5 \%$ e será adotado o teste de Mann-Whitney, utilizando-se o software SPSS versão 17.

Os resultados, para resumir as análises, estão apresentados no quadro 24 , sendo que os valores das estatísticas de testes serão apresentados por U e o nível de significância da estatística (Valor-p) será representado por P:

\begin{tabular}{|c|c|c|}
\hline Questão & Estatística U & Valor-P \\
\hline 1 & 26,0 & $0,002^{*}$ \\
\hline 2 & 27,5 & $0,002^{*}$ \\
\hline 3 & 46,0 & $0,049^{*}$ \\
\hline 4 & 70,0 & 0,479 \\
\hline 5 & 54,0 & 0,125 \\
\hline 6 & 53,5 & 0,113 \\
\hline 7 & 37,0 & $0,014^{*}$ \\
\hline 8 & 21,5 & $0,001^{*}$ \\
\hline 9 & 76,5 & 0,687 \\
\hline 10 & 68,0 & 0,418 \\
\hline 11 & 56,5 & 0,153 \\
\hline 12 & 38,0 & $0,016^{*}$ \\
\hline 13 & 68,5 & 0,418 \\
\hline 14 & 54,0 & 0,125 \\
\hline 15 & 52,5 & 0,101 \\
\hline 16 & 73,5 & 0,579 \\
\hline 17 & 25,5 & $0,002^{*}$ \\
\hline 18 & 56,5 & 0,153 \\
\hline 19 & 37,0 & $0,014^{*}$ \\
\hline 20 & 57,0 & 0,169 \\
\hline 21 & 58,5 & 0,186 \\
\hline 22 & 57,0 & 0,169 \\
\hline 23 & 52,5 & 0,101 \\
\hline 24 & 58,5 & 0,186 \\
\hline 25 & 70,0 & 0,479 \\
\hline 26 & 44,0 & $0,039^{*}$ \\
\hline 27 & 38,0 & $0,016^{*}$ \\
\hline 28 & 58,5 & 0,186 \\
\hline
\end{tabular}

\begin{tabular}{|c|c|c|}
\hline Questão & Estatística U & Valor-P \\
\hline 29 & 71,5 & 0,511 \\
\hline 30 & 64,0 & 0,311 \\
\hline 31 & 71,5 & 0,511 \\
\hline 32 & 34,0 & $0,009^{*}$ \\
\hline 33 & 52,0 & 0,101 \\
\hline 34 & 64,0 & 0,311 \\
\hline 35 & 65,0 & 0,336 \\
\hline 36 & 53,5 & 0,113 \\
\hline 37 & 26,0 & $0,002^{*}$ \\
\hline 38 & 39,0 & $0,019^{*}$ \\
\hline 39 & 59,0 & 0,204 \\
\hline 40 & 75,0 & 0,650 \\
\hline 41 & 69,5 & 0,448 \\
\hline 42 & 52,5 & 0,101 \\
\hline 43 & 52,0 & 0,101 \\
\hline 44 & 64,0 & 0,311 \\
\hline 45 & 64,5 & 0,311 \\
\hline 46 & 64,5 & 0,311 \\
\hline 47 & 57,5 & 0,169 \\
\hline 48 & 52,0 & 0,101 \\
\hline 49 & 70,0 & 0,479 \\
\hline 50 & 30,0 & $0,004^{*}$ \\
\hline 51 & 71,0 & 0,511 \\
\hline 52 & 61,0 & 0,243 \\
\hline 53 & 30,0 & $0,004^{*}$ \\
\hline 54 & 64,0 & 0,311 \\
\hline 55 & 42,5 & $0,029^{*}$ \\
\hline & & \\
\hline
\end{tabular}

* Diferença significativa entre as duas medidas a 5\% de significância.

Quadro 24 - Resumo das análises utilizando o teste de Mann-Whitney

Analisando o quadro 24, verifica-se que para as 55 questões em 16 delas a diferença entre as escalas de importância e ocorrência foi significativa, ou seja, são aquelas em que é 
mais significativa a discrepância entre as escalas.

Em todas as demais, existe uma igualdade estatística (a 5\% de significância), ou seja, não se rejeita o fato das escalas serem similares entre as duas medidas, considerando-se globalmente os docentes.

Contudo, pode-se aprimorar a análise do nível de significância e identificar onde ocorreram as maiores diferenças e as maiores igualdades. Para isso, procede-se da seguinte maneira: considerando os níveis de significância menores que 0,05 (5\%), quanto mais próximos de zero, maior é a diferença entre as medidas. Assim, em forma ordenada, tem-se:

$\begin{array}{cc}\text { Valor-P } & \text { Questão } \\ 0,001 & 8 \\ 0,002 & 1 \\ 0,002 & 2 \\ 0,002 & 17 \\ 0,002 & 37 \\ 0,004 & 50 \\ 0,004 & 53 \\ 0,009 & 32 \\ 0,014 & 7 \\ 0,014 & 19 \\ 0,016 & 12 \\ 0,016 & 27 \\ 0,019 & 38 \\ 0,029 & 55 \\ 0,039 & 26 \\ 0,049 & 3\end{array}$

Pode-se observar que o teste não-paramétrico confirmou as expectativas levantadas pela análise descritiva. As 10 mais discrepantes identificadas pelos índices aparecem entre as mais diferentes quanto ao nível de significância, ou seja, as seguintes questões:

$01-02-07-08-17-19-32-37-50-53$.

De forma similar, pode-se avaliar a outra situação, cujos níveis de significância indicam uma igualdade estatística entre as medidas. Ordenando-se os casos em que os níveis de significância foram maiores que $0,05(5 \%)$ e considerando que quanto mais próximo de 1 maior a similaridade, tem-se: 


$\begin{array}{cccc}\text { Valor-P } & \text { Questão } & \text { Valor-P } & \text { Questão } \\ 0,101 & 15 & 0,311 & 30 \\ 0,101 & 23 & 0,311 & 34 \\ 0,101 & 33 & 0,311 & 44 \\ 0,101 & 42 & 0,311 & 45 \\ 0,101 & 43 & 0,311 & 46 \\ 0,101 & 48 & 0,311 & 54 \\ 0,113 & 6 & 0,336 & 35 \\ 0,113 & 36 & 0,418 & 10 \\ 0,125 & 5 & 0,418 & 13 \\ 0,125 & 14 & 0,448 & 41 \\ 0,153 & 11 & 0,479 & 4 \\ 0,153 & 18 & 0,479 & 25 \\ 0,169 & 20 & 0,479 & 49 \\ 0,169 & 22 & 0,511 & 29 \\ 0,169 & 47 & 0,511 & 31 \\ 0,186 & 21 & 0,511 & 51 \\ 0,186 & 24 & 0,579 & 16 \\ 0,186 & 28 & 0,650 & 40 \\ 0,204 & 39 & 0,687 & 9 \\ 0,243 & 52 & & \end{array}$

Pode-se observar que nesse caso o teste não-paramétrico não confirmou de forma perfeita as expectativas levantadas pela análise descritiva. As 10 questões mais similares identificadas pelos índices não coincidem com as 10 mais similares pelo nível de significância, mas a maioria sim, conforme abaixo:

$\begin{array}{ll}\text { Anteriormente: } & \underline{09}-\underline{16}-\underline{25}-28-\underline{29}-\underline{31}-\underline{41}-44-46-\underline{51} \\ \text { Pelo teste: } & 04-\underline{09}-\underline{16}-\underline{25}-\underline{29}-\underline{31}-40-\underline{41}-49-\underline{51}\end{array}$

Outra análise não-paramétrica realizada considera as duas medidas como medidas pareadas, admitindo o resultado individual de cada um dos 13 docentes. A análise seguirá a proposição de igualdade das escalas entre as duas medidas (que representa o equilíbrio da Situação 1) versus uma diferença estatística entre as escalas (como os valores de IDP foram todos negativos, a hipótese alternativa é que a escala da importância é menor que a da ocorrência).

Os testes serão realizados com um nível de significância de 5\% e será adotado o teste de Wilcoxon, utilizando-se o software SPSS versão 17.

Os resultados, para resumir as análises, estão apresentados no quadro 25, sendo que os 
valores das estatísticas de testes serão denotados por W e o nível de significância da estatística (Valor-p) será representado por P:

\begin{tabular}{|c|c|c|}
\hline Questão & Estatística W & Valor-P \\
\hline 1 & $-2,887$ & $0,004^{*}$ \\
\hline 2 & $-2,719$ & $0,007^{*}$ \\
\hline 3 & $-2,345$ & $0,019^{*}$ \\
\hline 4 & $-1,613$ & 0,107 \\
\hline 5 & $-2,280$ & $0,023^{*}$ \\
\hline 6 & $-2,081$ & $0,037^{*}$ \\
\hline 7 & $-2,481$ & $0,013^{*}$ \\
\hline 8 & $-2,840$ & $0,005^{*}$ \\
\hline 9 & $-0,707$ & 0,480 \\
\hline 10 & $-0,905$ & 0,365 \\
\hline 11 & $-2,388$ & $0,017^{*}$ \\
\hline 12 & $-2,392$ & $0,017^{*}$ \\
\hline 13 & $-1,382$ & 0,167 \\
\hline 14 & $-1,890$ & 0,059 \\
\hline 15 & $-2,530$ & $0,011^{*}$ \\
\hline 16 & $-1,342$ & 0,180 \\
\hline 17 & $-2,836$ & $0,005^{*}$ \\
\hline 18 & $-1,613$ & 0,107 \\
\hline 19 & $-2,555$ & $0,011^{*}$ \\
\hline 20 & $-1,265$ & 0,206 \\
\hline 21 & $-1,857$ & 0,063 \\
\hline 22 & $-1,841$ & 0,066 \\
\hline 23 & $-2,070$ & $0,03 *^{*}$ \\
\hline 24 & $-1,890$ & 0,059 \\
\hline 25 & $-1,633$ & 0,102 \\
\hline 26 & $-2,251$ & $0,024^{*}$ \\
\hline 27 & $-2,401$ & $0,016^{*}$ \\
\hline 28 & $-1,857$ & 0,063 \\
\hline
\end{tabular}

\begin{tabular}{|c|c|c|}
\hline Questão & Estatística W & Valor-P \\
\hline 29 & $-1,414$ & 0,157 \\
\hline 30 & $-1,119$ & 0,263 \\
\hline 31 & $-1,342$ & 0,180 \\
\hline 32 & $-2,448$ & $0,014^{*}$ \\
\hline 33 & $-2,041$ & $0,041^{*}$ \\
\hline 34 & $-1,725$ & 0,084 \\
\hline 35 & $-1,131$ & 0,258 \\
\hline 36 & $-2,251$ & $0,024 *$ \\
\hline 37 & $-2,251$ & $0,007 *$ \\
\hline 38 & $-2,460$ & $0,014 *$ \\
\hline 39 & $-1,841$ & 0,066 \\
\hline 40 & $-0,966$ & 0,334 \\
\hline 41 & $-1,633$ & 0,102 \\
\hline 42 & $-2,333$ & $0,020 *$ \\
\hline 43 & $-2,041$ & $0,041^{*}$ \\
\hline 44 & $-1,857$ & 0,063 \\
\hline 45 & $-2,070$ & $0,038^{*}$ \\
\hline 46 & $-1,633$ & 0,102 \\
\hline 47 & $-1,841$ & 0,066 \\
\hline 48 & $-2,060$ & $0,039 *$ \\
\hline 49 & $-1,242$ & 0,214 \\
\hline 50 & $-2,539$ & $0,011^{*}$ \\
\hline 51 & $-1,633$ & 0,102 \\
\hline 52 & $-1,897$ & 0,058 \\
\hline 53 & $-2,859$ & $0,004 *$ \\
\hline 54 & $-2,121$ & $0,034 *$ \\
\hline 55 & $-2,157$ & $0,031^{*}$ \\
\hline
\end{tabular}

* Diferença significativa entre as duas medidas a 5\% de significância.

Quadro 25 - Resumo das análises utilizando o teste de Wilcoxon

Analisando o quadro anterior, observa que para as 55 questões, em 28 delas a diferença entre as escalas de importância e ocorrência foi significativa, ou seja, são aquelas em que é mais significativa a discrepância entre as escalas.

Em todas as demais, existe uma igualdade estatística (a 5\% de significância), ou seja, não se rejeita o fato das escalas serem similares entre as duas medidas, considerando-se cada docente isoladamente.

Contudo, pode-se aprimorar a análise do nível de significância e identificar onde ocorreram as maiores diferenças e as maiores igualdades. Para isso, procede-se da seguinte maneira: considerando os níveis de significância menores que 0,05 (5\%), quanto mais próximos de zero, maior é a diferença entre as medidas. Assim, em forma ordenada, tem-se: 


$\begin{array}{cc}\text { Valor-P } & \text { Questão } \\ 0,004 & 1 \\ 0,004 & 53 \\ 0,005 & 8 \\ 0,005 & 17 \\ 0,007 & 2 \\ 0,007 & 37 \\ 0,011 & 15 \\ 0,011 & 19 \\ 0,011 & 50 \\ 0,013 & 7 \\ 0,014 & 32 \\ 0,014 & 38 \\ 0,016 & 27 \\ 0,017 & 11 \\ 0,017 & 12 \\ 0,019 & 3 \\ 0,020 & 42 \\ 0,023 & 5 \\ 0,024 & 26 \\ 0,024 & 36 \\ 0,031 & 55 \\ 0,034 & 54 \\ 0,037 & 6 \\ 0,038 & 23 \\ 0,038 & 45 \\ 0,039 & 48 \\ 0,041 & 33 \\ 0,041 & 43 \\ & \\ 0\end{array}$

Pode-se observar que o teste não-paramétrico confirmou as expectativas levantadas pela análise descritiva. Das 10 apontadas anteriormente pelos índices, 9 aparecem como as mais discrepantes quanto ao nível de significância, ou seja, as seguintes questões:

Anteriormente: $\quad \underline{01}-\underline{02}-\underline{07}-\underline{08}-\underline{17}-\underline{19}-32-\underline{37}-\underline{50}-\underline{53}$

Nesta Análise: $\quad \underline{01}-\underline{02}-\underline{07}-\underline{08}-15-\underline{17}-\underline{19}-\underline{37}-\underline{50}-\underline{53}$

De forma similar, pode-se avaliar a outra situação, cujos níveis de significância indicam uma igualdade estatística entre as medidas. Ordenando-se os casos em que os níveis 
de significância foram maiores que 0,05 (5\%) e considerando que quanto mais próximo de 1 maior a similaridade, tem-se:

\begin{tabular}{cc} 
Valor-P & Questão \\
\hline 0,058 & 52 \\
0,059 & 14 \\
0,059 & 24 \\
0,063 & 21 \\
0,063 & 28 \\
0,063 & 44 \\
0,066 & 22 \\
0,066 & 39 \\
0,066 & 47 \\
0,084 & 34 \\
0,102 & 25 \\
0,102 & 41 \\
0,102 & 46 \\
0,102 & 51 \\
0,107 & 4 \\
0,107 & 18 \\
0,157 & 29 \\
0,167 & 13 \\
0,180 & 16 \\
0,180 & 31 \\
0,206 & 20 \\
0,214 & 49 \\
0,258 & 35 \\
0,263 & 30 \\
0,334 & 40 \\
0,365 & 10 \\
0,480 & 9 \\
\hline
\end{tabular}

Pode-se observar que nesse caso o teste não-paramétrico não confirmou as expectativas levantadas pela análise descritiva. As 10 mais similares identificadas pelos índices não coincidem com as 10 mais similares pelo nível de significância, apenas a minoria: Anteriormente: $\quad \underline{09}-\underline{16}-25-28-29-\underline{31}-41-44-46-51$

Pelo teste:

$$
\underline{09}-10-13-\underline{16}-20-30-\underline{31}-35-40-49
$$

Diante deste contexto e considerando os aspectos dos dados existentes para análise, verificou-se que embora a taxa de retorno fosse alta $(76,47 \%)$ houve limitação de aplicação de 
testes estatísticos mais elaborados e/ou análises multivariadas, tendo em vista o número pequeno de respondentes.

Desta forma, com base nas análises, podem ser identificadas as questões em que:

1. As escalas são próximas entre as duas medidas, indicando que a ocorrência do uso das práticas é observada na mesma escala de importância da mesma.

2. As escalas entre as duas medidas não são próximas, indicando que a ocorrência se dá em uma escala menor que a importância da mesma.

Diante deste panorama, verifica-se que por meio destas análises é possível mapear a percepção dos professores que atuaram no curso de especialização a distância. Além disso, a coordenação terá elementos que mostram as ações em que o professor julga importante e não incorpora em sua prática, bem como, ações que os docentes realizam, porém, não as julgam tão importantes, dentre outras. Estas informações possibilitarão à coordenação elaborar e definir estratégias que melhor atendem aos objetivos propostos do curso.

\subsection{Análise Geral}

Ao analisar a construção da arquitetura de orientação, bem como os instrumentos dela derivados, verifica-se que todos os padrões internacionais preconizados pelo The Joint Commitee on Standards for Educacional Evaluation (2009) foram contemplados, uma vez que os instrumentos elaborados cumpriram o seu papel de atender às necessidades de informação dos envolvidos (Utilidade) e os procedimentos adotados asseguraram uma avaliação realista, prudente, diplomática e acima de tudo simples (Viabilidade). Logo, todo processo avaliativo foi realizado de forma a assegurar uma avaliação legal, ética e levando em conta as pessoas envolvidas (Propriedade). Além disso, procedeu-se de forma que a avaliação pudesse revelar e transmitir informações tecnicamente adequadas sobre o objeto em estudo (Precisão/Acurácia) e que propiciasse à coordenação do curso, subsídios para a tomada de decisão.

Outrossim, buscou-se ao longo da análise dos dados, identificar os pontos de divergência e convergências, bem como sinalizar possíveis tendências entre as respostas dos sujeitos participantes do estudo. Além disso, com o intuito de aprofundar sobre o contexto de algumas questões que se apresentaram ambíguas para a análise, foi realizada uma verificação in loco (entrevista, conversa informal, observação) para se ter clareza sobre princípios de causalidade de algumas respostas. 
No tocante às evidências de confiabilidade e validade, bem como as estratégias adotas para minimização de seus pontos críticos, diversas ações foram realizadas, tais como:

- O planejamento da pesquisa atende a definição de conteúdo e explicitação dos objetivos, construção dos itens do questionário e análise de especialistas, como forma de assegurar rigor científico.

- Para a validade de conteúdo buscou-se agregar aspectos quantitativos e qualitativos que focam nas questões chave do plano.

- Para a validade de constructo, os itens do questionário foram organizados segundo sugestões dos juízes.

- A validade de construto foi assegurada pela correspondência entre o conteúdo de cada sentença (pergunta) do instrumento com as questões-chave do plano de assessment.

- A triangulação metodológica foi incorporada no plano de assessment, uma vez que foram utilizados diferentes métodos para a coleta de dados com abordagem quantitativa e qualitativa, com foco nas questões-chave.

- A triangulação de dados foi incorporada por meio da aplicação de questionário em um grupo de professores, seguida de entrevista. Para isso, o docente confirmou as conclusões da pesquisadora.

- O pré-teste foi incorporado no plano como forma de aumentar a validade do instrumento.

- Revisões nos instrumentos foram realizadas com base no feedback da coordenação, professores avaliadores e especialistas que os analisaram. Este procedimento se concretiza na medida em que as contribuições de cada grupo são incorporadas no plano de assessment.

- Os instrumentos utilizados (questionário e entrevista) foram aplicados mediante consentimento e adesão do professor participante do Curso de Especialização em estudo, sendo que cada respondente assinou o Termo de Consentimento Livre e Esclarecido, conforme apêndice E.

- A aplicação do instrumento foi realizado somente pela pesquisadora, o que minimiza a variabilidade interobservador.

- Para evitar a variabilidade da amostra foi trabalhado com amostra significativa $(76,47 \%)$.

- Ressalta-se que a coordenadora do curso foi eliminada da população de professores respondentes, para evitar respostas tendenciosas. Com isso, insere-se mais um dos elementos de confiabilidade. Logo, o total de docentes do curso de especialização em Gestão Escolar passou a ser dezessete. 
- Elaborou-se um questionário com um número significativo de itens para assegurar índice de precisão.

- A construção do instrumento atendeu ao protocolo de rigor científico, apresentando layout agradável ao respondente, bem como facilidade de uso, o qual foi apreciado no pré-teste.

- Foram utilizados os mesmos procedimentos de aplicação tanto no teste piloto como no split-halves, assegurando validade de conteúdo.

- Procurou-se eliminar as ambiguidades dos instrumentos, seguindo etapa por etapa da arquitetura de orientação, eliminando apenas os itens não aplicáveis.

- Utilizou-se questões de controle para triangulação, as quais se apresentam na medida em que as questões são organizadas de forma a facilitar o entendimento e encadeamento, bem como na abordagem qualitativa e quantitiva utilizadas.

- Houve preocupação em deixar bem explícito o enunciado de cada questão, usando um vocabulário compreensível aos respondentes, conforme aferido no pré-teste.

- O instrumento é único e foi respondido após explicitação dos objetivos, aceite de participação e assinatura do Termo de Consentimento Livre e Esclarecido, evitando interferência de múltiplos tratamentos.

- Não houve nenhuma especificidade de variável.

- Como todos os procedimentos da investigação foram conduzidos por uma única pesquisadora, não houve efeito resultante do investigador.

- As questões foram elaboradas de forma diferente para evitar arranjos reativos.

- O guia de entrevista é flexível de modo a permitir a inserção de questões que se deseja averiguar. Isso permite obter mais detalhes qualitativos de algumas respostas. No entanto, apenas comentários adicionais foram inseridos.

- As anotações e percepções da pesquisadora acerca das entrevistas foram apresentadas aos respondentes para validação, assegurando confiabilidade.

- Para evitar viés da pesquisadora foi solicitado que um avaliador/pesquisador da área de ciências agrárias apreciasse as conclusões da pesquisadora, ampliando a credibilidade da investigação, bem como se efetivasse a triangulação de investigador. Ressalta que a escolha do avaliador se deu por comodidade.

- Considerando que todo o processo de assessment foi conduzido por uma única pesquisadora, é possível assegurar que os quatro critérios de adequação ou rigor na pesquisa qualitativa, foram atendidos, tais como: credibilidade, aplicabilidade, consistência e neutralidade, conforme preconizado por Lincoln e Guba (1985). E isso 
amplia as evidências de validade no processo qualitativo.

- A consistência da investigação ou auditoria pode ser aferida por meio de análise detalhada da metodologia adotada, das técnicas de triangulação aplicadas e da documentação da coleta de dados, permitindo assegurar validade.

- Todo o estudo foi documentado e cópias serão entregues à coordenação do Curso de Especialização em estudo, bem como arquivada com a pesquisadora. Este procedimento assegura confirmação da pesquisa e consequentemente confiabilidade. 


\section{CAPÍTULO 9 - Conclusões e Considerações Finais sobre o Estudo}

Este estudo apresentou uma arquitetura que orienta o desenvolvimento de instrumentos de avaliação de Programas de Educação a Distância. A arquitetura foi avaliada por meio da proposição de uma solução, a qual foi baseada em seus conceitos e pressupostos, e a aplicação desta solução foi realizada em um caso real.

Assim, o primeiro conjunto de resultados se refere à construção da arquitetura de orientação, que apresenta todos os elementos que permearam seu desenvolvimento. $\mathrm{O}$ segundo conjunto se deve às discussões sobre a construção de uma solução. E. por fim, a aplicação desta solução em um caso real, compreendendo a etapa de pesquisa de campo. Adicionalmente, considerações sobre a confiabilidade e validade da proposta são realizadas.

\subsection{CONSIDERAÇÕes SOBREA CONSTRUÇÃo da ARQUITETURA DE ORIENTAÇÃo}

Uma importante conclusão acerca da proposição da arquitetura de orientação é a própria ideia de criá-la, tendo em vista que a Educação a Distância é carente de instrumentos que auxiliem na avaliação de seus programas, destacadamente no tocante às evidências de confiabilidade e validade, pois nem sempre existe esta preocupação. E esta situação pode comprometer os resultados para a tomada de decisão.

Este fato motivou a criação da arquitetura como um modelo conceitual capaz de auxiliar na construção de instrumentos de avaliação (assessment) de programas de EaD, de maneira fácil, flexível e com evidências de confiabilidade e validade.

Enquanto se avançava no desenvolvimento da arquitetura mais evidente ficava a necessidade de se ter um modelo e robusto e flexível que pudesse atender às diferentes realidades e modelos de $\mathrm{EaD}$, mas que resultassem em uma proposta concisa e confiável de avaliação (assessment).

Outra conclusão importante é a capacidade da arquitetura de atender diferentes modelos e contextos de EaD, o que, naturalmente, possibilita que qualquer tipo de Instituição de Ensino possa utilizar a arquitetura para a construção de seus instrumentos de avaliação (assessment) para a Educação a Distância, contribuindo para cessar o uso acrítico de modelos outros. 
Além disso, a arquitetura contribui para a demonstração de um caminho para o desenvolvimento de soluções, isto é, a arquitetura como um modelo conceitual, que se baseou em um arcabouço teórico sólido e consistente para a proposição de uma ferramenta de Avaliação (assessment) em Programas de Educação a Distância.

Isso se fortalece na medida em que se inserem ingredientes de confiabilidade e validade no processo. Logo, o resultado final é uma representação estruturada de itens que possibilitam a realização de avaliação (assessment) em EaD com evidências de confiabilidade e validade e que podem ser averiguados pelo próprio usuário, ou seja, não necessita de experts em avaliação (assessment).

Diante deste contexto, pode-se inferir que estas características unidas tornam a proposta da arquitetura bastante promissora.

\subsection{CONSIDERAÇÕES SOBRE A CONSTRUÇÃo DE UMA SOLUÇÃo BASEADA NA ARQUITETURA DEORIENTAÇÃO}

A construção de uma solução permitiu muitas considerações acerca da viabilidade da arquitetura de orientação desenvolvida, bem como a análise dos pontos críticos de sua aplicação. Em termos gerais, essa experiência demonstrou que a arquitetura pode ser considerada viável, em termos práticos, isto é, não foram encontradas situações impossíveis de serem implementadas.

Um resultado bastante importante nesta etapa é que os envolvidos (coordenação e assessoria pedagógica do curso de especialização em Gestão Escolar) consideraram a arquitetura interessante e fácil de ser utilizada, uma vez que toda esta etapa foi desenvolvida com a participação dos mesmos.

Adicionalmente, em termos mais qualitativos, a experiência de construção da solução baseada na arquitetura possibilitou conhecer mais profundamente as práticas de EaD do curso investigado, bem como ter uma visão geral da EaD na IES pesquisada.

Além disso, seguir etapa por etapa da arquitetura para a construção do plano de assessment (solução) foi um exercício muito interessante para avaliar criticamente a arquitetura proposta.

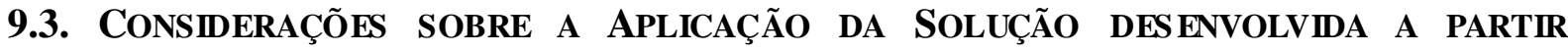 ARQUiTETURA DE ORIENTAÇÃo}


A partir da aplicação da solução desenvolvida foi possível identificar os pontos frágeis da gestão em EaD do curso pesquisado e da IES mantenedora. Isso exigiu um estudo mais aprofundado, buscando informações em diferentes fontes para entender os motivos desta fragilidade. Além disso, esta identificação exigiu uma verificação in loco, de algumas situações, para melhor entendimento das dinâmicas dos fatos.

Verificou-se que a aplicação da solução propiciou um diagnóstico amplo e preciso da realidade pesquisada. Portanto, pode-se inferir que a coordenação do curso dispõe de informações precisas para a tomada de decisão.

Por meio da aplicação da solução percebeu-se que nem todos os itens da arquitetura se aplicam em todas as situações. Assim, alguns itens foram considerados "não se aplicam" e isso não prejudicou os resultados.

Os resultados obtidos com a aplicação dos instrumentos criados a partir da arquitetura apresentaram informações bastante úteis para a coordenação do curso pesquisado, isso possibilitará uma tomada de decisão mais segura.

Uma observação interessante foi que os respondentes da aplicação não demonstraram receio ou preocupação em participar do estudo. Isso mostra que a forma de construção dos instrumentos não intimidou nem criou sentimentos de medo nos participantes.

\subsection{Conclus ão Final e Perspectivas Futuras}

Analisando todas as etapas do estudo, verifica-se a importância e a necessidade de um modelo conceitual que oriente a construção de instrumentos de assessment para o Programa de Educação a Distância, com evidências de confiabilidade e validade. Verifica-se, ainda, que diferentes teorias podem contribuir fortemente para o avanço do processo de assessment em EaD. Como consequência, estes resultados sinalizam para a continuidade da utilização da arquitetura para a construção de instrumentos, como forma de validação e testagem da proposta.

Além disso, pode-se concluir que o objetivo principal deste estudo: "propor uma arquitetura que oriente a construção de instrumentos para avaliação (assessment) de Programas de Educação a Distância, com evidências de confiabilidade e validade", foi alcançado, uma vez que foram obtidas uma arquitetura e uma primeira validação de sua aplicação, confirmando a viabilidade. Na prática, isso significa a proposição de um referencial para a criação de instrumentos de assessment para Programas de EaD.

Os resultados deste estudo são as primeiras validações da arquitetura e da solução 
desenvolvidas. Assim, a real avaliação da arquitetura se dará por meio da continuidade desta pesquisa, que utilizará a referida arquitetura para a construção e aplicação de novos planos de assessment.

Uma proposta de trabalho futuro, bem como a continuidade do processo de validação da arquitetura, é a construção de instrumentos de assessment para mapear o perfil e o grau de satisfação de estudantes de um curso de especialização a distância, que já se encontra em andamento na mesma Instituição de Ensino. 


\section{REFERÊNCIAS BIBLIOGRÁFICAS}

ALVES, D. (1964). O teste sociométrico. Rio de Janeiro: FGV.

ALVES, R. (1994). Filos ofia da ciência: introdução ao jogo e suas regras. São Paulo: Brasiliense.

ANDER-EGG, E. (1978). Introducción a las técnicas de investigación social, para trabajadores socials. 7.ed. Buenos Aires: Hu manitas.

AMERICAN EDUCATIONAL RESEA RCH ASSOCIATION (AERA); AMERICAN PSYCHOLOGICAL ASSOCIATION (APA); NATIONAL COUNCIL ON MEASUREMENT IN EDUCATION (NCME) (1999). Standar ds for Educational and Psychological Testing. Washington, DC: AERA.

ANGELO, T.; CROSS, K.P. (1993). Classroom assessment techni ques a handbook for college teachers . Jossey-Bass A Wiley Imprint, San Francisco, CA. Disponível em: <http://web.duke.edu/arc/documents/The\%20 difference\% 20between \%20assessment\%20and\%20evaluation.pdf > Acesso em: 20 jan. 2010.

BARDIN, L. (2002). Análise de conteúdo. Trad. Luís Antero e Augus to Pinheiro. Lisboa: Ed ições 70. . (2004). Análise de conteúdo. 3.ed. Lisboa: Edições 70.

BATES, A.W. (1995). Technology: open learning and distance education. London: Routledge.

BELANGER, F.; JORDAN, D.H. (2000). Evaluation and implementation of distance learning : Technologies, tools, and techni ques. Hershey, PA: Idea Group Publishing.

BELLONI, I. (1995). A experiência de avaliação institucional da Un B. Revista Educación Superior y Sociedad, Madri, v. 25, p. 29-34.

BERELSON, B. (1971). Content analysis in communications research. Nova York: Hafner.

BERG, B.L. (2007). Qualitative research methods for the social sciences. 6.ed. New York: Pearson.

BERTELLI, E. M.; EYNG, A. M. (2004). Avaliação institucional: a relação dialógica dos dados da avaliação interna e externa na melhoria educacional. In: COLOQUIO INTERNACIONAL SOBRE GESTÃO UNIVERSITÁ RIA NA AMÉRICA DO SUL. 4., 2004, Florianópolis. Anais... Florianópolis: Universidade Federal de Santa Catarina, v. 1.p. 1-15.

BRASIL. (1996). Ministério da Educação e Cultura. Lei no. 9394, de 20 de De ze mbro de 1996. Estabelece as diretrizes e bases da educação nacional. Brasília, DF. BRASIL. Dis ponível em:

<http://www.planalto.gov.br/ccivil_03/LEIS/19394.htm>. Acesso em: 10 dez. 2009

BRASIL. (2002). Ministério da Educação e Cultura. Secretaria de Educação Superior. Comissão Assessora para Educação Superior à Distância (Portaria 335/2002). Relatório. Brasília: MEC/SESU. Dis ponível em: <http://portal.mec.gov. br/seed/arquivos/pdf/legis lacao/refead1.pdf> Acesso em: 5 out. 2009.

BRASIL.(2004). Ministério da Educação e Cu ltura. Lei no. 10861, de 14 de Abril de 2004. Institui o Sistema Nacional de Avaliação da Educação Superior - SINAES. Brasília, DF. Disponível em: <http://www.inep.gov.br/superior/SINAES/> . Acesso em: 20 jan. 2010.

BRASIL. (2005). Ministério da Educação e Cultura. Decreto no 5.622, de 19 de de ze mbro de 2005. Regulamenta o art. 80 da Lei no 9.394, de 20 de deze mbro de 1996, que estabelece as diretrizes e bases da educação nacional. Disponível em: <http://www.planalto.gov.br/ccivil 03/ Ato20072010/2007/Decreto/D6303.htm> Acesso em: 5 out. 2009. (2005a)

BRASIL. (2006). Ministério da Educação. Instituto Nacional de Estudos e Pesquisas Educacionais. Censo da Educação Superior: Sinopse da Educação Superior 2004. Disponível em: <http://www.inep.gov.br/superior/avaliacao institucional/legislacao.htm> Acesso em: 5 out. 2009. 
BRASIL. (2008). Ministério da Educação. Avaliação Institucional. Disponível em: < http:// portal.mec.gov.br/arquivos/ pdf / informativo4.pdf>Acesso em: 20 nov. 2008.

BRASIL. (2007). Ministério da Educação. Portaria 1047, de 7 de novembro de 2007. Estabelece diretrizes para a elaboração, pelo INEP, dos instrumentos de avaliação para o credenciamento de instituições de educação superior e seus polos de apoio presencial, para a modalidade de educação a distância. Disponível em: < http://www.anaceu.org.br/conteudo/legislacao/portarias/2007\% 20-\% 20Portaria\%20MEC\% 201047\% 20$\% 207 \% 20$ novembro.pdf $>$ Acesso em: 10 jul. 2010.

BRASIL. (2007). Ministério da Educação. Portaria 1050, de 7 de novembro de 2007. Aprova instrumentos de avaliação do INEP para credenciamento de instituições de educação superior e seus polos de apoio presencial, para a oferta da modalidade de educação a distância.BRASIL. Disponível em: <

http://www.anaceu.org.br/conteudo/legislacao/portarias/2007\% 20-\%20Portaria\%20MEC\% 201050\% 20\%207\%20novembro.pdf > Acesso em 10 jul. 2010.

BRASIL. (2007). Ministério da Educação. Portaria 1051, de 7 de novembro de 2007. Aprova, em extrato, o instrumento de avaliação do INEP para autorização de curso superior na modalidade de educação a distância. Disponível em: <http://www.anchietavirtual.com.br/site/arquivos/27 portaria n 1051 de 7 de novembro de 2007.pdf>. Acesso em: 10 jan. 2010.

BRASIL. (2009). Instituto Nacional de Estudos e Pesquisas Educacionais Anísio Teixeira (INEP).

Credenciamento de polo de apoio presencial para educação a distância. Disponível em: <http://www.inep.gov.br/superior/avaliacao_institucional/EAD.htm> Acesso em: 10 jan. 2010.

BRASIL. (2010). Instituto Nacional de Estudos e Pesquisas Educacionais Anísio Teixeira (INEP). Instrumento de credenciamento institucional para oferta da modalidade de educ ação a distância. Disponível em:

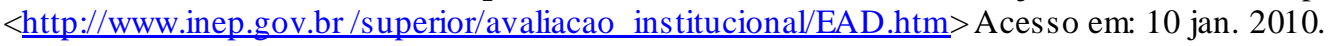

BRASIL. (2010). Instituto Nacional de Estudos e Pesquisas Educacionais Anísio Teixeira (INEP). Instrumento de autorização de curso para oferta na modalidade a distância. Disponível em: < http://www.inep.gov.br Isuperior/avaliacao institucional/EAD.htm> Acesso em: 10 jan. 2010.

BUARQUE, C. (1994). A Aventura da uni versi dade. São Paulo : Ed itora UNESP/Rio de Janeiro: Paz e Terra.

BUSSA B, W.O.; MORETTIN, P. (2004). Estatística Básica. São Paulo: Saraiva.

CAMPBELL, D.; STANLEY, J. (1963). Experimental and quasi-experimental designs for research.

Chicago, IL: Rand-McNally.

CANEN, A. (1999). Des mitificando a avaliação. In: BRASIL. Ministério da Educação - Secretaria de Educação a Distância. Salto para o futuro. Brasília: MEC/SEED, p. 97-107.

COORDENAÇÃO DE APERFEIÇOAMENTO DE PESSOAL DE NÍVEL SUPERIOR. (2009). Uni versidade Aberta do Brasil. Disponível em < www.capes.gov.br > Acesso em: 5 jan 2010.

CARMINES, E.G.; ZELLER, R.A. (1979). Reliability and validity assessment. California: SA GE.

CASANOVA, M.A. (1999). Evaluación y mejora de la calidad educati va; Para qué evaluar? Venezuela: Candidus.

CASEY, V.; RICHARDSON, I. (2002). A Practical application of the IDEAL model (2002). Disponível em < www.springerlink. com/inde x/n5tfcpv5rj1bpg47.pdf> Acesso em: 21 jul. 2009.

CERVO, A.L.; BERVIAN, P.A. (1983). Metodol ogia científica: para uso dos estudantes uni versitári os. 3.ed. São Paulo: Mcgraw-Hill.

CHA GAS, I. (2004). Ameaças à validade de uma investigação. Disponível em<

http://www.educ.fc.ul.pt/docentes /ichagas /mi1/ameacas validade.pdf > Acesso em: 29 jan. 2010. 
CHIDAMBARAM, L.; ZIGURS, I. (2001). Our virtual world: The transformation of work, play and life via technology. Hershey, PA: IDEA Group Publishing.

CICONELLI, R.M. (1997). Tradução para o português e validação do questionário genérico de avaliação de qualidade de vida. Medical Outcomes Study 36-Item Shot Form Survey (SF-36). Tese (Doutorado)Escola Pau lista de Medicina, Universidade Federal de São Paulo, São Pau lo, 1997.

COOK, T. D.; CAMPBELL, D. T. (Eds.) (1979).Quasi-experimentation: Design and anal ysis issues for field settings. Chicago: Rand-McNally.

COORDENAÇÃO DE APERFEIÇOAMENTO DE NÍVEL SUPERIOR - CAPES (2009). Uni versidade

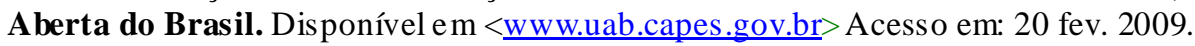

DEMO. P. (1981). Metodologia do Conhecimento Científico. São Paulo: Atlas.

. (1990). Qualidade da educação: tentativa de definir conceitos e critérios de avaliação. Es tudos em Avaliação Educacional, São Paulo, n. 2, p. 11-26, jul./dez.

DIAS SOBRINHO, J. (1999). Concepções de universidade e de avaliação institucional. Avaliação/Rede de Avaliação Institucional da Educação Superior - RAIES, São Paulo, v.4, n.2, jun.

(2003). Avaliação: políticas educacionais e refor mas da educação superior. São Paulo: Cortez. . (2005). Avaliação Institucional: instrumento de qualidade educativa. A experiência da UNICAMP. In: DIAS SOBRINHO, J.; BALZAN, N. C. Avaliação institucional: te oria e experiência. 3.ed. São Pau lo: Cortez.

DICK, W.; CAREY, L.; CAREY, J.O. (2001). The systematic design of instruction. 6. ed. Upper Saddle River, NJ: Pearson Allyn \& Bacon.

DRISCOLL, M. (1998). Web-based training: using technologyto design adult learning experiences . San Francisco: Jos sey-Bass Pfeiffer.

DUSILEK, D. (1986). A arte da investigação criadora. Rio de Janeiro: Junta de Educação Re lig iosa e Publicações - JERP.

FACHIN, O. (2006). Fundamentos de Metodologia. 5 ed. [rev.]. São Paulo: Saraiva.

FEELEY, M.M. (2001). Triangulation: methodology. In: SMELSER, N.J.; BALTES, P.B. International Encyclopedia of the Social \& Behavioral Sciences. Amsterdam: Elsevier Science.

FELIX, G. T. (2008). Reconfiguração dos modelos de uni versidade pelos formatos de avaliação: efeitos no Brasil e Portugal. 295 f. Tese (Doutorado) - Faculdade de Educação, Universidade Federal do Rio Grande do Sul, Porto Alegre, 2008.

FITZPATRICK, J. L.; SANDERS, J. R.; WORTHEN, B. R. (2004). Program e valuation: alternative approaches and practical guidelines. 3. ed. New York: Pearson.

FITZSIMMONS, J.A.; FITZSIMMONS, M.J. (2000). Administração de serviços: operações, estratégia e tecnologia da informação. 2 ed. Tradução de Francisco José Soares. Porto Alegre: Bookman.

FONSECA, D. G. F. (2007). Implicações do exame nacional de desempenho dos estudantes (ENADE) nos pr ocess os avaliati vos internos do curso de educação física do IPA. 182 f. Tese (Doutorado) - Programa de Pós-Graduação em Educação, Universidade do Vale do Rio dos Sinos, Porto Alegre, 2007.

FOURNIER, D.M. (1995). Establishing evaluative conclusions: a distinction between general and working logic. New Directions for Evaluation, Malden, v. 68, p. 15-32.

FRIZZO, M. (2003). A importância da avaliação institucional para a melhoria da qualidade de ensino - a experiência de u ma instituição de ensino superior. In: ENCONTRO NACIONAL DE ENGENHARIA DE 
PRODUÇÃO, 23., 2003, Ouro Preto. Anais... Ouro Preto: ENEGEP.

GA LETTI, A.M. (2006). Desen vol vimento e avaliação psicométrica da escala de seguimento de jog adores : uma medida de avaliação para jogadores patológicos em tratamento. 143 f. Dis sertação (Mestrado) - Facu ldade de Medicina, Universidade de São Paulo, São Paulo, 2006.

GA RVIN, D. (1984). What does product quality really mean? MIT Sloan Management Review, New York, 15 oct.

GERMUTH, A.A. (2010). The fantastic fi ve checklist for improving survey reliability - writing better questions. A mericam Evaluation Association (2010). Disponível e m:

$<$ http://comm.eval.org/EVAL/EVAL/Resources/ View Document/Default.as px? DocumentKey=53951031-ef7a4036-bc8f-3563f3946026> Aces so em: 20 jan. 2010.

GIANESI, I.G.N.; CORRÊA, H.L. (1996). Admi nistração estratégica de ser viços: operações para satisfação do cliente. São Paulo: Atlas.

GIL, A.C. (1999). Métodos e técnicas de pesquisa social. São Paulo: Atlas.

GRINNELL, R.M. (1997). Social work research \& e valuation: quantitative and qualitative approaches. 5. ed. Itasca, Illinois: E. E. Peacock Publishers.

GRÖNROOS, C. (1995). Marketing - gerenciamento e services: a competição por serviços de verdade. Traduçção de Cristina Bázan. Rio de Janeiro: Campus.

GUION, L. (2002). Triangulation: establishing the validity of qualitative studies. Gaines ville: University of Florida/ Institute of Food and Agricultural Sciences.

HA GUETTE, T. M. F. (2003). Metodologias qualitati vas na Sociologia. 10.ed. Petrópolis: Vo zes, 224p.

HAIR JR, J.F.; BABIN, B.; SAMOUEL, P. (2005). Fundamentos de métodos de pes quisa em Admi nistração. Tradução de Lene Belon Ribeiro. Porto Alegre: Bookman.

HILL, M. M.; HILL, A. (1998). A construção de um questionário. Lisboa: Dinâmica.

HOFFMANN, J. M. L. (1991a). Avaliação e construção do conhecimento. Educação e Realidade, Porto Alegre, v. 16, n. 2, p. $53-58$, jul/dez.

. (1991b). Avaliação mito \& desafios: u ma perspectiva construtiva, Porto Alegre, Educaçãoe

Realidade, Porto Alegre, v.1.

. (1994). Avaliação mediadora: u ma relação dialógica na construção do conhecimento. Idéias, São

Paulo, n. 22. p. 5-9.

HUGHES, J.; ATTW ELL, G. (2002). A framework for the evaluation of e-learning. Disponível em: <http://www.pontydysgu.org/pontydysgu-and-people/graham-attwell/> Acesso em: 25 set. 2009.

HUITT, W.; HUMMEL, J.; KAECK, D. (2001). Ass essment, measure ment, evaluation, and research. Educational Psychology Inter acti ve. Valdosta, GA: Valdosta State University. Dis ponível em: <http://www.edpsycinteractive.org/ topics/intro/sciknow.html > Acesso em: 25 jan. 2010.

INSTITUTE FOR HIGHER EDUCATION POLICY (IHEP). (2000). Quality On the Line: benchmarks for success in Internet-based distance education. Disponível em: < http://www.ihep.org/Publications/mostpopular.cfm > Acesso em: 20 jul. 2007.

JENSEN, S. (2010). Mindset for Ass essment. Seattle University. Disponível em: $<$ http://seniordesign.engr.uidaho.edu/second semester docs/team toolbox/mindsetAssessment.pdf $>$ Acesso em: 25 jan 2010. 
JOINT COMMITTEE ON STANDA RDS FOR EDUCATIONAL EVALUATION. (1994). The Program e valuation standar ds. Dis ponível em: < http://www. wmich.edu/evalctr/jc/PGMSTNDS -SUM.htm > Acesso em: 30 ago. 2009.

JOVELL, A.J.; NA VA RRO-RUBIO, M.D. (1995). Eval uación de la e vi dencia cientifica. Disponível em: <http://lbe.uab.es/vm/sp/old/docs/metodologia/evidencia.pdf> Acesso em: 13 set. 2009.

KAPLAN, R.S.; NORTON, D.P. (1997). A estratégia em ação: balanced scorecard. Rio de Janeiro: Campus.

KAUFMAN, P.; KELLER, J.M. (1994). Levels of evaluation: Beyond Kirkpatrick. Human Resource De velopment Quarterly, San Francisco, v. 5, n. 4, p. 371-380,Winter.

KEEGAN, D. (1996). Foundations of distance education. 3.ed. London: Routledge.

KIRKPATRICK, D. L. (1959). Evaluating training programs. 2. ed. Berrett Koehler, San Francisco.

KRIPPENDORFF, K. (1980). Content analysis. Bevery-Hills: Sage Publications.

LAM, P.; McNAUGHT, C. (2005). Build ing an evaluation culture and evidence base for e-learning in tree Hong Kong universities. British Journal of Educational Technology, Oxford, v. 36, n. 4, p. 599-614.

LIKERT, R. (1932). A TECHNIQUE FOR THE MEASUREMENT OF ATTITUDES. A RCHIVES OF PSYCHOLOGY, New York, v.22, n.140, p.1-55.

LINCOLN, Y.; GUBA, E. (1985). Naturalistic inquiry. New York: Sage.

LINN, R. L.; MILLER, M. D. (2005). Measurement and assessment in teaching. Colu mbus, Ohio: Pearson.

LITWIN, M.S. (1995). How to measure survey realiability and vali dity. Californ ia: Sage Publications.

LOO, R. (2002). The Delphi method: a powerful tool for strategic management. An International Journal of Police Strategies \& Management, Oxford, v. 25, n. 4; p. 762-769.

LUCKESI, C.C. (1996). Avaliação da aprendizagem. São Paulo, Cortez.

, C. C. (2001). Avaliação da aprendizagem. Produção de ATTA mídia e Educação. São Pau lo: ATTA.

[Fita de vídeo, VHS, Son., color.].

MARCHESI, A. (2003). Qualidade do ensino em tempos de mudança. Porto Alegre: Art med.

MARCONI, M.A.; LA KATOS, E.M. (1996). Técnicas de pes quisa. 3ed. São Paulo: Atlas.

MARYNOWSKI, S. (2006). Best practices guide to program evaluation. Gainesville: Recreational Boating \& Fishing Foundation.

MATIAS-PEREIRA, J. (2008). Políticas públicas de Educação no Brasil: a utilização da EaD co mo instrumento de inclusão social. Journal Technology Management Innovations, Santiago, Chile, v. 3, Special Issue 1.

McFEELEY, B. (1996). IDEAL: a user's guide for software process improvement. Pittsburgh: Software Engineering Institute, Carnegie Mellon University.

McNAMARA, C. (2008). Basic guide to program evaluation. Disponível em: <http://managementhelp.org/ evaluatn /fnl eval. htm> Acesso em: 16 ago. 2009.

MY ENVIRONMENT EDUCATION EVALUATION RESOURCE ASSISTANT (MEERA). UNIVERSITY OF

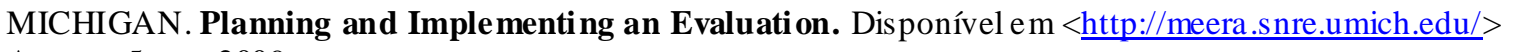
Acesso: 5 nov. 2009. 
MESSICK, S. Validity. In: LINN, R.L. (Ed.) Educational measurement. 3rd. Ed. New York: MacMillan, 1989.

MEZOMO, J.C. (1997). Educação de quali dade total: a escola volta às aulas. 2.ed. Petrópolis: Vo zes.

MICHAELIS. (2009). Moderno dicionário da língua portuguesa. Disponível em: <www.uol.com.br/ michaelis >. Acesso em: 20 mar 2009.

MINAYO, M.C.S.; HA RTZ, Z.M.A.; BUSS, P.M. (2000). Qualidade de vida e saúde: u m debate necessário. Ciência e Saúde Coletiva, Rio de Janeiro, v. 5, n. 1, p. 7-18.

MINISTÉRIO DA EDUCAÇÃO E CULTURA. SECRETA RIA DE EDUCAÇÃO SUPERIOR - MEC/SESU. (1994). Programa de avaliação institucional das Uni versi dades Brasileiras. (PAIUB). Brasília: MEC/SESU.

MINISTÉRIO DA EDUCAÇÃO E CULTURA. SECRETA RIA DE EDUCAÇÃO SUPERIOR - MEC/SESU. (2007). Referenciais de Qualidade para a Educação a Distância. Disponível em:

<http://portal.mec.gov.br/seed/arquivos/pdf/legislacao/refead1.pdf > Acesso em: 01 abr. 2008.

MINISTÉRIO DA EDUCAÇÃO E CULTURA. SECRETARIA DE EDUCAÇÃO SUPERIOR - MEC/SESU. (2009). Instrumento de Credenciamento Institucional para a Oferta da Modalidade de Educação a Distância. Disponível em: <www.inep.gov.br/superior/avaliacao institucional/EAD.htm> Acesso em Acesso em: 20set. 2009.

MINISTÉRIO DA SAÚDE. (2007). Diretrizes metodológicas para estudos de avaliação econômica de tecnol ogias para o Ministério da Saúde. Disponível em: <http://portal.saude.gov.br/portal/arquivos/pdf/diretrizes metodologicas ave.pdf > Acesso em: 01 abr. 2008.

MOREIRA, D. (1996). Dimensões do desempenho em manufatura e serviços. São Paulo: Pioneira.

MUNGANIA, P.; HATCHER, T. (2004). A Systemic, fle xible, and mu ltidimensional model for evaluating elearning programs. Performance Improvement, United Kingdom, v. 43 n. 7 p. 33-39, Aug.

NATIONAL SCIENCE FOUNDATION. (2009). User-friendly handbook for mixed method evaluations. Disponível em: < http://www.nsf.gov/pubs/1997/nsf97153/start.htm > Acesso em: 01 set. 2009.

NATURE JOURNAL. (2009). Editorial policies: authors \& referees. Dis ponível em: <http://www.nature.com/authors/ editorial policies/index.html > Acesso em: 13 set. 2009.

NEDER, M. L.C. (1996). Avaliação na educação a distância: significações para defin ição de percursos. In: PRETI, O. (Org.) Educação a distância: inícios e indícios de um percurso. Cu iabá: NEAD/IE-UFMT.

(1999). A for mação do professor a distância: diversidade co mo base conceitual. 250 f. Tese (Doutorado) - Instituto de Educação Pública, Universidade Federal de Mato Grosso, Cuiabá, 1999.

PÁDUA, E.M.M. (1997). Metodologia de pesquisa: abordagem teórico-prática. Campinas-SP: Papirus, 1997.

PALADINI, E. (1990). Controle de quali dade: u ma abordagem abrangente. São Paulo: Atlas.

PALOMBA, C.A.; BANTA, T.W. (1999). Assessment essentials. San Francisco: Jos sey-Bass.

PARASURAMAN, A.; ZEITHAML, V.A.; BERRY, L.L. (1985). A conceptual model of service quality and its implications for future research. Journal of Marketing, Chicago, v. 49, p. 41-50, Fall.

PARKER, P.E. et al. (2001). Defferentiating as sessment from evaluation as continuous improvement tool. In: ASEE/IEEE FRONTIERS IN EDUCATION CONFERENCE, 31., 2001, Reno, NV, Proceedings... Reno: ASEE/IEEE.

PARRY, S. (1996). Measuring training's ROI. Training and De velopment, Detroit, v. 50, n. 5, May.

PASQUALI, L. (1997). Psicometria: teoria e aplicações. Brasília: Editora Universidade de Brasília. 
PASQUALI, L. (1999). Instrumentos psicológicos : manual prático de elaboração. Brasília: LabPAM/ IBAPP.-

PASQUALI, L. (2000). Princípios de elaboração de escalas psicológicas. In: GORENSTEIN, C.; PASQUALI, L. (2003). Psicometria: teoria dos testes na psicologia e na educação. Petrópolis/RJ: Vozes.

PASQUALI, L. (2003). Psicometria: teoria dos testes na Psicologia e na Educação. Petrópolis: Vo zes.

PEREIRA, F.C.B. (2003). Determinantes da evas ão de alunos e os custos ocultos para as Instituições de Ensino Superior: u ma aplicação na Universidade do Extre mo Sul Catarinense. 174 f. Tese (Doutorado) Engenharia de Produção,Universidade Federal de Santa Catarina, Florianópolis, 2003.

PHILLIPS, J. (1997). Handbook of training e valuation and measureme nt methods. Texas: Houston Gu lf.

POLIDORI, M.M. (2009). Políticas de avaliação da educação superior brasileira: provão, SINAES, IDD, CPC, IGC e ... outros índices. Avaliação, Campinas, Sorocaba, SP, v. 14, n.2, p. 439-452, ju 1.

POLIT, D.F.; BECK, C.T.; HUNGLER, B.P. (2004). Fundamentos de pesquisa em Enfer magem: métodos, avaliação e utilização. 5.ed. Tradução de Ana Thorrell. Porto Alegre: Art med.

POSA VAC, E. J.; CAREY, R. G. (2002). Program evaluation: methods and case studies. 6.ed. Engle wood Cliffs, NJ: Prentice-Hall.

REA, M.L.; PA RKER, R.A. (2002). Metodologia de Pes quisa: do planeja mento à e xecução. São Paulo: Pioneira.

RECKASE, M.D. (1998). The interaction of values and validity assessment: does a test's level valid ity depend on a research's value? Social Indicators Research, New York, v. 45, n. 1, p. 45-54.

RICHARDSON, R.J. (1999). Pes quisa social : métodos e técnicas. São Paulo: Atlas.

RISTOFF, D. I. (1999). Uni versidade em Foco: refle xões sobre a educação superior. Florianópolis: Insular.

ROSSI, P.H.; FREEMAN, H.E. (1993). Evaluation: a systematic approach. 5.ed. Newbury Park: Sage.

ROSSI, P. H.; FREEMAN, H.E.; LIPSEY, M.W. (1999). Evaluation: a systematic approach. Ne wbury Park, CA: Sage.

ROSSI, P.H.; LIPSEY, M.W.; FREEMAN, H.E. (2004). Eval uation: a systematic approach. London: Sage Book.

ROVAI, A.P. (2003). A practical framework for evaluating online distance education programs. Internet and Higher Education, A msterdam, v. 6, p. 109-124.

RUHE, V.; ZUMBO, B.D. (2009). Evaluation in distance education and e-Learning: the unfold ing model. New York: The Guilford Press.

RUIZ, J.A. (2006). Metodol ogia científica: guia para a eficiência nos estudos. 6.ed. São Paulo: Atlas.

RUSS-EFT, D.; PRESKILL, H. (2001). Evaluation in Organizations: a systematic approach to enhancing learning, performance and change. New York: Basic Books, 2001.

(2009). Evaluation in Organizations: a systematic approach to enhancing learning, performance and change. 2. ed. New York: Basic Books.

SAMPIERI, R.H.; COLLADO, C.F.; LUCIO, P.B. (2006). Metodologia de Pes quisa. 3.ed. Tradução de Fátima Conceição Murad, Melissa Kassner, Sheila Clara Dystyler Ladeira.. São Paulo: Mc Graw-Hill.

SANDER, B. (1995). Gestão da educação na América Lati na: construção e reconstrução do conhecimento. Campinas: Editora Autores Associados. 
SCANLON, E. et al. (2000). Evaluating information and communication Technologies for learning.

Educational Technology and Society, New Zealand, v. 3, n. 4, p. 1-10.

SCHILKE, R.A. (2001). A case study of attrition in web-based instruction for adults: updating Garland's model of barriers to persistence in distance education. $115 \mathrm{f}$. Dis sertation (Doctoral), Northern Illinois University, United States - Illinois, 2001.

SCRIVEN, M. (1991). Eval uation thesaurus. 4. ed. Thousand Oaks, California: Sage.

SEGENREICH, S.C.D. (2006). Desafios da educação à distância ao sistema de educação superior: novas refle xões sobre o papel da avaliação. Educar, Curitiba, n. 28, p. 161-177.

SOFTWARE ENGINEERING INSTITUTE - SEI (1996). CARNEGIE MELLON UNIVERSITY. IDEAL Model. Disponível em: 〈www.sei.c mu.edu > Acesso em: 10 dez. 2009.

. (2009). IDEAL Model. Carnegie Mellon University. Disponível em: 〈www.sei.cmu .edu $>$ Acesso em: 10 dez. 2009.

SHADISH, W. R.; COOK, T. D.; CAMPBELL, D. T. (2002). Experimental and quasi-experimental designs for gener alized causal inference. Boston, MA: Houghton Mifflin.

SHEPHERD, C. (1999). Assessing the ROI of Training. Disponível em: < http://fastrak-consulting.co.uk/ tactix/ Features /tngroi/tngroi.htm> Acesso em: 21 set. 2009.

SILVA RES, E.F.M.; ARANTES, M.C. (2010). Texto em fase de elabor ação para li vro sobre Me todol ogia de Pesquisa em Psicologia Clínica. Disponível em:

<http://www.ip.usp.br/docentes/efdmsilv/\% 5Cpdf\% 5Cbasesmetodologicas 1907.pdf > Acesso em: 20 jan. 2010.

STAKE, R. (2000). Case studies. In: DENZIN, N.; LINCOLN, Y. (Eds.) Handbook of qualitati ve research. Thous and Oaks, CA: Sage Publications.

STONE, J.; WATSON, V. (1999). Evaluation of Training. Disponível em: < www.ispi-atlanta.org > Acesso em: 21 set. 2009.

STUFFLEBEAM, D.L. (2001). Evaluation models. In : STUFFLEBEAM, D.L. New directions for e valuation. San Francisco: Jossey-Bass, n. 89, p. 7-98.

SYNODINOS, N. (2003). The "art"of questionnary construction: some important considerations for manufacturing studies. Integrated Manufacturing Systems, Bing leym v.14, n. 3, p. 221-237.

TANQUIST, S. (2000). Evaluating e-learning. Issue 0009. Ale xandria, VA: Info-line and ASTD.

TAROUCO, L. (2007). O processo de avaliação na educação a distância. Disponível em:

<http://www.pgie.ufrgs.br/webfolioead/biblioteca/artigo6/artigo6.html > Acesso em: 13 mar. 2007.

TASHAKKORI, A.; CRESWELL, J.W. (2007). The New era of mixed methods. Journal of Mixed Me thod Research, Thous and Oaks, v.1, n.1, Jan.

THE EVALUATION CENTER. (2009). Students e valuation standar ds strengths and limitations. Dis ponível em: < http://www.wmich.edu/evalctr/jc/>. Acesso em: 30 ago. 2009.

TRIGUEIRO, M. (1994). Indicadores de quali dade na uni versidade: um desafio para a avaliação institucional. Universidade, São Paulo, v. 1, n.6, p. 320-30.

TUBINO, M. J. G. (Org.). (1997). A uni versidade, qualidade e avaliação. Rio de Janeiro: Quality Mark/Dunya.

TUROFF, M. (1975). The policy Delphi. Technological Forecasting and Social Change. v. 2, p. 149-171, 1975. 
TURRA, C.M.G. et al. (1998). Planejamento de ensino e avaliação. 11. ed. Porto Alegre, Sagra.

URBINA, S. (2004). Essentials of ps ychological testing. New Jersey: John Wiley \& Sons, Inc.

UNIVERSITY OF MICHIGAN - MY ENVIRONMENT EDUCATION EVALUATION RESOURCE ASSISTANT (MEERA). Planning and Implementing an Evaluation. Disponível em <http://meera.snre.u mich.edu/> Acesso: 5 nov. 2009.

VAN DIJK, T.A. (1998). Ideology: a multi-d is ciplinary approach. Thousand Oaks, C.A : Sage.

VAN SLYKE, C; KITTNER, M.; BELA NGER, F. (1998). Distance education: a teleco mmuting perspective. In: AMERICAS CONFERENCE ON INFORMATION SYSTEM. 14., 1998, Baltimore, Proceedings... Atlanta: AMCIS.

VERDUNG, E. (1993). Modelos de evaluación. Revista de Servicios Sociales y Política Social, Madrid, jun.dez.

WARR, P. B., BIRD, M. AND RACKHAM, N. (1970). The Eval uation of Management Training, Gower. Disponível em <http://www.businessballs.com/train ingprogramevaluation.htm > Acesso em: 25 set 2009.

WEISS, C. (1972). Evaluation research: methods of as sessing program effectiveness. Engle wood Cliffs: Prentice-Hall.

WIDRICK, S.M.; MERGEN, E.; GRANT, D. (2002). Measuring the dimension of quality in higher education. Total quality management, Minnesota, v. 13, n. 1, p. 123-131.

WORTHEN, B. R.; SANDERS, J. R.; FITZPATRICK, J. L. (1997). Program e valuation: alternative approaches and practical guidelines. 2. ed. New York: Long man.

XAVIER, O.S. (1990). A socio metria na admin istração de recursos humanos. Re vista de Administração de Empresas, São Paulo, v. 30, n.1, p. 45-54, jan/mar.

YIN, R.K. (2001). Es tudo de Caso: planejamento e métodos. 2 ed. Porto A legre: Bookman. (2003). Es tudo de Caso: planejamento e métodos. 3 ed. Porto A legre: Bookman.

ZAHARIAS, P. (2004). Developing a usability evaluation method for e-learning applications: From functional usability to motivation to learning. (2004). Disponível em: < http://www.eltrun.gr/eltrun/phd-studies/completedphds/a-usability-evaluation-method-for-e-learn ing-courses-1/paper-of-phd-thesis-dr-zaharias.doc/file $>$ Aces so em: 25 set. 2009.

(2005). E-Learning design quality: a holistic conceptual framework. In: HOWARD, J.;

BOETTCHER, L.; JUSTICE, R.; BERG, G.A. (Eds.). Encyclope dia of distance learning. New York: Idea Group.

ZAHRA N, S. (1998). Software process improvement: practical guidelines for business success. New York: Addison- Wesley.

ZUMBO, B.D. (1998). Opening remarks to the special is sue on validity theory and the methods used in validation: perspectives from the social and behavioral science. Social Indicators Research: An International and Interdisciplinary Journal for Quality-of-Life Measurement, New York, v. 45, p. 1-3.

. (2007). Valid ity: foundational is sues and statistical methodology. In: RA O, C.R.; SINHA RA Y, S.

(Eds.) Handbook of statistic. A ms terdam: Elservier Science. 


\section{APÊNDICE A - Detalhamento dos Padrões Internacionais de Avaliação}

\section{Identificação dos stakeholders}

- Identificar as pessoas em cargos de liderança e pedir-lhes para identificar outros interessados na avaliação. Contatar os representantes dos grupos identificados e interessados para saber como eles veem a importância da avaliação, como eles gostariam de utilizar os resultados e quais informações seriam úteis. Quando necessário, ajudá-los a desenvolver expectativas realistas que levem em conta as limitações metodológicas, financeiras e políticas sobre a avaliação. (U1)

- Solicitar aos interessados que ajudem a identificar e contatar outros que tenham interesse. (U1)

- Chegar a um entendimento com o cliente sobre a importância relativa dos potenciais interessados e as informações que desejam. Planejar e implementar a coleta de dados e relatar adequadamente as atividades desenvolvidas. (U1)

- Ao longo da avaliação, esteja a lerta para identificar as partes adicionais que devem ser atendidas e, dentro dos limites de tempo e recursos, mantenha a flexibilidade e capacidade de resposta às necessidades surgidas. (U1)

- Envolva os clientes e outras partes diretamente interessadas na concepção e condução da avaliação. (U1)

- Não exclua nenhum interessado devido ao gênero, etnia ou origem da língua. (U1)

- Não permita que os clientes restrinjam inadequadamente o contato do avaliador com outros interessados envolvidos ou afetados. (U1)

- Não tente resolver todas as necessidades de informação das partes interessadas, quando na realidade elas não podem ser tratadas. (U1)

- Não assuma que pessoas reconhecidas como líderes ou tomadores de decisão são mais importantes que os outros interessados. (U1)

- Evite uma super-identificação dos interessados, tornando o trabalho impossível de prosseguir. (U1)

- Não deixe de distinguir o cliente de outras partes interessadas. (U1)

\section{Credibilidade do Avaliador}

- Fique atento às forças políticas e sociais associadas à a valiação, especialmente àquelas relacionadas à raça, gênero e diferenças linguísticas e culturais; e ao uso desse conhecimento quando da concepção e condução da avaliação. (U2) 
- Assegure-se de que tanto o plano de trabalho como a composição da equipe de avaliação são compreensíveis às preocupações dos interessados-chave. (U2)

- Considere ter que revisar o plano e auditar o trabalho de avaliação de outro avaliador, cujas credenciais não são aceitáveis pelo cliente. (U2)

- Seja claro na descrição do plano de avaliação para todos os interessados e demonstre que ele é realista e tecnicamente executável. (U2)

- Determine a audiência das principais necessidades de informações para o andamento da avaliação, mantendo-os informados por meio de boletins, relatórios, telefonemas, memorandos e releases. (U2)

- Inclua na proposta da avaliação uma declaração descrevendo as qualificações relevantes do avaliador para o programa avaliado. (U2)

- Procure avaliadores experientes no cenário da avaliação. (U2)

- Não invista demasiados recursos para conseguir credibilidade e aceitação. (U2)

- Não assuma que a abordagem de avaliação do avaliador seja aceitável para o cliente. (U2)

- Evite turning over entre as pessoas experientes ou assistentes. (U2)

\section{Escopo e seleção da informação}

- Compreenda os requisitos do cliente para a avaliação. (U3)

- Entreviste representantes dos principais interessados para obter uma compreensão de seus diferentes e talvez conflitantes pontos de vista e suas necessidades de informação. (U3)

- Evite dar a impressão de que todas as questões serão respondidas. (U3)

- Ajude os interessados a desenvolver expectativas realistas em função dos recursos financeiros, tempo e pessoal disponível. (U3)

- Tenha o rank dos potenciais clientes em ordem de importância e trabalhe com os representantes de cada grupo de interessados para classificar os temas em ordem de importância para cada público. (U3)

- Trabalhe com o cliente para agrupar os temas ordenados para cada público, removendo itens e/ou adicionando outros que o avaliador considere importantes, mesmo que isso não tenha sido solicitado. (U3)

- Permita certa flexibilidade para a adição de perguntas e inclusão de informações não previstas que podem surgir durante a avaliação. (U3)

- Distribua todo o esforço de avaliação (coleta de dados, análise, interpretação e 
relatórios) sobre a lista final de temas, priorizando os itens melhor ranqueados. (U3)

- Considere as compensações entre entendimento e seletividade em todas as fases da avaliação: desenvolvimento do plano, definição do orçamento, coleta, análise, interpretação e comunicação das informações. (U3)

- Dê voz aos diversos grupos de interessados no processo de seleção das questões prioritárias da avaliação. (U3)

- Não coletar informações porque são convenientes (como, por exemplo, instrumentos já existentes) e sim porque são necessárias. (U3)

- Delimitar o escopo da avaliação, ou seja, ter as questões que serão respondidas e seus respectivos propósitos em todas as fases da avaliação. (U3)

- Não coletar informações que sejam irrelevantes para o propósito central da avaliação. (U3)

\section{Identificação dos Valores}

- Considere bases alternativas para a interpretação dos resultados, como, por exemplo: objetivos do programa, especificações de procedimentos, leis e regulamentos, objetivos institucionais, ideais democráticos, normas sociais, desempenho por comparação entre grupos, a valiação das necessidades de um grupo de consumidores, desempenho esperado de uma amostra do grupo, padrões profissionais e julgamentos relatados pelos vários grupos de referência. (U4)

- Considere quem fará as interpretações, por exemplo, os avaliadores, os clientes, as partes interessadas, um grupo regulatório ou alguma combinação desses. (U4)

- Considere técnicas alternativas que possam ser usadas para atribuir significados às informações coletadas, como, por exemplo: ter diferentes equipes escrevendo relatórios; conduzir um júri ou julgamento administrativo do programa que está sendo avaliado; ou procurar convergência por meio de estudo delphi. (U4)

- Não assumir que as avaliações podem ser objetivas no sentido de serem desprovidas de juízo de valor. (U4)

- Não projetar a coleta de dados e procedimentos de análise, sem considerar quais critérios, tais como, a comparação de desempenho entre grupos ou o desempenho em termos de padrões pré-determinados, os quais serão necessários para a interpretação dos resultados. (U4)

- Não se concentre tão pesadamente em esclarecer valores, utilize o tempo e os esforços para a coleta e análise das informações necessárias para criar julgamento de valores. (U4) 
- Reconheça que as regras de decisão muitas vezes são arbitrárias e, portanto, discuta sobre os assuntos. (U4)

\section{Procedimentos Práticos}

- Assegure a disponibilidade de pessoal qualificado para concluir a avaliação, tal como planejada, incluindo as necessidades de treinamento para o pessoal envolvido. (V1)

- Escolha procedimentos que possam ser realizados com esforços razoáveis e que sejam compatíveis com as habilidades do pessoal disponível para o estudo. (V1)

- Selecione os procedimentos em função das limitações conhecidas de tempo e disponibilidade dos participantes ou respondentes. (V1)

- Sempre que apropriado, crie atividades de avaliação como parte dos eventos rotineiros. (V1)

- Desenvolva procedimentos alternativos para antecipar potenciais problemas e seja flexível para com o plano e orçamento, bem como os problemas imprevistos. (V1)

- Verifique com os clientes a viabilidade do cronograma para a realização da avaliação e a praticidade dos procedimentos de coleta antes de finalizar o plano de coleta de dados. (V1)

- Verifique os procedimentos e instrumentos em um teste piloto para determinar a praticidade e o tempo requerido. (V1)

- Evite escolher um plano de coleta e análise de dados sem considerar que o referido plano pode ser executado em um determinado ambiente/contexto. (V1)

- Não deixe de comparar a praticidade e a precisão: ao verificar que as circunstâncias inibirão a validade e confiabilidade da coleta de dados, trabalhe com os clientes para remover ou alterar estas circunstâncias. Se isso não prover êxito, considere seriamente usar outros procedimentos ou não faça a avaliação. (V1)

- Evite interromper as atividades do programa na tentativa de coletar informações. (V1)

\section{Acordo Formal}

- Inclua o design da avaliação em um contrato formal. (P2)

- Não espere a participação na avaliação de pessoas que não tenham concordado previamente em participar. (P2)

- Não aja unilateralmente em um assunto que foi acordado em colaboração com o avaliador/cliente e para o qual sejam necessárias decisões. (P2)

- Não altere o projeto sem corrigir os acordos formais. (P2) 
- Não adira tão rapidamente às mudanças ditadas nos contratos, entretanto, evite atrasos desnecessários. (P2)

- Não desenvolva contratos demasiadamente detalhados para não sufocar a criatividade da equipe ou infamar a condução da avaliação. (P2)

\section{Avaliações completas e legíveis}

- Planejar a avaliação e registrar os pontos fortes e fracos do programa que estão sendo avaliados. (P5)

\section{Documentação do Programa}

- Solicite aos clientes e aos outros interessados que descrevam oralmente e, se possível, por escrito, a intenção e a atual referência do programa, assim como, o custo, pessoal, procedimentos, atividades, objetivos, natureza da participação e potenciais efeitos colaterais. (A1)

- Coletar e analisar as diferenças e semelhanças das descrições disponíveis do programa, incluindo propósitos, relatórios das relações públicas, apresentações, progresso dos assessores e relatório final. (A1)

- Envolva observadores independentes para descrever o programa, se o tempo e o orçamento permitirem. (A1)

- Destine um tempo no início da avaliação para observar o programa, os assessores e participantes envolvidos. (A1)

- Como parte do processo de avaliação, mantenha atualizadas as descrições do programa com fontes de informações (exemplos: observadores participantes, atas das reuniões com os assessores, entrevistas com os participantes e relatórios de progressos), dando especial atenção às mudanças na descrição. (A1)

- Considere a elaboração das descrições em separado para cada aspecto do programa que está sendo estudado. (A1)

- Não depender exclusivamente dos clientes ou da descrição da proposta do programa para financiamento. (A1)

- Não encobrir a descrição do programa e sempre descrever os eventos reais. (A1)

- Não se concentre demasiadamente na descrição do programa quando o tempo disponível for insuficiente para avaliar os pontos fortes e fracos. (A1)

- Não assuma que o programa será uniformemente implementado como previsto. (A1) 


\section{Descrição dos Propósitos e Procedimentos}

- Discuta exaustivamente e registre as concepções iniciais dos clientes sobre os propósitos da avaliação e a intenção de uso dos resultados obtidos. (A3)

- Discuta exaustivamente e registre as concepções iniciais dos clientes sobre como os propósitos da avaliação serão atingidos. (A3)

- Mantenha uma cópia do plano e contrato (se foi negociado) de avaliação. (A3)

- Busque um claro entendimento com os clientes sobre as maiores mudanças nos propósitos e procedimentos, bem como de que forma estas mudanças serão realizadas. (A3)

- Registre qualquer grande alteração nos propósitos e procedimentos e a data em que ela ocorreu. (A3)

- Descreva os propósitos e procedimentos na conclusão da avaliação, tanto no relatório resumo, como no executivo, e no relatório técnico completo, observando os desvios do plano original. (A3)

- Envolva avaliadores independentes para monitorar os propósitos e procedimentos da avaliação e verificar se são viáveis, especialmente em caso de avaliações em grande escala. (A3, A12)

- Permitir ajustes nos propósitos e procedimentos que sejam necessários durante a avaliação. (A3)

\section{Descrição das Fontes de Informação}

- Utilize as informações coletadas previamente na avaliação, desde que confirmada sua validade. (A4)

- Não presuma que a informação baseada em entrevistas pessoais, depoimentos, observações ou análise de documentos contém distorções e, portanto, não merece ser considerada. (A4)

- Para cada atividade de coleta de dados, descreva e justifique as fontes de informação que serão utilizadas no estudo. (A4)

- Avalie a adequação das fontes de informação como parte da documentação técnica da avaliação, reconhecendo as limitações que possam existir. (A4)

\section{Validação das Informações}

- Verifique os procedimentos de coleta de informações relacionadas, sobretudo os relacionados aos objetivos e conteúdo do programa que está sendo avaliado para 
determinar se há necessidade de ajustes ou se há congruência entre eles. Esta verificação deverá ser informada pelo menos em parte para o pessoal responsável pelo funcionamento do programa e para os representantes dos grupos de interessados. (A5)

- Considere os Standards for Educational and Psycological Testing e outros conjuntos de normas disponíveis, na tomada de decisão sobre testes educacionais ou psicológicos que serão utilizadas na avaliação. (A5)

- Considere as evidências de validade de outras avaliações similares em que os procedimentos propostos foram utilizados. (A5)

- Assegure que os indivíduos em que irão administrar ou usar um procedimento especial sejam qualificados e adequadamente preparados (em termos de conhecimento, treinamento e prática) para fazer o uso devido. (A5)

- Para procedimentos recentemente desenvolvidos, apresente a justificativa para assegurar a validade necessária. Saliente que tais procedimentos são exploratórios e que os resultados obtidos a partir deles devem ser cuidadosamente interpretados e ter um claro entendimento sobre as limitações das evidências de validade. Além disso, deve-se levar em conta o contexto, as características dos sujeitos ou grupos em que os procedimentos foram utilizados, bem como as qualificações e treinamento (se necessário) dos indivíduos que administrarão ou utilizarão o procedimento. Use várias medidas para auxiliar a clarificar a validade das inferências que a partir das informações geradas possam gerar novo procedimento. (A5)

- Use vários procedimentos para obter uma avaliação mais abrangente, mas faça sem interrupções e de uma forma parcimoniosa. Muitas vezes é conveniente utilizar procedimentos não reativos e avaliar as amostras ao invés das populações. Utilize os registros existentes, se forem relevantes. (A5)

- Avalie a compreensão das informações fornecidas pelos procedimentos, como um conjunto em relação à informação necessária para responder ao grupo de questões da avaliação. (A5)

- Considere as características dos respondentes, tais como a habilidade de leitura, proficiência na língua ou limitações físicas, que podem afetar a validade dos resultados da avaliação. (A5)

- Não tome decisões importantes com base em apenas um procedimento ou definição operacional de uma variável crítica. (A5)

- Não espere que os procedimentos produzam inferências válidas que possam ser construídas ou desenvolvidas com rapidez e facilidade. (A5) 
- Utilize os procedimentos existentes para produzir inferências válidas, quando eles estiverem disponíveis. (A5)

- Assegure que o pessoal responsável pela coleta de informações seja devidamente qualificado e preparado para desempenhar suas tarefas. (A5)

- Assegure que as observações e descrições do processo sejam adequadamente conduzidas e completadas. (A5)

- Permita que os interessados tenham a oportunidade de rever um instrumento ou procedimento prévio à sua utilização. (A5)

\section{Confiabilidade das Informações}

- Sempre que possível, os avaliadores devem escolher procedimentos de coleta de informações que, no passado, resultaram em dados e informações com confiabilidade aceitável para os fins propostos. Contudo, a generalização dos resultados de confiabilidade não pode ser assumida. A confiabilidade das informações coletadas está diretamente relacionada às formas em que os procedimentos de coleta serão utilizados na avaliação. (A6)

- Para os procedimentos de coleta de dados recém-desenvolvidos, apresente justificativa para o tipo e extensão da confiabilidade exigida. Considere se o conteúdo ou comportamento avaliado pelo procedimento foi apropriado, as formas pelas quais os procedimentos foram administrados aos indivíduos ou grupos e a heterogeneidade das pessoas em termos de características a serem mensuradas ou observadas, para todos os fatores que influenciam a confiabilidade. (A6)

- Discuta o desenvolvimento de proposições, interpretações e conclusões com os pares imparciais, para auxiliar a clarificar a postura e valores próprios, bem como seus papéis na investigação. (A6)

- Em caso de instrumentos e procedimentos abertos, verifique a consistência dos scores, categorização e codificação por duas ou mais pessoas, independentemente da análise do mesmo conjunto de informações ou por um auditor externo, aferindo se os dados foram analisados de forma consistente. (A6)

- Proporcionar formação adequada aos analistas das informações para assegurar que estejam sensibilizados com os tipos de erros que são susceptíveis de ser cometidos e saber os procedimentos para evitá-los. (A6)

- Não interprete a evidência de apenas um tipo de confiabilidade (exemplo: consistência interna, estabilidade ao longo do tempo e concordância em observação) como evidência 
de outro tipo, ou seja, confiabilidades diferentes refletem diferentes fontes de medição de erros que influenciam a interpretação da informação sob diversas formas. (A6)

- Não confie nas evidências de confiabilidade que são relatadas por um instrumento ou procedimento sem considerar seu valor em relação às diferenças entre a amostra do estudo e sua avaliação. (A6)

- Leve em conta o fato de que a confiabilidade dos resultados fornecidos por um instrumento ou procedimento pode variar dependendo de como, quando e para quem o instrumento ou procedimento foi aplicado. (A6)

- Não assuma que em função da confiabilidade do resultado individual ser baixo, a confiabilidade dos resultados médios do grupo também o será. (A6)

- Não interprete os coeficientes de confiabilidade para medição de variáveis contínuas como evidência da confiabilidade das decisões dicotômicas. (A6)

- Reconheça que a confiabilidade de um conjunto de escores diferentes é tipicamente menor do que a confiabilidade de outros dois grupos de escores usados para calcular as diferenças. (A6)

- Não utilize escores com baixa confiabilidade como resultado influente da informação. (A6)

- Não assuma que porque a confiabilidade é alta, a validade também o será. (A6)

- Não assuma que as observações de um avaliador não são afetadas por suas perspectivas, treinamento ou experiência prévia. (A6)

\section{Análise das Informações Quantitativas}

- Escolha procedimentos analíticos que sejam apropriados para as questões da avaliação e natureza dos dados. (A8)

- Conduza múltiplas análises dos dados. (A8)

- Relatar as potenciais limitações no design do estudo ou análise dos dados e descrever as possíveis influências nas interpretações e conclusões. (A8)

- Não assumir que os resultados estatísticos significativos, são, necessariamente, resultados práticos. (A8)

- Não suponha que os escores, análise de correspondência ou covariância irão prover um adequado ajuste nas diferenças preexistentes nos grupos. (A8)

- Use a unidade correta para análise quando se tratar de informação quantitativa. (A8)

- Não use técnicas complexas de estatística quando a audiência for mais bem servida com métodos analíticos e gráficos mais simples. (A8) 
- Evite enfatizar o rigor em detrimento da relevância e vice-versa. (A8)

- Nem todas as avaliações necessitam de análises estatísticas. (A8)

- Nem todas as avaliações necessitam ter estudos comparativos. (A8)

- Reconheça e explore a complementaridade entre as análises qualitativas e quantitativas e as interpretações que podem ser suportadas por ambas. (A8)

\section{Análise das Informações Qualitativas}

- Escolha procedimentos e métodos analíticos de sumarização que sejam apropriados às questões a serem respondidas pelo estudo e à natureza da informação qualitativa que foi coletada. (A9)

- Focar a análise nas questões de interesse e definir as fronteiras das informações a serem examinadas, por exemplo: período de tempo, atividades financeiras, público-alvo ou outros clientes da população e localização geográfica. (A9)

- Buscar corroboração das evidências qualitativas usando métodos e fontes independentes. (A9)

- Não considerar a análise de dados qualitativos como relativamente sem rigor e como algo que pode ser feito de forma intuitiva, sem treinamento. (A9)

- Considere interpretações alternativas da realidade e as múltiplas perspectivas de que podem existir em uma situação de avaliação. (A9)

- Distinguir entre as diferentes fontes de informações qualitativas, tais como: credibilidade, especialização e grau de envolvimento. (A9)

\section{Conclusões Justificadas}

- Planeje gerar, avaliar e relatar plausivelmente explanações alternativas dos resultados e, quando possível, indique por que estas explicações deveriam ser desconsideradas. (A10)

- Solicitar feedback de vários participantes do programa sobre a credibilidade das interpretações, explicações, conclusões e recomendações antes de finalizar os relatórios. Pontue sobre as não-interpretações e inferências não apropriadas que podem ser extraídas das informações coletadas. (A10)

- Observe possíveis efeitos colaterais do programa ao chegar às conclusões sobre sua efetividade. (A10) 


\section{Relatórios Imparciais}

- Chegue a um acordo com o cliente durante as fases iniciais da avaliação sobre as medidas a serem tomadas para assegurar a equidade de todos os relatórios. (A11)

- Estabeleça e esclareça a natureza e a autoridade para edição. (A11)

- Assegure que os relatórios da avaliação incluam perspectivas independentes daqueles cujo trabalho está sendo avaliado. (A11)

- Procure elaborar relatórios alternativos, talvez até mesmo com conclusões e recomendações conflitantes. (A11)

- Esforce-se para estabelecer e manter a independência na comunicação, usando técnicas como a auditoria externa ou a rotatividade dos membros da equipe de avaliação para os contatos com a audiência. (A11)

- Não assuma que todas as partes em uma avaliação são neutras. (A11)

- Evite delegar a edição dos relatórios. (A11)

- Esteja envolvido em apresentações públicas dos resultados, conforme necessidade da situação. (A11)

- Não se torne tão isolado em relação ao desenvolvedor do programa, evitando que informações potencialmente úteis não sejam relatadas. Não há melhor feedback do que o do avaliador do programa para o desenvolvedor. (A11)

\section{Meta-avaliação}

- O orçamento financeiro e os outros recursos devem ser suficientes para conduzir avaliações formativas, somativas e meta-avaliações. (A12)

- Atribuir responsabilidade a alguém pela documentação e avaliação do processo e produto do programa de avaliação. (A12)

- Considere solicitar a um respeitável corpo profissional a nomeação de alguém para presidir a equipe de meta-avaliadores externos em grandes avaliações. $\mathrm{Na}$ falta deste, designe à equipe a eleição do presidente ou selecione você mesmo, criteriosamente, alguém competente e confiável como presidente, para que este nomeie outros membros da equipe. (A12)

- Determine e registre as regras pelas quais os membros da equipe da meta-avaliação chegarão a um consenso e/ou emitirão relatórios da minoria. (A12)

- Estipule que qualquer membro da equipe de meta-avaliação que não cumprir as obrigações contratadas pode ser demitido a critério do presidente. (A12) 
- Tenha autoridade para edição do relatório dos avaliadores sobre a meta-avaliação. (A12)

- Determine e registre qual o público que receberá os relatórios da meta-avaliação e como estes serão transmitidos. (A12)

- Avalie a instrumentação, coleta e manipulação de dados, codificação e análise do programa de avaliação para determinar quão cuidadosamente e efetivamente estas etapas foram executadas. (A12)

- Espere que a própria meta-avaliação seja objeto de contradição e avaliação, e mantenha o registro de todas as etapas da avaliação, informações e análises. (A12)

- Não conduza somente uma meta-avaliação interna quando há conflito de interesses ou outras considerações claramente estabelecidas pela necessidade de uma meta-avaliação externa. (A12)

- Não presuma que todo programa de avaliação requer um estudo formal da metaavaliação. (A12) 


\section{APÊNDICE B - Modelo de Relatório do Plano de Assessment}

- Página de Título (nome da organização, produto, serviço ou programa que está sendo avaliado, data).

- Tabela de Conteúdos.

- Sumário Executivo (uma página concisa das conclusões e recomendações).

- Objetivo do Relatório (que tipo de avaliação foi realizada, quais as decisões que estão sendo tomadas pelos resultados da a valiação, quem é o tomador de decisão, etc).

- Antecedentes sobre organização e produto/serviço/programa que está sendo avaliado:

○ História, descrição da organização.

O Descrição do produto/serviço (que está sendo avaliado).

○ Definição do problema.

O Objetivos gerais.

○ Meta geral do produto/serviço.

O Resultados (impactos para o cliente) e medidas de desempenho (que podem ser medidos como indicadores para os resultados).

○ Atividades/ tecnologias do programa/produto/serviço (descrição de como o programa/produto/serviço é desenvolvido e entregue).,

○ Pessoal (descrição das funções das pessoas na organização, as quais são relevantes para o desenvolvimento e fornecimento do programa/serviço/produto, bem como o número de envolvidos).

- Objetivos gerais da avaliação (por exemplo: que perguntas estão sendo respondidas pela avaliação).

- Metodologia:

a) Tipos de dados/informações que foram coletadas.

b) Como os dados/informações foram coletadas (que instrumentos foram utilizados, etc).

c) Como os dados/informações foram analisadas.

d) Limitações da avaliação (por exemplo: adverte sobre os resultados/conclusões e como utilizá-los, etc).

- Interpretações e conclusões (a partir da análise dos dados/informações).

- Recomendações (a respeito das decisões que devem ser feitas sobre o produto/serviço/programa).

- Apêndices (o conteúdo dos anexos depende dos objetivos do relatório de avaliação), como, por exemplo: 
10.1. os instrumentos utilizados para coletar dados/informações;

10.2. data;

10.3. depoimentos, comentários feitos pelos usuários do produto/serviço/programa;

10.4. os estudos de caso dos usuários do produto/serviço/programa;

10.5. toda a documentação relacionada. 


\section{APÊNDICE C - Detalhamento da Técnica Análise de Conteúdo}

De acordo com a definição de Berelson (1971), a análise de conteúdo é uma técnica para estudar e analisar a comunicação de uma maneira objetiva, sistemática e qualitativa, a qual foi ampliada para uma técnica de pesquisa para fazer inferências válidas e confiáveis de dados com relação a seu contexto (KRIPPENDORFF, 1980).

Para Ander-Egg (1978) essa é a técnica apropriada para investigar o conteúdo das comunicações de massa, mediante a classificação, em categorias, dos elementos da comunicação. Desta forma, destaca que a técnica abrange três principais fases:

- Estabelecer unidade de análise.

A unidade de análise, padronizada, constitui-se no elemento básico da investigação e pode ser realizada de duas maneiras:

○ Análise geral de todos os termos ou vocabulário e/ou palavras-chave.

○ Análise do tema, ou seja, de uma proposição, afirmativa ou sentença sobre determinado assunto.

- Determinar as categorias de análise.

A seleção e classificação da informação de que se necessita, depende da determinação das categorias. Não há uma regra geral para o estabelecimento das categorias, das variedades possíveis ou da complexidade da escolha. A mais abrangente apresenta cinco categorias:

○ De matéria - referente ao assunto abordado:

- Temas tratados.

- Métodos ou técnicas.

O De forma - diz respeito apenas à forma:

- De forma propriamente dita: fatos e comentários.

- De intensidade: efeitos produzidos sobre o público em virtude da repetição contínua ou carga emocional.

○ De apreciação - maior ou menor aceitação:

- Tomada de posição: aprovação ou refutação, otimismo ou pessimismo, afirmação ou ne gação.

- Valores.

- Autoridade.

○ De pessoas e atores:

- Status pessoal e traços de caráter. 
○ De origem e de destino - variam quanto a:

- Origem das notícias.

- Destino - público a que se destina.

- Selecionar uma amostra do material de análise.

A seleção da amostra vai depender dos objetivos, questões e hipóteses estabelecidas e encontra-se condicionada pelos itens anteriores.

Corroborando com Ander-Egg (1978), Bardin (2002) aponta como pilares a fase da descrição ou preparação do material, a inferência ou dedução e a interpretação. Dessa forma, os principais pontos da pré-análise são a leitura flutuante (primeiras leituras dos textos); a escolha dos documentos; a formulação das hipóteses e objetivos; a referenciação dos índices e elaboração de indicadores (a frequência de aparecimento); e a preparação do material.

Para o tratamento dos dados recomenda-se a técnica da análise temática ou categorial, que, de acordo com Bardin (2002), baseia-se em operações de desmembramento do texto em unidades, ou seja, descobrir os diferentes núcleos de sentido que constituem a comunicação, e, posteriormente, realizar o seu reagrupamento em classes ou categorias, parece ser a mais apropriada.

Desta forma, na fase da exploração do material tem-se o período mais duradouro: a etapa da codificação, na qual são feitos recortes em unidades de registro (é o menor recorte de ordem semântica que se liberta do texto, podendo ser uma palavra-chave, um tema, objetos, personagens, etc) e em unidade de contexto (deve fazer compreender a unidade de registro, tal qual a frase para a palavra) (BARDIN, 2002).

$\mathrm{Na}$ fase de categorização, os requisitos de exclusão mútua, homogeneidade, pertinência, objetividade, fidelidade e produtividade devem ser observados com vistas a uma boa categoria. Já a última fase, do tratamento e inferência à interpretação, permite que os conteúdos recolhidos se constituam em dados quantitativos e/ou análises reflexivas, em observações individuais e gerais das entrevistas (BARDIN, 2002).

De acordo com Berelson (1971), a análise de conteúdo aponta para vários usos, entre os quais se destacam:

- Descrever tendências no uso da comunicação.

- Revelar diferenças no conteúdo da comunicação (entre pessoas, grupos, instituições, países).

- Comparar mensagens, níveis e meios de comunicação.

- Fazer auditoria do conteúdo da comunicação e compará- lo com padrões ou objetivos.

- Construir e aplicar padrões de comunicação (políticas, normas, etc.). 
- Expor técnicas publicitárias e de propaganda.

- Medir a clareza de mensagens.

- Descobrir estilos de comunicação.

- Identificar intenções, apelações e características de comunicadores.

- Decifrar mensagens ocultas e outras aplicações à inteligência militar e à segurança política.

- Revelar "centros" de interesse e atenção para uma pessoa, um grupo ou uma comunidade.

- Determinar o estado psicológico de pessoas ou grupos.

- Obter indícios de desenvolvimento verbal.

- Antecipar respostas a comunicações.

- Refletir atitudes, valores e crenças de pessoas, grupos ou comunidades.

- Fechar questões abertas.

Bardin (2004) aponta a importância de se dar atenção especial aos tipos, qualidades e distinções do conteúdo, ressaltando a análise de conteúdo como técnica utilizada para fazer inferências por meio da identificação objetiva e sistemática de características específicas da mensagem.

Enfim, verifica que a análise de conteúdo se realiza pelo processo de codificação, para o qual é necessário definir o universo, as unidades de análise e as categorias de análise. Esse procedimento seleciona as características relevantes do conteúdo de uma mensagem, permitindo sua descrição e análise fidedignas. 


\section{APÊNDICE D - Detalhamento sobre Análise Quantitativa de Dados}

Na obra de Sampieri, Collado e Lucio (2006) há uma revisão bem fundamentada sobre diferentes conceitos acerca da análise quantitativa por meio de ferramentas da estatística. Portanto, fez-se alguns recortes que compõem um repositório de definições (observações) para a etapa de análise dos dados:

- A primeira tarefa é descrever os dados, os valores ou as pontuações obtidas para cada variável.

- Uma distribuição de frequências é um conjunto de pontuações ordenadas em suas respectivas categorias.

- As distribuições de frequências podem ser completadas adicionando-se as frequências relativas e as acumuladas. As frequências relativas são as porcentagens de casos em cada categoria e as acumuladas são o que vai se acumulando em cada categoria, da mais baixa à mais alta.

- As frequências acumuladas também podem ser expressas em porcentagem (então o que são acumuladas são as porcentagens).

- Os polígonos de frequência relacionam as pontuações com suas respectivas frequências.

- Para cada uma das variáveis da pesquisa é obtida a sua distribuição de frequências e, se possível, é colocado no gráfico e traçado seu polígono de frequências correspondentes. Mas além do polígono, devem ser calculadas as medidas de tendência central e de variabilidade ou dispersão.

- As medidas de tendência central são valores médios ou centrais de uma distribuição que servem para localizá-la dentro da escala de medição. As principais medidas de tendência central são: moda, mediana e média. O nível de medição da variável determina qual é a medida de tendência central apropriada.

- A moda é a categoria ou pontuação que ocorre com maior frequência.

- A mediana é o valor que divide a distribuição pela metade, isto é, a metade dos casos fica abaixo da mediana e a outra metade se localiza acima da mediana. A mediana reflete a posição intermediária da distribuição.

- A média é a medida de tendência central mais utilizada e pode ser definida como a média aritmética de uma distribuição.

- As medidas da variabilidade indicam a dispersão dos dados na escala de medição e respondem à questão: onde estão espalhadas as pontuações ou os valores em uma 
distribuição e as medidas de variabilidade são intervalos, indicam distâncias ou um número de unidades na escala de medição. As medidas de variabilidade mais utilizadas são: posição, desvio-padrão e variância.

- A posição, também chamada percurso, é a diferença entre a pontuação maior e a menor, e indica o número de unidades necessárias na escala de medição para incluir os valores máximos e mínimos.

- O desvio-padrão é a média de desvio das pontuações com relação à média. Essa medida é expressa nas unidades originais de medição da distribuição. É interpretada em relação à média. Quanto maior a dispersão dos dados ao redor da média, maior será o desvio-padrão.

- O desvio-padrão é interpretado como "quanto, em média, um conjunto de pontuações é desviado da média". Só é utilizado em variáveis medidas por intervalos ou razões.

- A variância é o desvio-padrão elevado ao quadrado.

- A assimetria é a estatística usada para conhecer quanto se parece uma distribuição com uma distribuição teórica chamada de curva normal e que é um indicador ao lado da curva, cujas frequências se agrupam mais.

- A curtose é um indicador de quão plana ou pontiaguda é uma curva. Quando for zero, significa que se trata de uma curva normal; se for positiva, quer dizer que a curva, a distribuição ou o polígono são mais pontiagudos ou levantados; se forem negativas, que é mais plana.

- Uma hipótese, no contexto da estatística inferencial, é uma proposta com relação a um ou vários parâmetros e o que o pesquisador faz por meio do teste de hipótese é determinar se a hipótese é coerente com os dados obtidos na amostra.

- Uma distribuição amostralé um conjunto de valores sobre uma estatística calc ulada de todas as amostras possíveis de determinado tamanho.

- O nível de significância é o valor de certeza que o pesquisador fixa a priori com relação a não errar.

- O nível de confiança está para o intervalo de confiança, assim como o nível de significância esta está para o teste de hipótese, isto é, trata-se de uma probabilidade definida de que um parâme tro será localizado em determinado intervalo.

- Os níveis de confiança são expressos em unidades de desvio-padrão.

- Trabalha-se com altos níveis de confiança ou segurança em estatística inferencial, mas mesmo que o risco seja mínimo, um erro poderia ser cometido. Os resultados possíveis ao testar hipóteses seriam: 
O Aceitar uma hipótese verdadeira (decisão correta).

○ Rejeitar uma hipótese falsa (decisão correta).

O Aceitar uma hipótese falsa (conhecida como erro do tipo II ou erro beta).

○ Rejeitar uma hipótese verdadeira (conhecida como erro do tipo I ou erro alfa).

- Ambos os tipos de erro são indesejáveis, a possibilidade de que se apresentem pode ser reduzida mediante:

○ Amostras representativas probabilísticas.

○ Verificação cuidadosa dos dados.

○ Seleção dos testes estatísticos apropriados.

○ Maior conhecimento da população.

- Existem dois tipos de análises que podem ser realizadas: as análises paramétricas e as não-paramétricas.

- Para as análises paramétricas parte-se das seguintes suposições:

○ A distribuição populacional da variável dependente é normal (o universo possui uma distribuição normal).

○ O nível de medição da variável dependente é por intervalos ou razão.

○ Quando duas ou mais populações são estudadas, possuem uma variância homogênea (as populações possuem uma dispersão similar em suas distribuições).

- O coeficiente de correlação de Pearson é um teste estatístico para analisar a relação entre duas variáveis medidas em um nível por intervalos ou de razão.

- A regressão linear é um modelo matemático para estimar o efeito de uma variável sobre outra e está associado ao coeficiente de Pearson.

- O teste $t$ é um teste estatístico para avaliar se dois grupos diferem entre si de maneira significativa com relação às suas médias.

- O teste de diferenças de proporções é um teste para analisar se duas proporções diferem significativamente entre si.

- A análise de variância unidirecional (one way) é um teste estatístico para analisar se mais de dois grupos diferem significativamente entre si com relação a suas médias e variâncias. O teste $t$ é utilizado para dois grupos e a análise de variância unidimensional é usada para três, quatro ou mais grupos, embora com dois grupos possa ser empregada a análise de variância unidimensional.

- A análise fatorial de variância (ANOVA) é um teste estatístico para avaliar o efeito de duas ou mais variáveis independentes sobre uma variável dependente.

- A análise de covariância é um teste estatístico que analisa a relação entre uma variável 
dependente e duas ou mais independentes, eliminando e controlando o efeito de pelo menos uma destas independentes.

- Na análise de covariância destacam-se três perspectivas:

- Perspectiva experimental: aplicada nas situações em que o interesse está focado nas diferenças observadas na variável dependente, por meio das categorias da variável independente (ou variáveis independentes).

- Perspectiva de interesses pela covariância: é exemplificada com aquelas instâncias cujo interesse principal está focado em analisar a relação entre a variável dependente e a covariável (variável quantitativa contínua) ou as covariáveis. Aqui o enfoque é diferente, a influência que é removida é a das variáveis categóricas. Primeiro controla-se o efeito (nesse caso, contaminante) dessas variáveis e depois se analisa o efeito "purificado" das covariáveis.

- Perspectiva de regressão: tanto as variáveis independentes categóricas como as covariáveis são de interesse para o pesquisador, que pode querer examinar o efeito de cada variável independente (covariáveis e não covariáveis) e depois ajustar os efeitos das demais variáveis independentes.

- Em qualquer caso, a análise de covariância elimina influências indesejadas sobre a variável dependente. Pode ser utilizada em contextos experimentais e não experimentais.

- A análise de covariância "tira" a variabilidade da dependente por causa da covariável. Ajusta a variância da variável dependente nas categorias da independente, baseando-se na covariável.

- Para realizar análises não-paramétricas, deve-se partir das seguintes considerações:

○ A maioria dessas análises não requer pressuposições em relação à maneira da distribuição populacional. Aceitam distribuições não normais.

○ As variáveis não devem ser necessariamente medidas em um nível por intervalos ou de razão, podem analisar dados nominais ou ordinais. De fato, caso pretenda aplicar análises não-paramétricas a dados por intervalos ou razão, estes se resumem a categorias discretas (algumas). As variáveis devem ser categóricas.

- O qui-quadrado é um teste estatístico para avaliar hipótese sobre a relação entre duas variáveis categóricas.

- O qui-quadrado é calculado por meio de uma tabela de contingências ou tabulação cruzada, que é um quadro de duas dimensões em que cada dimensão contém uma variável. Por sua vez, cada variável se subdivide em duas categorias.

- As tabelas de contingência, além de servir para o cálculo do qui-quadrado e outros 
coeficientes, são úteis para descrever conjuntamente duas ou mais variáveis. Isso é, convertendo as frequências observadas em frequências relativas ou porcentagens.

- Os coeficientes de Spearman e Kendall são medidas de correlação para variáveis em um nível de medição ordinal, de tal modo que os indivíduos ou objetos da amos tra podem ser ordenados por posições (hierarquias).

- Para o cálculo do coeficiente de confiabilidade de Cronbach, existem dois procedimentos:

○ Baseando-se na variância dos itens.

○ Baseando-se na matriz de correlação dos itens, onde o procedimento seria:

- Aplica-se a escala.

- Obtêm-se os resultados.

- Calculam-se os coeficientes de correlação de Pearson entre todos os itens (todos contra todos de par em par).

- Elabora-se a matriz de correlação com os coeficientes obtidos.

- Calcula-se $\bar{\rho}$ (média das correlações e NP o número de correlações não repetidas ou não excluídas).

- Aplica-se a fórmula:

$$
\alpha=\frac{\mathrm{N} \bar{\rho}}{1+\bar{\rho}(N-1)}
$$

Na qual $N$ é o número de itens e $\bar{\rho}$ é a média das correlações entre itens.

- Os métodos de análise multivariada são aqueles em que se analisa a relação entre diversas variáveis independentes e pelo menos uma dependente.

- A regressão múltipla é um método para analisar o efeito de duas ou mais variáveis independentes sobre uma dependente. Também é uma extensão da regressão linear, mas com um maior número de variáveis independentes, ou seja, serve para prever o valor de uma variável dependente conhecendo o valor e a influência das variáveis independentes incluídas na análise.

- A análise linear de padrões ou análise path é uma técnica multivariada para representar as interrelações entre variáveis a partir de regressões, assim como analisar a magnitude da influência de uma variável sobre outra influência direta ou indireta. Trata-se de um modelo causal. 
- A análise path é um método para ser submetido ao teste. A informação principal que proporciona são os coeficientes path, os quais representam a força das relações entre as variáveis (são coeficientes de regressão padronizados).

- A análise de fatores é um método estatístico multivariado que é usado para determinar o número e a natureza de um grupo de constructos subjacentes em um conjunto de med ições.

- Um constructo é um atributo para explicar um fenômeno. Nessa análise são geradas "variáveis artificiais" (denominadas como fatores) que representam constructos. Os fatores são obtidos por meio das variáveis originais e devem ser interpretados de acordo com elas. É uma técnica para explicar um fenômeno complexo em função de algumas variáveis.

- A análise multivariada de variância (MANOVA) é um modelo para analisar a relação entre duas ou mais variáveis independentes e duas ou mais variáveis dependentes.

- Uma variável canônica é uma variável artificial gerada dos dados. Representa constructos e é composta por variáveis reais (as variáveis dependentes), que devem ser descritas em termos de variáveis dependentes.

- Nos cálculos feitos na MANOVA são geradas variáveis canônicas até que se encontre que não existe uma diferença estatística significativa entre as categorias ou grupos, ou até que se esgotem os graus de liberdade da variável independente (o que ocorrer primeiro). O número de variáveis canônicas não pode exceder o número de variáveis dependentes, mas é comum que o número seja maior que o de variáveis canônicas estatisticamente significativas ou os graus de liberdade.

- Os pacotes que contêm a MANOVA geralmente posicionam os grupos das variáveis independentes por pontuações discriminantes e estas são calculadas com uma função discriminante, que é uma equação de regressão para um composto de variáveis dependentes. A cada grupo se determina uma pontuação discriminante e m cada variável canônica. As pontuações discriminantes de uma variável independente seriam zero (arredondamento). Uma pontuação discriminante positiva e elevada para um grupo indica que este é colocado acima dos demais na respectiva variável canônica e que devem ser consideradas as cargas, que são positivas ou negativas.

- A análise discriminante é quando as variáveis independentes são medidas por intervalos ou razão e a dependente é categórica. Tal análise serve para prever se um caso pertence a uma das categorias da variável dependente, baseando-se em várias independentes (duas ou mais). Utiliza-se uma equação de regressão denominada função discriminante. 
- Para a análise de agrupamentos ou conglomerados (cluster) - técnica para agrupar os casos ou elementos de uma amostra em grupos baseados em uma ou mais variáveis, a escala multidimensional (para desenhar escalas que meçam os indivíduos em diversas variáveis e os localizem simultaneamente nos eixos das diferentes variáveis, assim como para conhecer a estrutura das variáveis entre si), a análise de séries cronológicas ou de tempo (para analisar a evolução dos casos em uma ou mais variáveis mediante o tempo e prever o comportamento das variáveis ou fatos) e a elaboração de mapas multidimensionais (onde se estabelece distâncias entre casos, baseando-se em medições múltiplas de várias dimensões ou variáveis) requerem-se bases sólidas em matéria de estatística e matemática avançada.

Além dessas observações, Russ-Eft e Preskill (2009) apresentam exemplos de distribuição de frequência (Quadro 26).

\begin{tabular}{|c|c|c|c|}
\hline \multirow[b]{2}{*}{ Descrição dos Dados } & $\begin{array}{l}\text { Medida de } \\
\text { tendência } \\
\text { central? }\end{array}$ & $\begin{array}{l}\text { Qual o nível dos } \\
\text { dados? }\end{array}$ & $\begin{array}{l}\text { Nominal: Moda } \\
\text { Ordinal: Mediana } \\
\text { Intervalo: Média }\end{array}$ \\
\hline & $\begin{array}{l}\text { Medida de } \\
\text { dispersão? }\end{array}$ & $\begin{array}{l}\text { Qual o nível dos } \\
\text { dados? }\end{array}$ & $\begin{array}{l}\text { Nominal: Faixa } \\
\text { Ordinal: Faixa de interquartil } \\
\text { Intervalo: Desvio padrão }\end{array}$ \\
\hline \multirow{2}{*}{$\begin{array}{c}\text { Busca ou } \\
\text { especificação de } \\
\text { relações }\end{array}$} & \multirow{2}{*}{$\begin{array}{l}\text { Quantas } \\
\text { variáveis? }\end{array}$} & $\begin{array}{l}\text { Somente } 2 \\
\text { variáveis }\end{array}$ & $\begin{array}{l}\text { Análise de correlação (Pearson } \\
\text { e Spearman) }\end{array}$ \\
\hline & & $\begin{array}{l}\text { Mais de } 2 \\
\text { variáveis }\end{array}$ & $\begin{array}{l}\text { Fator de análise e análise de } \\
\text { cluster }\end{array}$ \\
\hline \multirow{2}{*}{$\begin{array}{c}\text { Relações preditivas } \\
\text { entre preditor e } \\
\text { critério }\end{array}$} & \multirow{2}{*}{$\begin{array}{l}\text { Quantas } \\
\text { variáveis? }\end{array}$} & $\begin{array}{l}\text { Somente } 2 \\
\text { variáveis }\end{array}$ & $\begin{array}{l}\text { Regressão e análise } \\
\text { discriminante }\end{array}$ \\
\hline & & $\begin{array}{l}\text { Mais de } 2 \\
\text { variáveis }\end{array}$ & $\begin{array}{l}\text { Regressão múltipla e análise } \\
\text { discriminante múltipla }\end{array}$ \\
\hline \multirow{3}{*}{$\begin{array}{c}\text { Teste de diferença } \\
\text { significativa }\end{array}$} & \multirow{3}{*}{$\begin{array}{l}\text { Quantas } \\
\text { variáveis? }\end{array}$} & Dados nominais & $\begin{array}{l}\text { Qui-quadrado e teste exato de } \\
\text { Fisher }\end{array}$ \\
\hline & & Dados ordina is & Mann Whitney $U$ e teste de sinal \\
\hline & & $\begin{array}{l}\text { Dados em } \\
\text { interva los }\end{array}$ & $\begin{array}{l}\text { Análise de variância, análise de } \\
\text { covariância e test } t\end{array}$ \\
\hline
\end{tabular}

Quadro 26 - Exemplos de distribuição de frequência 
Medidas de tendência central: para melhor descrever um grupo de dados.

Medidas de variabilidade: descreve o grau em que os clusters de dados estão juntos ou separados, refere-se à diferença entre os valores mais altos e os mais baixos.

Relações entre 2 variáveis: a correlação zero indica que não há relação entre as duas variáveis. Geralmente, correlações entre 0.7 a 1.0 ou -0.7 a -1.0 são consideradas correlações altas. Porém, valores entre 0.3 a 0.0 ou -0.3 a 0.0 são consideradas baixas correlações.

Relações entre mais de 2 variáveis: pode, por exemplo, querer examinar a relação entre duas ou mais variáveis para determinar se os itens do assessment se enquadram em um determinado grupo ou representam certos fatores.

Relações preditivas entre 2 variáveis: quando se tem somente duas variáveis e se quer predizer uma variável de critério para uma variável preditiva, deve-se computar a análise de regressão ou a análise discriminante, que são similares (técnicas de dependência), para generalizar um grupo de funções de ponderação.

Relações preditivas entre duas ou mais variáveis: sugere-se o uso da regressão múltipla, que é uma técnica para predizer escores de critério combinando variáveis preditivas.

Teste de significância: indica a necessidade de determinar se há diferença significativa entre dois ou mais grupos ou no mesmo grupo em diferentes tempos.

As informações auxiliam na decisão de qual análise estatística utilizar. Entretanto, segundo Russ-Eft e Preskill (2009), a questão fundamental é ter clareza sobre qual o tipo de informação se quer com os dados ou que tipo de perguntas se quer responder com eles, visto que o foco deve ser a obtenção de resultados claros e compreensíveis, que facilitem a tomada de decisão. 


\section{APÊNDICE E - Termo de Consentime nto Liv re e Esclarecido}

$\mathrm{Eu}$,

$\mathrm{CPF} \mathrm{n}^{\mathrm{o}}$ concordo em participar da pesquisa de doutorado “Arquitetura de Orientação para Avaliação de Programas de Educação a Distância: desenvolvimento, implementação e análise", sob a responsabilidade de Elaine Maria dos Santos, a qualé orientada pelo Prof. Dr. José Dutra de Oliveira Neto, vinculados ao Programa de Pós-Graduação em Engenharia de Produção, da Escola de Engenharia de São Carlos da Universidade de São de Paulo.

Ressalto que fui informado(a) sobre os procedimentos da pesquisa, bem como o sigilo e privacidade dos participantes.

Guarapuava/PR, de de 2010. 